\title{
Guía ESC/ERS 2015 sobre diagnóstico y tratamiento de la hipertensión pulmonar
}

\author{
Grupo de Trabajo Conjunto para el diagnóstico y tratamiento de la hipertensión pulmonar \\ de la Sociedad Europea de Cardiología (ESC) y la European Respiratory Society (ERS)
}

\section{Aprobada por la Association for European Paediatric and Congenital Cardiology (AEPC) y la International Society for Heart and Lung Transplantation (ISHLT)}
Autores/Miembros del grupo de trabajo: Nazzareno Galiè* (coordinador de la ESC) (Italia), Marc Humberta,** (coordinador de la ERS) (Francia), Jean-Luc Vachieryc (Bélgica), Simon Gibbs (Reino Unido), Irene Lang (Austria), Adam Torbicki (Poland), Gérald Simonneau ${ }^{a}$ (Francia), Andrew Peacock ${ }^{a}$ (Reino Unido), Anton Vonk Noordegraafa (Países Bajos), Maurice Beghettib (Suiza), Ardeschir Ghofrania (Alemania), Miguel Ángel Gómez Sánchez (España), Georg Hansmannb (Alemania), Walter Klepetkoc (Austria),

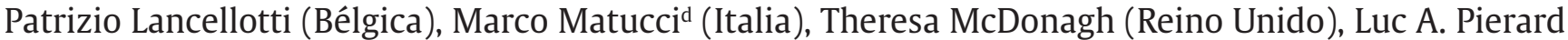 (Bélgica), Pedro T. Trindade (Suiza), Maurizio Zompatorie (Italia) y Marius Hoeper ${ }^{\text {a }}$ (Alemania)

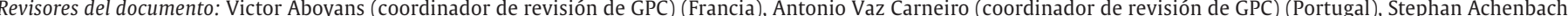

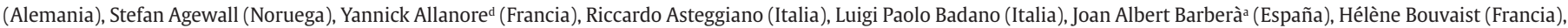

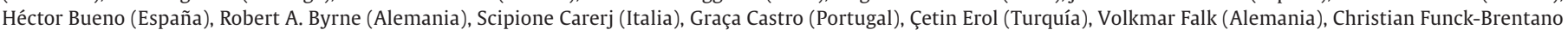

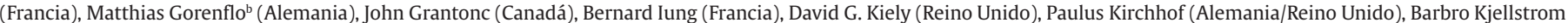

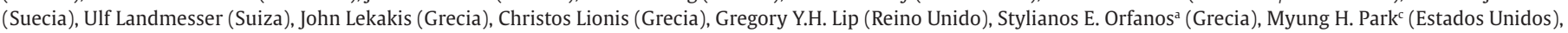

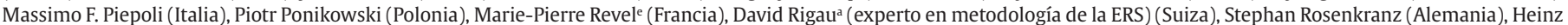
Völler (Alemania) y José Luis Zamorano (España)
\end{abstract}

${ }^{a}$ Representante de la European Respiratory Society

${ }^{\circ}$ Representante de la Association for European Paediatric and Congenital Cardiology

'Representante de la International Society for Heart and Lung Transplantation

${ }^{\mathrm{d}}$ Representante de la European League Against Rheumatism

eRepresentante de la European Society of Radiology

VÉASE CONTENIDO RELACIONADO:

http://dx.doi.org/10.1016/j.recesp.2015.11.032, Rev Esp Cardiol. 2016;69:102-8.

*Autores para correspondencia:

Department of Experimental, Diagnostic and Specialty Medicine-DIMES, University of Bologna, Via Massarenti 9, 40138 Bologna, Italia. Correo electrónico: nazzareno.galie@unibo.it (N. Galiè).

Service de Pneumologie, Hôpital Bicêtre, Université Paris-Sud, Assistance Publique Hôpitaux de Paris, 78 rue du Général Leclerc, 94270 Le Kremlin-Bicetre, Francia. Correo electrónico: marc.humbert@aphp.fr (M. Humbert).

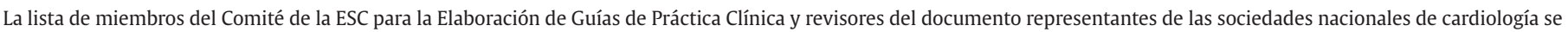
recoge en el apéndice.

\section{Entidades de la ESC que han participado en el desarrollo de este documento:}

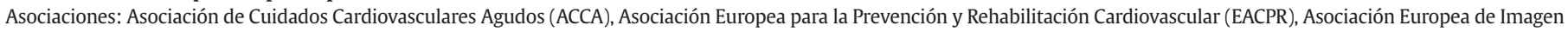

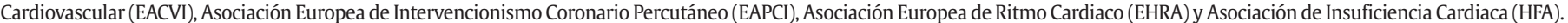
Consejos: Consejo de Práctica Cardiológica (CCP), Consejo de Enfermería Cardiovascular y Profesiones Afines (CCNAP) y Consejo de Cuidados Cardiovasculares Primarios (CCPC).

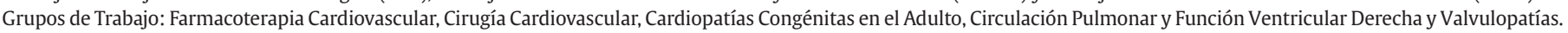

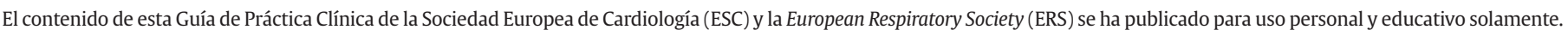

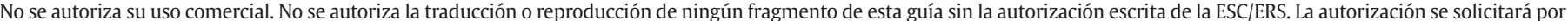
escrito a Oxford University Press, editorial de European Heart Journal, al European Respiratory Journal o a los representantes autorizados de la ESC y la ERS para estas cuestiones.

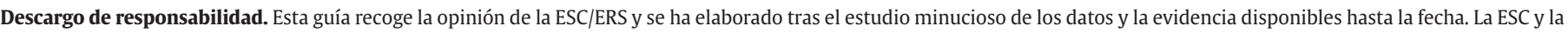

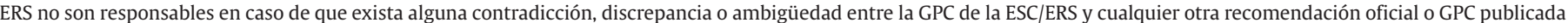

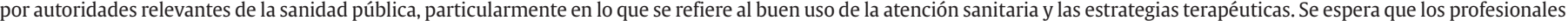

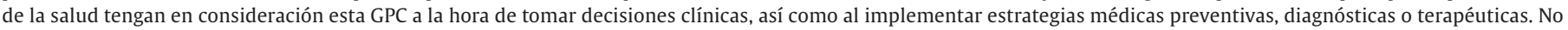

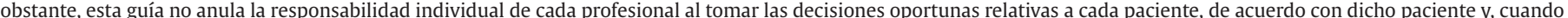

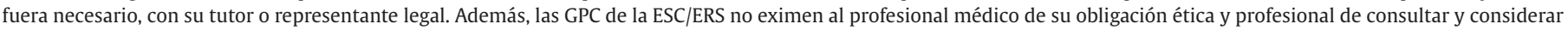

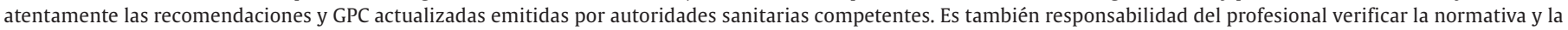
legislación sobre fármacos y dispositivos médicos a la hora de prescribirlos.

(C2015 Sociedad Europea de Cardiología y European Respiratory Society. Publicado en nombre de la Sociedad Europea de Cardiología. Reservados todos los derechos.

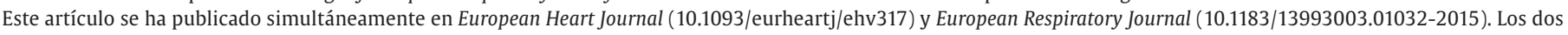

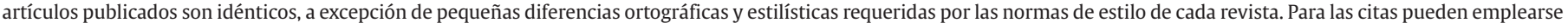
ambas publicaciones.

Las declaraciones de conflicto de intereses de los expertos participantes en el desarrollo de esta guía están disponibles en la página web de la ESC: www.escardio.org/guidelines

Palabras clave:

Guía de práctica clínica • Hipertensión pulmonar • Hipertensión arterial pulmonar • Hipertensión pulmonar tromboembólica crónica • Enfermedad cardiaca congénita $\bullet$ Enfermedad del tejido conectivo $\bullet$ Insuficiencia cardiaca $\bullet$ Insuficiencia respiratoria $\bullet$ Antagonistas de los receptores de la endotelina $\bullet$ Inhibidores de la fosfodiesterasa tipo $5 \bullet$ Análogos de la prostaciclina $\bullet$ Enfermedad pulmonar $\bullet$ Cardiopatía izquierda 


\section{TABLA DE CONTENIDOS}

Abreviaturas 3

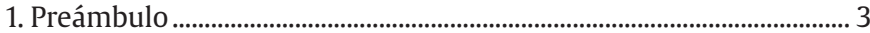

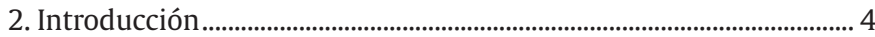

3. Definiciones y clasificaciones ........................................................................ 5

3.1. Definiciones ................................................................................. 5

3.2. Clasificaciones ...................................................................................... 5

4. Epidemiología y genética de la hipertensión pulmonar ...................... 6

4.1. Epidemiología y factores de riesgo .............................................. 6

4.2. Genética............................................................................................ 8

5. Diagnóstico de la hipertensión pulmonar ................................................. 8

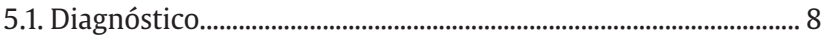

5.1.1. Presentación clínica ................................................................ 8

5.1.2. Electrocardiograma …………..................................................... 8

5.1.3. Radiografía torácica................................................................. 8

5.1.4. Pruebas de función pulmonar y gases arteriales ............ 9

5.1.5. Ecocardiografía ........................................................................ 9

5.1.6. Gammagrafía pulmonar de ventilación/perfusión ...... 10

5.1.7. Tomografía computarizada de alta resolución, tomografía computarizada de contraste y angiografía pulmonar

5.1.8. Técnicas de imagen con resonancia magnética cardiaca ............................................................................ 11

5.1.9. Análisis de sangre e inmunología ..................................... 11

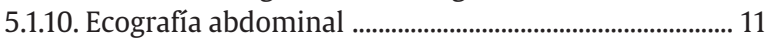

5.1.11. Cateterismo cardiaco derecho y vasorreactividad ..... 11

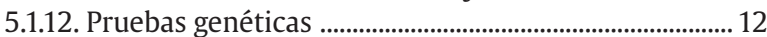

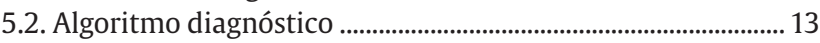

6. Hipertensión arterial pulmonar (grupo 1) ........................................... 13

6.1. Características clínicas...................................................................... 13

6.2. Evaluación de la gravedad ............................................................. 14

6.2.1. Parámetros clínicos, hemodinámicos y de imagen ............................................................................. 14

6.2.2. Capacidad de ejercicio ............................................................. 15

6.2.3. Marcadores bioquímicos.................................................... 15

6.2.4. Evaluación pronóstica integral y evaluación

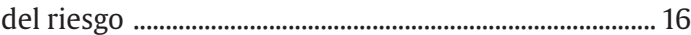

6.2.5. Definición del estado del paciente .................................... 17

6.2.6. Objetivos del tratamiento y estrategia

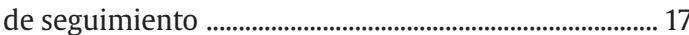

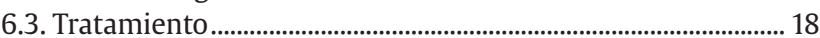

6.3.1. Medidas generales ............................................................. 18

6.3.1.1. Actividad física y rehabilitación supervisada

18

6.3.1.2. Embarazo, control de natalidad y terapia hormonal posmenopáusica .................................. 18

6.3.1.3. Cirugía electiva .......................................................... 19

6.3.1.4. Prevención de infecciones.................................... 19

6.3.1.5. Apoyo psicosocial .................................................... 19

6.3.1.6. Adherencia a los tratamientos ............................. 19

6.3.1.7. Desplazamientos .......................................................... 19

6.3.1.8. Consejo genético ....................................................... 19

6.3.2. Terapia de apoyo …………………………………………….... 19

6.3.2.1. Anticoagulantes orales ............................................. 19

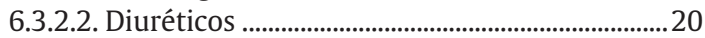

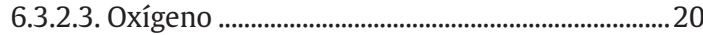

6.3.2.4. Digoxina y otros fármacos cardiovasculares ....................................................20

6.3.2.5. Anemia y estado férrico ..........................................22

6.3.3. Tratamiento farmacológico específico ..............................20

6.3.3.1. Bloqueadores de los canales del calcio ..............20

6.3.3.2. Antagonistas de los receptores

de la endotelina

6.3.3.3. Fosfodiesterasa 5 y estimuladores de la guanilato ciclasa
6.3.3.4. Análogos de la prostaciclina y agonistas de los receptores de la prostaciclina .................22

6.3.3.5. Compuestos y estrategias experimentales .....23

6.3.4. Terapia combinada ............................................................23

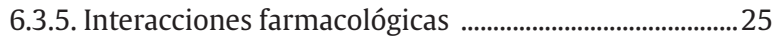

6.3.6. Septostomía auricular con balón.........................................2. 25

6.3.7. Insuficiencia ventricular derecha avanzada .................. 25

6.3.7.1. Manejo en la unidad de cuidados intensivos ....................................................................25

6.3.7.2. Asistencia ventricular derecha ............................22

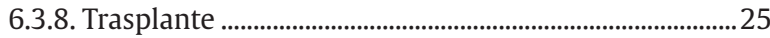

6.3.9. Algoritmo de tratamiento ....................................................2

6.3.10. Diagnóstico y tratamiento de las complicaciones

de la hipertensión arterial pulmonar ............................28

6.3.10.1. Arritmias .....................................................................2 28

6.3.10.2. Hemoptisis ............................................................. 28

6.3.10.3. Complicaciones mecánicas ..............................28

6.3.11. Cuidados terminales y cuestiones éticas ........................28

7. Grupos específicos de hipertensión arterial pulmonar ......................28

7.1. Hipertensión arterial pulmonar pediátrica ................................28

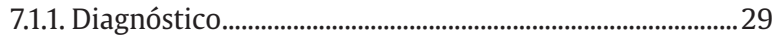

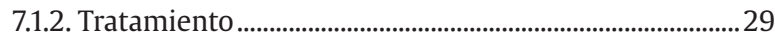

7.2. Hipertensión arterial pulmonar asociada a cardiopatía

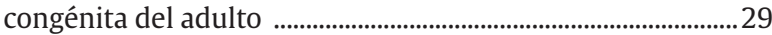

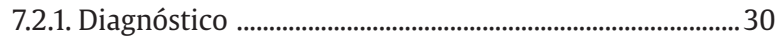

7.2.2. Tratamiento ............................................................................... 30

7.3. Hipertensión arterial pulmonar asociada a enfermedad

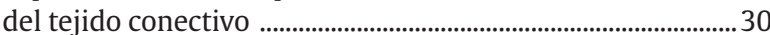

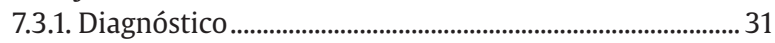

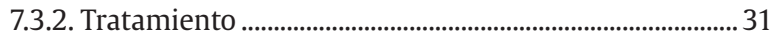

7.4. Hipertensión arterial pulmonar asociada a hipertensión

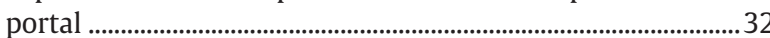

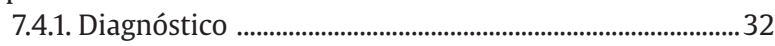

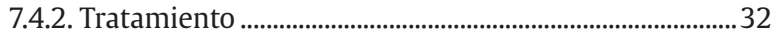

7.5. Hipertensión arterial pulmonar asociada a infección por el virus de la inmunodeficiencia humana ...........................32

7.5.1. Diagnóstico .............................................................................. 33

7.5.2. Tratamiento ................................................................................ 33

7.6. Enfermedad venooclusiva pulmonar y hemangiomatosis

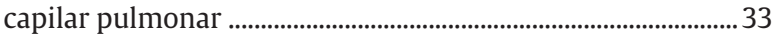

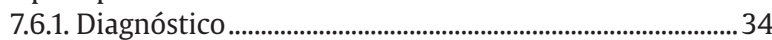

7.6.2. Tratamiento ................................................................................ 34

8. Hipertensión arterial pulmonar causada por cardiopatía

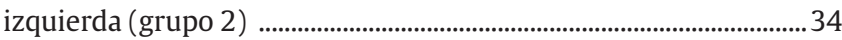

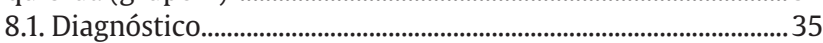

8.2. Tratamiento .......................................................................................... 36

9. Hipertensión pulmonar causada por enfermedades

pulmonares o hipoxia (grupo 3) ........................................................... 36

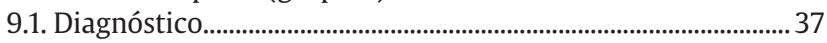

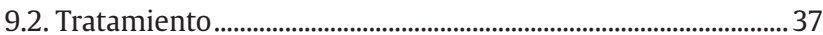

10. Hipertensión pulmonar tromboembólica crónica (grupo 4) ........37

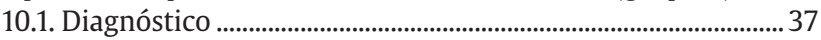

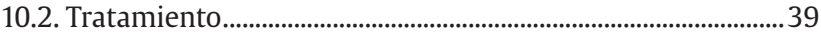

10.2.1. Tratamiento quirúrgico .......................................................39

10.2.2. Tratamiento médico ............................................................. 39

10.2.3. Tratamiento intervencionista................................................ 40

11. Hipertensión pulmonar con mecanismos indefinidos o multifactoriales (grupo 5) ....................................................................... 40

12. Definición de un centro de referencia de hipertensión

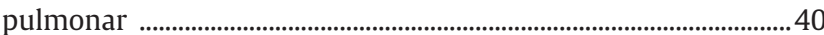

12.1. Instalaciones y experiencia requeridos para un centro de referencia

13. Mensajes sobre qué hacer y qué no hacer ......................................... 41

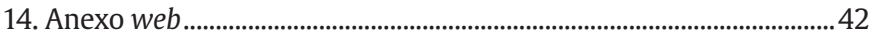

15. Apéndice...................................................................................................... 52

16. Bibliografía ............................................................................................. 53 


\section{Abreviaturas}

AD: aurícula derecha

AI: aurícula izquierda

AP: arteria pulmonar

APB: angioplastia pulmonar con balón

ARE: antagonista de los receptores de la endotelina

BCC: bloqueadores de los canales del calcio

BMPR2: receptor de proteínas morfogenéticas óseas tipo 2

BNP: péptido natriurético cerebral

CC: cardiopatía congénita

CCD: cateterismo cardiaco derecho

$\mathrm{CF}$ : clase funcional

CF-OMS: clase funcional de la Organización Mundial de la Salud

DLCO: capacidad de difusión de monóxido de carbono

EACVI: European Association of Cardiovascular Imaging

EAP: endarterectomía pulmonar

ECA: ensayo clínico aleatorizado

ECG: electrocardiograma

ECI: enfermedad cardiaca izquierda

ECMO: oxigenador extracorpóreo de membrana

EIF2AK4: factor de iniciación de la traducción de alfa cinasa 4

EMEA: Agencia Europea para la Evaluación de Medicamentos

EP: embolia pulmonar

EPOC: enfermedad pulmonar obstructiva crónica

ETC: enfermedad del tejido conectivo

EVOP: enfermedad venooclusiva pulmonar

FDA: Food and Drug Administration

FE: fracción de eyección

GC: gasto cardiaco

GCs: guanilato ciclasa soluble

GMPc: monofosfato de guanosina cíclico

GTP: gradiente transpulmonar (PAPm - PEPm)

GTPd: gradiente transpulmonar diastólico (PAP diastólica - PEP

media)

HAP: hipertensión arterial pulmonar

HAPA: hipertensión arterial pulmonar asociada

HAPD: hipertensión arterial pulmonar inducida por drogas

o tóxicos

HAPH: hipertensión arterial pulmonar heredable

HAPI: hipertensión arterial pulmonar idiopática

HCP: hemangiomatosis capilar pulmonar

HP: hipertensión pulmonar

HPPo: hipertensión portopulmonar

HPPRN: hipertensión pulmonar persistente del recién nacido

HPTC: hipertensión pulmonar tromboembólica crónica

i.v.: intravenoso

IC: insuficiencia cardiaca

INR: razón normalizada internacional

NO: óxido nítrico

NT-proBNP: fracción N-terminal del propéptido natriurético cerebral

NYHA: New York Heart Association

PAD: presión auricular derecha

$\mathrm{PaO}_{2}$ : presión parcial de oxígeno en sangre arterial

PAP: presión arterial pulmonar

PAPm: presión arterial pulmonar media

PAPs: presión arterial pulmonar sistólica

$\mathrm{pCO}_{2}$ : presión parcial de dióxido de carbono

PDE-5i: inhibidor de la fosfodiesterasa tipo 5

PEP: presión de enclavamiento pulmonar

PM6M: prueba de marcha de 6 minutos

RM: resonancia magnética

RMC: resonancia magnética cardiaca
RVP: resistencia vascular pulmonar

RVS: resistencia vascular sistémica

SAB: septostomía auricular con balón

$\mathrm{SvO}_{2}$ : saturación de oxígeno en sangre venosa mixta

TAPSE: desplazamiento sistólico del plano del anillo tricuspídeo

TC: tomografía computarizada

TCAR: tomografía computarizada de alta resolución

TGF $\beta$ : factor de crecimiento transformador beta

UW: unidades de Wood

V/Q: ventilación/perfusión

VCI: vena cava inferior

VD: ventrículo derecho

$\mathrm{VE} / \mathrm{VCO}_{2}$ : relación entre ventilación por minuto y producción

de dióxido de carbono

VI: ventrículo izquierdo

VIH: virus de la inmunodeficiencia humana

VRT: velocidad de regurgitación tricuspídea

\section{PREÁMBULO}

Las guías de práctica clínica (GPC) tienen como objetivo reunir y evaluar toda la evidencia relevante disponible durante el proceso de elaboración sobre un tema particular para ayudar a los médicos a seleccionar la mejor estrategia posible de tratamiento para un paciente en particular, que sufre una enfermedad determinada, no solo teniendo en cuenta el resultado final, sino también sopesando los riesgos y los beneficios de un procedimiento diagnóstico o terapéutico concreto. Las GPC y las recomendaciones deben ayudar a los profesionales de la salud en la toma de decisiones clínicas en su ejercicio diario. No obstante, la decisión final sobre un paciente concreto la debe tomar el médico responsable de su salud, en consulta con el propio paciente o, cuando proceda, con la persona encargada de sus cuidados.

En los últimos años, la Sociedad Europea de Cardiología (ESC) y la European Respiratory Society (ERS), además de otras sociedades y organizaciones científicas, han publicado un gran número de GPC. Debido al impacto de las GPC, se han establecido criterios de calidad para su elaboración de modo que todas las decisiones se presenten de manera clara y transparente al usuario. Las recomendaciones de la ESC para la elaboración y publicación de GPC están disponibles en la sección de guías de la página web de la ESC (http://www.escardio. org/Guidelines-\&-Education/Clinical-Practice-Guidelines/Guidelinesdevelopment/Writing-ESC-Guidelines). Las GPC de la ESC representan la postura oficial de la ESC sobre un tema particular y se actualizan con regularidad.

Los miembros de este Grupo de Trabajo fueron seleccionados por la ESC y la ERS en representación de los profesionales de la salud dedicados a los cuidados médicos de la patología tratada en el presente documento. Los expertos seleccionados realizaron una revisión exhaustiva de la evidencia publicada sobre el manejo de una entidad concreta (incluidos el diagnóstico, el tratamiento, la prevención y la rehabilitación) según las normas establecidas por el Comité de la ESC para la Elaboración de GPC y con la aprobación de la ERS. Además, llevaron a cabo la evaluación crítica de los procedimientos diagnósticos y terapéuticos, incluida la valoración de la razón riesgo/beneficio. Cuando se dispone de datos, se incluye también una estimación de los resultados sanitarios para grandes grupos de población. Se valoraron el nivel de evidencia y la fuerza de la recomendación de una opción terapéutica particular de acuerdo con escalas predefinidas, tal como se indica en las tablas 1 y 2. 
Tabla 1

Clases de recomendación

\begin{tabular}{lll}
\hline Grados de recomendación & Definición & Expresiones propuestas \\
\hline Clase I & $\begin{array}{l}\text { Evidencia y/o acuerdo general en que un determinado procedimiento diagnóstico/tratamiento } \\
\text { es beneficioso, útil y efectivo }\end{array}$ & Se recomienda/está indicado \\
\hline Clase II & Evidencia conflictiva y/o divergencia de opinión acerca de la utilidad/eficacia del tratamiento & Se debe considerar \\
\hline Clase IIa & El peso de la evidencia/opinión está a favor de la utilidad/eficacia & Se puede recomendar \\
\hline Clase IIb & La utilidad/eficacia está menos establecida por la evidencia/opinión & No se recomienda \\
\hline Clase III & $\begin{array}{l}\text { Evidencia o acuerdo general en que el tratamiento no es útil/efectivo y en algunos casos puede } \\
\text { ser perjudicial }\end{array}$ &
\end{tabular}

Tabla 2

Niveles de evidencia

\begin{tabular}{|ll|}
\hline Nivel de evidencia A & $\begin{array}{l}\text { Datos procedentes de múltiples ensayos clínicos } \\
\text { aleatorizados o metanálisis }\end{array}$ \\
\hline Nivel de evidencia B & $\begin{array}{l}\text { Datos procedentes de un único ensayo clínico } \\
\text { aleatorizado o de grandes estudios no aleatorizados }\end{array}$ \\
\hline Nivel de evidencia C & $\begin{array}{l}\text { Consenso de opinión de expertos y/o pequeños } \\
\text { estudios, estudios retrospectivos, registros }\end{array}$ \\
\hline
\end{tabular}

Los miembros del Grupo de Trabajo y los revisores del documento han declarado por escrito cualquier relación que se pueda considerar conflicto de intereses real o potencial. Estas declaraciones escritas están archivadas y disponibles en la página web de la ESC (http://www.escardio.org/guidelines). Durante el periodo de redacción, las modificaciones en las relaciones que se pudieran considerar conflicto de intereses se notificaron a la ESC/ERS y se actualizaron. El informe del Grupo de Trabajo fue financiado en su totalidad por la ESC/ERS y se desarrolló sin ninguna participación de la industria.

El Comité para la elaboración de GPC de la ESC supervisa y coordina la preparación de nuevas GPC elaboradas por los Grupos de Trabajo, grupos de expertos o paneles de consenso. El Comité es responsable también del proceso de aprobación de las GPC. El Comité de la ESC y expertos externos, además de expertos nombrados por la ERS, realizaron una revisión exhaustiva del documento, tras lo cual fue aprobado por todos los miembros del Grupo de Trabajo. Por último, el documento final fue aprobado por el Comité de la ESC y la ERS para su publicación en European Heart Journal y European Respiratory Journal. La elaboración de la presente GPC se realizó tras la meticulosa evaluación del conocimiento científico y médico y de la evidencia disponible hasta la fecha de su redacción.

La tarea de elaboración de GPC incluye no solo la integración de la investigación más reciente, sino también la creación de herramientas educativas y programas de implementación de las recomendaciones. Para su implementación, se desarrollan ediciones de bolsillo, resúmenes en diapositivas y tarjetas, folletos con mensajes clave y versiones electrónicas para aplicaciones digitales (smartphones, etc.). Estas versiones son resumidas y, por lo tanto, en caso de necesidad, debe consultarse la versión completa que se encuentra disponible gratuitamente en la página web de la ESC. Se recomienda a las sociedades nacionales que forman parte de la ESC suscribir, traducir e implementar las GPC de la ESC. Los programas de implementación son necesarios porque se ha demostrado que los resultados clínicos se ven favorablemente influidos por la aplicación de las recomendaciones clínicas.

Asimismo es necesario realizar encuestas y registros para verificar si la práctica clínica en la vida real se corresponde con las recomenda- ciones de las guías y de esta forma se completa el ciclo entre la investigación clínica, la elaboración de las guías y su implementación en la práctica clínica.

Se recomienda a los profesionales de la salud que tengan en consideración la presente guía de la ESC/ERS en la toma de decisiones clínicas en su ejercicio diario, así como en la determinación y la implementación de estrategias preventivas, diagnósticas y terapéuticas; no obstante, la decisión final sobre el cuidado de un paciente concreto, en consulta con dicho paciente y, si fuera necesario, con su representante legal, debe tomarla el médico responsable de su cuidado. Además, es responsabilidad del profesional de la salud comprobar la normativa aplicable a fármacos y dispositivos médicos antes de su prescripción.

\section{INTRODUCCIÓN}

La hipertensión pulmonar (HP) es un trastorno fisiopatológico que puede encontrarse en numerosas entidades clínicas y puede complicar la mayoría de las enfermedades cardiovasculares y respiratorias. La composición del grupo de trabajo para esta guía, que incluye a miembros de diferentes sociedades médicas, asociaciones y grupos de trabajo, refleja la naturaleza multidisciplinaria de la HP. El presente documento es una continuación de las guías publicadas en 2004 y 2009 por la ESC/ERS y está centrado en el manejo clínico de la HP. Se realizó una revisión sistemática de la literatura a través de MEDLINE ${ }^{\circledR}$ para identificar nuevos estudios sobre HP publicados desde 2009. La selección de estudios se realizó según su pertinencia y su relevancia. Los cambios y las adaptaciones más importantes de este documento respecto a la guía publicada en 2009 son los siguientes:

- Se ha simplificado la estructura del índice de contenidos, con 3 capítulos generales sobre la clasificación, los aspectos básicos y el diagnóstico diferencial, 2 capítulos sobre la hipertensión arterial pulmonar (HAP) y un capítulo para cada uno de los siguientes temas: HP causada por enfermedad cardiaca izquierda (ECI), enfermedad pulmonar o hipoxia, hipertensión pulmonar tromboembólica crónica (HPTC) y mecanismos multifactoriales e indeterminados.

- Se han adoptado nuevos términos y parámetros para la definición hemodinámica de los subgrupos de HP poscapilar. Se ha incluido la resistencia vascular pulmonar (RVP) en la definición hemodinámica de la HAP.

- Se incluye una clasificación clínica común actualizada para los pacientes adultos y pediátricos.

- Se incluyen nuevos avances en patología, biopatología, epidemiología, genética y factores de riesgo.

- En un capítulo separado, se proporciona un algoritmo diagnóstico actualizado y en el anexo web se proponen nuevas estrategias de cribado. 
- Tanto en el algoritmo diagnóstico como en el terapéutico se señala la importancia de los centros de referencia especializados en el manejo de la HP.

- Se incluyen nuevos avances sobre la evaluación de la gravedad de la HAP, tratamientos y objetivos de tratamiento, incluidos el tratamiento combinado y 2 fármacos recientemente aprobados. El algoritmo de tratamiento se ha actualizado debidamente.

- Se han actualizado los capítulos dedicados a la HP causada por ECI y enfermedades pulmonares. Se ha abandonado el término «HP desproporcionada" para ambas entidades.

- En el capítulo sobre HPTC se incluyen nuevos algoritmos diagnósticos y terapéuticos, con criterios generales sobre operabilidad y angioplastia pulmonar con balón (APB), además de un fármaco recientemente aprobado.

- Se ha añadido un capítulo corto sobre la HP causada por mecanismos multifactoriales o indeterminados.

\section{DEFINICIONES Y CLASIFICACIONES}

\subsection{Definiciones}

La HP se define como un aumento de la presión arterial pulmonar (PAP) media (PAPm) $\geq 25 \mathrm{mmHg}$ en reposo, calculada mediante cateterismo cardiaco derecho $(\mathrm{CCD})^{1}$. Los datos disponibles muestran que la PAPm normal en reposo es $14 \pm 3 \mathrm{mmHg}$, con un límite superior de la normalidad de aproximadamente $20 \mathrm{mmHg}^{1,2}$. La importancia clínica de una PAPm en 21-24 mmHg no está clara. Se debe seguir estrechamente a los pacientes cuya PAP está en esa franja si hay riesgo de HAP (p. ej., pacientes con enfermedad del tejido conectivo [ETC] o familiares de pacientes con HAP heredable [HAPH]) $)^{1}$

Debido a la falta de datos fiables para definir qué grado de cambio inducido por el ejercicio en la PAPm o la RVP podría tener implicaciones pronósticas, no se puede definir una entidad denominada "HP durante el ejercicio», por lo que no se debe emplear ${ }^{1}$. En un estudio retrospectivo reciente se ha propuesto una definición de HP durante el ejercicio basada en la combinación de datos sobre PAPm y RVP total, pero esta definición no se ha validado de manera prospectiva ${ }^{3}$.

El término HAP describe a un grupo de pacientes con HP caracterizados hemodinámicamente por HP precapilar, definida por una presión de enclavamiento pulmonar (PEP) $\leq 15 \mathrm{mmHg}$ y una RVP $>3$ UW en ausencia de otras causas de HP precapilar, como la HP causada por enfermedades pulmonares, HPTC u otras enfermedades raras ${ }^{1}$.
En la tabla 3 se muestran diferentes definiciones hemodinámicas de HP según distintas combinaciones de valores de PAP, PEP, gasto cardiaco (GC), gradiente transpulmonar diastólico (GTPd) y RVP determinados en condiciones clínicas estables, y en la tabla 4 , su correspondiente clasificación clínica ${ }^{1,4}$. Los motivos de la actualización de las definiciones de HP poscapilar se tratan en la sección 8.

\subsection{Clasificaciones}

La clasificación clínica de la HP pretende categorizar múltiples entidades clínicas en 5 grupos por similitud en la presentación clínica, hallazgos patológicos, características hemodinámicas y estrategia de tratamiento ${ }^{5}$. Esta clasificación clínica podría actualizarse cuando se disponga de nuevos datos sobre estos aspectos o cuando se describan entidades clínicas adicionales. La versión completa de la clasificación clínica se encuentra en la tabla 4 de la guía ${ }^{6}$ y la versión resumida, en la tabla 1 del anexo web.

Los nuevos hallazgos son los siguientes:

- Se han incluido nuevas entidades que se encuentran frecuentemente en niños de diferentes grupos clínicos para proporcionar una clasificación completa adecuada para pacientes tanto adultos como pediátricos.

- Se han incluido mutaciones genéticas recientemente identificadas en el subgrupo de HAPH del grupo clínico 1 (HAP). Estas nuevas mutaciones son más raras que las mutaciones tradicionales del receptor de proteínas morfogenéticas óseas de tipo 2 (BMPR2) (tabla 4).

- La HP precapilar asociada a anemia hemolítica crónica parece ser muy diferente de otras formas de HAP en cuanto a los hallazgos patológicos (ausencia de lesiones plexiformes), las características hemodinámicas (RVP baja y GC alto) y la respuesta a tratamientos específicos de la HAP (eficacia no demostrada). Por ello, se ha cambiado estas entidades clínicas del grupo 1 (HAP) al 5 (mecanismos multifactoriales o indeterminados).

- El grupo 1' (enfermedad venooclusiva pulmonar [EVOP] y hemangiomatosis capilar pulmonar [HCP]) se ha extendido para incluir la HP idiopática, la heredable, la inducida por drogas, toxinas o radiación y otras formas asociadas.

- La HP persistente del recién nacido (HPPRN) incluye un grupo heterogéneo de entidades que pueden diferir de la HAP clásica. Como consecuencia, la HPPRN se ha subcategorizado como grupo 1"7-9.

Tabla 3

Definiciones hemodinámicas de la hipertensión pulmonara

\begin{tabular}{|c|c|c|}
\hline Definición & Características $^{\mathrm{a}}$ & Grupo clínico $^{\mathrm{b}}$ \\
\hline HP & $\mathrm{PAPm} \geq 25 \mathrm{mmHg}$ & Todos \\
\hline HP precapilar & $\begin{array}{l}\mathrm{PAPm} \geq 25 \mathrm{mmHg} \\
\mathrm{PEP} \leq 15 \mathrm{mmHg}\end{array}$ & $\begin{array}{l}\text { 1. Hipertensión arterial pulmonar } \\
\text { 3. HP secundaria a enfermedades pulmonares } \\
\text { 4. HP tromboembólica crónica } \\
\text { 5. HP de mecanismo no aclarado o multifactorial }\end{array}$ \\
\hline HP poscapilar & $\begin{array}{l}\mathrm{PAPm} \geq 25 \mathrm{mmHg} \\
\mathrm{PEP}>15 \mathrm{mmHg}\end{array}$ & $\begin{array}{l}\text { 2. HP secundaria a cardiopatía izquierda } \\
\text { 5. HP de mecanismo desconocido o multifactorial }\end{array}$ \\
\hline HP poscapilar aislada & $\begin{array}{l}\text { GTPd }<7 \mathrm{mmHg} \text { y/o } \\
\mathrm{RVP} \leq 3 \mathrm{UW}^{\mathrm{c}}\end{array}$ & \\
\hline HP combinada precapilar y poscapilar & $\begin{array}{l}\text { GTPd } \geq 7 \mathrm{mmHg} y / 0 \\
\text { RVP }>3 \mathrm{UW}^{\mathrm{c}}\end{array}$ & \\
\hline
\end{tabular}

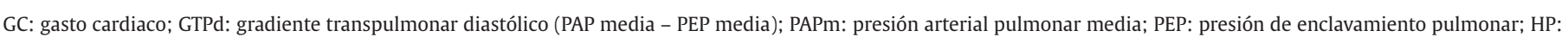
hipertensión pulmonar; RVP: resistencia vascular pulmonar; UW: unidades de Wood.

aTodos los valores medidos en reposo. Véase también la sección 8.

bSegún la tabla 4.

'Se prefieren las unidades de Wood antes que din.s. $\mathrm{cm}^{-5}$. 
Tabla 4

Clasificación clínica completa de la hipertensión pulmonar (actualizada de acuerdo a Simonneau et $\mathrm{al}^{5}$ )

\begin{tabular}{l}
\hline 1. Hipertensión arterial pulmonar \\
\hline 1.1. Idiopática \\
\hline 1.2. Heredable \\
\hline 1.2.1. Mutación en BMPR2 \\
\hline 1.2.2. Otras mutaciones \\
\hline 1.3. Inducida por drogas y toxinas \\
\hline 1.4. Asociada con: \\
\hline 1.4.1. Enfermedad del tejido conectivo \\
\hline 1.4.2. Infección por el VIH \\
\hline 1.4.3. Hipertensión portal \\
\hline 1.4.4. Cardiopatías congénitas (tabla 6 ) \\
\hline 1.4.5. Esquistosomiasis \\
\hline 1'. Enfermedad venooclusiva pulmonar/hemangiomatosis capilar pulmonar \\
\hline 1'1. Idiopática \\
\hline 1'2. Heredable \\
\hline 1'.2.1. Mutación en EIF2AK4 \\
\hline 1'.2.2. Otras mutaciones \\
\hline 1'3. Inducida por drogas, toxinas y radiación \\
\hline 1'.4. Asociada con: \\
\hline 1'.4.1. Enfermedad del tejido conectivo \\
\hline 1'.4.2. Infección por el VIH \\
\hline 1'.
\end{tabular}

1". Hipertensión pulmonar persistente del recién nacido

2. Hipertensión pulmonar secundaria a cardiopatía izquierda

2.1. Disfunción sistólica del ventrículo izquierdo

2.2. Disfunción diastólica del ventrículo izquierdo

2.3. Valvulopatías

2.4. Obstrucción del tracto de entrada/salida del ventrículo izquierdo congénita/ adquirida y miocardiopatías congénitas

2.5. Estenosis congénita/adquirida de las venas pulmonares

3. Hipertensión pulmonar secundaria a enfermedades pulmonares/hipoxia

3.1. Enfermedad pulmonar obstructiva crónica

3.2. Enfermedad intersticial pulmonar

3.3. Otras enfermedades pulmonares con patrón mixto restrictivo y obstructivo

3.4. Trastornos respiratorios del sueño

3.5. Trastornos de hipoventilación alveolar

3.6. Exposición crónica a grandes alturas

3.7. Enfermedades del desarrollo pulmonar (tabla web 3)

4. Hipertensión pulmonar tromboembólica crónica y otras obstrucciones de arterias pulmonares

4.1. Hipertensión pulmonar tromboembólica crónica

4.2. Otras obstrucciones de arterias pulmonares

4.2.1. Angiosarcoma

4.2.2. Otros tumores intravasculares

4.2.3. Arteritis

4.2.4. Estenosis congénita de arterias pulmonares

4.2.5. Parásitos (hidatidosis)

5. Hipertensión pulmonar de mecanismo desconocido y/o multifactorial

5.1. Trastornos hematológicos: anemia hemolítica crónica, trastornos

mieloproliferativos, esplenectomía

5.2. Trastornos sistémicos: sarcoidosis, histiocitosis pulmonar,

linfangioleiomiomatosis, neurofibromatosis

5.3. Trastornos metabólicos: enfermedades de depósito de glucógeno, enfermedad de Gaucher, trastornos tiroideos

5.4. Otros: microangiopatía trombótica tumoral pulmonar, mediastinitis fibrosante, insuficiencia renal crónica (con o sin diálisis), hipertensión pulmonar segmentaria

BMPR2: gen del receptor de proteínas morfogenéticas óseas tipo 2; EIF2AK4: gen del factor de iniciación de la traducción de alfacinasa 4; VIH: virus de la inmunodeficiencia humana.
- Las cardiopatías pediátricas, como la obstrucción congénita o adquirida del tracto de entrada o salida del corazón izquierdo y las miocardiopatías congénitas, se han incluido en el grupo 2 (HP causada por ECI).

- No se han propuesto cambios para el grupo 3 (HP causada por enfermedades pulmonares o hipoxia).

- El grupo 4 ha pasado a denominarse «HPTC y otras obstrucciones de la arteria pulmonar (AP)» que incluye HPTC, angiosarcoma pulmonar, otros tumores intravasculares, arteritis, estenosis arterial pulmonar congénita y parásitos (tabla 4).

- La HP segmentaria se observa en zonas pulmonares discretas perfundidas por colaterales aortopulmonares en algunas cardiopatías congénitas, como la atresia pulmonar o tricuspídea. Esta rara entidad hemodinámica se ha incluido en el grupo 5 (mecanismos multifactoriales o indeterminados).

- El anexo web incluye información adicional sobre la patología y fisiopatología de los grupos clínicos.

En la tabla 5 se muestran las definiciones clínicas y fisiopatológicas más importantes. La clasificación clínica de la HAP asociada a cardiopatías congénitas (CC) se muestra en la tabla 6.

La clasificación anatómica y fisiopatológica de los cortocircuitos sistemicopulmonares asociados con HAP se expone en la tabla 2 del anexo web y una lista de enfermedades del desarrollo pulmonar asociadas con HP, en la tabla 3 del anexo web.

Tabla 5

Definiciones clínicas y fisiopatológicas más importantes

\begin{tabular}{l} 
1. La HP es un estado hemodinámico y fisiopatológico definido como un aumento \\
de la presión arterial pulmonar media $\geq 25 \mathrm{mmHg}$ en reposo medido mediante \\
cateterismo cardiaco derecho (tabla 3). La HP puede objetivarse en múltiples \\
situaciones clínicas (tabla 4) \\
\hline 2. La HAP (grupo 1) es una entidad clínica caracterizada por HP precapilar (tabla 3) \\
y resistencia vascular pulmonar > 3 UW en ausencia de otras causas de HP \\
precapilar como la HP secundaria a enfermedad pulmonar, HP tromboembólica \\
crónica u otras enfermedades raras (tabla 4). La HAP incluye diferentes formas que \\
comparten un cuadro clínico similar y cambios patológicos de la microcirculación \\
pulmonar prácticamente idénticos (tabla 4) \\
\hline 3. No hay evidencia suficiente para apoyar la definición de «HP de ejercicio»
\end{tabular}

HAP: hipertensión arterial pulmonar; HP: hipertensión pulmonar.

\section{EPIDEMIOLOGíA Y GENÉTICA DE LA HIPERTENSIÓN PULMONAR}

\subsection{Epidemiología y factores de riesgo}

Los datos publicados sobre la incidencia mundial de HP son escasos. En el Reino Unido se ha calculado una prevalencia de 97 casos/ millón de habitantes, con un cociente mujeres/varones de 1,8. En Estados Unidos la tasa de muerte estandarizada por edad oscila entre 4,5 y 12,3 casos/100.000 habitantes. Aunque los datos epidemiológicos comparativos sobre la prevalencia de los distintos grupos de HP son escasos, la enfermedad cardiaca izquierda (grupo 2) parece ser la causa más común de HP, aunque en este grupo la HP grave es relativamente poco frecuente. A pesar de que los pacientes de los grupos 2 y 3 representan una parte importante de la práctica clínica, la información sobre la demografía y la evolución clínica de este segmento de población con HP es desproporcionadamente escasa, lo cual indica que podría ser útil emplear la metodología de las bases de datos de registros para estos grupos. En el mundo, la 
Tabla 6

Clasificación clínica de la hipertensión arterial pulmonar asociada con cardiopatías congénitas (actualizada según Simonneau et $\mathrm{al}^{5}$ )

\section{Síndrome de Eisenmenger}

Incluye todos los grandes defectos intracardiacos o extracardiacos que comienzan con cortocircuitos sistemicopulmonares y progresan con el tiempo a un aumento importante de la RVP, así como inversión de la dirección del cortocircuito (pulmonar-sistémico) o cortocircuito bidireccional; se suelen asociar con cianosis, policitemia secundaria y afección multiorgánica

\section{HAP asociada a cortocircuitos de predominio sistemicopulmonar \\ - Corregibles $^{a}$ \\ - No corregibles \\ Incluye defectos moderados a grandes; la RVP está de leve a moderadamente aumentada, predomina aún el cortocircuito sistemicopulmonar, mientras que la cianosis en reposo no es un rasgo típico}

\section{HAP con defectos pequeños/casuales}

Marcada elevación de la RVP en presencia de defectos cardiacos pequeños (habitualmente defectos del septo interventricular con diámetro efectivo medido por ecocardiograma $<1 \mathrm{~cm}$ y defectos del septo interauricular con diámetro efectivo medido por ecocardiograma $<2 \mathrm{~cm}$ ) que no implican por sí mismos un incremento de la RVP; el cuadro clínico es muy similar al de la HAP idiopática. El cierre de estos defectos está contraindicado

\section{HAP tras corrección del defecto}

La cardiopatía congénita se ha corregido, pero la HAP persiste inmediatamente tras la corrección o recurre/se desarrolla meses o años después de la corrección en ausencia de lesiones hemodinámicas posquirúrgicas significativas

HAP: hipertensión arterial pulmonar; RVP: resistencia vascular pulmonar.

aCon cirugía o procedimiento intravascular percutáneo.

bEl tamaño hace referencia a pacientes adultos. En cualquier caso, incluso en adultos, el diámetro puede no ser suficiente para establecer la relevancia hemodinámica del defecto y también se debe tener en consideración el gradiente de presión, el grado y la dirección del cortocircuito y el cociente entre el flujo sistémico y el pulmonar (tabla 2 del anexo web).

HAP asociada a esquistosomiasis y la HP relacionada con grandes altitudes constituyen un problema importante para muchos seres humanos.

- Grupo 1 (HAP): varios registros han descrito la epidemiología de la HAP ${ }^{10-12}$. Las estimaciones de las prevalencias de HAP y HAP idiopática (HAPI) más bajas son de 15 y 5,9 casos/millón de adultos respectivamente. La estimación más baja de la incidencia de HAP es de 2,4 casos/millón de adultos/año. En Europa, la prevalencia y la incidencia de la HAP están en la franja de 15-60 sujetos/millón de habitantes y 5-10 casos/millón de habitantes/año respectivamente ${ }^{11}$. Según los registros, aproximadamente la mitad de los pacientes con HAP tienen HAPI, HAPH o inducida por drogas (HAPD). En el subgrupo de enfermedades asociadas a HAP (HAPA), la causa más importante es la ETC, particularmente la esclerosis sistémica ${ }^{10}$. La HAP puede ocurrir en distintos contextos dependiendo de las entidades clínicas asociadas ${ }^{13}$. La HAPI es una enfermedad esporádica, sin relación con una historia familiar de HAP ni un factor desencadenante conocido. Mientras que la media de edad de los pacientes con HAPI según el primer registro de los National Institutes of Health de Estados Unidos, creado en 1981, era 36 años, actualmente la HAP se diagnostica a pacientes de más edad, con una media de edad al diagnóstico entre 50 y 65 años, según registros actuales. El predominio femenino es muy variable entre distintos registros y puede desaparecer en los pacientes ancianos, y la supervivencia ha mejorado con el transcurso del tiempo. Se ha identificado una serie de factores de riesgo de HAP, que se definen como cualquier factor o enfermedad sospechosa de predisponer o facilitar la aparición de la enfermedad. Los factores de riesgo se clasificaron como definitivos, probables o posibles, dependiendo de la fuerza de su asociación con la HP y su proba- ble papel causal ${ }^{13}$. Una asociación definitiva se reconoce en el caso de una epidemia, como ocurrió con los inhibidores del apetito, o cuando varios estudios epidemiológicos multicéntricos grandes demuestran asociación entre una entidad clínica o un fármaco y la HAP. Una asociación probable se reconoce si un estudio monocéntrico de casos y controles o varias series de casos demuestran una asociación o si la recuperación clínica y hemodinámica ocurre tras interrumpirse la exposición a un fármaco, como ocurrió con la HAP inducida por dasatinib. Una asociación posible puede sospecharse, por ejemplo, en el caso de fármacos con mecanismos de acción similares a los de las categorías definitiva y posible pero que aún no se han estudiado, como los fármacos empleados para tratar los trastornos de déficit de atención. Las asociaciones clínicas definitivas figuran junto a la HAPA en la tabla 4 y el nivel de riesgo de diferentes fármacos y toxinas, en la tabla 76,14-16.

- Grupo 2 (HP causada por ECI): la prevalencia de HP en pacientes con insuficiencia cardiaca (IC) crónica aumenta con el deterioro de la clase funcional. Hasta el $60 \%$ de los pacientes con disfunción sistólica grave del ventrículo izquierdo y hasta el 70\% de los pacientes con IC y fracción de eyección del ventrículo izquierdo (FEVI) conservada pueden presentar HP. En las valvulopatías izquierdas, la prevalencia de la HP aumenta con la gravedad del defecto y de los síntomas. Se puede encontrar HP en prácticamente todos los pacientes con valvulopatía mitral sintomática grave y en hasta el 65\% de los pacientes con estenosis aórtica sintomática ${ }^{17-19}$.

- Grupo 3 (HP causada por enfermedades pulmonares o hipoxia): la HP leve es frecuente en la enfermedad pulmonar intersticial y en la enfermedad pulmonar obstructiva crónica (EPOC) grave $^{20}$, pero la HP grave no es común ${ }^{21}$. Se puede encontrar HP grave en el síndrome combinado de fibrosis pulmonar y enfisema, en el que la prevalencia de la HP es alta ${ }^{22}$.

- Grupo 4 (HPTC y otras obstrucciones de la AP): en el registro español de HP, la prevalencia y la incidencia de HPTC fueron de 3,2/ millón y 0,9/millón/año respectivamente ${ }^{23}$. Aunque se ha llegado a observar una prevalencia de HPTC del 3,8\% de los supervivientes a embolia pulmonar (EP) aguda, la incidencia real de HPTC tras EP aguda es menor, de un 0,5-2\% ${ }^{24}$. En el International CTEPH Registry, el 74,8\% de los pacientes tenían antecedente de EP aguda ${ }^{25}$. Entre las enfermedades asociadas, se encontraban los trastornos trombofílicos (anticoagulante lúpico/anticuerpos antifosfolipídicos, deficiencia de proteínas S y C, resistencia a la proteína C activada con mutación del factor $\mathrm{V}$ Leiden, mutación del gen de protrombina, deficiencia de antitrombina III y factor VIII elevado) en el $31,9 \%$ de los pacientes y esplenectomía en el 3,4\%.

Tabla 7

Actualización sobre el nivel de riesgo de fármacos y toxinas conocidas por inducir hipertensión arterial pulmonar

\begin{tabular}{lll}
\hline Confirmado & Probable & Posible \\
\hline - Aminorex & - Anfetaminas & - Cocaína \\
- Fenfluramina & - Dasatinib & - Fenilpropanolamina \\
- Dexfenfluramina & - L-triptófano & - Hierba de San Juan \\
- Aceite de colza & • Metanfetaminas & - Análogos de las \\
- Benfluorex & & anfetaminas \\
- Inhibidores selectivos & & - Interferón alfa y beta \\
de la recaptación de & & - Ciertos quimioterápicos \\
serotonina & & como agentes \\
& & alquilantes (mitomicina \\
& & C, ciclofosfamida $)^{\mathrm{b}}$ \\
\hline
\end{tabular}

aRiesgo aumentado de hipertensión pulmonar persistente en recién nacidos de madres en tratamiento con inhibidores selectivos de la recaptación de serotonina.

bos agentes alquilantes pueden ser causa de enfermedad venooclusiva pulmonar. 


\subsection{Genética}

- Grupo 1 (HAP): las mutaciones heterocigotas del gen BMPR2 causan aproximadamente el 75\% de los casos de HAP familiar y hasta el 25\% de los casos de HAP aparentemente esporádica ${ }^{26}$. BMPR2 codifica un receptor de tipo 2 para proteínas morfogenéticas óseas que participan en el control de la proliferación celular vascular. Se han identificado mutaciones de genes que codifican la cinasa 1 similar a los receptores de activina y del gen de la endoglina en pacientes con HAP e historia personal o familiar de telangiectasia hemorrágica hereditaria, además de los genes BMPR1B y SMAD9, lo cual indica que los miembros de la familia del factor de crecimiento transformador beta (TGFß) desempeñan un papel importante en la $\mathrm{HAP}^{26}$. La secuenciación completa del exoma ha identificado mutaciones heterocigotas raras en genes que codifican proteínas, como la caveolina- 1 y el miembro 3 de la subfamilia del canal de potasio $\mathrm{K}(\text { KCNK3 })^{26,27}$.

- Grupo 1: se ha reconocido la EVOP/HCP heredable en familias consanguíneas, lo cual indica transmisión recesiva. La secuenciación completa del genoma demostró que las mutaciones bialélicas del factor de iniciación de la traducción de alfa cinasa 4 (EIF2AK4) estaban presentes en todos los casos de EVOP/HCP familiar y en el $25 \%$ de los casos de EVOP/HCP esporádica confirmados histológicamente $^{28}$. EIF2AK4 codifica una serina/treonina cinasa presente en todas las células eucariotas que puede inducir cambios en la expresión genética en respuesta a la privación de aminoácidos.

- Grupo 2 (HP causada por ECI): no se ha identificado ningún vínculo genético específico ${ }^{18}$.

- Grupo 3 (HP por enfermedades pulmonares o hipoxia): el polimorfismo genético puede contribuir a la determinación de la gravedad de la HP en pacientes hipoxémicos con EPOC ${ }^{29}$.

- Grupo 4 (HPTC y otras obstrucciones de la AP): no se ha establecido ningún vínculo entre mutaciones genéticas específicas y el desarrollo de HPTC.

- Grupo 5 (HP con mecanismos multifactoriales o indeterminados): la heterogeneidad de este grupo no permite realizar una descripción adecuada de los factores de riesgo, genéticos y epidemiológicos en esta guía.

\section{DIAGNÓSTICO DE LA HIPERTENSIÓN PULMONAR}

\subsection{Diagnóstico}

El diagnóstico de la HP requiere que exista sospecha clínica basada en los síntomas y la exploración física, realizar una amplia serie de pruebas para confirmar que se cumplen los criterios hemodinámicos, describir la etiología y evaluar el deterioro hemodinámico y funcional. La interpretación de los resultados de estas pruebas requiere, como mínimo, experiencia en cardiología, imagen y enfermedades respiratorias, y se debe realizar preferiblemente en consulta con un equipo multidisciplinario. Esto es particularmente importante para los pacientes cuya HP pueda tener más de una causa. Se debe identificar la causa principal de HP de acuerdo con la clasificación clínica de la tabla 4. La figura 1 muestra un algoritmo diagnóstico.

\subsubsection{Presentación clínica}

Los síntomas de HP no son específicos y están relacionados fundamentalmente con la disfunción el ventrículo derecho (VD) progresiva. Típicamente los síntomas iniciales están inducidos por el esfuerzo y entre ellos se incluyen falta de aire, fatiga, debilidad, angina y síncope. Con menos frecuencia los pacientes refieren tos seca, náuseas y vómitos inducidos por el esfuerzo. Los síntomas en reposo ocurren solo en casos de enfermedad avanzada. La distensión abdominal y el edema de tobillo suelen aparecen con la progresión de la insuficiencia del VD. La presentación de la HP puede estar modificada por enfermeda- des causantes o asociadas a la HP, además de otras enfermedades concurrentes.

En algunos pacientes la presentación clínica puede estar relacionada con complicaciones mecánicas de la HP y con la distribución anormal del flujo sanguíneo en el lecho vascular pulmonar. Estas incluyen hemoptisis relacionada con la rotura de arterias bronquiales hipertróficas, síntomas atribuibles a la dilatación arterial pulmonar, como ronquera producida por la compresión del nervio laríngeo izquierdo recurrente, sibilancias causadas por la compresión de vías aéreas importantes y angina por isquemia miocárdica causada por la compresión del tronco coronario común izquierdo. Una dilatación importante de la AP puede producir rotura o disección arterial con signos y síntomas de taponamiento cardiaco.

Los signos físicos de la HP incluyen elevación paraesternal izquierda, un componente pulmonar acentuado del segundo ruido cardiaco, un tercer ruido cardiaco del VD, un soplo pansistólico de regurgitación tricuspídea y un soplo diastólico de insuficiencia pulmonar. La presión venosa yugular elevada, la hepatomegalia, la ascitis, el edema periférico y las extremidades frías caracterizan a los pacientes con un estadio de la enfermedad avanzado. No se suele observar sibilancias y crepitantes pulmonares.

La exploración clínica puede apuntar a la causa subyacente de la HP. La telangiectasia, la ulceración digital y la esclerodactilia aparecen en la esclerodermia, los crepitantes inspiratorios pueden indicar enfermedad pulmonar intersticial y las arañas vasculares, la atrofia testicular y el eritema palmar pueden indicar enfermedad hepática. Si se encuentra acropaquia, se debe valorar la presencia de EVOP, cardiopatía congénita cianótica, enfermedad pulmonar intersticial o enfermedad hepática.

\subsubsection{Electrocardiograma}

El electrocardiograma (ECG) puede aportar evidencia que indique HP, pero un ECG normal no excluye el diagnóstico. Los hallazgos electrocardiográficos anormales son más probables en la HP grave que en la leve y pueden incluir P pulmonale, desviación del eje a la derecha, hipertrofia del VD, strain del VD, bloqueo completo de rama derecha y prolongación del complejo QTc. Mientras que la hipertrofia del VD tiene una sensibilidad (55\%) y una especificidad (70\%) insuficientes para ser una herramienta de cribado, el strain del VD es más sensible ${ }^{30}$. La prolongación del complejo QRS y QTc indica enfermedad grave ${ }^{31,32}$. El diagnóstico diferencial mediante ECG incluye la isquemia miocárdica anterolateral. Al contrario que en la $\mathrm{HP}$, los cambios electrocardiográficos en la isquemia se observan con más frecuencia en las derivaciones laterales e inferiores; cuando se producen en las derivaciones torácicas anteriores, suelen acompañarse de onda Q en V1 a V3 y raras veces causan la desviación del eje hacia la derecha.

Las arritmias supraventriculares pueden ocurrir en la enfermedad avanzada, particularmente flutter auricular, pero también fibrilación auricular, que tiene una incidencia acumulada del $25 \%$ a los 5 años ${ }^{33}$. Las arritmias auriculares comprometen el gasto cardiaco y casi invariablemente llevan a mayor deterioro clínico. Las arritmias ventriculares son raras.

\subsubsection{Radiografía torácica}

En el 90\% de los pacientes con HAPI, la radiografía torácica es anormal en el momento del diagnóstico ${ }^{34}$. Los hallazgos en pacientes con HAP incluyen dilatación arterial pulmonar central, que contrasta con la "poda» (pérdida) de los vasos sanguíneos periféricos. En casos más avanzados se puede observar agrandamiento de la aurícula derecha $(\mathrm{AD})$ y VD. La radiografía torácica puede ayudar en el diagnóstico diferencial de la HP si muestra signos indicativos de enfermedad pulmonar (grupo 3, tabla 4) o congestión venosa pulmonar causada por ECI (grupo 2, tabla 4). Además, puede ayudar a diferenciar entre HP 
arterial y HP venosa si se demuestra un cociente arterial:venoso aumentado o disminuido respectivamente ${ }^{35}$.

En general, el grado de HP en un paciente dado no se correlaciona con el grado de las anomalías radiográficas. Al igual que el ECG, una radiografía torácica normal no excluye el diagnóstico de HP.

\subsubsection{Pruebas de función pulmonar y gases arteriales}

Las pruebas de función pulmonar y los análisis de gases en sangre arterial permiten identificar la contribución de enfermedad de vías respiratorias o de enfermedad pulmonar parenquimatosa subyacentes. Los pacientes con HAP a menudo presentan una reducción de volúmenes pulmonares de leve a moderada, dependiendo de la gravedad de la enfermedad ${ }^{36,37}$. Aunque la capacidad de difusión puede ser normal en la HAP, la mayoría de los pacientes tienen una capacidad de difusión pulmonar de monóxido de carbono (DLCO) disminuida. Una DLCO anormalmente baja, definida como $<45 \%$ del valor previsto, se asocia con un resultado desfavorable ${ }^{36,37}$. El diagnóstico diferencial de una DLCO baja en pacientes con HAP incluye EVOP, HAP asociada a esclerodermia y enfermedad pulmonar parenquimatosa. Aunque la obstrucción al flujo aéreo no es frecuente, se puede detectar obstrucción de las vías aéreas periféricas. Debido a la hiperventilación alveolar en reposo, la presión parcial de oxígeno en sangre arterial $\left(\mathrm{PaO}_{2}\right)$ es normal o ligeramente más baja de lo normal y la presión parcial de dióxido de carbono en sangre arterial está disminuida ${ }^{38}$.

La EPOC, como una de las causas de HP hipóxica, se diagnostica si hay evidencia de obstrucción irreversible al flujo aéreo, además de aumento de los volúmenes residuales y DLCO disminuida ${ }^{39}$. La determinación de gases en sangre arterial de pacientes con EPOC muestra $\mathrm{PaO}_{2}$ disminuida con presión arterial de dióxido de carbono normal o aumentada ${ }^{40}$. Una disminución de volumen pulmonar combinada con DLCO disminuida puede indicar enfermedad pulmonar intersticial ${ }^{39}$. La gravedad del enfisema y la enfermedad pulmonar intersticial se puede diagnosticar mediante tomografía computarizada (TC) de alta resolución (TCAR). La combinación de enfisema y fibrosis pulmonar puede seudonormalizar la espirometría, aunque la DLCO está casi siempre disminuida, lo cual indica que se debe interpretar las pruebas de función junto con imagen pulmonar.

La prevalencia de hipoxemia nocturna y apnea central del sueño es alta en los pacientes con HAP $(70-80 \%)^{41,42}$. Si se sospecha de apnea obstructiva del sueño o hipoventilación, está indicado realizar una oximetría o polisomnografía durante la noche.

\subsubsection{Ecocardiografía}

La ecocardiografía transtorácica se emplea para visualizar los efectos de la HP en el corazón y estimar la PAP con mediciones de Doppler de onda continua. La ecocardiografía se debe realizar siempre que se sospeche HP y se puede emplear para deducir el diagnóstico de HP en pacientes cuyos resultados de múltiples mediciones ecocardiográficas sean coherentes con este diagnóstico. Cuando se considere el tratamiento de la HP, la ecocardiografía por sí sola no es suficiente para tomar una decisión sobre el tratamiento, y es necesario el cateterismo cardiaco. Se puede encontrar una guía detallada para la evaluación ecocardiográfica del corazón derecho en documentos creados o aprobados por la Asociación Europea de Imagen Cardiovascular (EACVI), asociación filial de la ESC, y a ellos se remite al lector para instruirse mejor ${ }^{43,44}$.

El cálculo de la PAP se basa en la velocidad pico de regurgitación tricuspídea (VRT) y la presión auricular derecha (PAD), como se describe en la ecuación simplificada de Bernoulli. La PAD se puede calcular mediante ecocardiografía según el diámetro y la variación respiratoria del diámetro de la vena cava inferior (VCI): un diámetro de $\mathrm{VCI}<2,1 \mathrm{~cm}$ con colapso $>50 \%$ acompañado de una inspiración indica PAD normal, de $3 \mathrm{mmHg}$ (intervalo, $0-5 \mathrm{mmHg}$ ), mientras que un diámetro de $\mathrm{VCI}>2,1 \mathrm{~cm}$ con colapso $<50 \%$ e inspiración profunda o $<20 \%$ con inspiración superficial indica una PAD de $15 \mathrm{mmHg}$ (rango de 10-20 mmHg). En los casos en los que el diámetro de la VCI o el colapso no encajen con este paradigma, se puede emplear un valor intermedio de $8 \mathrm{mmHg}$ (intervalo, 5-10 mmHg). La EACVI recomienda esta estimación en lugar de usar un valor fijo de 5 o $10 \mathrm{mmHg}$ para el cálculo de la presión sistólica pulmonar. No obstante, ante las imprecisiones en el cálculo de la PAD y la amplificación de los errores de medición por el uso de variables derivadas, se recomienda el Doppler continuo para la medición de la velocidad pico de regurgitación tricuspídea (y no la presión sistólica pulmonar calculada) como variable principal para determinar la probabilidad ecocardiográfica de HP.

Cuando resulta difícil técnicamente medir la VRT pico (regurgitación triscupídea muy leve o leve), algunos laboratorios emplean la ecocardiografía de contraste (p. ej., con una solución salina agitada por vía intravenosa), que mejora la señal Doppler y permite la medición. Por desgracia, a pesar de la fuerte correlación entre la velocidad y el gradiente de presión de regurgitación tricuspídea, el cálculo de la presión según la estimación por Doppler puede ser inexacto en los pacientes individuales. En pacientes con regurgitación tricuspídea grave, la VRT puede estar subestimada y no se puede emplear para descartar el diagnóstico de HP, y en algunos casos puede estar sobrestimada ${ }^{44}$. La HP no se puede definir con precisión por el valor de corte de la VRT. Por ello, el cálculo de la PAP basado únicamente en las mediciones ecocardiográficas con Doppler no es adecuado para el cribado de la HP leve y asintomática. Se debe considerar otras variables ecocardiográficas que puedan despertar o reforzar la sospecha de HP independientemente de la VRT.

Las conclusiones derivadas del examen ecocardiográfico deberían ayudar a establecer un grado de probabilidad de HP. Esta guía propone graduar la probabilidad de HP con base en la VRT en reposo y la presencia de otras variables ecocardiográficas predeterminadas compatibles con HP (tabla 8A). De ese modo la probabilidad de HP se puede considerar alta, intermedia o baja. En el contexto clínico, el resultado ecocardiográfico es necesario para decidir la indicación individualizada de cateterismo derecho. Para facilitar y estandarizar la asignación de nivel de probabilidad de HP, se proponen varios signos ecocardiográficos adicionales a los criterios basados en la VRT (tabla 8B). Estos signos permiten evaluar el tamaño y la sobrecarga de presión del VD, el patrón de velocidad de flujo de salida del VD y el diámetro de la AP y estimar la $\mathrm{PAD}^{43-45}$. Su medición está definida en recomendaciones aprobadas por la $\mathrm{EACVI}^{43,44}$.

El plan recomendado para estudios adicionales para pacientes sintomáticos según la probabilidad ecocardiográfica de HP se muestra en la tabla 9. En la tabla 9 del anexo web se propone un plan de cribado de pacientes asintomáticos con factores de riesgo de HAP o hallazgos incidentales en el ECG o en pruebas de imagen pulmonar que indiquen HP.

La ecocardiografía puede ser útil para detectar la causa de la HP sospechada o confirmada. El Doppler bidimensional y de contraste se puede emplear para identificar cardiopatías congénitas. Un flujo san-

Tabla 8A

Probabilidad ecocardiográfica de hipertensión pulmonar en pacientes sintomáticos con sospecha de hipertensión pulmonar

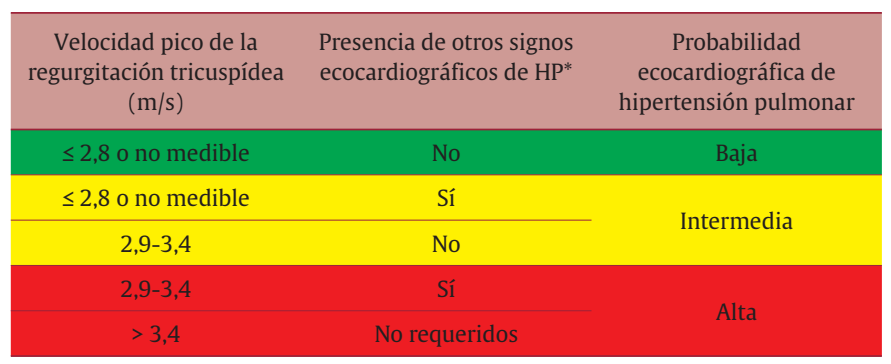

HP: hipertensión pulmonar.

*Véase la tabla 8B. 
Tabla 8B

Signos ecocardiográficos que indican hipertensión pulmonar empleados para evaluar la probabilidad de hipertensión pulmonar además de la medición de la velocidad de regurgitación tricuspídea (tabla $8 \mathrm{~A}$ )

\begin{tabular}{lll}
\hline \multicolumn{1}{c}{ A. Ventrículos* } & B. Arteria pulmonar* & $\begin{array}{c}\text { C. Vena cava inferior } \\
\text { y aurícula derecha* }\end{array}$ \\
\hline $\begin{array}{l}\text { Relación dimensión } \\
\text { VD/VI basal }>1,0\end{array}$ & $\begin{array}{l}\text { Tiempo de aceleración } \\
\text { del Doppler del tracto de } \\
\text { salida del VD }<105 \mathrm{~ms} \text { o } \\
\text { muesca mesosistólica }\end{array}$ & $\begin{array}{l}\text { Diámetro de la vena cava } \\
\text { inferior }>21 \mathrm{~mm} \text { con } \\
\text { disminución del colapso } \\
\text { inspiratorio }(<50 \% \text { con } \\
\text { inspiración profunda o } \\
<20 \% \text { con inspiración } \\
\text { calmada) }\end{array}$ \\
\hline $\begin{array}{l}\text { Aplanamiento del septo } \\
\text { interventricular } \\
\text { (índice de excentricidad } \\
\text { del VI }>1,1 \text { en sístole } \\
\text { o diástole) }\end{array}$ & $\begin{array}{l}\text { Velocidad de } \\
\text { regurgitación pulmonar } \\
\text { en protodiástole }\end{array}$ & $\begin{array}{l}\text { Área de la aurícula } \\
\text { derecha (telesistólica) } \\
>2,2 \text { m/s }\end{array}$ \\
\hline
\end{tabular}

AP: arteria pulmonar; VD: ventrículo derecho; VI: ventrículo izquierdo.

*Deben estar presentes signos ecocardiográficos de al menos 2 categorías diferentes (A, B o C) de la lista para modificar el nivel de probabilidad ecocardiográfica de hipertensión pulmonar.

guíneo pulmonar elevado detectado con Doppler de onda pulsada, en ausencia de un cortocircuito detectable o una dilatación significativa de la AP proximal, a pesar de la presencia de HP moderada puede justificar un estudio transesofágico con contraste o resonancia magnética (RM) cardiaca para descartar la existencia de una comunicación interauricular senovenosa o un retorno venoso pulmonar anómalo. En los casos de sospecha de disfunción diastólica del VI, se debe evaluar los signos típicos de la ecocardiografía con Doppler aunque se considere que su fiabilidad es baja. Cuando el diagnóstico sigue siendo incierto tras la realización de pruebas no invasivas (véase la sección 8.1), se debe considerar la realización de cateterismo derecho. La utilidad clínica práctica de la ecocardiografía Doppler de esfuerzo para identificar casos de HP durante el ejercicio no está clara por la falta de criterios validados y datos prospectivos que la confirmen.

\subsubsection{Gammagrafía pulmonar de ventilación/perfusión}

Para detectar HPTC en pacientes con HP, se debe realizar una gammagrafía de ventilación/perfusión (V/Q). La gammagrafía $\mathrm{V} / \mathrm{Q}$ ha sido el método de cribado preferido para la HPTC por su mayor sensibilidad, comparada con la angio-TC de arterias pulmonares, especialmente en centros con poca experiencia ${ }^{47}$. Una gammagrafía $\mathrm{V} / \mathrm{Q}$ normal o de probabilidad baja excluye eficazmente la HPTC con una sensibilidad del 90-100\% y una especificidad del 94-100\%; no obstante, muchas gammagrafías $\mathrm{V} / \mathrm{Q}$ no son diagnósticas. Aunque la gammagrafía $\mathrm{V} / \mathrm{Q}$ en la HAP puede ser normal, también puede mostrar pequeños defectos periféricos únicos o defectos no segmentarios en la perfusión. El problema es que también se puede encontrar defectos únicos en la perfusión en otras enfermedades vasculares pulmonares, como la EVOP. A pesar de que la gammagrafía V/Q es el método de cribado de elección, la gammagrafía se sustituye con frecuencia por una radiografía torácica reciente o una TCAR pulmonar, aunque estas prácticas no están basadas en la evidencia. Además, en muchos centros se prefiere la TC por estar más disponible. Algunos estudios señalan que la TC por emisión monofotónica, una técnica también de medicina nuclear, puede ser superior a la gammagrafía V/Q planar o la angio-TC, pero aún se tiene que estudiar sus resultados con más profundidad ${ }^{48}$. Más recientemente se ha demostrado que nuevas técnicas, como el mapeo de perfusión por RM tridimensional, tienen la misma sensibilidad que la gammagrafía tradicional de perfusión para el cribado de HPTC; la RM también puede emplearse como una modalidad sin radiación para evaluar la ventilación y la perfusión en la HPTC ${ }^{49}$.

\subsubsection{Tomografía computarizada de alta resolución, tomografía computarizada de contraste y angiografía pulmonar}

La TC es una técnica de imagen ampliamente disponible que puede proporcionar información importante sobre las alteraciones vasculares, cardiacas, parenquimatosas y mediastinales. Puede indicar el diagnóstico de HP (agrandamiento de la AP o el VD), identificar la causa de la HP, como HPTC o enfermedad pulmonar, proporciona pistas sobre la forma de HAP (p. ej., dilatación esofágica en la esclerosis sistémica o defectos cardiacos congénitos, como un drenaje venoso pulmonar anormal) y además proporciona información diagnóstica ${ }^{50}$.

La TC puede despertar la sospecha de HP en pacientes sintomáticos o en estudio por otras indicaciones si se observa un aumento del diámetro de la $\mathrm{AP}(\geq 29 \mathrm{~mm})$ o del cociente diámetro pulmonar:aorta ascendente $(\geq 1,0)$. Se ha observado que un cociente segmentario arteria:bronquio > 1:1 en 3 o 4 lóbulos tiene alta especificidad para la $\mathrm{HP}^{51,52}$. La TCAR proporciona vistas detalladas del parénquima pulmonar y facilita el diagnóstico de enfermedad pulmonar intersticial y enfisema. También es muy útil cuando hay sospecha clínica de EVOP.

Tabla 9

Propuesta de manejo diagnóstico según la probabilidad ecocardiográfica de hipertensión pulmonar en pacientes con síntomas compatibles con esta enfermedad, con o sin factores de riesgo de hipertensión arterial pulmonar o hipertensión pulmonar tromboembólica crónica

\begin{tabular}{|c|c|c|c|c|c|c|c|}
\hline $\begin{array}{c}\text { Probabilidad } \\
\text { ecocardiográfica de HP }\end{array}$ & $\begin{array}{l}\text { Sin factores de riesgo o enfermedades } \\
\text { asociadas con HAP o HPTC }^{d}\end{array}$ & Clase $^{\mathrm{a}}$ & Nivel $^{\mathrm{b}}$ & $\begin{array}{l}\text { Con factores de riesgo o enfermedades } \\
\text { asociadas con HAP o HPTC }\end{array}$ & Clase $^{\mathrm{a}}$ & Nivel $^{\mathrm{b}}$ & $\operatorname{Ref}^{c}$ \\
\hline Baja & Se debe considerar un diagnóstico alternativo & Ila & $\mathrm{C}$ & $\begin{array}{l}\text { Se debe considerar seguimiento } \\
\text { ecocardiográfico }\end{array}$ & IIa & $\mathrm{C}$ & \\
\hline \multirow[t]{2}{*}{ Intermedia } & $\begin{array}{c}\text { Se debe considerar un diagnóstico alternativo } \\
\text { y seguimiento ecocardiográfico }\end{array}$ & Ila & \multirow[t]{2}{*}{ C } & \multirow[t]{2}{*}{$\begin{array}{l}\text { Se debe considerar ampliar el estudio } \\
\text { de HP incluyendo } \mathrm{CCD}^{\mathrm{e}}\end{array}$} & \multirow[t]{2}{*}{ IIa } & \multirow[t]{2}{*}{ B } & \multirow[t]{2}{*}{45,46} \\
\hline & $\begin{array}{l}\text { Se puede recomendar ampliar el estudio } \\
\text { de HPe }\end{array}$ & IIb & & & & & \\
\hline Alta & $\begin{array}{l}\text { Se recomienda ampliar el estudio de HP } \\
\text { (incluyendo } C C D^{\mathrm{e}} \text { ) }\end{array}$ & I & $\mathrm{C}$ & $\begin{array}{c}\text { Se recomienda ampliar el estudio de } \mathrm{HP}^{\mathrm{e}} \\
\text { incluyendo CCD }\end{array}$ & I & C & \\
\hline
\end{tabular}

CCD: cateterismo cardiaco derecho; HAP: hipertensión arterial pulmonar; HP: hipertensión pulmonar; HPTC: hipertensión pulmonar tromboembólica crónica.

aClase de recomendación.

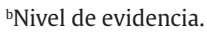

'Referencias que respaldan las recomendaciones.

dEstas recomendaciones no se aplican a pacientes con enfermedad difusa del parénquima pulmonar o cardiopatía izquierda.

eEn función de la presencia de factores de riesgo de HP de los grupos 2, 3 o 5.

La estrategia de ampliación del estudio puede variar dependiendo de si los factores de riesgo/enfermedades asociadas indican mayor probabilidad de HAP o HPTC; consúltese el algoritmo diagnóstico. 
Los cambios característicos del edema intersticial, con opacificación difusa central en vidrio esmerilado y engrosamiento del tabique interlobular, indican el diagnóstico de EVOP; otros hallazgos adicionales son la linfadenopatía o las sombras y los derrames pleurales ${ }^{53}$. Los indicios de hemangiomatosis capilar pulmonar son el engrosamiento bilateral difuso del tabique interlobular y las pequeñas opacidades centrolobulares nodulares apenas circunscritas. Sin embargo, la opacidad difusa en vidrio esmerilado también aparece en la HAP y se puede observar en más de un tercio de estos pacientes ${ }^{50}$.

La angio-TC de contraste de la AP es útil para determinar si la HPTC es accesible por cirugía. Puede identificar los hallazgos angiográficos típicos de la HPTC, como una obstrucción completa, bandas, membranas e irregularidades de la íntima, con las mismas fiabilidad y precisión que la angiografía por sustracción digital ${ }^{54,55}$. Con esta técnica se puede identificar colaterales procedentes de las arterias bronquiales.

La angiografía pulmonar tradicional todavía es necesaria para el estudio de la HPTC de la mayoría de los pacientes, con el fin de identificar a los que podrían beneficiarse de la endarterectomía pulmonar (EAP) o la $\mathrm{APB}^{56,57}$. Un personal experimentado puede llevar a cabo de manera segura una angiografía en pacientes con HP grave utilizando inyecciones selectivas de medio de contraste moderno. La angiografía también puede ser útil para valorar la presencia de vasculitis o malformaciones arteriovenosas pulmonares, aunque la angio-TC tiene una precisión similar o incluso mayor para ambos diagnósticos y es menos invasiva ${ }^{58,59}$.

\subsubsection{Técnicas de imagen con resonancia magnética cardiaca}

La RMC es una técnica de imagen precisa y reproducible para la evaluación del tamaño, la morfología y la función del VD; además permite evaluar de manera no invasiva el flujo sanguíneo, incluidos el volumen latido, el gasto cardiaco, la distensibilidad de la AP y la masa del VD.

En pacientes con sospecha de HP, la presencia de realce tardío de gadolinio, distensibilidad reducida de la AP y flujo retrógrado tiene alto valor predictivo de HP; no obstante, ninguna medición única por RMC puede excluir el diagnóstico de HP60-62. En pacientes con HP, la RMC también puede ser útil en caso de sospecha de cardiopatía congénita si la ecocardiografía no es concluyente.

La angiografía por RM con/sin realce de contraste tiene un valor potencial en el estudio de la vasculatura pulmonar de pacientes con sospecha de HPTC, especialmente en algunos contextos clínicos, como cuando se sospecha embolias crónicas en mujeres embarazadas o pacientes jóvenes o cuando el uso de medios de contraste yodados está contraindicado ${ }^{63}$.

La RMC proporciona información pronóstica útil en pacientes con HAP tanto en la fase inicial como durante el seguimiento ${ }^{64-66}$.

\subsubsection{Análisis de sangre e inmunología}

El análisis de sangre no es útil para el diagnóstico de HP, pero es necesario para identificar la etiología de algunas formas de HP y detectar el daño de órganos finales. De todos los pacientes, es preciso realizar sistemáticamente pruebas bioquímicas, hematológicas y de función tiroidea, además de otros análisis de sangre específicos. Las pruebas de la función hepática pueden ser anormales debido a presión venosa hepática elevada, enfermedad hepática o tratamiento con antagonistas de los receptores de la endotelina (ARE). Se debe realizar la serología para la hepatitis si se observan anomalías clínicas. La enfermedad tiroidea es frecuente en la HAP y puede desarrollarse durante el curso de la enfermedad, por lo que siempre se debe tener en cuenta en caso de un deterioro clínico brusco.

Las pruebas serológicas son necesarias para detectar ETC subyacente, hepatitis y virus de la inmunodeficiencia humana (VIH). Hasta el $40 \%$ de los pacientes con HAPI tienen anticuerpos antinucleares elevados, normalmente en títulos bajos (1:80). Es importante buscar evidencia de esclerosis sistémica, ya que esta enfermedad tiene una prevalencia de HAP relativamente alta. La esclerodermia limitada presenta típicamente anticuerpos antinucleares, incluidos anticuerpos anticentroméricos, ADN-ds, anti-Ro, U3-RNP, B23, Th/To y U1-RNP. La esclerodermia difusa se asocia típicamente con títulos positivos de U3-RNP. Los pacientes con lupus eritematoso pueden presentar anticuerpos anticardiolipínicos.

Los pacientes con HPTC deben someterse a cribado de trombofilia que incluya la determinación de anticuerpos antifosfolipídicos, anticardiolipínicos y anticoagulantes lúpicos. La prueba del VIH es obligatoria en la HAP. Los títulos de NT-proBNP pueden estar elevados en los pacientes con HP y son un predictor independiente de riesgo en estos pacientes.

\subsubsection{Ecografía abdominal}

Al igual que el análisis de sangre, la ecografía abdominal puede ser útil para identificar algunas entidades clínicas asociadas con la HAP. La ecografía abdominal puede confirmar pero no descartar formalmente la hipertensión portal. El uso de agentes de contraste y la adición de Doppler color pueden mejorar la precisión del diagnóstico ${ }^{67}$. La hipertensión portal se puede confirmar o descartar de manera fiable midiendo el gradiente entre la presión venosa hepática libre y la de oclusión (de enclavamiento) en el momento del cateterismo derecho ${ }^{68}$.

\subsubsection{Cateterismo cardiaco derecho y vasorreactividad}

El CCD es necesario para confirmar el diagnóstico de HAP e HPTC, evaluar el grado de deterioro hemodinámico y realizar pruebas de vasorreactividad de la circulación pulmonar en algunos pacientes seleccionados (tabla 10). Estos procedimientos tienen bajas tasas de morbilidad ( $1,1 \%)$ y mortalidad $(0,055 \%)$ cuando se realizan en centros con experiencia ${ }^{69}$. El umbral para la indicación de cateterismo cardiaco izquierdo, además de CCD, debe ser bajo para los pacientes con factores clínicos de riesgo de enfermedad arterial coronaria o IC con FEVI conservada, además de los pacientes con signos ecocardiográficos de disfunción del VI sistólica o diastólica. Las recomendaciones específicas para la cateterización de pacientes con cardiopatía izquierda o enfermedad pulmonar se describen en las tablas 31 y 33 , respectivamente, y en la tabla 10 . La medición de la presión diastólica final del VI es importante para evitar la clasificación errónea de pacientes con una PEP elevada cuando esta es inesperada o pudiese estar equivocada (ausencia de factores de riesgo de IC con FEVI conservada, tamaño normal de la AI y ausencia de marcadores ecocardiográficos de presiones de llenado del VI elevadas).

En la interpretación de las pruebas hemodinámicas invasivas se tendrá en cuenta el cuadro clínico y las pruebas de imagen, particularmente la ecocardiografía. El cateterismo cardiaco se debe realizar después de otras pruebas para que pueda dar respuesta a preguntas específicas que surjan en ellas y evitar un procedimiento innecesario si se descubre un diagnóstico alternativo.

El CCD es un procedimiento técnicamente complejo que requiere una atención meticulosa a los detalles para obtener información clínicamente útil. Para obtener resultados de calidad y reducir el riesgo de los pacientes, estos procedimientos solo deben realizarse en centros con experiencia. Se debe prestar atención a las siguientes cuestiones:

- El transductor de presión externo se debe poner a cero en la línea torácica media con el paciente en posición supina, a media distancia entre el esternón anterior y la superficie de la cama ${ }^{70}$. Esto representa el nivel de la AI.

- Se debe medir la presión en la AP, la posición de enclavamiento de la AP, el VD y la AD. Cuando se usa un catéter de balón, este se debe inflar en la AD desde donde se avanza hasta alcanzar la posición de 
la PEP. Se debe evitar inflar y desinflar el balón repetidas veces en las arterias pulmonares finales porque esto se asocia con rotura de arterias pulmonares. La PEP es un subrogado de la presión de la AI y se debe registrar como la media de 3 mediciones. Se debe considerar la toma de una muestra de sangre con el balón inflado en la posición de enclavamiento para confirmar que se mide la verdadera PEP, ya que la muestra debería tener la misma saturación que la sangre sistémica. Se debe determinar todas las mediciones de la presión al final de la espiración normal (no es necesario realizar pausa de apnea). Opcionalmente, asumiendo que las presiones intratorácicas inspiratorias negativas y espiratorias positivas se anulan mutuamente, es aceptable calcular la media de las presiones vasculares pulmonares registradas durante varios ciclos respiratorios, excepto en pacientes con tórax hiperinsuflados ${ }^{70}$. Es preferible emplear trazados de alta fidelidad que se puedan imprimir en papel, en lugar de trazados pequeños en monitor cardiaco. Es necesario registrar de manera no invasiva la presión arterial en el momento del procedimiento si no se va a realizar cateterismo cardiaco izquierdo.

- Como mínimo es necesario tomar muestras de sangre para la oximetría en la VC superior alta, la VCI y la AP. Se debe determinar la saturación de oxígeno en sangre arterial sistémica. Se debe realizar una búsqueda sistemática de la presencia de un salto en la saturación de oxígeno entre las distintas determinaciones de saturación de $\mathrm{O}_{2}$ realizadas cuando la saturación de arteria pulmonar sea > $75 \%$ o cuando se sospeche cortocircuito izquierda-derecha.

- El GC se debe medir mediante termodilución o con el método directo de Flick. La termodilución medida por triplicado es el método preferido porque proporciona mediciones fiables incluso en pacientes con bajo GC o regurgitación tricuspídea grave ${ }^{71}$. En pacientes con cortocircuitos intracardiacos, la termodilución puede ser inexacta debido a la pronta recirculación del inyectado. El método de Flick requiere la medición directa de consumo de oxígeno, una técnica que no está ampliamente disponible. El método indirecto de Flick, que emplea valores del consumo de $\mathrm{O}_{2}$ estimados, es aceptable pero no totalmente fiable.

- Las pruebas de vasorreactividad pulmonar para identificar a los pacientes candidatos a tratamiento con altas dosis de bloqueadores de los canales del calcio (BCC) solo están recomendadas para pacientes con HAPI, HAPH o HAPD. Estas pruebas deben realizarse en el momento del CCD. En otras formas de HAP o HP, los resultados pueden llevar a error y los respondedores son raros. La prueba estándar de vasorreactividad se realiza con óxido nítrico (NO) inhalado a 10-20 partes por millón ( $\mathrm{ppm}$ ), pero se puede emplear opcionalmente el epoprostenol i.v., la adenosina i.v. y el iloprost inhalado (tabla 4 del anexo web). Una respuesta aguda positiva se define como una reducción de la PAPm $\geq 10 \mathrm{mmHg}$ para alcanzar un valor absoluto de PAPm $\leq 40 \mathrm{mmHg}$ con un GC invariable o aumentado. Solo un $10 \%$ de los pacientes con HAPI cumplen estos criterios. Se desaconseja el uso de BCC, oxígeno, inhibidores de la fosfodiesterasa tipo $5 \mathrm{u}$ otros vasodilatadores para realizar la prueba de vasorreactividad.

- Para la interpretación de la PEP en un momento determinado, es necesario tener en cuenta el contexto clínico. En muchos pacientes con cardiopatía izquierda, la PEP puede estar reducida a $<15 \mathrm{mmHg}$ por el tratamiento con diuréticos ${ }^{72-74}$. Por esta razón se ha considerado evaluar el efecto de la sobrecarga aguda de volumen en las presiones de llenado del corazón izquierdo ${ }^{75}$. Algunos datos indican que la administración de un bolo de fluido de $500 \mathrm{ml}$ es segura y permite discriminar a los pacientes con HAP de los pacientes con disfunción diastólica del VI ${ }^{76,77}$, pero son necesarios más estudios para que se pueda considerarlo en la práctica clínica habitual. Del mismo modo, la evaluación de parámetros hemodinámicos durante el ejercicio para identificar a los pacientes con disfunción diastólica del VI podría ser útil, pero este procedimiento no está estandarizado y requiere más estu- dio ${ }^{17}$. Además, la PEP podría subestimar la presión diastólica final del VI ${ }^{80}$.

- Las variables derivadas calculadas a partir de las mediciones del CCD deben incluir el gradiente transpulmonar de presión (GTP) y la RVP. Es necesaria una RVP > 3 UW para el diagnóstico de HAP1. Aunque la RVP se emplea con frecuencia, tiene la desventaja de ser una variable compuesta muy sensible a los cambios en el flujo y en las presiones de llenado y podría no reflejar los cambios de la circulación pulmonar en reposo ${ }^{81,82}$. El GTP diastólico (GTPd) entre la PEP media y la PAP diastólica media está menos afectado por el flujo y las presiones de llenado ${ }^{81}$, pero podría no tener valor pronóstico ${ }^{83}$. El GTPd podría ser útil en pacientes con sospecha de HP relacionada con cardiopatía izquierda, como se trata en la sección $8^{4}$.

- La coronariografía podría ser necesaria en pacientes con angina, factores de riesgo de enfermedad arterial coronaria o en lista de espera para endarterectomía de la AP o trasplante de pulmón. Con esta técnica se puede detectar una compresión del tronco coronario común izquierdo por el agrandamiento de la AP, además de enfermedad arterial coronaria.

Las recomendaciones para el cateterismo cardiaco derecho e izquierdo y para las pruebas de vasorreactividad se resumen en las tablas 10 y 11 .

Tabla 10

Recomendaciones para el cateterismo cardiaco derecho en la hipertensión pulmonar

\begin{tabular}{|c|c|c|c|}
\hline Recomendaciones & Clase $^{\mathrm{a}}$ & Nivel $^{\mathrm{b}}$ & $\operatorname{Ref}^{c}$ \\
\hline $\begin{array}{l}\text { Se recomienda CCD para confirmar el diagnóstico de } \\
\text { hipertensión arterial pulmonar (grupo 1) y respaldar } \\
\text { las decisiones terapéuticas }\end{array}$ & I & C & \\
\hline $\begin{array}{l}\text { Para pacientes con HP, se recomienda realizar el CCD } \\
\text { en centros con experiencia (véase sección 12), ya que } \\
\text { es un procedimiento técnicamente exigente y puede } \\
\text { conllevar complicaciones graves }\end{array}$ & I & B & 69 \\
\hline $\begin{array}{l}\text { Se puede considerar el CCD en hipertensión arterial } \\
\text { pulmonar (grupo 1) para monitorizar el efecto } \\
\text { del tratamiento farmacológico (tabla 16) }\end{array}$ & Ila & C & \\
\hline $\begin{array}{l}\text { Se recomienda el CCD para pacientes con } \\
\text { cortocircuitos cardiacos congénitos para respaldar } \\
\text { la decisión de corregirlos (tabla 24) }\end{array}$ & I & C & \\
\hline $\begin{array}{l}\text { Se recomienda el CCD para pacientes con HP } \\
\text { secundaria a cardiopatía izquierda (grupo 2) o } \\
\text { enfermedad pulmonar (grupo 3) si se considera } \\
\text { el trasplante de órganos }\end{array}$ & I & C & \\
\hline $\begin{array}{l}\text { Cuando la medición de la PEP no es fiable, debería } \\
\text { considerarse el cateterismo cardiaco izquierdo para } \\
\text { medir la PTDVI }\end{array}$ & IIa & C & \\
\hline $\begin{array}{l}\text { Se puede considerar el CCD para pacientes con } \\
\text { sospecha de HP y cardiopatía izquierda o enfermedad } \\
\text { pulmonar para ayudar en el diagnóstico diferencial } \\
\text { y respaldar las decisiones terapéuticas }\end{array}$ & IIb & C & \\
\hline $\begin{array}{l}\text { El CCD está indicado para pacientes con HPTC } \\
\text { (grupo 4) para confirmar el diagnóstico y respaldar } \\
\text { las decisiones terapéuticas }\end{array}$ & I & C & \\
\hline
\end{tabular}

CCD: cateterismo cardiaco derecho; HP: hipertensión pulmonar; HPTC: hipertensión pulmonar tromboembólica crónica; PEP: presión de enclavamiento pulmonar; PTDVI: presión telediastólica del ventrículo izquierdo.

aClase de recomendación.

bNivel de evidencia.

cReferencias que respaldan las recomendaciones.

\subsubsection{Pruebas genéticas}

La disponibilidad del diagnóstico genético molecular ha abierto un nuevo campo en la atención sanitaria, incluido el asesoramiento 
Tabla 11

Recomendaciones para las pruebas de vasorreactividad

\begin{tabular}{|c|c|c|c|}
\hline Recomendaciones & Clase $^{\mathrm{a}}$ & Nivel $^{\mathrm{b}}$ & $\operatorname{Ref}^{c}$ \\
\hline $\begin{array}{l}\text { El test de vasorreactividad está indicado solo en } \\
\text { centros con experiencia }\end{array}$ & I & C & 69 \\
\hline $\begin{array}{l}\text { Se recomienda el test de vasorreactividad para } \\
\text { pacientes con HAPI, HAPH y HAP asociada al } \\
\text { consumo de drogas para detectar a los pacientes } \\
\text { tratables con altas dosis de BCC }\end{array}$ & I & C & 84,85 \\
\hline $\begin{array}{l}\text { Una respuesta positiva al test de vasorreactividad se } \\
\text { define como una reducción de la PAPm } \geq 10 \mathrm{mmHg} \\
\text { para alcanzar un valor absoluto de PAPm } \leq 40 \mathrm{mmHg} \\
\text { con un gasto cardiaco igual o aumentado }\end{array}$ & I & C & 85,86 \\
\hline $\begin{array}{l}\text { Se recomienda el empleo de NO para realizar el test } \\
\text { de vasorreactividad }\end{array}$ & I & C & 85,86 \\
\hline $\begin{array}{l}\text { Como alternativa, se recomienda el epoprostenol i.v. } \\
\text { para realizar el test de vasorreactividad }\end{array}$ & I & C & 85,86 \\
\hline $\begin{array}{l}\text { Se debe considerar la adenosina como alternativa } \\
\text { para realizar el test de vasorreactividad }\end{array}$ & IIa & C & 87,88 \\
\hline $\begin{array}{l}\text { Se puede considerar el iloprost inhalado como } \\
\text { alternativa para realizar el test de vasorreactividad }\end{array}$ & IIb & C & 89,90 \\
\hline $\begin{array}{l}\text { No se recomienda el uso de BCC orales o i.v. para el } \\
\text { test de vasorreactividad agudo }\end{array}$ & III & C & \\
\hline $\begin{array}{l}\text { No se recomienda el test de vasorreactividad para } \\
\text { detectar a qué pacientes es seguro tratar con dosis } \\
\text { altas de BCC para pacientes con HAP distinta de } \\
\text { HAPI, HAPH e HAP asociada a drogas ni para los } \\
\text { grupos 2-5 de HP }\end{array}$ & III & C & \\
\hline
\end{tabular}

BCC: bloqueadores de los canales del calcio; HAPH: hipertensión arterial pulmonar heredable; HAPI: hipertensión arterial pulmonar idiopática; PAP: presión arterial pulmonar; HAP: hipertensión arterial pulmonar.

${ }^{a}$ Clase de recomendación.

bNivel de evidencia.

'Referencias que respaldan las recomendaciones.

genético para la HAP (tratado en la sección 6.3.1.8)26. Las pruebas y el asesoramiento genético están sujetos en cada país a estrictas regulaciones que establecen las condiciones para la prescripción e investigación de las características genéticas de los pacientes. Los principios éticos fundamentales son informar adecuadamente al paciente para evitar perjuicios, permitir que el paciente conserve su autonomía (información sobre el proceso, riesgos y beneficios de las pruebas genéticas, sin presiones externas) y permitir el acceso igualitario a las pruebas y asesoramiento genético. Los pacientes con HAP esporádica o familiar o EVOP/HCP deben recibir información sobre las pruebas y asesoramiento genético porque tienen una probabilidad muy alta de ser portadores de una mutación que causa la enfermedad. Personal entrenado se encargará de ofrecer las pruebas y el asesoramiento genético a los pacientes. Se debe referir a centros especializados a los pacientes con HAPI considerada esporádica o inducida por anorexígenos y los pacientes con HAP familiar para que reciban asesoramiento genético y se sometan al cribado de la mutación del gen BMPR2 (mutación puntual o deleción grande). Cuando no se identifica ninguna mutación del gen BMPR2 en pacientes con HAP familiar o HAPI $<40$ años o cuando la HAP se produce en pacientes con historia personal o familiar de telangiectasia hemorrágica hereditaria, se puede considerar el cribado de los genes ACVRL1 y ENG. Cuando no se identifican mutaciones en los genes BMPR2, ACVRL1 y ENG, se puede considerar el cribado de mutaciones raras (KCNK3, caveolina-1, etc.).

En pacientes con EVOP/HCP esporádica o familiar, se deben realizar pruebas genéticas para mutaciones del gen EIF2AK428. La presencia de una mutación bialélica en el gen EIF2AK4 es suficiente para confirmar el diagnóstico de EVOP/HCP y evitar los riesgos de la biopsia pulmonar para la confirmación histológica.

\subsection{Algoritmo diagnóstico}

El algoritmo diagnóstico se representa en la figura 1. El proceso diagnóstico comienza tras la sospecha de HP y la ecocardiografía compatible con esta (según los diferentes grados de probabilidad de las tablas 8 y 9), continúa con la identificación de los grupos clínicos de HP más frecuentes (grupo 2, ECI, y grupo 3, enfermedades pulmonares), después diferencia el grupo 4 (HPTC) y finalmente establece el diagnóstico e identifica los diferentes tipos en el grupo 1 (HAP) y las entidades raras en el grupo 5.

Se debe considerar la presencia de HAP en el diagnóstico diferencial de disnea de esfuerzo, síncope, angina o disminución progresiva de la capacidad de ejercicio, especialmente en pacientes sin factores de riesgo, síntomas o signos evidentes de trastornos cardiovasculares o pulmonares más comunes. Se debe prestar especial atención a los pacientes con enfermedades asociadas con HAP o factores de riesgo de HAP, como la historia familiar, ETC, ECI, infección por el VIH, hipertensión portal o historia de consumo de drogas o toxinas que inducen a la HAP (tabla 7). En la práctica clínica cotidiana, el grado de sospecha puede ser bajo. Es más habitual encontrar HAP inesperadamente en una ecocardiografía transtorácica indicada por otra causa.

Si la ecocardiografía transtorácica es compatible con una probabilidad de HAP intermedia o alta (tabla 9), es necesario investigar los síntomas y los signos, y realizar historia clínica, ECG, radiografía torácica, pruebas de la función pulmonar (incluidos DLCO, análisis de gases arteriales y oximetría nocturna, si fuera preciso) y TCAR torácica para detectar HP de los grupos 2 (cardiopatía izquierda) o 3 (enfermedades pulmonares). Si la probabilidad ecocardiográfica de HP es baja (tabla 9), no es necesario realizar más exploraciones, se buscará otra causa para los síntomas y se seguirá al paciente. Si se confirma el diagnóstico de cardiopatía izquierda o enfermedad pulmonar, se considerará el tratamiento adecuado de estas enfermedades. En caso de HP grave o disfunción del VD, el paciente debe ser referido a un centro especializado donde se explorarán otras causas de la HP. Si no se confirma el diagnóstico de cardiopatía izquierda o enfermedad pulmonar, se debe realizar una gammagrafía $\mathrm{V} / \mathrm{Q}$ para el diagnóstico diferencial entre HPTC y HAP. Además, el paciente debe ser referido a un centro especializado en HP.

Si la gammagrafía V/Q muestra múltiples defectos de perfusión segmentarios, se considerará el diagnóstico de HP del grupo 4 (HPTC) ${ }^{91}$. El diagnóstico final de HPTC (y la evaluación de la viabilidad de una EAP) requiere la realización de angio-TC pulmonar, CCD y angiografía pulmonar selectiva. La TC también puede mostrar signos de HP del grupo 1' (EVOP). Si la gammagrafía VI/Q es normal o muestra solamente defectos de perfusión subsegmentarios (dispersos), se considerará el diagnóstico de HP del grupo 1 (HAP) o enfermedades raras del grupo 5. En la tabla 9 se muestran las recomendaciones para el manejo según la probabilidad de HP, incluidas las indicaciones para el CCD. Otras pruebas diagnósticas adicionales, como hematología, bioquímica, inmunología, serología, ultrasonografía y genética, permitirán concretar el diagnóstico final.

La biopsia pulmonar abierta o transtorácica conlleva un riesgo sustancial de morbilidad y mortalidad ${ }^{92}$. No se recomienda realizar una biopsia a pacientes con HAP debido a la baja probabilidad de que esta prueba cambie el diagnóstico y el tratamiento.

Las recomendaciones para la estrategia diagnóstica se encuentran en la tabla 12 .

En el anexo web se presenta un programa de cribado de la HAP.

\section{HIPERTENSIÓN ARTERIAL PULMONAR (GRUPO 1)}

\subsection{Características clínicas}

Las características clínicas de la HAP no son específicas y pueden extraerse de la descripción general que se trata en la sección 5.1.1. Las 


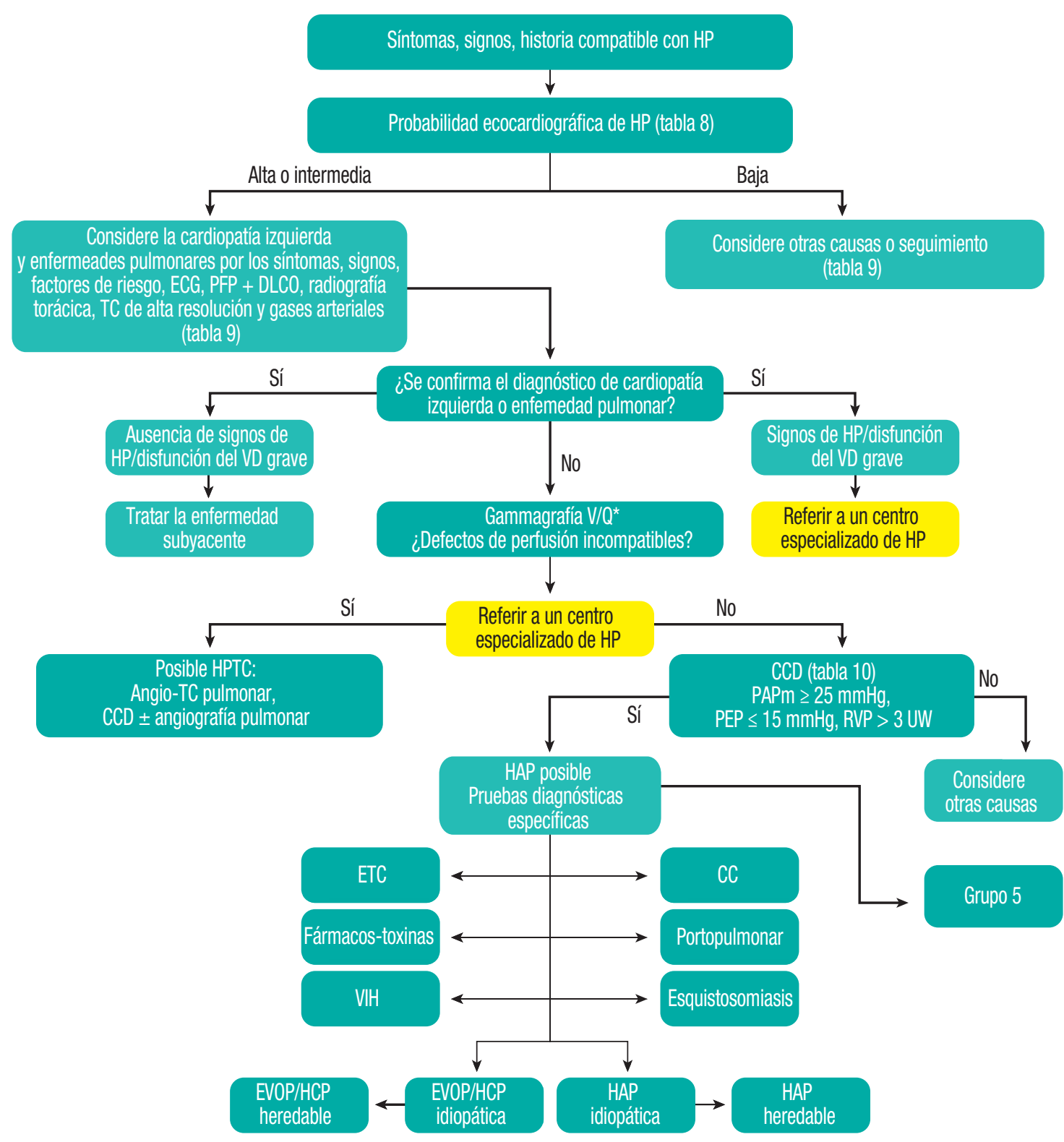

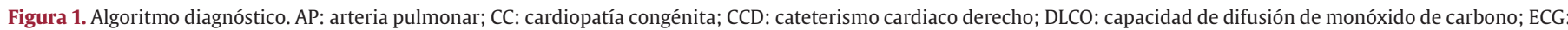

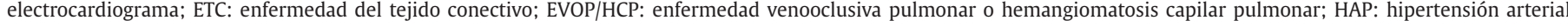

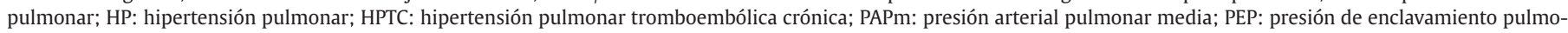

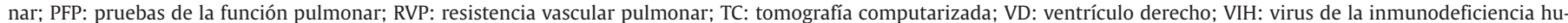
mana; V/Q: ventilación/perfusión.

*La angio-TC pulmonar por sí sola puede no lograr el diagnóstico de HPTC.

descripciones más detalladas de los subgrupos de HAP se encuentran en la sección 7.

\subsection{Evaluación de la gravedad}

\subsubsection{Parámetros clínicos, hemodinámicos y de imagen}

La evaluación clínica sigue siendo una parte esencial de la evaluación de los pacientes con HP, ya que proporciona información importante sobre la gravedad de la enfermedad y los posibles mejoría, deterioro o estabilidad del paciente. Las partes más importantes de la historia clínica entre consultas de seguimiento incluyen cambios en la capacidad de ejercicio, episodios de dolor torácico, arritmias, hemoptisis o síncope, cambios en la medicación y adherencia a los tratamientos prescritos. La exploración física proporciona información sobre la presencia o ausencia de cianosis central o periférica, agrandamiento de venas yugulares, edema, ascitis y derrames pleurales, además de la frecuencia y el ritmo cardiacos y la presión arterial.

La clase funcional de la Organización Mundial de la Salud (CFOMS) (tabla 5 del anexo web), a pesar de la variabilidad interobservador ${ }^{95}$, sigue siendo la más potente herramienta pronóstica de la supervivencia no solo en el momento del diagnóstico, sino también en el seguimiento ${ }^{96-98}$. El deterioro de la CF es uno de los indicadores más alarmantes del progreso de la enfermedad e indica la necesidad de realizar pruebas diagnósticas adicionales para identificar las causas del deterioro clínico ${ }^{9799}$.

Dado que la función del VD es un factor determinante de la capacidad de ejercicio y de la evolución de los pacientes con HP, la ecocar- 
Tabla 12

Recomendaciones para la estrategia diagnóstica

\begin{tabular}{|c|c|c|c|}
\hline Recomendaciones & Clase $^{\mathrm{a}}$ & Nivel $^{\mathrm{b}}$ & $\operatorname{Ref}^{c}$ \\
\hline $\begin{array}{l}\text { Se recomienda el ecocardiograma como prueba } \\
\text { diagnóstica no invasiva de primera elección en caso } \\
\text { de sospecha de HP }\end{array}$ & I & C & \\
\hline $\begin{array}{l}\text { Se recomienda la gammagrafía de ventilación/ } \\
\text { perfusión o de perfusión pulmonar para descartar } \\
\text { HPTC en pacientes con HP no explicada }\end{array}$ & I & C & 47 \\
\hline $\begin{array}{l}\text { Se recomienda la angiografía de la AP con TC de } \\
\text { contraste en el estudio de pacientes con HPCT }\end{array}$ & I & C & 93 \\
\hline $\begin{array}{l}\text { Se recomienda para todos los pacientes con HAP } \\
\text { análisis de bioquímica, hemograma, inmunología, } \\
\text { serología de VIH y perfil tiroideo para identificar } \\
\text { enfermedad específica asociada }\end{array}$ & I & C & \\
\hline $\begin{array}{l}\text { Se recomienda la ecografía abdominal para el cribado } \\
\text { de hipertensión portal }\end{array}$ & I & C & 67 \\
\hline $\begin{array}{l}\text { Se recomienda el test de función pulmonar con DLCO } \\
\text { en la evaluación inicial de pacientes con HP }\end{array}$ & I & C & 36 \\
\hline $\begin{array}{l}\text { Se debe considerar la TC de alta resolución para todo } \\
\text { paciente con HP }\end{array}$ & Ila & C & 94 \\
\hline $\begin{array}{l}\text { Se debe considerar la angiografía pulmonar en el } \\
\text { estudio de pacientes con HPTC }\end{array}$ & IIa & C & \\
\hline $\begin{array}{l}\text { No se recomienda la biopsia pulmonar abierta } \\
\text { o por toracoscopia para pacientes con HAP }\end{array}$ & III & C & \\
\hline
\end{tabular}

DLCO: capacidad de difusión de monóxido de carbono; HAP: hipertensión arterial pulmonar; HP: hipertensión pulmonar; HPTC: hipertensión pulmonar tromboembólica crónica; TC: tomografía computarizada.

aClase de recomendación.

Nivel de evidencia.

cReferencias que respaldan las recomendaciones.

diografía sigue siendo una herramienta importante durante el seguimiento. Al contrario de lo que se cree normalmente, la PAP sistólica calculada en reposo no tiene valor pronóstico y no es relevante para las decisiones sobre el tratamiento ${ }^{96,97,100}$. Un aumento de la PAPs no refleja necesariamente el progreso de la enfermedad y una disminución tampoco indica necesariamente una mejoría. Un estudio ecocardiográfico completo incluye la descripción del tamaño de las cámaras, particularmente del área de la AD y el VD, el grado de regurgitación tricuspídea, el índice de excentricidad del VI y la contractilidad del VD, que se pueden determinar mediante distintas variables, como el strain/strain rate longitudinal sistólico y el cambio del área fraccional del VD, el índice de Tei y el desplazamiento sistólico del plano del anillo tricuspídeo o TAPSE ${ }^{101-108}$.

La ecocardiografía tridimensional puede proporcionar una estimación más precisa que la ecocardiografía bidimensional estándar, aunque se ha observado que también puede subestimar los volúmenes y las fracciones de eyección ${ }^{109}$.

La ecocardiografía con speckle tracking mejora la cuantificación de la función del VD ${ }^{110}$. Dada la compleja geometría del VD, ninguna de estas variables por sí sola es suficiente para describir la función del VD, y la valoración global de un médico experto suele ser más importante que las variables aisladas. La ecocardiografía durante el ejercicio proporciona información adicional sobre la función del VD. Hay que señalar que un incremento significativo (> $30 \mathrm{mmHg}$ ) de la PAPs durante el ejercicio refleja una mejor función del VD y se asocia con una evolución más favorable a largo plazo que un incremento moderado o nulo ${ }^{111}$. Recientemente se ha demostrado que la reserva contráctil es un marcador pronóstico independiente en pacientes con HP grave ${ }^{111}$.

La RMC proporciona una evaluación más precisa de la morfología y la función del VD, además permite medir el volumen latido y el GC. Se ha identificado una serie de marcadores pronósticos de RMC, como volumen del VD aumentado, volumen del VI reducido, FEVD reducida y volumen latido reducido. Hay cierta evidencia de que las RMC durante el seguimiento pueden ser útiles para el manejo de la HAP a largo plazo, ya que permiten detectar insuficiencia del VD antes de que se manifiesten síntomas clínicos ${ }^{64,66,112,113}$.

Los parámetros hemodinámicos evaluados en el cateterismo cardiaco derecho proporcionan importante información diagnóstica en el momento del diagnóstico y durante el seguimiento. La presión de la $\mathrm{AD}$, el índice cardiaco y la saturación de oxígeno en sangre venosa mixta $\left(\mathrm{SvO}_{2}\right)$ son los indicadores más fiables de la función del VD y el pronóstico, mientras que la PAPm tiene un valor pronóstico bajo

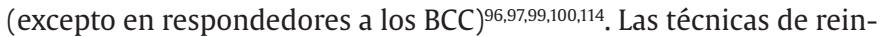
halación ${ }^{71}$ o biorreactancia ${ }^{115}$ para la evaluación no invasiva del GC todavía no han tenido la adecuada validación que permita su uso en la práctica clínica cotidiana o la toma de decisiones sobre el tratamiento.

No está claro cuál es el mejor momento para el CCD de seguimiento. La estrategia de seguimiento varía según los centros, algunos optan por una estrategia invasiva regular, mientras que otros siguen una estrategia predominantemente no invasiva. No hay evidencia de que la estrategia de CCD regular se asocie a mejores resultados que la estrategia no invasiva. Sin embargo, hay consenso entre los expertos en que el CCD se debe realizar siempre que se esperen resultados que puedan influir en las decisiones terapéuticas, incluidos los cambios en la medicación o las decisiones sobre la indicación de trasplante.

\subsubsection{Capacidad de ejercicio}

La prueba de marcha de 6 minutos (PM6M) es la prueba de ejercicio (submáximo) más empleada en los centros especializados en HP. Es una prueba sencilla, económica y conocida por pacientes y centros. $\mathrm{Al}$ igual que otras pruebas de HP, se debe interpretar los resultados de la PM6M teniendo en cuenta el contexto clínico. En la PM6M influyen varios factores, como el sexo, la edad, la talla, el peso, las comorbilidades, la necesidad de $\mathrm{O}_{2}$, la curva de aprendizaje y la motivación. Sin embargo, los resultados se presentan normalmente en valores absolutos, en lugar de porcentajes predichos. Aunque los valores absolutos, y no los cambios en la PM6M, proporcionan información pronóstica, no se ha establecido un único umbral para todos los pacientes (véase a continuación) ${ }^{96,99,116-118}$. Se recomienda emplear la escala de Borg al final de la PM6M para determinar el nivel de esfuerzo. Además, algunos estudios señalan que el uso adicional de mediciones de $\mathrm{O}_{2}$ periférico y frecuencia cardiaca puede mejorar el valor predictivo de la prueba, pero estos hallazgos están a la espera de confirmación independiente ${ }^{119,120}$.

La prueba de esfuerzo cardiopulmonar se realiza normalmente como una prueba de ejercicio máximo y proporciona información importante sobre la capacidad de ejercicio, el intercambio de gases, la eficacia de la ventilación y la función cardiaca durante el ejercicio. La mayoría de los centros de HP emplean pruebas con protocolos en rampa, aunque este tipo de prueba aún no está estandarizado para esta población de pacientes. Los pacientes con HAP presentan un patrón típico con una presión parcial de dióxido de carbono $\left(\mathrm{pCO}_{2}\right)$ baja al final de la espiración, una relación alta entre la ventilación por minuto y la producción de dióxido de carbono $\left(\mathrm{VE} / \mathrm{VCO}_{2}\right)$, un pulso de $\mathrm{O}_{2}$ bajo $\left(\mathrm{VO}_{2} /\right.$ frecuencia cardiaca $)$ y un bajo consumo de oxígeno pico $\left(\mathrm{VO}_{2} \text { pico }\right)^{121}$. La prueba de esfuerzo cardiopulmonar permite determinar distintas variables que proporcionan información pronóstica, aunque la más utilizada para tomar decisiones sobre el tratamiento es el $\mathrm{VO}_{2}$ pico ${ }^{106,122-125}$. La información diagnóstica y pronóstica de la prueba de esfuerzo cardiopulmonar es adicional a la proporcionada por la PM6M ${ }^{122}$

\subsubsection{Marcadores bioquímicos}

Aunque se han investigado distintos biomarcadores, todavía no existe un biomarcador específico para la HAP o el remodelado vascular pulmonar. Pueden agruparse en marcadores de disfunción vascular (dimetilarginina asimétrica [ADMA], angiopoyetinas de la 
endotelina 1, factor de von Willebrand ${ }^{126-131}$, marcadores de inflamación (proteína $C$ reactiva, interleucina 6, quimiocinas) ${ }^{132-135}$, marcadores de estrés miocárdico (péptido natriurético auricular, BNP/ NT-proBNP, troponinas) $)^{97,118,136-139}$, marcadores de GC bajo o hipoxia tisular $\left(\mathrm{pCO}_{2}\right.$, ácido úrico, factor de crecimiento diferenciador 15 [GDF15], osteopontina $)^{38,140-142}$ y marcadores de daño orgánico secundario (creatinina, bilirrubina) ${ }^{97,137}$. Esta lista crece continuamente, pero actualmente el BNP y el NT-proBNP siguen siendo los únicos biomarcadores empleados habitualmente en los centros de HP y en ensayos clínicos. Las concentraciones de BNP/NT-proBNP se correlacionan con la disfunción miocárdica y proporcionan información pronóstica en el momento del diagnóstico y durante el seguimiento ${ }^{143}$. Estos marcadores son específicos para la HP, pero suelen estar elevados en prácticamente todas las cardiopatías. Las concentraciones de BNP/ NT-proBNP suelen tener alta variabilidad y hay que interpretarlas en el contexto clínico. No hay ventajas claras del uso del BNP frente al NT-proBNP. Parece que el BNP tiene una correlación más fuerte con los parámetros hemodinámicos pulmonares y la función renal le afecta menos, mientras que el NT-proBNP parece ser un predictor pronóstico más fuerte ${ }^{137}$.

\subsubsection{Evaluación pronóstica integral y evaluación del riesgo}

Está recomendado evaluar periódicamente a los pacientes con HAP en centros especializados en HP. Es necesario realizar una evaluación integral, dado que no existe ninguna variable única que proporcione suficiente información diagnóstica y pronóstica. Las preguntas más importantes que se debe plantear en cada consulta son: a) ¿hay evidencia de deterioro clínico desde el último examen?; b) en caso afirmativo, ¿el deterioro clínico está causado por la progresión de la HP o por enfermedades concomitantes?; c) ¿la función del VD es estable y suficiente?, y d) ¿el estado actual del paciente es compatible con un buen pronóstico a largo plazo, es decir, el paciente cumple criterios de riesgo bajo? (véase más adelante).

Con el fin de responder a estas preguntas, es necesaria una estrategia multidimensional. La tabla 13 relaciona las variables más empleadas en los centros especializados en HP. No es necesario evaluar todos estos parámetros en cada consulta de seguimiento. El programa básico de evaluación debe incluir la determinación de la CF y al menos una medición de la capacidad de ejercicio (PM6M o prueba de esfuerzo cardiopulmonar). También se recomienda obtener información sobre la función del VD determinando las concentraciones de BNP/NT-proBNP o mediante ecocardiografía. La mayoría de las variables propuestas y los valores de corte se basan en la opinión de expertos. Proporcionan información diagnóstica y pueden emplearse para guiar las decisiones terapéuticas, pero su aplicación a pacientes individuales se debe hacer con precaución. Las tasas de mortalidad indicadas son estimaciones brutas y las variables descritas se han estudiado fundamentalmente en pacientes con HAPI. No todas las variables se encuentran en el mismo grupo de riesgo y la evaluación integral del paciente individual es lo que debe guiar las decisiones terapéuticas. El riesgo individual se modifica además por otros factores, como el grado de progreso de la enfermedad y la presencia o ausencia de signos de IC derecha, síncope o comorbilidades, además de la edad, el sexo, el tratamiento de base y el subtipo de HAP, entre otros.

Por último, la evaluación de los pacientes con HAP debe proporcionar información sobre comorbilidades y complicaciones de la enfermedad. Se debe obtener periódicamente un ECG para detectar arritmias clínicamente significativas, ya que son frecuentes en este tipo de pacientes ${ }^{33}$. En algunas ocasiones los pacientes con HAP presentan hipoxemia progresiva y pueden ser candidatos a tratamiento con $\mathrm{O}_{2}$ a largo plazo. Además, una $\mathrm{pCO}_{2}$ arterial baja se asocia con flujo sanguíneo pulmonar reducido y tiene implicaciones pronósticas ${ }^{38}$. Por lo tanto, los gases sanguíneos arteriales y capilares proporcionan información pronóstica y deben estar incluidos en la evaluación periódica, al menos en los casos de deterioro clínico. Como alternativa se puede emplear la saturación periférica de $\mathrm{O}_{2}$, pero es menos fiable y no proporciona información sobre la $\mathrm{pCO}_{2}$ arterial. Los análisis básicos de laboratorio recomendados (además del BNP/NT-proBNP) incluyen el recuento sanguíneo y la razón internacional normalizada (INR) de los pacientes tratados con antagonistas de la vitamina K, además de concentraciones séricas de sodio, potasio, creatinina, ácido úrico, aspartato aminotransferasa, alanina aminotransferasa (pacientes tratados con ARE) y bilirrubina. Además se debe evaluar la troponina, el

Tabla 13

Evaluación del riesgo en la hipertensión arterial pulmonar

\begin{tabular}{|c|c|c|c|}
\hline $\begin{array}{l}\text { Factores pronósticos }{ }^{\text {a }} \text { (mortalidad } \\
\text { estimada a } 1 \text { año) }\end{array}$ & Riesgo bajo $(<5 \%)$ & Riesgo intermedio (5-10\%) & Riesgo alto (> 10\%) \\
\hline Signos clínicos de IC derecha & Ausentes & Ausentes & Presentes \\
\hline Progresión de los síntomas & No & Lenta & Rápida \\
\hline Síncope & No & Síncope ocasional ${ }^{\mathrm{b}}$ & Síncopes de repetición ${ }^{c}$ \\
\hline CF-OMS & I, II & III & IV \\
\hline PM6M & $>440 \mathrm{~m}$ & $165-440 \mathrm{~m}$ & $<165 \mathrm{~m}$ \\
\hline Test de esfuerzo cardiopulmonar & $\begin{array}{c}\mathrm{VO}_{2} \text { pico }>15 \mathrm{ml} / \mathrm{min} / \mathrm{kg}(>65 \% \\
\text { del predicho) } \mathrm{VE} / \mathrm{VCO}_{2}<36\end{array}$ & $\begin{array}{c}\mathrm{VO}_{2} \text { pico } 11-15 \mathrm{ml} / \mathrm{min} / \mathrm{kg}(35-65 \% \\
\text { del predicho) } \mathrm{VE} / \mathrm{VCO}_{2} 36-44,9\end{array}$ & $\begin{array}{c}\mathrm{VO}_{2} \text { pico }<11 \mathrm{ml} / \mathrm{min} / \mathrm{kg}(<35 \% \\
\text { del predicho), } \mathrm{VE} / \mathrm{VCO}_{2} \geq 45\end{array}$ \\
\hline Concentración plasmática de NT-proBNP & $\mathrm{BNP}<50 \mathrm{ng} / \mathrm{l}, \mathrm{NT}$-proBNP $<300 \mathrm{ng} / \mathrm{l}$ & $\begin{array}{c}\text { BNP 50-300 ng/l, NT-proBNP } \\
\text { 300-1.400 ng/l }\end{array}$ & $\mathrm{BNP}>300 \mathrm{ng} / \mathrm{l}, \mathrm{NT}-\mathrm{proBNP}>1.400 \mathrm{ng} / \mathrm{l}$ \\
\hline Imagen (ecocardiografía, RMC) & $\begin{array}{c}\text { Área de } \mathrm{AD}<18 \mathrm{~cm}^{2} \text { sin derrame } \\
\text { pericárdico }\end{array}$ & $\begin{array}{l}\text { Área de } \mathrm{AD} 18-26 \mathrm{~cm}^{2} \text { con derrame } \\
\text { pericárdico mínimo o ausente }\end{array}$ & $\begin{array}{c}\text { Área de } \mathrm{AD}>26 \mathrm{~cm}^{2} \text { con derrame } \\
\text { pericárdico }\end{array}$ \\
\hline Parámetros hemodinámicos & $\begin{array}{c}\mathrm{PAD}<8 \mathrm{mmHg} \text {, índice cardiaco } \\
\geq 2,5 \mathrm{l} / \mathrm{min} / \mathrm{m}^{2}, \mathrm{SvO}_{2}>65 \%\end{array}$ & $\begin{array}{l}\text { PAD 8-14 mmHg, índice cardiaco } \\
2,0-2,41 / \mathrm{min} / \mathrm{m}^{2}, \mathrm{SvO}_{2} 60-65 \%\end{array}$ & $\begin{aligned} \mathrm{PAD} & >14 \mathrm{mmHg} \text {, índice cardiaco } \\
& <2,0 \mathrm{l} / \mathrm{min} / \mathrm{m}^{2}, \mathrm{SvO}_{2}<60 \%\end{aligned}$ \\
\hline
\end{tabular}

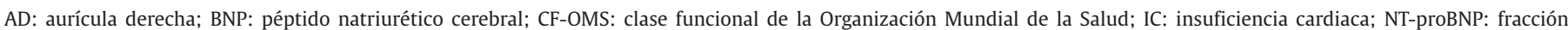

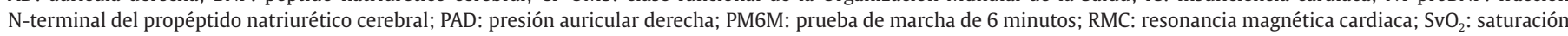

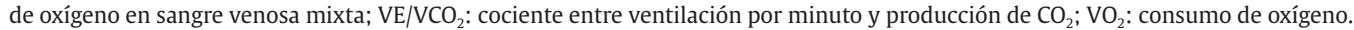

aLa mayoría de las variables y los valores de corte propuestos se basan en la opinión de expertos. Pueden aportar información pronóstica y se pueden usar para guiar las

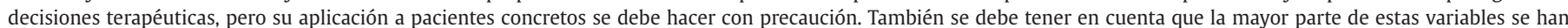

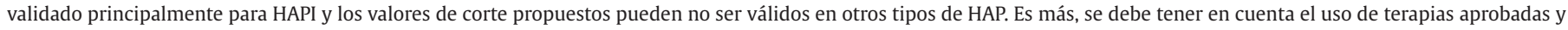
su influencia en las variables para la evaluación del riesgo.

bSíncope durante el ejercicio intenso ocasional o síncope ortostático ocasional en un paciente por lo demás estable.

'Episodios sincopales repetidos incluso con actividad física reducida o habitual. 
Tabla 14

Evaluaciones aconsejadas y su planificación para el seguimiento de pacientes con hipertensión arterial pulmonar

\begin{tabular}{|c|c|c|c|c|c|}
\hline & Basal & Cada 3-6 meses ${ }^{\mathrm{a}}$ & Cada 6-12 meses ${ }^{\mathrm{a}}$ & $\begin{array}{l}\text { A los 3-6 meses de } \\
\text { cambios en el tratamiento }^{\text {a }}\end{array}$ & $\begin{array}{l}\text { En caso de } \\
\text { empeoramiento clínico }\end{array}$ \\
\hline $\begin{array}{l}\text { Valoración clínica y determinación de clase } \\
\text { funcional }\end{array}$ & + & + & + & + & + \\
\hline ECG & + & + & + & + & + \\
\hline PM6M/índice de disnea de Borg & + & + & + & + & + \\
\hline PECP & + & & + & & $+\mathrm{b}$ \\
\hline Ecocardiograma & + & & + & + & + \\
\hline Analítica básicab & + & + & + & + & + \\
\hline Analítica ampliadac & + & & + & & + \\
\hline $\mathrm{GAB}^{\mathrm{d}}$ & + & & + & + & + \\
\hline Cateterismo cardiaco derecho & + & & $+f$ & $+e$ & $+e$ \\
\hline
\end{tabular}

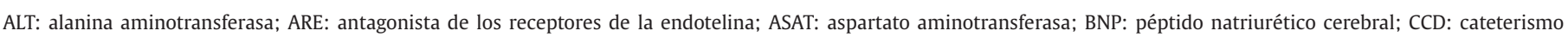

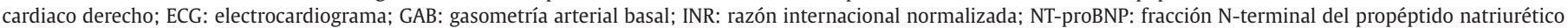
cerebral; PECP: prueba de esfuerzo cardiopulmonar; PM6M: prueba de marcha de 6 minutos; TSH: tirotropina.

aLos intervalos deben ajustarse a las necesidades individuales de cada paciente.

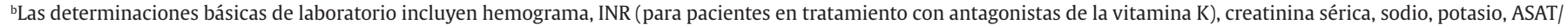
ALT (para pacientes en tratamiento con ARE), bilirrubina y BNP/NT-proBNP.

'Las determinaciones de laboratorio ampliadas incluyen TSH, troponina, ácido úrico, perfil férrico (hierro, ferritina, receptor soluble de transferrina) y otros parámetros en función de las necesidades de cada paciente.

dProcedente de sangre arterial o sangre capilar arterializada; se puede sustituir por saturación periférica de oxígeno en pacientes estables o si la GAB no está disponible.

eSe debe considerar.

${ }^{\mathrm{f}}$ Algunos centros realizan CCD a intervalos regulares en el seguimiento.

ácido úrico, el estado férrico y la función tiroidea como mínimo una vez al año o siempre que el paciente sufra un empeoramiento clínico. Las tablas 14 y 15 contienen recomendaciones detalladas sobre las evaluaciones de seguimiento de los pacientes con HAP.

\subsubsection{Definición del estado del paciente}

En base a la evaluación integral descrita anteriormente, los pacientes se pueden clasificar en pacientes con riesgo bajo, intermedio o alto de empeoramiento clínico o muerte (tabla 13). Además, existen otros factores que pueden influir en la manifestación y el pronóstico de la enfermedad que no se ven afectados por el tratamiento de la HAP, entre ellos la edad, el sexo, la enfermedad subyacente y las comorbilidades. Aunque siempre resulta difícil realizar una predicción indivi-

Tabla 15

Recomendaciones para evaluar la gravedad de la hipertensión arterial pulmonar y la respuesta clínica al tratamiento

\begin{tabular}{|c|c|c|c|}
\hline Recomendaciones & Clase $^{\mathrm{a}}$ & Nivel $^{\mathrm{b}}$ & $\operatorname{Ref}^{c}$ \\
\hline $\begin{array}{l}\text { Se recomienda evaluar la gravedad de los pacientes } \\
\text { con HAP con un panel de datos basados en valoración } \\
\text { clínica, pruebas de ejercicio, marcadores bioquímicos } \\
\text { y evaluaciones ecocardiográficas y hemodinámicas } \\
\text { (tablas } 13 \text { y 14) }\end{array}$ & I & C & $\begin{array}{c}96,97 \\
99\end{array}$ \\
\hline $\begin{array}{l}\text { Se recomienda seguimiento regular de los pacientes } \\
\text { estables cada 3-6 meses (tabla 14) }\end{array}$ & I & C & 98 \\
\hline $\begin{array}{l}\text { Se considera adecuada respuesta al tratamiento de } \\
\text { pacientes con HAP alcanzar/mantener un perfil } \\
\text { de riesgo bajo (tabla 13) }\end{array}$ & I & C & $96-99$ \\
\hline $\begin{array}{l}\text { Para la mayoría de los pacientes con HAP, se debe } \\
\text { considerar respuesta al tratamiento inadecuada } \\
\text { alcanzar/mantener un perfil de riesgo intermedio } \\
\text { (tabla 13) }\end{array}$ & IIa & C & $96-99$ \\
\hline
\end{tabular}

HAP: hipertensión arterial pulmonar.

${ }^{a}$ Grado de recomendación.

bNivel de evidencia.

'Referencias que respaldan las recomendaciones. dual fiable, los pacientes considerados de bajo riesgo tienen una mortalidad al año estimada $<5 \%$. Básicamente estos pacientes tienen enfermedad no progresiva con CF-OMS I o II y PM6M > $440 \mathrm{~m}$ y no presentan signos de disfunción VD clínicamente relevante. La tasa estimada de mortalidad al año de los pacientes con riesgo intermedio es de un 5-10\%. Estos pacientes se presentan típicamente con CF-OMS III, con una disminución moderada de la capacidad de ejercicio y signos de disfunción del VD, pero sin insuficiencia. Los pacientes del grupo de alto riesgo tienen una mortalidad al año estimada $>10 \%$, CF-OMS III o IV con enfermedad progresiva y signos de disfunción del VD grave o insuficiencia del VD y disfunción orgánica secundaria. Las variables que se muestran en la tabla 13 pueden comportarse de manera poco firme, es decir, pueden estar incluidas en distintas categorías de riesgo. Una vez más hay que señalar que la evaluación integral es lo que debe guiar las decisiones terapéuticas.

\subsubsection{Objetivos del tratamiento y estrategia de seguimiento}

El objetivo general del tratamiento de los pacientes con HAP es lograr un estado de riesgo bajo (tabla 13), lo cual normalmente se asocia con buena capacidad de ejercicio, buena calidad de vida, buena función del VD y bajo riesgo de muerte. Esto significa concretamente lograr que el paciente se mantenga en CF-OMS II siempre que sea posible. En la mayoría de los pacientes esto se acompaña de una PM6M normal o casi normal. Se han propuesto varios objetivos de tratamiento según la PM6M para distancias $>380,>440 \mathrm{y}>500 \mathrm{~m}^{96,99,116-118,144}$. Estas distancias se basan en análisis de supervivencia de cohortes seleccionadas o en la opinión de expertos. La presente guía adopta el umbral $>440 \mathrm{~m}$ propuesto en el 5. ${ }^{\circ}$ Simposio Mundial sobre Hipertensión Pulmonar ${ }^{145}$ porque se deriva de la cohorte más grande estudiada hasta la fecha ${ }^{99}$. No obstante, se debe tener en cuenta los factores individuales de cada paciente, y puede ser aceptable un umbral más bajo para ancianos y pacientes con comorbilidades, mientras que en pacientes jóvenes sin otras enfermedades un umbral $>440 \mathrm{~m}$ podría ser insuficiente. Especialmente a estos se les debe realizar regularmente una prueba de esfuerzo cardiopulmonar, ya que esta prueba proporciona información más objetiva sobre la capacidad de ejercicio y la función del VD. 
Hay que señalar que estos objetivos de tratamiento no siempre son realistas y quizá no se logren en pacientes con enfermedad avanzada, comorbilidades graves o muy ancianos.

\subsection{Tratamiento}

El tratamiento de los pacientes con HAP ha evolucionado progresivamente en la última década, a la vez que ha aumentado su complejidad y la evidencia de su eficacia ${ }^{146-148}$. No se puede considerar el proceso de tratamiento de los pacientes con HAP una mera prescripción de fármacos, sino una estrategia compleja que incluye la evaluación inicial de la gravedad de la enfermedad y la posterior respuesta al tratamiento.

La estrategia actual para el tratamiento de los pacientes con HAP se puede dividir en 3 pasos fundamentales ${ }^{149}$ :

1. El enfoque inicial incluye medidas generales (actividad física y rehabilitación supervisada, embarazo, anticoncepción, terapia hormonal posmenopáusica, cirugía electiva, prevención de infecciones, apoyo psicosocial, adherencia a los tratamientos, asesoramiento genético y desplazamientos), terapia de apoyo (anticoagulantes orales, diuréticos, $\mathrm{O}_{2}$, digoxina), derivación del paciente a un centro especializado y pruebas de vasorreactividad aguda para la indicación de tratamiento indefinido con BCC.

2. El segundo paso incluye el tratamiento inicial con dosis altas de BCC para pacientes vasorreactivos o fármacos aprobados para la HAP para pacientes no vasorreactivos, de acuerdo con el riesgo pronóstico del paciente (tabla 13), el grado de recomendación y el nivel de evidencia de cada componente individual o de la combinación de componentes.

3. El tercer paso tiene relación con la respuesta al tratamiento inicial; si la respuesta es inadecuada, se propone la combinación de fármacos aprobados y el trasplante pulmonar.

\subsubsection{Medidas generales}

Los pacientes con HAP requieren asesoramiento específico sobre las actividades de la vida diaria y deben adaptarse a la incertidumbre que conlleva una enfermedad crónica grave que puede poner en peligro su vida. El diagnóstico suele producir cierto grado de aislamiento social ${ }^{150}$. Animar a los pacientes y sus familias a formar parte de grupos de apoyo puede tener efectos positivos a la hora de abordar la enfermedad y ganar seguridad y una perspectiva positiva frente a ella. Las recomendaciones sobre las medidas generales se encuentran en la tabla 16.

\subsubsection{Actividad física y rehabilitación supervisada}

La guía sobre HP de 2009 recomendaba animar a los pacientes a mantenerse activos dentro de los límites de sus síntomas ${ }^{151}$. También recomendaba que los pacientes debían evitar una actividad física excesiva que les causara síntomas dolorosos, pero que los pacientes en baja forma física debían realizar ejercicios de rehabilitación supervisados. Esta recomendación se basaba en un ensayo clínico aleatorizado (ECA) que demostró una mejora de la capacidad física y funcional y de la calidad de vida de los pacientes con HP que participaron en un programa de entrenamiento, comparados con el grupo de control sin entrenamiento físico ${ }^{152}$. Desde entonces, los resultados de varios estudios sin grupo de control que emplearon distintos modelos de entrenamiento físico respaldan estos datos ${ }^{153-157}$. Otros 2 ECA publicados recientemente indican que los pacientes con $\mathrm{PAH}$ que realizaban entrenamiento físico alcanzaron niveles más altos de actividad física y menor grado de fatiga y mostraron mejores resultados de la PM6M y la función cardiorrespiratoria y una mejor calidad de vida referida por el paciente que los controles sin entrenamiento ${ }^{158,159}$. Los tamaños muestrales de todos estos estudios son bastante pequeños (de 19 a
Tabla 16

Recomendaciones sobre las medidas generales

\begin{tabular}{lcccc}
\hline Recomendaciones & Clase $^{\mathrm{a}}$ & Nivel $^{\mathrm{b}}$ & Ref $^{\mathrm{c}}$ \\
\hline $\begin{array}{l}\text { Se recomienda a las pacientes con HAP evitar } \\
\text { el embarazo }\end{array}$ & $\mathrm{I}$ & $\mathrm{C}$ & 160,161 \\
\hline $\begin{array}{l}\text { Se recomienda la inmunización de pacientes } \\
\text { con HAP contra gripe y neumococos }\end{array}$ & $\mathrm{I}$ & $\mathrm{C}$ & \\
\hline $\begin{array}{l}\text { Se recomienda proporcionar apoyo psicosocial } \\
\text { a pacientes con HAP }\end{array}$ & $\mathrm{I}$ & $\mathrm{C}$ & 168 \\
\hline $\begin{array}{l}\text { Se debe considerar el entrenamiento físico } \\
\text { supervisado de pacientes con HAP y mala forma } \\
\text { física en tratamiento médico }\end{array}$ & Ila & B & $153-157$ \\
\hline $\begin{array}{l}\text { Se debe considerar la administración de } \mathrm{O}_{2} \text { en los } \\
\text { viajes en avión de pacientes en CF-OMS III/IV } \\
\text { o con PaO }\end{array}$ sistemáticamente $<8$ kPa (60 mmHg) & Ila & C & \\
\hline $\begin{array}{l}\text { En cirugía electiva, se prefiere la anestesia epidural } \\
\text { a la general siempre que sea posible }\end{array}$ & Ila & C & \\
\hline $\begin{array}{l}\text { Para pacientes con HAP, no se recomienda una } \\
\text { actividad física excesiva que pueda conducir a una } \\
\text { exacerbación de los síntomas }\end{array}$ & III & C & \\
\hline
\end{tabular}

HAP: hipertensión arterial pulmonar; CF-OMS: clase funcional de la Organización Mundial de la Salud.

${ }^{a}$ Grado de recomendación.

bNivel de evidencia.

cReferencias que respaldan las recomendaciones.

183 pacientes) y todo el programa de entrenamiento o su fase inicial estaban estrechamente supervisados, y en algunos casos se realizó en un contexto hospitalario.

Esta recomendación está limitada por la falta de datos sobre el método óptimo de ejercicio de rehabilitación y las mejores intensidad y duración del programa de entrenamiento. Además, no están claras las características de la supervisión ni los mecanismos para la mejoría de los síntomas, la capacidad funcional y física o sus posibles efectos en el pronóstico. Los programas de entrenamiento físico deben ser implementados por centros especializados en HAP y en rehabilitación de pacientes con deterioro clínico. Además, los pacientes deben recibir un tratamiento farmacológico óptimo y estar clínicamente estables antes de comenzar un programa de rehabilitación supervisada.

\subsubsection{Embarazo, control de natalidad y terapia hormonal posmenopáusica}

Entre las pacientes con HAP, el embarazo sigue estando asociado con una importante tasa de mortalidad. Sin embargo, un informe reciente indica que los resultados de los embarazos en la HAP han mejorado, al menos cuando la HAP está bien controlada y, particularmente, en las pacientes que responden al tratamiento con BCC a largo plazo $^{160}$. Durante un periodo de 3 años los 13 centros participantes en este estudio notificaron 26 embarazos; 3 mujeres (12\%) fallecieron y 1 (4\%) sufrió una IC derecha que precisó trasplante urgente de corazónpulmón. Hubo 8 abortos, 2 espontáneos y 6 inducidos. Un total de 16 embarazos (62\%) llegaron a buen término y las mujeres dieron a luz hijos sanos sin complicaciones. Un estudio americano de 5 centros realizado entre 1999 y 2009 notificó 3 muertes (17\%) en 18 embara$\operatorname{zos}^{161}$. Estos datos deben confirmarse en series más grandes para que se pueda considerar una recomendación general de evitar el embarazo para todas las pacientes con HAP. Hay menos consenso cuando se trata de los métodos de control de natalidad más apropiados. Los métodos anticonceptivos de barrera son seguros para las pacientes, pero su efecto es impredecible. Los preparados de progesterona sola, como el acetato de medroxiprogesterona y el etonogestrel, son efectivos para la anticoncepción y evitan los problemas potenciales de los estrógenos, como los que se asociaron con la minipíldora de generaciones anteriores ${ }^{162}$. Hay que recordar que el bosentán (ARE) puede 
reducir la eficacia de los anticonceptivos orales. El dispositivo intrauterino liberador de levonorgestrel (DIU-LNG) también es efectivo pero, aunque en raras ocasiones, al insertarlo puede producir una reacción vasovagal que sería mal tolerada en la HAP grave ${ }^{162}$. También puede emplearse una combinación de ambos métodos. La paciente que queda embarazada debe ser informada del alto riesgo del embarazo y se debería hablar con ella sobre su interrupción. Las pacientes que deciden continuar con su embarazo deben recibir tratamiento con objetivos basados en la enfermedad; se debe planificar el parto electivo, y es fundamental la estrecha colaboración entre los obstetras y el equipo de HAP163,164.

No está claro si es aconsejable emplear terapia hormonal en mujeres posmenopáusicas con HAP. Puede considerarse combinarla con anticoagulantes orales en los casos de síntomas menopáusicos no tolerados.

\subsubsection{Cirugía electiva}

La cirugía electiva se asocia con un aumento del riesgo en los pacientes con HAP. No está claro qué tipo de anestesia es preferible, pero probablemente la epidural se tolere mejor que la anestesia general $^{165-167}$. Los pacientes que reciben tratamiento oral pueden requerir una conversión temporal a tratamiento intravenoso o nebulizado hasta que puedan tragar y absorber fármacos administrados por vía oral.

\subsubsection{Prevención de infecciones}

Los pacientes con HAP son susceptibles de sufrir neumonía, que es la causa de muerte del $7 \%$ de los $\operatorname{casos}^{34}$. Aunque no existen datos de estudios con controles, se recomienda vacunar a los pacientes contra la gripe y la neumonía neumocócica.

\subsubsection{Apoyo psicosocial}

La HP es una enfermedad que tiene un impacto importante en aspectos psicológicos, sociales (incluidos los financieros), emocionales y espirituales de los pacientes y sus familias ${ }^{168}$. Los equipos encargados de estos pacientes deben tener habilidades y experiencia en la evaluación y el manejo de este tipo de problemas, y acceso a profesionales de otras disciplinas relevantes, como psiquiatría, psicología clínica y asuntos sociales, para los pacientes con problemas graves. Los grupos de apoyo a los pacientes también desempeñan un papel importante y se debe aconsejar a los pacientes que se unan a ellos.

La HP es una enfermedad que puede limitar la vida de manera importante. Por ello, además del apoyo psicológico y social, es preciso planificar con antelación otras medidas de atención, como la derivación del paciente a un servicio de cuidados paliativos cuando sea necesario.

\subsubsection{Adherencia a los tratamientos}

Es necesario supervisar periódicamente la adherencia a los tratamientos debido a la complejidad de los tratamientos para la HAP y la posibilidad de que el régimen de tratamiento sea reducido o modificado por decisión espontánea del paciente o por consejo de médicos sin experiencia en este campo.

\subsubsection{Desplazamientos}

Ningún estudio ha empleado la simulación de vuelo para determinar la necesidad de $\mathrm{O}_{2}$ suplementario durante los vuelos prolongados de pacientes con HAP. Los efectos fisiológicos de la hipoxia conocidos indican que se debe considerar la administración de $\mathrm{O}_{2}$ durante el vuelo de pacientes en CF-OMS III o IV o con $\mathrm{PaO}_{2}$ habitualmente $<8 \mathrm{kPa}(60 \mathrm{mmHg})^{169}$. Un flujo de $2 \mathrm{l} / \mathrm{min}$ aumentará la presión de $\mathrm{O}_{2}$ inspirado hasta valores observados a nivel del mar. Del mismo modo, estos pacientes deben evitar las altitudes superiores a $1.500-2.000 \mathrm{~m}$ $\sin \mathrm{O}_{2}$ suplementario. Hay que recomendar a los pacientes que viajen con información escrita sobre su HAP e información de contacto sobre centros de HP que se encuentren en las proximidades del lugar al que viajan.

\subsubsection{Consejo genético}

Se debe ofrecer consejo genético a algunos pacientes con HAP seleccionados (más información en la sección 5.1.12) 26. Debido al impacto psicológico que pueden causar los resultados, ya sean positivos o negativos, las pruebas y el consejo genético deben realizarse según la normativa aplicable y en el contexto de un equipo multidisciplinario en el que colaboren especialistas de HP, asesores genéticos, genetistas, psicólogos y personal de enfermería. Los individuos afectados o los miembros de familias en riesgo pueden requerir información sobre el estado de la mutación para su planificación familiar. Las opciones reproductivas actuales para parejas con un portador de la mutación del gen BMPR2 son no tener hijos, no realizar pruebas genéticas prenatales (oportunidad reproductiva), someterse a diagnóstico genético prenatal o preimplante ${ }^{170}$, emplear la donación de gametos o adoptar.

\subsubsection{Terapia de apoyo}

Las recomendaciones para la terapia de apoyo se recogen en la tabla 17.

\subsubsection{Anticoagulantes orales}

Hay una alta prevalencia de lesiones trombóticas vasculares en los estudios post mortem de pacientes con HAPI ${ }^{171}$. También se han observado anomalías en las vías de la coagulación y la fibrinolisis ${ }^{172-174}$. Estos hallazgos, junto con el aumento de factores de riesgo de tromboembolia venosa inespecíficos, como la IC y la inmovilidad, son los fundamentos principales de la anticoagulación oral en la HAP. La

Tabla 17

Recomendaciones para la terapia de apoyo

\begin{tabular}{|c|c|c|c|}
\hline Recomendaciones & Clase $^{\mathrm{a}}$ & Nivel $^{\mathrm{b}}$ & $\operatorname{Ref}^{c}$ \\
\hline $\begin{array}{l}\text { Se recomienda el tratamiento diurético para } \\
\text { pacientes con HAP con datos de insuficiencia del VD } \\
\text { y retención de líquidos }\end{array}$ & I & C & 178 \\
\hline $\begin{array}{l}\text { Se recomienda la oxigenoterapia continua } \\
\text { para pacientes con } \mathrm{HAP} \text { cuando la } \mathrm{PaO}_{2} \text { sea } \\
\text { sistemáticamente }<8 \mathrm{kPa}(60 \mathrm{mmHg})^{\mathrm{d}}\end{array}$ & I & C & 179 \\
\hline $\begin{array}{l}\text { Se podría considerar el tratamiento con } \\
\text { anticoagulantes orales para pacientes con HAPI, } \\
\text { HAPH y HAP secundaria a anorexigénicos }\end{array}$ & IIb & C & $\begin{array}{r}84,171 \\
175-177\end{array}$ \\
\hline $\begin{array}{l}\text { Se podría considerar la corrección de la anemia y el } \\
\text { perfil férrico de pacientes con HAP }\end{array}$ & IIb & C & 184 \\
\hline $\begin{array}{l}\text { No se recomienda el uso de inhibidores de la enzima } \\
\text { de conversión de la angiotensina, antagonistas del } \\
\text { receptor de la angiotensina II, bloqueadores beta e } \\
\text { ivabradina para pacientes con HAP, a menos que sea } \\
\text { necesario por otras comorbilidades (p. ej., presión } \\
\text { arterial sistémica elevada, enfermedad coronaria } \\
\text { o insuficiencia cardiaca izquierda) }\end{array}$ & III & C & \\
\hline
\end{tabular}

HAP: hipertensión arterial pulmonar; $\mathrm{HAPH}$ : hipertensión arterial pulmonar heredable; HAPI: hipertensión arterial pulmonar idiopática; $\mathrm{PaO}_{2}$ : presión arterial de oxígeno; VD: ventrículo derecho.

arado de recomendación.

bNivel de evidencia.

'Referencias que respaldan las recomendaciones.

dVéase también las recomendaciones para la HAP asociada con cortocircuitos cardiacos congénitos. 
evidencia a favor de la anticoagulación oral se limita a pacientes con HAPI, HAPH y HAP causada por anorexígenos y generalmente proviene de estudios retrospectivos y experiencias de un único centro $^{84,171}$. Los datos de registros y ECA son heterogéneos y no concluyentes ${ }^{175-177}$. Los beneficios potenciales de la anticoagulación oral para pacientes con HAPA están incluso menos claros. Por lo general, los pacientes con HAP que reciben tratamiento i.v. con prostaglandinas a largo plazo están anticoagulados en ausencia de contraindicaciones debido en parte al riesgo adicional de trombosis asociada al catéter. Se desconoce el papel de los nuevos anticoagulantes orales en la HAP. En las secciones correspondientes se encuentra información adicional sobre la HAPA.

\subsubsection{Diuréticos}

La IC derecha descompensada produce retención de líquidos, un aumento de la presión venosa central, congestión hepática, ascitis y edema periférico. Aunque no hay ningún ECA sobre el uso de diuréticos en la HAP, la experiencia clínica muestra que esta terapia alivia los síntomas de pacientes con sobrecarga de fluidos. La elección y la dosis del tratamiento diurético deben quedar a discreción del médico de HAP ${ }^{178}$. Se debe considerar la adición de antagonistas de la aldosterona, junto con evaluaciones sistemáticas de las concentraciones plasmáticas de electrolitos. Es importante observar la función renal y la bioquímica sanguínea de los pacientes tratados con diuréticos para evitar la hipopotasemia y los efectos de la disminución del volumen intravascular que llevan a la insuficiencia prerrenal.

\subsubsection{Oxígeno}

Aunque se ha demostrado que la administración de $\mathrm{O}_{2}$ reduce la RVP de pacientes con HAP, no hay datos de ECA que indiquen que una terapia de $\mathrm{O}_{2}$ a largo plazo es beneficiosa. La mayoría de los pacientes con HAP, excepto aquellos con CC y cortocircuitos sistemicopulmonares, tienen grados leves de hipoxemia arterial en reposo, a menos que tengan un foramen oval permeable. Hay datos que demuestran que la terapia nocturna con $\mathrm{O}_{2}$ no modifica la historia natural del síndrome de Eisenmenger avanzado ${ }^{179}$. El tratamiento se puede guiar por la evidencia obtenida de pacientes con EPOC; cuando la presión de $\mathrm{O}_{2}$ en sangre arterial es constantemente $<8 \mathrm{kPa}(60 \mathrm{mmHg} 0<91 \%$ de la saturación arterial de $\mathrm{O}_{2}$ ) se aconseja a los pacientes que reciban $\mathrm{O}_{2}$ para llegar a una $\mathrm{PaO}_{2}>8 \mathrm{kPa}^{169}$. Se puede considerar el $\mathrm{O}_{2}$ ambulatorio si hay evidencia de beneficio sintomático y desaturación corregible durante el ejercicio.

\subsubsection{Digoxina y otros fármacos cardiovasculares}

Se ha demostrado que la digoxina mejora el GC en los episodios agudos de HAPI, pero se desconoce su eficacia cuando se administra crónicamente ${ }^{180}$. Puede emplearse para reducir la frecuencia ventricular de pacientes con HAP que sufren taquiarritmias auriculares.

No existen datos convincentes sobre la utilidad y la seguridad de los inhibidores de la enzima de conversión de la angiotensina, los antagonistas del receptor de la angiotensina II, los bloqueadores beta o la ivabradina para pacientes con HAP.

\subsubsection{Anemia y estado férrico}

La deficiencia de hierro es frecuente en pacientes con HAP y se ha observado en el $43 \%$ de los pacientes con HAPI, el $46 \%$ de los pacientes con HAP asociada a esclerosis sistémica y el 56\% de los pacientes con síndrome de Eisenmenger ${ }^{181-183}$. En todas estas entidades, datos preliminares indican que la deficiencia de hierro puede estar asociada con una capacidad de ejercicio reducida y quizá también con una mortalidad más alta, independientemente de la presencia y el grado de ane- mia $181,182,184,185$. Con base en estos datos, se debe considerar la monitorización regular del estado férrico en pacientes con HAP y, en caso de que se detecte una deficiencia de hierro, explorar las posibles causas. Para pacientes con deficiencia de hierro se debe considerar el tratamiento de sustitución. Algunos estudios señalan que en los pacientes con HAP la absorción oral de hierro está reducida, por lo que es preferible la administración i.v. ${ }^{181,184,186}$; sin embargo, faltan estudios controlados sobre esta cuestión.

\subsubsection{Tratamiento farmacológico específico}

\subsubsection{Bloqueadores de los canales del calcio}

Cada vez se reconoce más que solo un pequeño número de pacientes con HAPI que muestran una respuesta favorable a la prueba de vasodilatación aguda (tabla 11) durante el CCD se benefician del tratamiento con $\mathrm{BCC}^{84,85}$. Los BCC más utilizados en ensayos clínicos son nifedipino, diltiazem y amlodipino, especialmente los 2 primeros $^{84,85}$. La elección del BCC se basa en la frecuencia cardiaca del paciente en la fase inicial; la presencia de bradicardia relativa favorece el uso de nifedipino y amlodipino, mientras que la taquicardia relativa favorece el uso de diltiazem. Las dosis diarias de estos fármacos que se han demostrado eficaces son bastante altas: 120-240 mg de nifedipino, 240-720 mg de diltiazem y hasta $20 \mathrm{mg}$ de amlodipino. Es aconsejable comenzar con dosis más bajas, por ejemplo, $30 \mathrm{mg}$ de nifedipino de liberación lenta 2 veces al día o $60 \mathrm{mg}$ de diltiazem 3 veces al día o 2,5 mg de amlodipino una vez al día, y después ir aumentando la dosis progresivamente y con precaución hasta llegar a la dosis máxima tolerada. Los factores que suelen limitar el aumento de la dosis son la hipotensión sistémica y el edema periférico en extremidades inferiores. Los pacientes con HAPI que cumplen los criterios de respuesta positiva a la vasodilatación y están tratados con BCC deben tener un seguimiento estricto, por motivos tanto de seguridad como de eficacia, y se debe realizar una revaluación completa que incluya el CCD a los 3-4 meses del inicio del tratamiento.

Si el paciente no muestra una respuesta adecuada, definida como CF-OMS I-II y una mejoría hemodinámica notable (cercana a la normalización), se debe instaurar un tratamiento adicional para la HAP. En algunos casos es necesaria la combinación de BCC y otros fármacos aprobados para la HAP, dado que la interrupción de BCC puede producir un mayor deterioro clínico. Los pacientes que no hayan pasado por una prueba de vasorreactividad o tengan resultados negativos en esta prueba no deben recibir tratamiento con BCC debido al riesgo de efectos secundarios graves (hipotensión, síncope e insuficiencia del VD) $)^{187}$.

No parece que la respuesta a la vasodilatación prediga una respuesta favorable a largo plazo al tratamiento con BCC en pacientes con HAP asociada a ETC, VIH, hipertensión portopulmonar (HPPo) y EVOP ${ }^{188,189}$.

Las recomendaciones sobre el tratamiento con BCC se resumen en la tabla 18. Para las dosis específicas aprobadas, consúltese la información actualizada del prospecto del fármaco.

\subsubsection{Antagonistas de los receptores de la endotelina}

La activación del sistema de la endotelina se ha demostrado tanto en plasma como en tejidos pulmonares de los pacientes con HAP190. Aunque no está claro si el aumento de las concentraciones plasmáticas de endotelina-1 son la causa o la consecuencia de la HP191, los datos obtenidos indican que el sistema de la endotelina tiene un papel importante en la patogenia de la HAP ${ }^{192}$. La endotelina-1 tiene efectos vasoconstrictores y mitogénicos al unirse a las isoformas de 2 receptores distintos (receptores de las endotelinas A y B) en las células de músculo liso de los vasos pulmonares. Las características de los ensayos clínicos sobre fármacos para la HAP que interfieren en la vía de la endotelina se resumen en la tabla 6 del anexo web. 
Tabla 18

Recomendaciones de tratamiento con bloqueadores de los canales del calcio para pacientes que responden a la prueba de vasorreactividad aguda

\begin{tabular}{lcccc}
\hline Recomendaciones & Clase $^{\mathrm{a}}$ & Nivel $^{\mathrm{b}}$ & Ref $^{\mathrm{c}}$ \\
\hline $\begin{array}{l}\text { Se recomiendan altas dosis de BCC para pacientes } \\
\text { con HAPI, HAPH y HAPD que responden a la prueba } \\
\text { de vasorreactividad aguda }\end{array}$ & I & C & 84,85 \\
\hline $\begin{array}{l}\text { Se recomienda estrecho seguimiento con revaluación } \\
\text { completa (incluido el CCD) a los 3-4 meses de iniciar } \\
\text { el tratamiento de pacientes con HAPI, HAPH y HAPD } \\
\text { que reciben altas dosis de BCC }\end{array}$ & & I & & \\
\hline $\begin{array}{l}\text { Se recomienda mantener altas dosis de BCC para } \\
\text { pacientes con HAPI, HAPH y HAPD en CF-OMS I/II } \\
\text { con marcada mejoría hemodinámica (próxima a la } \\
\text { normalización) }\end{array}$ & & I & C & 84,85 \\
\hline $\begin{array}{l}\text { Se recomienda iniciar terapias específicas para } \\
\text { la HAP de pacientes en CF-OMS III/IV o que no } \\
\text { presenten marcada mejoría hemodinámica (próxima } \\
\text { a la normalización) tras recibir altas dosis de BCC }\end{array}$ & & I & C & \\
\hline $\begin{array}{l}\text { No está indicado el tratamiento con altas } \\
\text { dosis de BCC para pacientes sin una prueba de } \\
\text { vasorreactividad aguda o sin respuesta a ella, si } \\
\text { bien se puede prescribir dosis estándar para otras } \\
\text { indicaciones (p. ej., fenómeno de Raynaud) }\end{array}$ & & & \\
\hline
\end{tabular}

BCC: bloqueadores de canales de calcio; CCD: cateterismo cardiaco derecho; CF-OMS: clase funcional de la Organización Mundial de la Salud; HAP: hipertensión arterial pulmonar; HAPD: hipertensión arterial pulmonar inducida por drogas o tóxicos; HAPH: hipertensión arterial pulmonar heredable; HAPI: hipertensión arterial pulmonar idiopática; VD: ventrículo derecho.

${ }^{\mathrm{a}} \mathrm{Grado}$ de recomendacion.

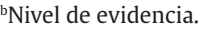

'Referencias que respaldan las recomendaciones.

\section{Ambrisentán}

El ambrisentán es un ARE que se une preferentemente a los receptores de la endotelina A. El ambrisentán se ha evaluado en un estudio piloto $^{193}$ y 2 amplios ECA que han demostrado su eficacia en cuanto a síntomas, capacidad de ejercicio, estado hemodinámico y tiempo hasta el empeoramiento clínico de los pacientes con HAPI y HAP asociada a ETC e infección por el VIH ${ }^{194}$. La incidencia de anomalías en las pruebas de la función hepática oscila entre el 0,8 y el 3\%. En Estados Unidos no es obligatorio realizar mensualmente pruebas de función hepática ${ }^{195}$. El uso de ambrisentán causa un aumento de la incidencia de edema periférico.

\section{Bosentán}

El bosentán es un antagonista dual del receptor de las endotelinas A y B, activo por vía oral y la primera molécula de su tipo que se ha sintetizado. El bosentán se ha evaluado en la HAP (idiopática, asociada a ETC y síndrome de Eisenmenger) en 6 ECA (Study-351, BREATHE-1, BREATHE-2, BREATHE-5, EARLY y COMPASS 2) en los que se observó mejora de la capacidad de ejercicio, la clase funcional, los parámetros hemodinámicos, los parámetros ecocardiográficos y de Doppler y el tiempo al empeoramiento clínico ${ }^{196-200}$. Se produjeron aumentos de las aminotransferasas hepáticas en aproximadamente el $10 \%$ de los pacientes, pero se observó que dependen de la dosis y son reversibles tras la reducción de la dosis o la suspensión del tratamiento. Por esta razón, se debe realizar pruebas de la función hepática una vez al mes a los pacientes tratados con bosentán.

\section{Macitentán}

El ARE dual macitentán se ha evaluado en un ensayo clínico «dirigido por eventos" (event-driven) ${ }^{201}$ en el que se aleatorizó a 742 pacientes a tratamiento con 3 o $10 \mathrm{mg}$ de macitentán o placebo durante una media de 100 semanas. El criterio primario de valoración fue el tiempo transcurrido desde la instauración del tratamiento hasta la aparición de algún evento del resultado compuesto de muerte, septostomía auricular, trasplante de pulmón, instauración de trata- miento i.v. o subcutáneo con prostanoides o empeoramiento de la HAP. El macitentán redujo significativamente la morbilidad y la mortalidad de los pacientes con HAP y también aumentó la capacidad de ejercicio. Los beneficios se observaron tanto en pacientes no tratados previamente como en los que recibían tratamiento adicional para la HAP. Aunque no se detectó toxicidad hepática, se observaron reducciones de hemoglobina en sangre $\leq 8 \mathrm{~g} / \mathrm{dl}$ en el $4,3 \%$ de los pacientes tratados con $10 \mathrm{mg}$ de macitentán.

\subsubsection{Fosfodiesterasa 5 y estimuladores de la guanilato ciclasa}

La inhibición de la fosfodiestarasa 5 (PDE-5), enzima que degrada el monofosfato de guanosina clíclico (GMPc), produce vasodilatación a través de la vía del NO/GMPc en sitios que expresan esta enzima. Dado que la vasculatura pulmonar contiene cantidades sustanciales de PDE-5, se ha investigado el posible beneficio clínico de los inhibidores de la PDE en la HAP. Además, estos inhibidores tienen efectos antiproliferati$\operatorname{vos}^{202,203}$. Los 3 inhibidores de la PDE-5 aprobados para el tratamiento de la disfunción eréctil, el sildenafilo, el tadalafilo y el vardenafilo, producen una importante vasodilatación pulmonar y sus efectos máximos se observan a los 60, 75-90 y 40-45 min respectivamente ${ }^{204}$. Las características de los ECA sobre fármacos para la HAP que interfieren con la vía del NO (estimuladores de la guanilato ciclasa soluble [GCs], inhibidores de la PDE-5) se resumen en la tabla 6 del anexo web.

\section{Sildenafilo}

El sildenafilo es un inhibidor de PDE-5 potente, selectivo y activo por vía oral. Cuatro ECA sobre pacientes con HAP tratados con sildenafilo confirmaron resultados favorables en capacidad de ejercicio, síntomas y parámetros hemodinámicos ${ }^{205-208}$. Un ECA que investigó los efectos de la combinación de sildenafilo con epoprostenol mostró a las 12 semanas una mejora en la PM6M y el tiempo hasta el empeoramiento clínico. Cabe señalar que en ese estudio se produjeron 7 muertes, todas en el grupo de placebo ${ }^{209}$. La dosis de sildenafilo aprobada es $20 \mathrm{mg} 3$ veces al día. La mayoría de los efectos secundarios del sildenafilo son leves o moderados y están relacionados con la vasodilatación (dolor de cabeza, rubor, epistaxis). Con base en datos farmacocinéticos, se ha propuesto ${ }^{210}$ una formulación de sildenafilo i.v. como tratamiento puente para pacientes con HAP en tratamiento oral a largo plazo que temporalmente son incapaces de ingerir pastillas.

\section{Tadalafilo}

El tadalafilo es un inhibidor selectivo de la PDE-5 que se administra una vez al día. Un ECA que incluyó a 406 pacientes con HAP (el 53\% en tratamiento base con bosentán), tratados con 2,5, 10, 20 o $40 \mathrm{mg}$ de tadalafilo una vez al día, mostró resultados favorables en la capacidad de ejercicio, los síntomas, los parámetros hemodinámicos y el tiempo hasta el empeoramiento clínico en el grupo de la dosis más alta $^{211}$. El perfil de efectos secundarios es similar al del sildenafilo.

\section{Vardenafilo}

El vardenafilo es un inhibidor de la PDE-5 que se administra 2 veces al día. Un ECA que incluyó a 66 pacientes no tratados previamente para la HAP que recibieron tratamiento con $5 \mathrm{mg}$ de vardenafilo 2 veces al día mostró resultados favorables en la capacidad de ejercicio, los síntomas, los parámetros hemodinámicos y el tiempo hasta el empeoramiento clínico ${ }^{212}$. El perfil de efectos secundarios es similar al del sildenafilo.

\section{Riociguat}

Mientras que los inhibidores de la PDE-5, como sildenafilo, tadalafilo y vardenafilo, potencian la vía del NO-GMPc ralentizando la degradación del GMPc, los estimuladores del GCs potencian su producción ${ }^{213}$. Además, varios estudios preclínicos han mostrado efectos antiproliferativos y antirremodelado de los estimuladores del GCs en modelos animales. 
Un ECA ${ }^{214}$ que incluyó a 443 pacientes con HAP (el 44 y el 6\% en tratamiento base con ARE o prostanoides respectivamente) tratados con dosis de hasta $2,5 \mathrm{mg}$ de riociguat 3 veces al día mostró resultados favorables en la capacidad de ejercicio, los parámetros hemodinámicos, la CF-OMS y el tiempo hasta el empeoramiento clínico. Se demostró aumento de la capacidad de ejercicio también en los pacientes en tratamiento basal. El evento adverso grave más frecuente, tanto en el grupo de placebo como en el de tratamiento con 2,5 mg de rigociguat, fue el síncope (el 4 y el 1\% respectivamente). La combinación de riociguat e inhibidores de la PDE-5 está contraindicada debido al riesgo de hipotensión y otros efectos secundarios detectados en un ECA sin enmascaramiento ${ }^{215}$.

\subsubsection{Análogos de la prostaciclina y agonistas de los receptores de la prostaciclina}

La prostaciclina se produce de manera predominante por células endoteliales e induce una fuerte vasodilatación en todos los lechos vasculares. Este compuesto es el más potente inhibidor endógeno de la agregación plaquetaria y parece que también tiene efectos citoprotectores y antiproliferativos ${ }^{216}$. Se ha demostrado que los pacientes con HAP tienen alterada la regulación de las vías metabólicas de la prostaciclina, determinada por la reducción de la expresión de la prostaciclina sintasa en las arterias pulmonares y de los metabolitos urinarios de prostaciclina ${ }^{217}$. El uso clínico de la prostaciclina en pacientes con HAP se ha extendido por la síntesis de análogos estables que poseen diferentes propiedades farmacocinéticas pero comparten efectos farmacodinámicos cualitativamente similares.

Las características de los ensayos clínicos sobre fármacos para la HAP que interfieren en la vía de la prostaciclina (prostanoides y agonistas de los receptores de la prostaciclina) se resumen en la tabla $6 \mathrm{C}$ del anexo web.

\section{Beraprost}

El beraprost es el primer análogo de la prostaciclina químicamente estable y activo por vía oral. Un ECA en Europa ${ }^{218}$ y otro en Estados Unidos $^{219}$ han demostrado una mejora de la capacidad de ejercicio que persiste hasta 3-6 meses. No se observaron beneficios en cuanto a los parámetros hemodinámicos o los resultados a largo plazo. Los efectos secundarios más frecuentes fueron cefalea, rubor, dolor de mandíbula y diarrea.

\section{Epoprostenol}

El epoprostenol (prostaciclina sintética) tiene una vida media corta (3-5 min) y solo es estable a temperatura ambiente durante $8 \mathrm{~h}$; requiere refrigeración y administración continua mediante bomba de infusión y catéter permanente. La eficacia de la administración i.v. continua de epoprostenol se ha evaluado en 3 ECA sin enmascaramiento sobre pacientes con HAPI en CF-OMS III y IV ${ }^{220,221}$ y con HAP asociada al espectro de enfermedades esclerodérmicas ${ }^{222}$. El epoprostenol mejora los síntomas, la capacidad de ejercicio y los parámetros hemodinámicos en ambas entidades clínicas y es el único tratamiento con que se ha demostrado reducción de la mortalidad en la HAPI, según los resultados de un ECA ${ }^{221}$. Un metanálisis sobre la mortalidad total de 3 ECA que evaluaron el epoprostenol ${ }^{220-222}$ mostró una reducción del riesgo de muerte de aproximadamente un $70 \%$. Asimismo, se ha demostrado la persistencia de su eficacia ${ }^{96,107}$ en la HAPI, otras entidades de la HAPA ${ }^{223-225}$ y la HPTC no operable ${ }^{226}$.

El tratamiento con epoprostenol se inicia con una dosis de 2-4 ng/ $\mathrm{kg} /$ min y su aumento depende de los efectos secundarios (rubor, cefalea, diarrea, dolor de piernas). Las dosis óptimas varían dependiendo del paciente y oscilan entre 20 y $40 \mathrm{ng} / \mathrm{kg} / \mathrm{min}^{96,107}$.

Las complicaciones graves relacionadas con el sistema de administración son mal funcionamiento de la bomba, infecciones en el lugar de acceso, obstrucción del catéter y sepsis. Se han propuesto recomendaciones para la prevención de infecciones de la vía venosa central per- manente ${ }^{227}$. Se debe evitar la interrupción brusca de la infusión de epoprostenol porque en algunos pacientes esto puede producir un rebote de la HP con deterioro sintomático e incluso muerte. Está disponible una formulación de epoprostenol estable a temperatura ambiente que no requiere el uso de bolsas de refrigeración para mantener la estabilidad después de 8-12 $\mathrm{h}^{228}$.

\section{Iloprost}

El iloprost es un análogo de la prostaciclina químicamente estable que se puede administrar por vía i.v., oral o en aerosol. El iloprost inhalado se ha evaluado en un ECA que comparó el empleo de inhalaciones diarias de iloprost repetidas (de 6 a 9 veces, $2,5-5 \mu \mathrm{g} /$ inhalación; media, $30 \mu$ g diarios) con la inhalación de placebo en pacientes con HAP o HPTC ${ }^{229}$. El estudio mostró un aumento de la capacidad de ejercicio y una mejoría de los síntomas, la RVP y los eventos clínicos en los pacientes participantes. Un segundo ECA que incluyó a 60 pacientes tratados previamente con bosentán mostró un aumento de la capacidad de ejercicio $(\mathrm{p}<0,051)$ de los pacientes aleatorizados a la adición de iloprost inhalado, comparado con placebo ${ }^{230}$. Otro estudio similar se interrumpió prematuramente por falta de utilidad ${ }^{231}$. En general, el iloprost inhalado se toleró bien y sus efectos secundarios más frecuentes fueron el rubor y el dolor de mandíbula. Según los datos de pequeñas series de pacientes con HAP o HPTC, la administración i.v. continua de iloprost es tan efectiva como el epoprostenol ${ }^{232}$. Los efectos del iloprost oral no se han evaluado en la HAP.

\section{Treprostinil}

El treprostinil es un bencideno tricíclico análogo del epoprostenol, con la suficiente estabilidad química para administrarlo a temperatura ambiente. Estas características permiten la administración del compuesto por vía i.v. y subcutánea. La administración subcutánea de treprostinil puede efectuarse por medio de una bomba de microinfusión y un pequeño catéter subcutáneo. Los efectos del treprostinil en la HAP se evaluaron en un ECA, que mostró mejoría de la capacidad de ejercicio, los parámetros hemodinámicos y los síntomas ${ }^{233}$. El mayor aumento de la capacidad de ejercicio se observó en los pacientes con mayor deterioro basal y los que toleraron la dosis en el cuartil superior ( $>13,8 \mathrm{ng} / \mathrm{kg} / \mathrm{min}$ ). El más frecuente efecto adverso del treprostinil fue el dolor en el lugar de la infusión, que causó el abandono del tratamiento en el $8 \%$ de los casos que recibían el fármaco activo y limitó el aumento de la dosis en un porcentaje adicional de pacientes $^{233}$. El tratamiento con treprostinil subcutáneo se inicia con una dosis de 1-2 ng/kg/min, con un aumento de dosis limitado por los efectos secundarios (dolor en la zona de acceso, rubor, cefalea). La dosis óptima varía según cada paciente; en la mayoría oscila entre 20 y $80 \mathrm{ng} / \mathrm{kg} / \mathrm{min}$.

Un ECA para la evaluación del treprostinil i.v. en pacientes con HAP se interrumpió prematuramente por cuestiones de seguridad tras la inclusión de 45 pacientes (36\%) de los 126 que se había programado ${ }^{234}$. Los datos obtenidos de los 31 supervivientes (25\%) aleatorizados (23 a tratamiento activo y 8 a placebo) no son fiables. La dosis de treprostinil i.v. es 2 o 3 veces más alta que la dosis de epoprostenol i.v. ${ }^{235,236}$.

En otro ECA de treprostinil inhalado para pacientes con HAP que recibían tratamiento basal con bosentán o sildenafilo, se obtuvieron mejores resultados en la PM6M (aumento de $20 \mathrm{~m}$ con la dosis máxima y 12 m con la mínima), las determinaciones de NT-proBNP y las mediciones de la calidad de vida ${ }^{237}$.

El treprostinil oral se evaluó en 2 ECA que incluyeron a pacientes con HAP tratados con bosentán o sildenafilo. En ambos estudios el criterio de valoración para la PM6M no alcanzó significación estadística ${ }^{238,239}$.

Otro ECA realizado en pacientes que no habían recibido tratamiento previamente mostró una mejora en la PM6M, con un aumento de $26 \mathrm{~m}$ en el grupo asignado a la dosis máxima y $17 \mathrm{~m}$ en el de dosis mínima ${ }^{240}$. 


\section{Selexipag}

El selexipag es un agonista selectivo del receptor IP de la prostaciclina disponible por vía oral. Aunque el selexipag y su metabolito tienen mecanismos de acción similares a los de la prostaciclina endógena (agonistas del receptor IP), son químicamente distintos y tienen características farmacológicas diferentes. En un estudio piloto en pacientes con HAP (en tratamiento estable con ARE o inhibidores de la PDE-5), el selexipag redujo la RVP después de 17 semanas de tratamiento ${ }^{241}$. Un ECA de fase III «dirigido por eventos» que incluyó a 1.156 pacientes ${ }^{248}$ mostró que el selexipag, solo o añadido al tratamiento simple o doble con ARE o inhibidores de la PDE-5, fue capaz de reducir en un $40 \%$ (hazard ratio $[\mathrm{HR}]=0,60 ; \mathrm{p}<0,001$ ) el objetivo compuesto de morbilidad y mortalidad (que incluía muerte por todas las causas, hospitalización por empeoramiento de la HAP, empeoramiento de la HAP que requirió trasplante pulmonar o septostomía auricular, instauración de tratamiento parenteral con prostanoides o tratamiento con $\mathrm{O}_{2}$ por empeoramiento de la HAP y progresión de la enfermedad).

Las recomendaciones sobre la eficacia de monoterapias específicas se muestran en la tabla 19.

\subsubsection{Compuestos y estrategias experimentales}

A pesar de los progresos en el tratamiento de la HAP, la limitación funcional y la supervivencia de estos pacientes continúan siendo insatisfactorias. Existen 3 vías conocidas que contribuyen a la patogenia de la HAP: la vía de la endotelina, la del NO y la de la prostaciclina. Los tratamientos dirigidos a estas vías están bien establecidos en la práctica clínica e incluyen ARE, inhibidores de la PDE-5 y prostanoi- des. Se están investigando estrategias terapéuticas dirigidas a diversos cambios biopatológicos para mejorar los síntomas y el pronóstico. Se han investigado sin resultados satisfactorios 3 vías con los siguientes compuestos: péptido intestinal vasoactivo, inhibidores de la tirosincinasa (inhibidores del factor de crecimiento derivado de plaquetas) y antagonistas de la serotonina. Y los siguientes compuestos se encuentran en fases iniciales de desarrollo: inhibidores de la rho-cinasa, inhibidores del receptor del factor de crecimiento vascular endotelial, inhibidores de la angiopoyetina 1 e inhibidores de la elastasa. Las estrategias de terapia génica se han probado en animales. La terapia de células madre se ha demostrado efectiva en modelo murino expuesto a monocrotalina, y actualmente se está poniendo a prueba en estudios de prueba de concepto y búsqueda de dosis en pacientes con HAP. Un estudio controvertido ha mostrado favorables datos preliminares del efecto de la denervación de la AP mediante catéter de ablación por radiofrecuencia ${ }^{242,243}$.

\subsubsection{Terapia combinada}

La terapia combinada, definida como el uso simultáneo de 2 o más clases de fármacos, se ha empleado satisfactoriamente para el tratamiento de la hipertensión sistémica y la IC. Es también un concepto atractivo para el manejo de la HAP dado que se puede dirigir mediante fármacos específicos a las 3 vías conocidas que intervienen en la enfermedad: la vía de la prostaciclina (prostanoides), la vía de la endotelina (ARE) y la vía del NO (inhibidores de la PDE-5 y del GCs). El uso de la terapia combinada está aumentando y los resultados de un metanálisis de 6 ECA que incluyeron a 858 pacientes se han publicado recientemente ${ }^{244}$. Comparada con el grupo de control, la terapia com-

Tabla 19

Recomendaciones sobre la eficacia de la monoterapia farmacológica para la hipertensión arterial pulmonar (grupo 1) según la CF-OMS

\begin{tabular}{|c|c|c|c|c|c|c|c|c|c|}
\hline \multirow{3}{*}{$\begin{array}{l}\text { Medida/tratamiento } \\
\text { Bloqueadores de los canales de calcio }\end{array}$} & & & \multicolumn{6}{|c|}{ Clase $^{\mathrm{a}}-$ Nivel $^{\mathrm{b}}$} & \multirow{3}{*}{$\begin{array}{l}\operatorname{Ref}^{\mathrm{c}} \\
84,85\end{array}$} \\
\hline & & & \multicolumn{2}{|c|}{ CF-OMS II } & \multicolumn{2}{|c|}{ CF-OMS III } & \multicolumn{2}{|c|}{ CF-OMS IV } & \\
\hline & & & I & $C^{d}$ & I & $\mathrm{C}^{\mathrm{d}}$ & - & - & \\
\hline \multirow[t]{3}{*}{ Antagonistas del receptor de la endotelina } & Ambrisentán & & I & A & I & A & IIb & C & 194 \\
\hline & Bosentán & & I & A & I & A & IIb & C & $196-200$ \\
\hline & Macitentáne & & I & B & I & $\mathrm{B}$ & IIb & C & 201 \\
\hline \multirow[t]{3}{*}{ Inhibidores de la fosfodiesterasa-5 } & Sildenafilo & & I & A & I & A & IIb & C & 205-208 \\
\hline & Tadalafilo & & I & B & I & B & IIb & C & 211 \\
\hline & Vardenafilo ${ }^{g}$ & & IIb & B & IIb & B & IIb & C & 212 \\
\hline Estimuladores de la guanilato ciclasa & Riociguat & & I & B & I & B & IIb & C & 214 \\
\hline \multirow[t]{8}{*}{ Análogos de prostaciclina } & Epoprostenol & Intravenoso ${ }^{\mathrm{e}}$ & - & - & I & A & I & A & $220-222$ \\
\hline & Iloprost & Inhalado & - & - & I & B & IIb & C & 229-231 \\
\hline & & Intravenosog & - & - & IIa & C & IIb & C & 232 \\
\hline & Treprostinil & Subcutáneo & - & - & I & B & IIb & $\mathrm{C}$ & 233 \\
\hline & & Inhaladog $^{g}$ & - & - & I & B & IIb & C & 237 \\
\hline & & Intravenoso $^{\mathrm{f}}$ & - & - & IIa & $\mathrm{C}$ & IIb & $\mathrm{C}$ & 234 \\
\hline & & Oralg & - & - & IIb & B & - & - & $238-240$ \\
\hline & Beraprostg ${ }^{g}$ & & - & - & IIb & B & - & - & 218 \\
\hline Agonistas del receptor IP & Selexipag (or & & I & B & I & B & - & - & 241,248 \\
\hline
\end{tabular}

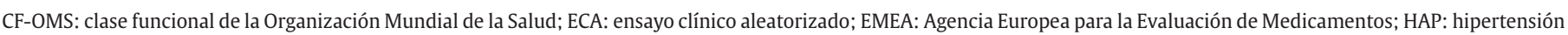
arterial pulmonar.

La secuencia se presenta por clase de fármaco en orden alfabético y por clase funcional.

${ }^{\mathrm{a}}$ Grado de recomendación.

'Nivel de evidencia.

'Referencias que respaldan las recomendaciones.

¿Solo para respondedores a la prueba de vasorreactividad aguda: clase I para HAP idiopática, HAP heredable y HAP secundaria a drogas o tóxicos; clase IIa para condiciones asociadas con HAP.

'Tiempo hasta empeoramiento clínico como objetivo primario en ECA o fármacos con demostrada reducción de la mortalidad por todas las causas.

fPara pacientes que no toleran la vía subcutánea.

${ }^{g}$ Este fármaco no estaba aprobado por la EMEA en el momento de publicarse el presente documento. 
binada redujo el riesgo de empeoramiento clínico (riesgo relativo $[R R]=0,48$; intervalo de confianza del 95\% [IC95\%], 0,26-0,91; $\mathrm{p}=0,023$ ), aumentó significativamente la distancia en la PM6M (22 m) y redujo los valores medios de PAP, RAP y RVP. La incidencia de complicaciones graves fue similar en ambos grupos ( $R R=1,17$; IC95\%, $0,40-3,42 ; p=0,77)$. La reducción de la mortalidad por todas las causas no fue estadísticamente significativa. No obstante, la incidencia de muertes en los ECA sobre tratamientos farmacológicos para la HAP suele ser baja, y para alcanzar significación estadística sería necesario un tamaño muestral de varios miles de pacientes ${ }^{244}$.

La terapia combinada se puede instaurar de entrada o en secuencia. La terapia combinada secuencial es la estrategia más utilizada en estudios clínicos y en la práctica clínica: a partir de la monoterapia, se agrega un segundo y después un tercer fármaco en caso de que se obtengan resultados clínicos inadecuados o deterioro del paciente. La denominada «terapia orientada por objetivos» es un programa prospectivo estructurado que aplica indicadores pronósticos conocidos como objetivos de tratamiento. La terapia solo se considera adecuada cuando se cumplen los objetivos. La diferencia fundamental entre la terapia orientada por objetivos y las estrategias no estructuradas es que los pacientes que están estabilizados, o incluso los que mejoran ligeramente, pueden recibir tratamiento adicional si no se alcanzan los objetivos del tratamiento. El tratamiento orientado por objetivos emplea diferentes objetivos, como la CF-OMS I-II y la normalización casi completa del índice cardiaco en reposo y los títulos plasmáticos de NT-proBNP. Un estudio reciente ha confirmado que los pacientes que cumplen estos objetivos tienen mejor pronóstico que los que no ${ }^{97}$.

Las recomendaciones y la evidencia sobre el uso de fármacos específicos para el tratamiento combinado inicial o secuencial para la HAP según la CF-OMS se muestran en las tablas 20 y 21 respectivamente.

El tratamiento combinado inicial se fundamenta en la mortalidad de la HAP, que es una reminiscencia de numerosas malignidades, y en el hecho de que dichas enfermedades malignas o críticas (IC, hipertensión maligna) no se tratan con una estrategia gradual, sino con un tratamiento combinado preventivo. La experiencia en ECA del tratamiento combinado inicial comenzó en el pequeño estudio BREATHE-2 (tabla 6D del anexo web), que no logró demostrar una diferencia significativa entre los pacientes tratados inicialmente con la combinación de epoprostenol y bosentán y los tratados solo con epoprostenol ${ }^{198}$. En un

\section{Tabla 20}

Recomendaciones sobre la eficacia del tratamiento para la hipertensión arterial pulmonar (grupo 1) combinado de entrada según la CF-OMS

\begin{tabular}{|c|c|c|c|c|c|c|c|}
\hline \multirow{3}{*}{$\begin{array}{l}\text { Medida/tratamiento } \\
\text { Ambrisentán+tadalafilo }^{d}\end{array}$} & \multicolumn{6}{|c|}{ Clase $^{\mathrm{a}}$-nivel ${ }^{\mathrm{b}}$} & \multirow{3}{*}{$\begin{array}{l}\operatorname{Ref}^{c} \\
247\end{array}$} \\
\hline & \multicolumn{2}{|c|}{ CF-OMS II } & \multicolumn{2}{|c|}{ CF-OMS III } & \multicolumn{2}{|c|}{ CF-OMS IV } & \\
\hline & I & B & I & B & IIb & $\mathrm{C}$ & \\
\hline Otro ARE+PDE-5i & IIa & $\mathrm{C}$ & IIa & $\mathrm{C}$ & IIb & $\mathrm{C}$ & - \\
\hline $\begin{array}{l}\text { Bosentán+sildenafilo+epopr } \\
\text { ostenol i.v. }\end{array}$ & - & - & IIa & C & IIa & C & 246 \\
\hline Bosentán+epoprostenol i.v. & - & - & IIa & $\mathrm{C}$ & IIa & $\mathrm{C}$ & $\begin{array}{l}198 \\
245\end{array}$ \\
\hline $\begin{array}{l}\text { Otro ARE o } \\
\text { PDE-5i+treprostinil s.c. }\end{array}$ & & & IIb & C & IIb & C & - \\
\hline $\begin{array}{l}\text { Otro ARE o PDE-5i+otros } \\
\text { análogos de prostaciclina i.v. }\end{array}$ & & & IIb & C & IIb & $\mathrm{C}$ & - \\
\hline
\end{tabular}

ARE: antagonista del receptor de la endotelina; CF-OMS: clase funcional de la Organización Mundial de la Salud; ECA: ensayo clínico aleatorizado; i.v.: intravenoso; PDE-5i: inhibidor de la fosfodiesterasa tipo 5; s.c.: subcutáneo.

El tratamiento secuencial se presenta por calificación.

aGrado de recomendación.

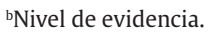

'Referencias que respaldan las recomendaciones.

${ }^{\mathrm{d} E}$ El tiempo hasta deterioro clínico fue el objetivo primario en ECA o fármacos con demostrada reducción de la mortalidad por todas las causas (definida prospectivamente).
Tabla 21

Recomendaciones sobre la eficacia del tratamiento combinado para la hipertensión arterial pulmonar (grupo 1) en secuencia según la CF-OMS

\begin{tabular}{|c|c|c|c|c|c|c|c|}
\hline \multirow{3}{*}{$\begin{array}{l}\text { Medida/tratamiento } \\
\text { Macitentán añadido }_{\text {a sildenafilo }}\end{array}$} & \multicolumn{6}{|c|}{ Clase $^{\mathrm{a}}$-nivel ${ }^{\mathrm{b}}$} & \multirow{3}{*}{$\begin{array}{c}\operatorname{Ref}^{\mathrm{c}} \\
201\end{array}$} \\
\hline & \multicolumn{2}{|c|}{ CF-OMS II } & \multicolumn{2}{|c|}{ CF-OMS III } & \multicolumn{2}{|c|}{ CF-OMS IV } & \\
\hline & I & B & I & B & IIa & C & \\
\hline $\begin{array}{l}\text { Riociguat añadido } \\
\text { a bosentán }\end{array}$ & I & B & I & B & IIa & C & 214 \\
\hline $\begin{array}{l}\text { Selexipage añadido a ARE } \\
\text { y/o PDE- } 5 i^{d}\end{array}$ & I & $\mathrm{B}$ & I & B & IIa & C & $\begin{array}{l}241, \\
248\end{array}$ \\
\hline $\begin{array}{l}\text { Sildenafilo añadido } \\
\text { a epoprostenol }\end{array}$ & - & - & I & B & IIa & B & 209 \\
\hline $\begin{array}{l}\text { Treprostinil inhalado } \\
\text { añadido a sildenafilo } \\
\text { o bosentán }\end{array}$ & IIa & B & Ila & B & IIa & C & 237 \\
\hline $\begin{array}{l}\text { Iloprost inhalado añadido } \\
\text { a bosentán }\end{array}$ & IIb & B & IIb & B & IIb & C & $\begin{array}{l}230 \\
231\end{array}$ \\
\hline $\begin{array}{l}\text { Tadalafilo añadido } \\
\text { a bosentán }\end{array}$ & IIa & $\mathrm{C}$ & IIa & $\mathrm{C}$ & IIa & C & 211 \\
\hline $\begin{array}{l}\text { Ambrisentán añadido } \\
\text { a sildenafilo }\end{array}$ & IIb & $C$ & IIb & C & IIb & C & 249 \\
\hline $\begin{array}{l}\text { Bosentán añadido } \\
\text { a epoprostenol }\end{array}$ & - & - & IIb & $\mathrm{C}$ & IIb & C & 250 \\
\hline $\begin{array}{l}\text { Bosentán añadido } \\
\text { a sildenafilo }\end{array}$ & IIb & $\mathrm{C}$ & IIb & C & IIb & C & $\begin{array}{l}251, \\
252\end{array}$ \\
\hline $\begin{array}{l}\text { Sildenafilo añadido } \\
\text { a bosentán }\end{array}$ & IIb & C & IIb & $\mathrm{C}$ & IIb & C & 252 \\
\hline Otras combinaciones dobles & IIb & $\mathrm{C}$ & IIb & $\mathrm{C}$ & IIb & $\mathrm{C}$ & - \\
\hline Otras combinaciones triples & IIb & $\mathrm{C}$ & IIb & C & IIb & $\mathrm{C}$ & - \\
\hline $\begin{array}{l}\text { Riociguat añadido a } \\
\text { sildenafilo u otro PDE-5i }\end{array}$ & III & B & III & B & III & B & 215 \\
\hline
\end{tabular}

ARE: antagonista del receptor de la endotelina; CF-OMS: clase funcional de la Organización Mundial de la Salud; ECA: ensayo clínico aleatorizado; EMEA: Agencia Europea para la Evaluación de medicamentos; HAP: hipertensión arterial pulmonar; PDE-5i: inhibidor de la fosfodiesterasa tipo 5.

El tratamiento secuencial se presenta por orden alfabético y por calificación.

aGrado de recomendación.

bNivel de evidencia.

'Referencias que respaldan las recomendaciones.

${ }^{\mathrm{d}}$ El tiempo hasta empeoramiento clínico fue el objetivo primario en ECA o fármacos con demostrada reducción de la mortalidad por todas las causas (definida prospectivamente)

eEste fármaco no estaba aprobado por la EMEA en el momento de publicarse el presente documento.

estudio más reciente, se trató a 23 pacientes que no habían recibido previamente tratamiento para la HAP mediante la combinación inicial de epoprostenol y bosentán, comparados con un grupo equivalente de control histórico de pacientes tratados solo con epoprostenol ${ }^{245}$. El estudio mostró una reducción estadísticamente significativa de la RVP en el grupo de tratamiento combinado, pero este beneficio hemodinámico no se tradujo en una diferencia estadísticamente significativa en la supervivencia total ni en la supervivencia libre de trasplante. Un estudio piloto sobre el tratamiento triple inicial en 19 pacientes en CF-OMS III-IV ha recabado evidencia preliminar sobre los beneficios a largo plazo de esta estrategia en pacientes con HAP avanzada ${ }^{246}$. En un reciente estudio multicéntrico, multinacional, con enmascaramiento y grupo de control con placebo (tabla 6D del anexo web) se comparó la monoterapia inicial con tadalafilo o ambrisentán frente a la terapia combinada inicial con tadalafilo y ambrisentán en pacientes con HAP de novo y CF-OMS II-III ${ }^{247}$. El criterio primario de valoración era la combinación de eventos de fracaso clínico (muerte, hospitalización, progresión de la HAP y estado clínico insatisfactorio). Los resultados del estudio fueron positivos, con una reducción del $50 \%$ de los eventos en el 
grupo de tratamiento combinado. Además, se observaron mejoras en la capacidad de ejercicio, las tasas de respuesta clínica satisfactoria y concentración plasmática de NT-proBNP247.

\subsubsection{Interacciones farmacológicas}

Las interacciones farmacológicas más importantes que afectan a los tratamientos específicos de la HAP se muestran en la tabla 7 del anexo web. Esta tabla presenta las interacciones conocidas más importantes, pero no incluye interacciones teóricas no probadas que de todas formas pueden ser clínicamente importantes. Además, se debe consultar la información actualizada de los prospectos oficiales de cada compuesto.

El bosentán es un inductor de las isoenzimas CYP3A4 y CYP2C9 del citocromo P450. Las concentraciones plasmáticas de los fármacos metabolizados por estas isoenzimas pueden estar reducidas cuando se administran conjuntamente con bosentán. El bosentán también se metaboliza por estas isoenzimas, de modo que su inhibición podría incrementar la concentración plasmática de este fármaco. Además de las interacciones que figuran en la tabla 7 del anexo web, la combinación de un potente inhibidor del CYP3A4 (ketoconazol, ritonavir) o un inhibidor del CYP2C9 (p. ej., amiodarona o fluconazol) con bosentán puede causar un aumento significativo de las concentraciones plasmáticas de bosentán, lo cual está contraindicado. Teóricamente, las interacciones pueden ocurrir con itraconazol, tacrolimus, sirolimus, carbamazepina, fenitoína, fenobarbitona, dapsona y la hierba de San Juan.

El sildenafilo se metaboliza por el citocromo P450, isoenzimas CYP3A4 (vía principal) y CYP2C9 (vía secundaria). Hay un aumento de la biodisponibilidad del sildenafilo y un aclaramiento reducido con los sustratos e inhibidores del CYP3A4 y los sustratos del CYP3A4 más los bloqueadores de los receptores betaadrenérgicos. Los inductores del CYP3A4, como carbamazepina, fenitoína, fenobarbital, rifampicina y hierba de San Juan, pueden disminuir las concentraciones de sildenafilo de manera significativa. Los valores de sildenafilo pueden aumentar ligeramente con el zumo fresco de pomelo, un inhibidor débil del CYP3A4.

Por último, se debe tomar precauciones cuando se administren simultáneamente fármacos específicos para la HAP y antihipertensivos, como bloqueadores de los receptores betaadrenérgicos, inhibidores de la enzima de conversión de la angiotensina, etc., para evitar la hipotensión sistémica excesiva.

\subsubsection{Septostomía auricular con balón}

La creación de un cortocircuito interauricular de derecha a izquierda puede descomprimir las cámaras cardiacas y aumentar la precarga del VD y el GC ${ }^{253,254}$. Además, esto mejoraría el transporte sistémico de $\mathrm{O}_{2}$ a pesar de la desaturación arterial de oxígeno ${ }^{253}$ y disminuye la hiperactividad simpática. La técnica recomendada es la septostomía auricular más dilatación gradual con balón, que en cuanto a los parámetros hemodinámicos y los síntomas ofrece beneficios equivalentes a los de la técnica original con cuchilla, pero con menos riesgo. Otras técnicas se consideran experimentales ${ }^{255}$.

Una cuidadosa evaluación del riesgo antes del procedimiento es esencial para reducir la mortalidad. La septostomía auricular con balón (SAB) debe evitarse en pacientes en fase terminal que tengan una PAD media basal $>20 \mathrm{mmHg}$ y una saturación de $\mathrm{O}_{2}$ en reposo $<85 \%$ en aire ambiental. Los pacientes deben seguir un tratamiento médico óptimo, que puede incluir el pretratamiento con inotrópicos intravenosos, antes de plantearse una SAB. Los informes publicados indican que pueden beneficiarse los pacientes en CF-OMS IV con IC derecha refractaria a tratamiento médico o con síntomas sincopales graves ${ }^{253,254}$. También se puede considerar para pacientes en espera de trasplante pulmonar que tienen una respuesta clínica insatisfactoria al tratamiento médico o cuando el tratamiento médico no está disponible. Algunos estudios muestran una mejora del índice cardiaco y una disminución de la PAD con mejores resultados en la $\mathrm{PM} \mathrm{M}^{253,254}$. El impacto de la SAB en la supervivencia a largo plazo no se ha establecido en $\mathrm{ECA}^{253,254}$. Se debe considerar la SAB como procedimiento paliativo o tratamiento puente, y solo debe realizarse en centros con experiencia en esta técnica ${ }^{256}$. Dado que la $S A B$ se realiza en raras ocasiones, no se ha incluido en el algoritmo de tratamiento (figura 2).

\subsubsection{Insuficiencia ventricular derecha avanzada}

\subsubsection{Manejo en la unidad de cuidados intensivos}

Los pacientes con HP pueden requerir el ingreso en una unidad de cuidados intensivos para el tratamiento de una entidad comórbida (incluso cirugía mayor), la IC derecha o ambas. En una serie de pacientes de Francia, la mortalidad de los pacientes con HAP ingresados en la UCI fue del $41 \%{ }^{257}$, lo cual subraya el mal pronóstico. Por ello, los pacientes con HAP que requieren cuidados intensivos deben ser tratados en centros especializados siempre que sea posible. La monitorización básica incluye signos vitales (frecuencia cardiaca, PA y saturación de $\mathrm{O}_{2}$ ), diuresis, presión venosa central, saturación de $\mathrm{O}_{2}$ venosa central y concentración de lactato en sangre. La combinación de una saturación de $\mathrm{O}_{2}$ venosa central baja (<60\%) con concentraciones sanguíneas de lactato en aumento y una diuresis baja o nula indican la inminente aparición de IC derecha. En algunas situaciones, es necesario emplear CCD para la monitorización completa de los parámetros hemodinámicos. Los principios básicos del manejo en la UCI de los pacientes con HP e insuficiencia del VD incluyen el tratamiento de factores desencadenantes (como anemia, arritmias, infecciones u otras comorbilidades), la optimización del balance de fluidos (normalmente con diuréticos i.v.), la reducción de la poscarga del VD (normalmente con análogos de la prostaciclina parenterales, pero a veces también con otros fármacos para la HAP), la mejora del GC con agentes inotrópicos (de los que la dobutamina es el preferido para tratar la insuficiencia del VD) y el mantenimiento de la PA sistémica con vasopresores cuando sea necesario ${ }^{258-260}$. Se debe evitar la intubación de los pacientes con insuficiencia del VD debido a que frecuentemente produce colapso hemodinámico.

\subsubsection{Asistencia ventricular derecha}

Se debe considerar el uso de ECMO para algunos pacientes con HP e insuficiencia del VD. La asistencia venovenosa puede mejorar la oxigenación, pero no descarga el VD, por lo que no es adecuada para este tipo de pacientes. Existen 2 conceptos básicos para el uso de ECMO en estos pacientes: como tratamiento puente hasta la recuperación o como tratamiento puente hasta el trasplante. Se han publicado pocos datos sobre el uso de ECMO como tratamiento puente hasta la recuperación ${ }^{261}$, y su empleo solo es razonable para pacientes a los que esta estrategia terapéutica ofrece posibilidades reales de recuperación. Sin embargo, varios estudios han mostrado resultados positivos del ECMO como tratamiento puente hasta el trasplante, especialmente cuando se emplea en pacientes despiertos ${ }^{261-263}$. Una estrategia alternativa consiste en conectar un dispositivo sin bomba a la circulación pulmonar ${ }^{264,265}$. Todos estos procedimientos solo se realizan en centros altamente especializados.

\subsubsection{Trasplante}

El desarrollo de tratamientos específicos para la HAP grave ha reducido y retrasado la derivación de los pacientes a programas de trasplante pulmonar ${ }^{256}$. Los resultados a largo plazo de los pacientes tratados farmacológicamente todavía son inciertos y el trasplante sigue siendo una opción terapéutica importante para pacientes que no responden al tratamiento farmacológico y permanecen en CF-OMS 


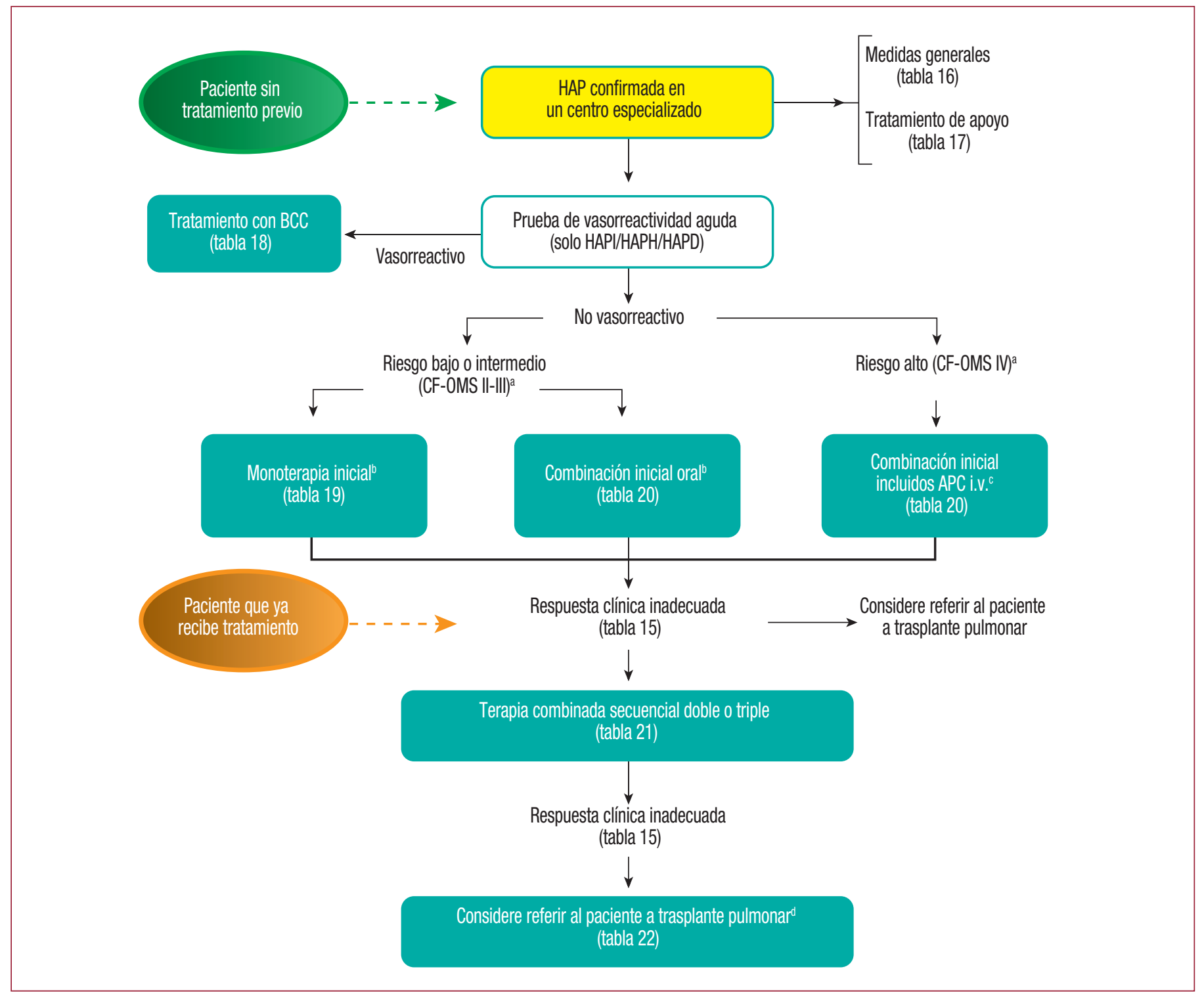

Figura 2. Algoritmo de tratamiento basado en la evidencia para los pacientes con HAP (solo para pacientes del grupo 1; consulte la descripción en esta documento). APC: análogos de la prostaciclina; BCC: bloqueadores de los canales del calcio; CF-OMS: clase funcional de la Organización Mundial de la Salud; HAP: hipertensión arterial pulmonar; HAPD: hipertension arterial pulmonar inducida por drogas o tóxicos; HAPH: hipertension arterial pulmonar heredable; HAPI: hipertensión arterial pulmonar idiopática; i.v.: intravenoso.

aA algunos pacientes en CF-OMS III se los puede considerar de alto riesgo (consulte la tabla 13).

bLa combinación inicial de ambrisentán más tadalafilo se ha probado superior a la monoterapia con ambrisentán o tadalafilo para retrasar el fracaso clínico.

'El epoprostenol intravenoso se debe priorizar, ya que reduce la tasa de mortalidad a los 3 meses en pacientes de alto riesgo con HAP, incluso en monoterapia.

${ }^{d}$ Considere también la septostomía auricular con balón.

III-IV ${ }^{96,107}$. El retraso en la derivación del paciente, combinado con el largo periodo de espera debido a la escasez de donantes, puede aumentar la mortalidad en lista de espera y agravar su estado clínico cuando llega la hora del trasplante.

Se estimaba que la mortalidad total a los 5 años del trasplante por HAP era del $45-50 \%$, con evidencia de buena calidad de vida ${ }^{266}$. Datos más recientes muestran que la supervivencia ha aumentado a un $52-75 \%$ a los 5 años y un 45-66\% a los 10 años ${ }^{267-269}$.

Teniendo en cuenta estos datos, parece razonable considerar el trasplante pulmonar si el paciente no responde adecuadamente a la monoterapia inicial y referir al paciente a trasplante cuando se confirme que la respuesta a la terapia combinada máxima no es adecuada (figura 2). Además, la etiología de la HAP puede ayudar en el proceso de toma de decisiones, dado que el pronóstico varía dependiendo de la enfermedad subyacente. De hecho, la HAP asociada con ETC tiene peor pronóstico que la HAPI, incluso cuando se trata con prostanoides, mientras que los pacientes con HAP asociada a cardiopatía congénita tienen una supervivencia mejor. El peor pronóstico se observa en los pacientes con EVOP y HCP debido a la falta de tratamientos médicos efectivos; estos pacientes deben ser referidos a trasplante en el momento del diagnóstico.

Tanto el trasplante cardiopulmonar como el pulmonar doble se han llevado a cabo en la HAP, aunque se desconoce el umbral de la disfunción sistólica del VD irrecuperable o la disfunción diastólica del VI. Actualmente, se somete a trasplante pulmonar bilateral a la gran mayoría de los pacientes en todo el mundo, como indican los datos del Registro de la Sociedad Internacional de Trasplante de Corazón y Pulmón ${ }^{270}$. A los pacientes con síndrome de Eisenmenger causado por 
cortocircuitos simples, se los ha tratado con trasplante solo pulmonar y reparación del defecto cardiaco o con trasplante cardiopulmonar ${ }^{266}$. Aunque inicialmente los datos de registros indicaban mejor supervivencia con el trasplante cardiopulmonar en pacientes con HAP asociada a comunicación interventricular ${ }^{271}$, la experiencia con el trasplante solo pulmonar bilateral ha aumentado, y los datos más recientes indican que este abordaje combinado con la reparación de la comunicación interventricular puede ser útil ${ }^{272}$.

Estudios recientes indican que el ECMO venoarterial puede emplearse en pacientes conscientes con HP terminal como tratamiento puente hasta el trasplante pulmonar ${ }^{263}$.

\subsubsection{Algoritmo de tratamiento}

La figura 2 muestra un algoritmo de tratamiento para pacientes con HAP. Las clases de recomendación y los niveles de evidencia para los tratamientos de la HAP aparecen en las tablas 19 (monoterapia), 20 (terapia combinada inicial), 21 (terapia combinada secuencial) y 22 UCI e intervenciones). Las definiciones sobre la respuesta clínica al tratamiento se resumen en la tabla 15 . Se parte de la base de que la estrategia terapéutica para la HAP puede depender de la disponibilidad (y la experiencia) de distintas opciones de tratamiento en distintos hospitales y contextos clínicos. Por lo tanto, las tablas 19-22 proporcionan información sobre estrategias de tratamiento alternativas basadas en la evidencia. Estas tablas incluyen únicamente fármacos aprobados oficialmente para el tratamiento de la HAP o que están en proceso de aprobación en al menos un país. Los expertos han propuesto una categorización en 4 niveles para los criterios primarios de valoración de los ECA según el nivel de evidencia relativo a la eficacia ${ }^{273,274}$. Según esta categorización, los fármacos o las combinaciones de fármacos en los que se

Tabla 22

Recomendaciones sobre la eficacia del manejo en la unidad de cuidados intensivos, la septostomía auricular con balón y el trasplante pulmonar para la hipertensión arterial pulmonar (grupo 1) según la CF-OMS

\begin{tabular}{|c|c|c|c|c|c|c|c|}
\hline \multirow[t]{2}{*}{ Medida/tratamiento } & \multicolumn{6}{|c|}{ Clase $^{\mathrm{a}}$-nivel ${ }^{\mathrm{b}}$} & \multirow[t]{2}{*}{$\operatorname{Ref}^{c}$} \\
\hline & \multicolumn{2}{|c|}{ CF-OMS II } & \multicolumn{2}{|c|}{ CF-OMS III } & \multicolumn{2}{|c|}{ CF-OMS IV } & \\
\hline $\begin{array}{l}\text { Se recomienda ingresar } \\
\text { en UCI a los pacientes con } \\
\text { HP y frecuencia cardiaca } \\
\text { elevada (> } 110 \mathrm{lpm} \text { ) o } \\
\text { hipotensión arterial } \\
\text { sistémica (presión sistólica } \\
<90 \mathrm{mmHg} \text { ), bajo ritmo de } \\
\text { diuresis e incremento de } \\
\text { lactato secundario a otras } \\
\text { comorbilidades o no }\end{array}$ & - & - & - & - & I & C & 257 \\
\hline $\begin{array}{l}\text { Se recomienda apoyo con } \\
\text { inotrópicos para pacientes } \\
\text { con hipotensión arterial } \\
\text { sistémica }\end{array}$ & & & I & C & I & C & \\
\hline $\begin{array}{l}\text { Se recomienda trasplante } \\
\text { pulmonar precoz } \\
\text { tras respuesta clínica } \\
\text { inadecuada a pesar del } \\
\text { tratamiento médico } \\
\text { optimizado }\end{array}$ & - & - & I & C & I & C & 270 \\
\hline $\begin{array}{l}\text { Si está disponible, se puede } \\
\text { considerar la SAB tras } \\
\text { fracaso de todo tratamiento } \\
\text { médico }\end{array}$ & - & - & $\mathrm{IIb}$ & C & IIb & C & $\begin{array}{l}253 \\
254\end{array}$ \\
\hline
\end{tabular}

CF-OMS: clase funcional de la Organización Mundial de la Salud; HP: hipertensión pulmonar; SAB: septostomía auricular con balón; UCI: unidad de cuidados intensivos. ${ }^{a} \mathrm{G}$ rado de recomendación.

'Nivel de evidencia.

'Referencias que apoyan las recomendaciones. evaluó el tiempo hasta el fracaso o el deterioro clínico como criterio primario de valoración en ECA o los fármacos de los que se ha demostrado una reducción de la mortalidad por todas las causas (definida prospectivamente) aparecen señalados con una nota al pie en las tablas 19-21. El algoritmo de tratamiento para la HAP no se aplica a otros grupos clínicos, particularmente a los pacientes con HP asociada con los grupos 2 (ECI) o 3 (enfermedades pulmonares). Además, los distintos tratamientos se han evaluado en ECA fundamentalmente en la HAPI, la HAPH, la HAPD y la HAP asociada a ETC o CC (corregida quirúrgicamente o no).

\section{Descripción del algoritmo de tratamiento (figura 2)}

- Tras la confirmación del diagnóstico de pacientes no tratados previamente para la HAP, la estrategia inicial propuesta es la adopción de medidas generales y la instauración de terapia de apoyo si fuera necesario (tablas 16 y 17).

- La prueba de vasorreactividad aguda solo debería realizarse en pacientes con HAPI, HAPH y HAPD. A los pacientes vasorreactivos, se los debería tratar con dosis altas de BCC (aumento progresivo de la dosis); la respuesta adecuada al tratamiento debería confirmarse a los 3-4 meses de tratamiento (tabla 18). Los pacientes respondedores que no tienen una respuesta adecuada al tratamiento con BCC deberían ser tratados con fármacos aprobados para la HAP de acuerdo con la estrategia de tratamiento empleada para los pacientes no vasorreactivos.

- A los pacientes no respondedores a la prueba de vasorreactividad aguda que tienen un riesgo bajo o intermedio (tabla 13), se los puede tratar con monoterapia inicial (tabla 19) o terapia oral combinada inicial (tabla 20).

- Si se elige la monoterapia inicial, como no existen comparaciones directas entre fármacos, no se puede proponer una monoterapia de primera línea basada en la evidencia. En estos casos, la elección del fármaco depende de varios factores, como el estado de aprobación, el etiquetado, la vía de administración, el perfil de efectos secundarios, las interacciones potenciales con tratamientos de fondo, las preferencias del paciente, las comorbilidades, la experiencia del médico y el coste.

- Dado que la comparación directa entre la terapia combinada inicial con ambrisentán más tadalafilo se ha demostrado superior a la monoterapia inicial con ambrisentán o tadalafilo para retrasar el fracaso clínico, esta combinación tiene un grado de recomendación más alto (tabla 20)247.

- Para pacientes no vasorreactivos, no tratados previamente y con riesgo alto (tabla 13), se debe considerar la terapia combinada inicial que incluya análogos de la prostaciclina (tabla 20). Se dará prioridad al epoprostenol intravenoso, ya que se ha demostrado una reducción de las tasas de mortalidad a los 3 meses en pacientes de alto riesgo con HAP, también como monoterapia (tabla 19) ${ }^{149}$. Se puede considerar distintas alternativas de terapia combinada inicial (tabla 20).

- En caso de respuesta clínica inadecuada a la terapia combinada o la monoterapia inicial (tabla 15), se recomienda la terapia combinada secuencial doble o triple de acuerdo con la tabla 21. La combinación de riociguat y un inhibidor de la PDE-5 está contraindicada.

- En caso de respuesta clínica inadecuada a la terapia combinada secuencial doble, se intentará la terapia secuencial triple (tablas 20 y 21).

- Parece razonable considerar el trasplante pulmonar si el paciente no responde adecuadamente a la monoterapia o la terapia combinada inicial y referir al paciente a trasplante cuando se confirme que la respuesta a la terapia combinada máxima no es adecuada. La SAB debe considerarse como tratamiento paliativo o como procedimiento puente para pacientes que sufren deterioro pese a recibir tratamiento médico máximo. 
6.3.10. Diagnóstico y tratamiento de las complicaciones de la hipertensión arterial pulmonar

\subsubsection{Arritmias}

Las arritmias representan un problema clínico en aumento en los pacientes con HAP. Particularmente, la presencia de una arritmia auricular sintomática puede conllevar un mal pronóstico 275 . Al contrario que en pacientes con ECI, las arritmias ventriculares malignas, como taquicardia, flutter y fibrilación, son raras en los pacientes con HAP. En una serie de 132 paradas cardiacas presenciadas en pacientes con HAP, se observó fibrilación ventricular solo en el $8 \%$ de los casos $^{276}$. En otra serie de 231 pacientes con HAP o HPTC observados durante 6 años, no se observó ningún caso de arritmia ventricular maligna ${ }^{275}$. En esa serie, las taquiarritmias supraventriculares tuvieron una incidencia anual del 2,8\%. El flutter y la fibrilación auriculares tuvieron la misma incidencia y ambas arritmias conllevaron invariablemente un deterioro clínico con signos de IC derecha. El tratamiento del flutter auricular se demostró más efectivo que el de la fibrilación auricular. La restauración del ritmo sinusal se asoció favorablemente con la supervivencia a largo plazo, mientras que la fibrilación auricular persistente se asoció con una mortalidad a los 2 años $>80 \%{ }^{275}$. Las arritmias supraventriculares son una indicación para la anticoagulación oral con antagonistas de la vitamina K o con nuevos anticoagulantes orales. Tanto la cardioversión eléctrica como la ablación por radiofrecuencia en los casos refractarios se han demostrado efectivas ${ }^{277}$.

Aunque faltan datos de estudios prospectivos y con grupo de control, estos hallazgos indican que mantener estable el ritmo sinusal tras la cardioversión debería ser un objetivo de tratamiento importante para los pacientes con HAP. Para conseguir un ritmo sinusal estable, la profilaxis con fármacos antiarrítmicos sin efectos inotrópicos negativos, como la amiodarona oral (véanse las interacciones en la tabla 7 del anexo web), también debería considerarse aunque falten datos específicos sobre su eficacia.

\subsubsection{Hemoptisis}

La hemoptisis es una reconocida complicación de la HP, que es un factor de riesgo de muerte y parece ser más frecuente en tipos específicos de HP, como la HAPH, la HAP asociada a CC y la HPTC. El grado de hemoptisis puede variar de leve a muy grave e incluso causar la muerte súbita. Los datos publicados sobre su prevalencia varían del 1 al $6 \% 278$. Se considera que la embolización de las arterias bronquiales es un procedimiento agudo de emergencia en caso de hemoptisis grave o una intervención electiva para los casos de episodios frecuentes de hemoptisis leve o moderada. La hemoptisis puede ser una contraindicación para el tratamiento anticoagulante.

\subsubsection{Complicaciones mecánicas}

Las complicaciones mecánicas de los pacientes con HAP se relacionan normalmente con la dilatación progresiva de la AP e incluyen aneurisma de la AP, rotura, disección y compresión de diferentes estructuras intratorácicas, como tronco coronario común izquierdo, venas pulmonares, bronquios principales y nervios laríngeos recurrentes ${ }^{279-281}$. Los síntomas y signos no son específicos, varían según las diferentes complicaciones e incluyen dolor torácico (de tipo anginoso o no), disnea, edema pulmonar regional y muerte súbita. La TCAR con realce de contraste es la mejor opción de diagnóstico por imagen para detectar complicaciones mecánicas.

Las opciones de tratamiento no están claramente establecidas para los casos de aneurisma, seudoaneurisma y disección de la $\mathrm{AP}^{279,280}$.

No se conocen las indicaciones ni los resultados del tratamiento quirúrgico tradicional en presencia de HP y los riesgos predecibles pueden ser muy altos. El tratamiento percutáneo (implante de stents) debe resolver importantes cuestiones técnicas, debido fundamentalmente a la pronta ramificación de la AP principal y lobares. Una estrategia posible es el trasplante pulmonar doble o el trasplante cardiopulmonar, pero esta solución solo se puede emplear en casos crónicos estabilizados, y no existe una indicación clara. Para los pacientes con compresión del tronco coronario común izquierdo, debe realizarse un procedimiento percutáneo con implante de stent $^{282}$.

\subsubsection{Cuidados terminales y cuestiones éticas}

El curso clínico de la HP consiste en el deterioro progresivo con intervalos de episodios de descompensación aguda. Es complicado prever cuándo morirán los pacientes, ya que la muerte puede aparecer súbita o lentamente por IC progresiva. Se ha demostrado que los médicos a cargo de estos pacientes tienden a ser demasiado optimistas y a menudo malinterpretan los deseos de sus pacientes.

La comunicación abierta y sensible con los pacientes permite planificar y discutir con antelación sus miedos, preocupaciones y deseos, lo cual es esencial para ofrecer una buena atención. La oportunidad para discutir el pronóstico debería surgir en el momento del diagnóstico inicial. Reconocer que la reanimación cardiopulmonar en la HAP grave tiene malos resultados puede posibilitar una orden de "no reanimar». Esto puede aumentar la posibilidad de que los pacientes se encuentren al final de sus vidas en su lugar de cuidado preferido.

Los pacientes que se acercan al final de su vida requieren la frecuente valoración de todas sus necesidades por un equipo multidisciplinario. Hay que prestar atención al control de los síntomas dolorosos y prescribir los fármacos apropiados al mismo tiempo que se retira la mediación innecesaria. También es esencial el apoyo psicológico, social y espiritual. Se debería consultar a los especialistas en cuidados paliativos acerca de los pacientes cuyas necesidades estén más allá de la experiencia del equipo de HP.

La HP es una enfermedad que puede limitar la vida sobremanera. Además del apoyo psicológico y social, debe haber una planificación proactiva y anticipatoria de la atención médica, con derivación del paciente al servicio de cuidados paliativos cuando sea necesario.

\section{GRUPOS ESPECÍFICOS DE HIPERTENSIÓN ARTERIAL PULMONAR}

\subsection{Hipertensión arterial pulmonar pediátrica}

La HP puede presentarse a cualquier edad, desde el periodo neonatal hasta la edad adulta. La HP pediátrica tiene algunas características peculiares que no se encuentran en la HP del adulto, como factores etiológicos prenatales y anomalías parenquimatosas y vasculares del desarrollo pulmonar posnatales ${ }^{283}$. Antes de la era del tratamiento con epoprostenol, el pronóstico de los niños era peor, con una supervivencia media estimada de 10 meses, frente a los 2,8 años de los adultos; sin embargo, los nuevos tratamientos orientados por objetivos han mejorado significativamente los resultados ${ }^{9,284}$.

Datos recientes procedentes de registros han arrojado luz sobre la prevalencia y la incidencia de la HP pediátrica. En los Países Bajos, la incidencia y la prevalencia de la HAPI son, respectivamente, 0,7 y 4,4/ millón de niños ${ }^{285}$. Cifras similares se han observado en el Reino Unido, con una tasa anual de HAPI de 0,48/millón y una prevalencia de 2,1/millón ${ }^{286}$. Varios registros nacionales y a gran escala que incluyeron a niños o dedicados exclusivamente a la población pediátrica ${ }^{28,288}$ han descrito las diferentes etiologías de la HAP, y las formas más comunes son HAPI, HAPH y HAP asociada a CC. Sin embargo, la HP asociada a enfermedades respiratorias también es una forma importante y puede estar subestimada ${ }^{287}$.

Aunque la clasificación de Dana Point de 2009 incluía la mayoría de las causas pediátricas, se consideró que las etiologías pediátricas deberían estar mejor descritas. Posteriormente se propuso la clasificación de Panamá (2011), que incluye diez subgrupos distintos de HP 
pediátrica $^{289}$. La clasificación de Niza de 2013 incluye nuevos grupos y etiologías específicas para los niños ${ }^{9}$, como la obstrucción congénita o adquirida del tracto de entrada/salida del corazón izquierdo y la HP segmentaria. Esta clasificación se ha adaptado para la presente guía de la ESC/ERS (tabla 4 y tabla 1 del anexo web) con la provisión de una clasificación clínica (tabla 6) y anatomofisiopatológica de los cortocircuitos sistemicopulmonares asociados a la HAP (tabla 2 del anexo web) y de la enfermedad del desarrollo pulmonar (tabla 3 del anexo web).

La HPPRN permanece en el grupo de HAP, pero se la ha incluido en un subgrupo, ya que se la considera una entidad específica de curso más transitorio en la mayoría de los casos (tabla 4 y tabla 4 del anexo web).

\subsubsection{Diagnóstico}

Los síntomas comunes son disnea, fatiga y desarrollo insuficiente; el síncope es más frecuente en niños, pero la insuficiencia del VD franca es un acontecimiento tardío y el niño puede morir súbitamente antes de la aparición de insuficiencia del VD ${ }^{284,287}$. Recientemente se ha recomendado un proceso diagnóstico específico y, aunque algunas causas son raras, hay que descartarlas antes de establecer un diagnóstico definitivo de $\mathrm{HAPI}^{284}$. Es esencial recoger minuciosamente la historia familiar y personal, con detalles del embarazo, el parto y el periodo posnatal ${ }^{290}$. El diagnóstico se debe confirmar por CCD y deben realizarse pruebas de vasorreactividad. Informes recientes indican que el CCD puede suponer un mayor riesgo para los niños que para los adultos, con la edad temprana ( $<1$ año) y una clase funcional peor (CF-OMS IV) como factores de riesgo. Se recomienda que el CCD se realice en centros especializado ${ }^{290}$. El esquema general del algoritmo diagnóstico para los adultos con HP (figura 1) se puede emplear para los niños, con algunas adaptaciones relacionadas con las diferencias en la epidemiología ${ }^{9}$.

Al igual que en los adultos, la evidencia clínica de insuficiencia del VD, la progresión de los síntomas, la CF-OMS III-IV y las concentraciones elevadas de BNP se asocian con mayor riesgo de muerte. En los niños, el retraso en el crecimiento, los parámetros hemodinámicos, como el cociente PAPm:PA sistémica, una PAD > $10 \mathrm{mmHg}$ y un índice de $\mathrm{RVP}>20 \mathrm{UW} / \mathrm{m}^{2}$, también se han asociado a mayor riesgo de muerte, mientras que la PM6M no es un parámetro pronóstico.

\subsubsection{Tratamiento}

Se carece de estudios aleatorizados sobre pacientes pediátricos, por lo cual es difícil establecer recomendaciones firmes ${ }^{291,292}$. Se ha recomendado un algoritmo de tratamiento específico, similar al empleado para adultos (figura 2). También se han propuesto factores determinantes del riesgo y la estratificación del riesgo ${ }^{9}$. Los BCC se emplean en niños respondedores, pero es imprescindible un seguimiento estricto, ya que la terapia a largo plazo puede fracasar en algunos niños.

Las indicaciones del tratamiento con epoprostenol son similares a las del adulto. La dosis óptima varía entre pacientes, por lo que se requiere una adaptación individualizada ${ }^{293,294}$. Se ha descrito el uso de iloprost y trepostinil i.v. y trepostinil subcutáeo ${ }^{295}$. El beraprost oral se emplea en algunos países, pero la falta de pruebas sobre su eficacia es un problema. El iloprost inhalado es difícil de administrar, pero algunos estudios han demostrado su eficacia, especialmente cuando se combina con otros tratamientos ${ }^{296}$. Las características farmacocinéticas del bosentán se evaluaron en 2 estudios ${ }^{297,298}$. Varios estudios sin grupo de control han mostrado resultados positivos similares a los observados en pacientes adultos, con tasas de supervivencia de un $80-90 \%$ a 1 año ${ }^{298}$. En Europa está disponible una formulación pediátrica $^{299}$. Los datos sobre el uso de ambrisentán son escasos y un estudio está actualmente en curso.

El sildenafilo se ha demostrado eficaz ${ }^{300} \mathrm{y}$ se ha aprobado su uso en Europa para niños de 1-17 años. El aumento de la mortalidad con altas dosis ha causado preocupación y por ello no deben emplearse en niños (altas dosis individuales de sildenafilo en 3 tomas diarias que no se recomiendan: dosis $>10 \mathrm{mg}$ con peso corporal de $8-20 \mathrm{~kg}$, $>20 \mathrm{mg}$ con peso corporal $>20 \mathrm{~kg}$ o $>1 \mathrm{mg} / \mathrm{kg}$ para bebés y niños pequeños) $)^{301}$.

Los datos sobre tadalafilo también indican eficacia ${ }^{302}$; actualmente está en curso un estudio para definir las dosis específicas para niños.

El número de pacientes pediátricos que reciben terapias combinadas está en aumento a pesar de que la evidencia sigue siendo escasa ${ }^{303}$.

Las estrategias de descompresión del VD incluyen la septostomía auricular ${ }^{304}$, el implante de stents en ductus arteriosus permeable ${ }^{305} \mathrm{y}$ el cortocircuito quirúrgico de Potts ${ }^{306}$. También se ha propuesto la creación de un cortocircuito de Potts transcatéter ${ }^{307}$. El trasplante pulmonar sigue siendo una opción terapéutica importante para los pacientes pediátricos con HP.

Para los niños, se debe aplicar objetivos específicos de tratamiento. Algunos se han extrapolado de los factores de riesgo definidos para los niños, pero todavía deben ser validados en cohortes grandes ${ }^{9}$. Recientemente se ha reconocido como objetivos de tratamiento la CF, el TAPSE y las concentraciones de NT-proBNP308.

Las recomendaciones sobre la HP pediátrica se muestran en la tabla 23.

Tabla 23

Recomendaciones para la hipertensión pulmonar pediátrica

\begin{tabular}{lccc}
\hline Recomendaciones & Clase $^{\mathrm{a}}$ & Nivel $^{\mathrm{b}}$ & Ref $^{\mathrm{c}}$ \\
\hline $\begin{array}{l}\text { Se recomienda un algoritmo diagnóstico de HP } \\
\text { para diagnosticar y establecer el grupo etiológico } \\
\text { específico de la HP de pacientes pediátricos }\end{array}$ & I & C & 9,290 \\
\hline $\begin{array}{l}\text { Se recomienda un algoritmo de tratamiento } \\
\text { específico de la HAP para pacientes pediátricos } \\
\text { con HPd }\end{array}$ & I & C & 9 \\
\hline $\begin{array}{l}\text { Se debería considerar una terapia combinada } \\
\text { para pacientes pediátricos con HP }\end{array}$ & Ila & C & $\begin{array}{c}295,298, \\
\text { Ila }\end{array}$ \\
\hline $\begin{array}{l}\text { Se debería considerar factores de riesgo específicos } \\
\text { de la población pediátrica }\end{array}$ & C & 9,308 \\
\hline
\end{tabular}

HAP: Hipertensión arterial pulmonar; HP: hipertensión pulmonar.

a Grado de recomendación.

${ }^{\mathrm{b}}$ Nivel de evidencia.

'Referencias que respaldan las recomendaciones.

${ }^{d}$ Véase Ivy et $\mathrm{al}^{3}$.

\subsection{Hipertensión arterial pulmonar asociada a cardiopatía congénita del adulto}

La HAP asociada a CC del adulto está incluida en el grupo 1 de la clasificación clínica de la HP (tabla 4) y es un grupo de pacientes muy heterogéneo. Se ha elaborado una clasificación clínica específica (tabla 6) y una clasificación anatomofisiopatológica (tabla 2 del anexo web) para una mejor caracterización del paciente individual con HAP asociada a $\mathrm{CC}^{13,309}$. Algunas malformaciones, como el ductus arteriosus permeable, la comunicación interauricular senovenosa o el retorno venoso pulmonar parcialmente anormal, a menudo permanecen ocultas y se clasifica a estos pacientes erróneamente en el grupo de HAPI. Por ello, se debe investigar específicamente estas anomalías congénitas.

Los datos epidemiológicos siguen siendo escasos, ya que no se ha diseñado ningún estudio para evaluar la prevalencia de la HAP en adultos con CC, aunque en un registro europeo se ha estimado una prevalencia del 5-10\% ${ }^{310}$. La exposición persistente de la vasculatura pulmonar a un flujo sanguíneo aumentado por cortocircuitos sistemicopulmonares y también a una presión aumentada puede causar una arteriopatía pulmonar obstructiva típica (idéntica a otras formas de HAP) que lleva a un aumento de la RVP. Si la RVP se acerca o supera la resistencia vascular sistémica (RVS), el cortocircuito se revierte (síndrome de Eisenmenger) ${ }^{311}$. 


\subsubsection{Diagnóstico}

Como se indica en la tabla 6, la presentación clínica de los pacientes con HAP puede ser diferente. El síndrome de Eisenmenger es un trastorno multisistémico y la forma más grave de la HAP en adultos con CC. Los signos y síntomas del síndrome de Eisenmenger resultan de la $\mathrm{HP}$, la baja saturación arterial de $\mathrm{O}_{2}$ y cambios hematológicos secundarios, como eritrocitosis, trombocitopenia y, en ocasiones, leucocitopenia. Los síntomas incluyen disnea, fatiga y síncope. En pacientes con HAP asociada a CC del adulto sin reversión del cortocircuito, el grado de cianosis y eritrocitosis puede ser de leve a moderado. Los pacientes con síndrome de Eisenmenger también presentan hemoptisis, accidentes cerebrovasculares, abscesos cerebrales, alteraciones de la coagulación y muerte súbita. Los sujetos con síndrome de Eisenmenger tienen una esperanza de vida reducida, aunque algunos pueden vivir hasta la tercera o la cuarta década y otros sobreviven hasta la séptima ${ }^{312}$. Entre los pacientes en lista de espera para trasplante cardiopulmonar cuando el tratamiento médico no está disponible, el síndrome de Eisenmenger tuvo mejor supervivencia que la HAPI, con tasas de supervivencia a los 3 años del 77 frente al 35\% de la HAPI no $\operatorname{tratada}^{313}$. En un estudio reciente sobre los diferentes grupos de HAP asociada a CC (tabla 6), la peor supervivencia se observó en los pacientes con HAP tras la reparación del defecto o con defectos pequeños/coincidentes, comparados con los pacientes con síndrome de Eisenmenger o aquellos con cortocircuitos sistemicopulmonares prevalentes ${ }^{314}$. La mejor supervivencia puede ser el resultado de la conservación de la función del VD, ya que este no sufre remodelado tras el nacimiento y permanece hipertrofiado ${ }^{315}$. El VD también se alivia con el cortocircuito de derecha a izquierda manteniendo el GC a expensas de la hipoxemia y la cianosis.

De todos los pacientes con CC, los que sufren síndrome de Eisenmenger son los que tienen mayor deterioro en cuanto a intolerancia al ejercicio $^{314,316}$.

Los pacientes con CC (particularmente los que no tienen cortocircuitos) pueden sufrir HP causada por cardiopatía izquierda (grupo 2 , tabla 4) o enfermedades pulmonares concomitantes (grupo 3, tabla 4). En estos casos, se recomienda realizar un proceso diagnóstico integral, como se describe en la sección 7.1.1.

\subsubsection{Tratamiento}

En pacientes con cortocircuitos sistemicopulmonares prevalentes, se debe valorar la operabilidad (tabla 6). Se han propuesto criterios para el cierre del cortocircuito basados en la RVP basal (tabla 24) y datos publicados ${ }^{317-319}$. Otros criterios adicionales son el tipo de defecto, la edad, el cociente RVP:RVS y el cociente Qp:Qs ${ }^{320}$. No hay datos prospectivos sobre la utilidad de las pruebas de vasorreactividad, las pruebas de cierre o la biopsia pulmonar para la evaluación de la operabilidad ${ }^{320}$. Las intervenciones quirúrgicas o percutáneas están contraindicadas para los pacientes con síndrome de Eisenmenger y tampoco son útiles para los pacientes con defectos pequeños o coincidentes.

La estrategia de tratamiento médico para los pacientes con HAP asociada a CC, y particularmente para aquellos con síndrome de Eisenmenger, se basa sobre todo en la experiencia clínica de los expertos en este campo y no se basa formalmente en la evidencia ${ }^{311}$. Se ha propuesto un algoritmo específico de tratamiento ${ }^{309}$.

Los pacientes con HAP asociada a CC deben ser tratados en centros especializados. La instrucción del paciente, las modificaciones del comportamiento y el conocimiento de los factores de riesgo potenciales son una parte importante del manejo de estos pacientes.

Los pacientes con HAP asociada a CC pueden presentar deterioro clínico en distintas circunstancias como, por ejemplo, durante la cirugía no cardiaca que requiere anestesia general, deshidratación, infecciones pulmonares o grandes altitudes. Se recomienda evitar el ejercicio intenso, aunque la actividad física suave parece ser benefi- ciosa. El embarazo se asocia con un riesgo muy alto tanto para la madre como para el feto, por lo que se desaconseja. Por ello, es imprescindible utilizar un método anticonceptivo eficaz. La anticoncepción doble está indicada para pacientes tratadas con ARE debido a su interacción con los compuestos basados en progesterona.

El tratamiento a largo plazo con oxígeno a domicilio puede mejorar los síntomas, aunque no se ha asociado a una modificación de la supervivencia, al menos cuando se administra solamente por la noche ${ }^{179}$. El uso de la terapia suplementaria de $\mathrm{O}_{2}$ está recomendado para los casos en que produce un aumento constante de la saturación arterial de $\mathrm{O}_{2}$ y cuando alivia los síntomas.

El uso del tratamiento anticoagulante oral para pacientes con síndrome de Eisenmenger es controvertido: se ha informado de una alta incidencia de trombosis de la AP e ictus, además de un aumento del riesgo de hemorragia y hemoptisis ${ }^{321}$. No hay datos sobre esta cuestión y, por lo tanto, no pueden establecerse recomendaciones definitivas. La anticoagulación oral se puede considerar para pacientes con trombosis de la AP, signos de IC y ausencia de hemoptisis o con hemoptisis leve ${ }^{321}$.

La eritrocitosis secundaria es beneficiosa para el adecuado transporte de $\mathrm{O}_{2}$, y se debe evitar la flebotomía sistemática. Si hay síntomas de hiperviscosidad, se debe realizar una flebotomía con sustitución isovolémica, normalmente cuando el hematocrito sea $>65 \%$. Se debe corregir la deficiencia de hierro. No hay datos definitivos que respalden el empleo de BCC en pacientes con síndrome de Eisenmenger; el uso empírico de estos fármacos es peligroso y se debe evitar.

Se ha realizado un ECA sobre un tratamiento farmacológico específico para pacientes con síndrome de Eisenmenger: el bosentán ha mostrado mejoras en la PM6M y reducción de la RVP tras 16 semanas de tratamiento en pacientes con CF-OMS III. Aunque se ha observado un efecto beneficioso del bosentán en la capacidad de ejercicio y la calidad de vida, su efecto en la mortalidad de este grupo de pacientes sigue siendo incierto ${ }^{200}$. El seguimiento a largo plazo (40 semanas) mostró una mejora persistente ${ }^{322}$. El uso de bosentán está aprobado en Europa para los pacientes con síndrome de Eisenmenger y CF-OMS III.

Las experiencias con otros ARE ${ }^{323}$ y los inhibidores de la PDE-5 sildenafilo ${ }^{314}$ y tadalafilo ${ }^{324}$ muestran resultados funcionales y hemodinámicos favorables en pacientes con HAP asociada a CC y síndrome de Eisenmenger.

El uso de epoprostenol intravenoso se ha probado en pacientes con síndrome de Eisenmenger, y se han observado efectos favorables en los parámetros hemodinámicos y la capacidad de ejercicio, aunque las líneas centrales exponen a los pacientes al riesgo de embolia paradójica y sepsis ${ }^{22}$. No hay datos disponibles sobre el uso de otros prostanoides.

Los datos publicados sobre la terapia combinada son escasos, pero los principios son similares a los de la $\mathrm{HAPI}^{207,314}$. El empleo de un tratamiento específico de la HAP para lograr los criterios de operabilidad en pacientes con HAP y cortocircuitos sistemicopulmonares (tabla 24), que permitiría la corrección del defecto (concepto «tratar para cerrar»), no tiene el respaldo de los datos disponibles.

El trasplante cardiopulmonar o pulmonar con cirugía cardiaca es una opción en casos especiales de pacientes que no responden al tratamiento médico, pero está limitado por la disponibilidad de órganos. Las tasas de supervivencia a corto y largo plazo son similares a las de otras formas de HAP. La supervivencia estimada de los pacientes con síndrome de Eisenmenger dificulta la decisión sobre la indicación de trasplante y cuándo debería realizarse ${ }^{309}$.

Las recomendaciones sobre la HAP asociada a CC se recogen en la tabla 25.

\subsection{Hipertensión arterial pulmonar asociada a enfermedad del tejido conectivo}

La HAP es una complicación muy conocida de las ETC, como la esclerosis sistémica, el lupus eritematoso sistémico, la ETC mixta y, en 
Tabla 24

Recomendaciones para la corrección de la cardiopatía congénita con cortocircuitos sistemicopulmonares prevalentes

\begin{tabular}{|c|c|c|c|c|c|}
\hline Recomendaciones & & & Clase $^{\mathrm{a}}$ & Nivel $^{\mathrm{b}}$ & $\operatorname{Ref}^{c}$ \\
\hline $\operatorname{RVPi}\left(\mathrm{UW} \times \mathrm{m}^{2}\right)$ & RVP (UW) & Corregible $^{d}$ & & & \\
\hline$<4$ & $<2,3$ & Sí & IIa & C & 317 \\
\hline$>8$ & $<4,6$ & No & IIa & C & 317 \\
\hline $4-8$ & $2,3-4,6$ & $\begin{array}{c}\text { Evaluación } \\
\text { individualizada } \\
\text { del paciente } \\
\text { en un hospital } \\
\text { terciario }\end{array}$ & Ila & C & 317 \\
\hline
\end{tabular}

RVP: resistencia vascular pulmonar; RVPi: resistencia vascular pulmonar indexada; UW: unidades de Wood.

aGrado de recomendación.

bNivel de evidencia.

'Referencias que apoyan las recomendaciones.

Quirúrgicamente o mediante procedimientos intravasculares percutáneos.

Tabla 25

Recomendaciones para la hipertensión arterial pulmonar asociada a enfermedad cardiaca congénita

\begin{tabular}{|c|c|c|c|}
\hline Recomendaciones & Clase $^{\mathrm{a}}$ & Nivel $^{\mathrm{b}}$ & $\operatorname{Ref}^{c}$ \\
\hline $\begin{array}{l}\text { El bosentán está indicado para pacientes en } \\
\text { CF-OMS III y con síndrome de Eisenmenger }\end{array}$ & I & B & 200,322 \\
\hline $\begin{array}{l}\text { Se debería considerar otros ARE, PDE-5i y } \\
\text { prostanoides para pacientes con síndrome } \\
\text { de Eisenmenger }\end{array}$ & IIa & C & $\begin{array}{l}223,314 \\
323,324\end{array}$ \\
\hline $\begin{array}{l}\text { En ausencia de hemoptisis significativa, se debería } \\
\text { considerar el tratamiento con anticoagulantes } \\
\text { orales para pacientes con trombosis de AP o datos } \\
\text { de insuficiencia cardiaca }\end{array}$ & IIb & C & \\
\hline $\begin{array}{l}\text { Se debería considerar la terapia con } \mathrm{O}_{2} \\
\text { suplementario para casos en que produce un } \\
\text { incremento constante en la } \mathrm{SatO}_{2} \text { y mejore los } \\
\text { síntomas }\end{array}$ & Ila & C & 179 \\
\hline $\begin{array}{l}\text { Si hay síntomas de hiperviscosidad, se debería } \\
\text { considerar la flebotomía con sustitución } \\
\text { isovolumétrica por lo general cuando el } \\
\text { hematocrito sea }>65 \%\end{array}$ & Ila & C & 183 \\
\hline $\begin{array}{l}\text { Se puede considerar la terapia con suplemento } \\
\text { de hierro para pacientes con concentraciones } \\
\text { plasmáticas de ferritina bajas }\end{array}$ & IIb & C & 184 \\
\hline $\begin{array}{l}\text { Se puede considerar la terapia combinada } \\
\text { para pacientes con síndrome de Eisenmenger }\end{array}$ & IIb & C & 207,314 \\
\hline $\begin{array}{l}\text { No se recomienda usar BBC para pacientes } \\
\text { con síndrome de Eisenmenger }\end{array}$ & III & $\mathrm{C}$ & 189 \\
\hline
\end{tabular}

AP: arteria pulmonar; ARE: antagonistas de los receptores de la endotelina; $B B C$ : bloqueadores de canales de calcio; CF-OMS: clase funcional de la Organización Mundial de la Salud; PDE-5i: inhibidores de la fosfodiesterasa tipo 5.

aGrado de recomendación.

Nivel de evidencia.

'Referencias que respaldan las recomendaciones.

menor grado, la artritis reumatoide, la dermatomiositis y el síndrome de Sjögren ${ }^{325-329}$. La HAP asociada a ETC es el segundo tipo de HAP más prevalente en países occidentales, después de la HAPI ${ }^{10}$. La esclerosis sistémica, especialmente en su variante limitada, es la principal ETC asociada a HAP en Europa y Estados Unidos (el lupus eritematoso es más común en Asia $)^{325,329}$. La prevalencia de la HP precapilar confirmada hemodinámicamente en grandes cohortes de pacientes con esclerosis sistémica oscila entre el 5 y el 12\%46,325,330,331. En estos pacientes, la HAP puede ocurrir conjuntamente con enfermedad pulmonar intersticial o como resultado de una vasculopatía pulmonar aislada, que podría afectar a las arteriolas precapilares (HAP) o las vénulas poscapilares (EVOP) ${ }^{326,332}$. Además, también puede haber hipertensión venosa pulmonar del grupo 2 por cardiopatía izquierda ${ }^{76,326,333}$. Es imperativo determinar cuál es el mecanismo operante, puesto que este determina el tratamiento en el contexto de una enfermedad multifacética.

\subsubsection{Diagnóstico}

Comparada con la HAPI, los pacientes con ETC y HAP son principalmente mujeres (en proporción 4:1) y personas mayores (media de edad al diagnóstico, > 60 años), que pueden presentar enfermedades concomitantes (enfermedad pulmonar intersticial, cardiopatía izquierda) y tienen una supervivencia más corta ${ }^{326,330,334-336}$. El riesgo no ajustado de muerte para la HAP asociada a esclerosis sistémica comparado con la HAPI es de 2,9 y los predictores de resultados son prácticamente iguales para ambas entidades ${ }^{336}$. Los síntomas y la presentación clínica también son similares a los de la HAPI y en algunos pacientes con diagnóstico de HAPI se puede detectar ETC concomitante mediante pruebas inmunológicas. La TCAR torácica es útil para evaluar la presencia de enfermedad pulmonar intersticial asociada o EVOP $^{326,332,337}$. Una reducción aislada de la DLCO es una de las alteraciones frecuentes en la esclerosis sistémica asociada a HAP ${ }^{327,338 .}$

La ecocardiografía en reposo es la prueba recomendada para el cribado de pacientes con esclerosis sistémica asintomática, seguida de un seguimiento anual con ecocardiografía, DLCO y biomarcadores ${ }^{325}$. En el estudio DETECT se propone una escala a 2 niveles para seleccionar a los pacientes que deben someterse a $\mathrm{CCD}^{327}$. Las recomendaciones para el cribado y la detección temprana se encuentran en la tabla 9 del anexo web. La relación coste-eficacia de estas estrategias no se ha establecido frente a la detección basada en los síntomas. La ecocardiografía es el método recomendado cuando haya síntomas de otras ETC. Al igual que en otras formas de HAP, el CCD está recomendado para todo caso en que se sospeche HAP asociada a ETC para confirmar el diagnóstico, determinar la gravedad y descartar cardiopatía izquierda.

\subsubsection{Tratamiento}

El tratamiento de la HAP asociada a ETC es más complejo que el de la HAPI. El tratamiento inmunosupresor que combina glucocorticoides y ciclofosfamida puede producir una mejoría clínica en pacientes con HAP asociada a lupus sistémico eritematoso o ETC mixta ${ }^{339}$.

Se observa respuesta favorable a largo plazo al tratamiento con BCC en menos del 1\% de los $\operatorname{casos}^{189}$. En la esclerosis sistémica, la relación riesgo:beneficio a largo plazo del tratamiento anticoagulante oral es menos favorable que en la HAPI debido a un mayor riesgo de sangrado ${ }^{175}$.

El tratamiento de los pacientes con ETC e HAP debe seguir el mismo algoritmo que para la HAPI (figura 2). Esta recomendación se basa en que la mayoría de los ECA más importantes realizados para la aprobación de tratamientos específicos (incluida la terapia combinada) para la HAP incluyeron a pacientes con ETC.

Los análisis de subgrupos de los pacientes con esclerosis sistémica incluidos en ECA diseñados para la evaluación de distintos fármacos, como bosentán, macitentán, sildenafilo, riociguat y treprostinil subcutáneo, han mostrado efectos favorables. En algunos de estos estudios, la magnitud de la respuesta en el subgrupo de pacientes con HAP asociada a ETC fue menor que en los pacientes con $\mathrm{HAPI}^{340}$. En la elección del tratamiento para la HAP en el contexto de la esclerosis sistémica y su microangiopatía generalizada se debe tener en cuenta otros daños vasculares, como las úlceras dactilares pasadas o presentes.

El tratamiento continuo con epoprostenol intravenoso mejoró la capacidad de ejercicio, los síntomas y los parámetros hemodinámicos en un estudio a 3 meses que incluyó a pacientes con HAP asociada a esclerosis sistémica ${ }^{222}$. Sin embargo, el análisis retrospectivo muestra que el epoprostenol i.v. tuvo mayor efecto en la supervivencia de los 
pacientes con HAPI que en la de los pacientes con HAP asociada a esclerosis sistémica. Esto puede explicarse en parte por la presencia de comorbilidades, como las afecciones cardiopulmonares.

La esclerosis sistémica no se debe considerar a priori una contraindicación para el trasplante pulmonar ${ }^{341}$. Se recomienda una estrategia multidisciplinaria para optimizar el manejo de los pacientes con esclerosis sistémica antes, durante y después de la cirugía ${ }^{341}$. Las indicaciones y contraindicaciones para el trasplante deben adaptarse a las características específicas de la esclerosis sistémicas, con especial atención a los trastornos gástricos (enfermedad por reflujo gastroesofágico y enfermedad intestinal), cardiacos, renales y cutáneos.

Las recomendaciones para la HAP asociada a ETC se recogen en la tabla 26.

\section{Tabla 26}

Recomendaciones para la hipertensión arterial pulmonar asociada a enfermedad del tejido conectivo

\begin{tabular}{lccc}
\hline Recomendaciones & Clase $^{\mathrm{a}}$ & Nivel $^{\mathrm{b}}$ & Ref $^{\mathrm{c}}$ \\
\hline $\begin{array}{l}\text { Para pacientes con HAP asociada a ETC, se } \\
\text { recomienda el mismo algoritmo de tratamiento que } \\
\text { para pacientes con HAPI }\end{array}$ & I & C & 46 \\
\hline $\begin{array}{l}\text { Para pacientes asintomáticos con ES, se } \\
\text { recomienda el ecocardiograma en reposo como } \\
\text { prueba de cribado, seguido de cribado anual } \\
\text { con ecocardiograma, DLCO y biomarcadores }\end{array}$ & I & C & 46 \\
\hline $\begin{array}{l}\text { Se recomienda un CCD en todo caso de sospecha } \\
\text { de HAP asociada a ETC }\end{array}$ & I & C & 46,327 \\
\hline $\begin{array}{l}\text { Se puede considerar la anticoagulación oral } \\
\text { individualizadamente y en presencia de trombofilia }\end{array}$ & IIb & C & 175,339 \\
\hline
\end{tabular}

CCD: cateterismo cardiaco derecho; DLCO: capacidad de difusión de monóxido de carbono; ES: esclerosis sistémica; ETC: enfermedad del tejido conectivo; HAP: hipertensión arterial pulmonar; HAPI: hipertensión arterial pulmonar idiopática.

aGrado de recomendación.

bNivel de evidencia.

'Referencias que respaldan las recomendaciones.

\subsection{Hipertensión arterial pulmonar asociada a hipertensión portal}

La HAP asociada a hipertensión portal se conoce normalmente como hipertensión portopulmonar (HPPo). No se debe confundir esta entidad con el síndrome hepatopulmonar, que se caracteriza por alteraciones de la vasodilatación pulmonar e hipoxemia ${ }^{342}$. Sin embargo, pueden ocurrir superposiciones entre ambas entidades ${ }^{343}$. Como su nombre indica, la HPPo se asocia a la presencia de hipertensión portal, pero no necesariamente acompañada de enfermedad hepática. Sin embargo, dado que la cirrosis hepática es con mucha diferencia la causa más común de hipertensión portal, la HPPo se encuentra con más frecuencia en pacientes con cirrosis. Aproximadamente un 1-5\% de los pacientes con hipertensión portal sufren $\mathrm{HAP}^{344} \mathrm{y}$ el riesgo parece ser independiente de la etiología de la enfermedad hepática y el grado de alteración de la función hepática ${ }^{345}$. Aunque se han descrito algunos factores de riesgo genéticos ${ }^{346}$, la relación patogénica de la hipertensión portal y la hipertensión pulmonar sigue siendo incierta.

\subsubsection{Diagnóstico}

En general, los signos y síntomas de la HPPo son similares o idénticos a los de la mayoría de las formas de HAP, con disnea progresiva durante el ejercicio como la queja principal. El cuadro clínico puede complicarse por la presencia y la gravedad de la enfermedad hepática subyacente. La evaluación diagnóstica sigue las mismas recomendaciones que para otras formas de HP, teniendo en cuenta siempre que la coexistencia de hipertensión portal e HP no implica necesaria- mente que estos pacientes sufran $\mathrm{HPPo}^{344}$. Es preciso un proceso diagnóstico completo, que incluya $\mathrm{CCD}$, para evaluar la gravedad de la enfermedad, el perfil hemodinámico y otras causas potenciales de HP, como enfermedades pulmonares, cardiopatía izquierda o enfermedad tromboembólica crónica. Como grupo, los pacientes con HPPo tienden a tener un índice cardiaco más elevado y una RVP más baja que los pacientes con $\mathrm{HAPI}^{347}$, aunque los valores se pueden solapar.

\subsubsection{Tratamiento}

El riesgo de mortalidad de los pacientes con HPPo es al menos tan alto como el de los pacientes con $\mathrm{HAP}^{347,348} \mathrm{y}$ hay que referirlos a centros especializados en el manejo tanto de la HAP como de la enfermedad hepática. En general, el tratamiento sigue las mismas normas que en otras formas de HAP, pero hay que tener en cuenta algunas consideraciones importantes. Los pacientes con HPPo suelen tener un riesgo hemorrágico alto, por lo que la anticoagulación normalmente no está recomendada. Los bloqueadores beta, que se emplean frecuentemente para reducir la presión portal, deben evitarse en pacientes con HPPo, ya que empeoran los parámetros hemodinámicos y la capacidad de ejercicio en esta población de pacientes ${ }^{349}$.

Los pacientes con HPPo han sido excluidos de casi todos los ECA en el campo de la HAP (excepto el estudio PATENT, que incluyó a 13 pacientes con $\mathrm{HPPo}$ ). Algunos informes puntuales indican que se puede administrar a esta población ARE, inhibidores de la PDE-5, estimuladores de la GCs y análogos de la prostaciclina ${ }^{214,350-356}$. Esto incluye algunos fármacos hepatotóxicos, como el bosentán, pero hay que señalar que este compuesto tiende a acumularse en pacientes con la función hepática muy afectada (clases B y C de Child-Pugh) ${ }^{356}$. Los nuevos ARE (ambrisentán, macitentán) tienen teóricas ventajas sobre el bosentán, ya que el riesgo de toxicidad hepática asociada al fármaco es menor ${ }^{194,201,357}$, aunque ninguno de estos fármacos se ha evaluado sistemáticamente en pacientes con HPPo.

La presencia de HP es especialmente importante para los pacientes a los que se va a someter a trasplante hepático ${ }^{358}$. La HP leve con RVP normal o casi normal en presencia de GC alto suele tolerarse bien y tiende a ser reversible tras el trasplante ${ }^{359}$. Por el contrario, la HAP se ha identificado como el factor de riesgo más importante en el contexto del trasplante hepático. En una serie de pacientes de la Mayo Clinic $^{359}$, la tasa de mortalidad fue del $100 \%$ de los pacientes con PAPm $\geq 50 \mathrm{mmHg}$ y del $50 \%$ de los pacientes con PAPm de 35-50 mmHg y RVP $\geq 250$ dinas.s.cm ${ }^{-5}$. Por ello, es preciso cribar los signos de HP en los pacientes evaluados para trasplante hepático, incluso cuando no se observen los síntomas clínicos correspondientes. En el pasado, la HAP significativa se consideraba una contraindicación para el trasplante hepático, pero algunas publicaciones puntuales indican que el pretratamiento de estos pacientes con fármacos específicos para la HAP puede mejorar los resultados después del trasplante ${ }^{360-363}$. No se dispone de suficiente evidencia para establecer recomendaciones generales y la decisión sobre el trasplante debe ser valorada por equipos multidisciplinarios en centros especializados. En algunos centros especializados se realizan trasplantes combinados de hígado-pulmón o hígado-pulmón-corazón en pacientes muy seleccionados ${ }^{364}$.

Las recomendaciones para la HAP asociada a hipertensión portal se resumen en la tabla 27.

\subsection{Hipertensión arterial pulmonar asociada a infección por el virus de la inmunodeficiencia humana}

El uso de terapias antirretrovirales de gran actividad y el manejo agresivo de las infecciones oportunistas han contribuido a mejorar la esperanza de vida de los pacientes infectados por el VIH ${ }^{366,367}$. Consecuentemente, el espectro de complicaciones ha girado hacia otras enfermedades a largo plazo, entre ellas la HAP. Es probable que el manejo moderno del VIH con la terapia antirretroviral también haya mejorado la supervivencia y haya disminuido la incidencia de la HAP 
Tabla 27

Recomendaciones para la hipertensión arterial pulmonar asociada a hipertensión portal

\begin{tabular}{lccc}
\hline Recomendaciones & Clase & Nivel & Ref \\
\hline $\begin{array}{l}\text { Se recomienda evaluación ecocardiográfica de } \\
\text { signos de HP para pacientes sintomáticos con } \\
\text { enfermedad hepática o hipertensión portal y todo } \\
\text { candidato a trasplante hepático }\end{array}$ & I & B & 344 \\
\hline $\begin{array}{l}\text { Se recomienda referir a los pacientes con HAP } \\
\text { asociada a hipertensión portal a centros con } \\
\text { experiencia en el manejo de ambas enfermedades }\end{array}$ & I & C & 344 \\
\hline $\begin{array}{l}\text { Se recomienda aplicar el algoritmo de tratamiento } \\
\text { de pacientes con otras formas de HAP a los } \\
\text { pacientes con HAP asociada a hipertensión portal } \\
\text { teniendo en cuenta la gravedad de la enfermedad } \\
\text { hepática }\end{array}$ & I & C & 214, \\
\hline $\begin{array}{l}\text { No se recomienda la anticoagulación para pacientes } \\
\text { con HP asociada a hipertensión portal }\end{array}$ & III & C & $350-356$ \\
\hline $\begin{array}{l}\text { Se puede considerar el trasplante hepático } \\
\text { para pacientes seleccionados que responden bien } \\
\text { al tratamiento de la HAP }\end{array}$ & IIb & C & $361-363$ \\
\hline $\begin{array}{l}\text { El trasplante hepático está contraindicado } \\
\text { para pacientes con HAP grave no controlada }\end{array}$ & III & C & $361-363$ \\
\hline
\end{tabular}

HAP: hipertensión arterial pulmonar; HP: hipertensión pulmonar.

a Grado de recomendación.

${ }^{\mathrm{b}}$ Nivel de evidencia.

'Referencias que respaldan las recomendaciones.

asociada a infección por el VIH ${ }^{368}$. Considerados en conjunto, estos efectos en la supervivencia y la incidencia han dado como resultado una prevalencia de la HAP en pacientes infectados por el VIH estable en las últimas décadas. Un estudio de población ha indicado que la prevalencia mínima de la HAP asociada al VIH fue del 0,46\%, una cifra muy similar a la observada antes del uso de los tratamientos actuales (terapia antirretroviral de gran actividad) ${ }^{369}$. La patogenia de la HAP asociada al VIH sigue siendo incierta. La ausencia de partículas virales en las lesiones plexiformes complejas encontradas en estos pacientes indica que una acción indirecta de la infección viral sobre factores de inflamación y crecimiento podría actuar como factor desencadenante en un paciente con predisposición.

\subsubsection{Diagnóstico}

La HAP asociada al VIH tiene una presentación clínica similar a la HAPI. En el momento del diagnóstico, la mayoría de los pacientes están en NYHA III-IV. Los pacientes pueden presentar otros factores de riesgo de HAP, como enfermedades hepáticas (hepatitis B o C crónica), exposición a drogas o toxinas o embolia pulmonar causada por toxicomanía i.v. La investigación experimental en animales respalda la noción de que el efecto aditivo de la cocaína en la infección por el VIH puede tener un papel en el desarrollo de la arteriopatía pulmonar. Dada su baja prevalencia, no se debe realizar un cribado de la HAP en pacientes asintomáticos infectados por el VIH. No obstante, la ecocardiografía está indicada para pacientes que sufren disnea sin una causa clara para detectar complicaciones cardiovasculares asociadas al VIH, como miocarditis, miocardiopatía o HAP. Es imprescindible realizar un CCD para confirmar el diagnóstico de HAP asociada al VIH y descartar cardiopatía izquierda ${ }^{369}$. La HAP es un factor independiente de riesgo de muerte para los pacientes infectados por el VIH.

\subsubsection{Tratamiento}

Debido a la falta de recomendaciones específicas, el tratamiento de la HAP asociada al VIH sigue las pautas del tratamiento para la HAPI combinado con terapia antirretroviral de gran actividad. Según un análisis multivariable, un índice cardiaco $>2,81 / \mathrm{min} / \mathrm{m}^{2}$ y un recuento de linfocitos CD4 > 200/ml son predictores de supervivencia independientes ${ }^{225}$. No está recomendada la anticoagulación sistemáticamente debido al aumento del riesgo hemorrágico, la falta de adherencia y las interacciones entre fármacos. Los pacientes con HAP asociada al VIH suelen ser no respondedores a la prueba de vasodilatación aguda, por lo que no deben recibir tratamiento con $\mathrm{BCC}^{189}$. Algunos estudios sin grupo de control apuntan que las prostaciclinas pueden mejorar la tolerancia al ejercicio, los parámetros hemodinámicos y los síntomas de pacientes con HAP asociada al VIH ${ }^{218}$. Un estudio sin enmascaramiento sobre los efectos del bosentán en este tipo de pacientes mostró mejoras en todas las variables de eficacia, incluida la PM6M y los parámetros hemodinámicos determinados de manera invasiva ${ }^{370}$. Algunos casos esporádicos fueron incluidos en estudios sobre el ambrisentán ${ }^{194}$. La tolerancia hepática fue similar a la observada previamente en otras formas de HAP. La interpretación de estos estudios está limitada por el pequeño tamaño muestral y por su propia naturaleza abierta. Si se administra sildenafilo combinado con ritonavir y saquinavir, se debe reducir la dosis debido a las interacciones entre fármacos. La infección por el VIH se considera generalmente criterio de exclusión para el trasplante pulmonar, aunque en algunos centros se ha implementado un programa específico. Hay que destacar que se han descrito casos de reversión de la enfermedad en pacientes con HAP asociada al VIH tratados con terapia antirretroviral de gran actividad y terapias específicas. Este hallazgo, junto a la reducción de la incidencia de la HP asociada al VIH debido a los tratamientos actuales, podría indicar que el manejo agresivo mejora los resultados en esta población de pacientes. Son necesarios más estudios de investigación para comprender los mecanismos subyacentes a estos resultados más favorables en estos pacientes.

Las recomendaciones para la HAP asociada a infección por el VIH se recogen en la tabla 28 .

Tabla 28

Recomendaciones para la hipertensión arterial pulmonar asociada a infección por el virus de la inmunodeficiencia humana

\begin{tabular}{lccc}
\hline Recomendaciones & Clase $^{\mathrm{a}}$ & Nivel $^{\mathrm{b}}$ & Ref $^{\mathrm{c}}$ \\
\hline $\begin{array}{l}\text { No se recomienda el cribado ecocardiográfico de } \\
\text { pacientes asintomáticos con VIH para detectar HP }\end{array}$ & III & C & 369 \\
\hline $\begin{array}{l}\text { Para pacientes con HAP asociada a infección por } \\
\text { el VIH, se debe considerar el mismo algoritmo } \\
\text { de tratamiento que el usado para pacientes con }\end{array}$ & IIa & C & 194,367 \\
$\begin{array}{l}\text { HAP teniendo en cuenta las comorbilidades y las } \\
\text { interacciones farmacológicas }\end{array}$ & & & \\
\hline $\begin{array}{l}\text { No se recomienda la anticoagulación, pues se carece } \\
\text { de datos acerca de su razón riesgo/beneficio }\end{array}$ & III & C & 175,367 \\
\hline
\end{tabular}

HAP: hipertensión arterial pulmonar; HP: hipertensión pulmonar; VIH: virus de la inmunodeficiencia humana.

${ }^{a}$ Grado de recomendación.

bNivel de evidencia.

'Referencias que respaldan las recomendaciones.

\subsection{Enfermedad venooclusiva pulmonar y hemangiomatosis capilar pulmonar}

Aunque la EVOP y la HCP son entidades poco frecuentes, se las reconoce cada vez más como causa de HP ${ }^{92,371}$. Se encuentran características patológicas de HCP en el 73\% de los pacientes con EVOP y, viceversa, se encuentran características patológicas de EVOP en el $80 \%$ de los pacientes con $\mathrm{HCP}^{372}$. La similitud de las características patológicas y clínicas, además del riesgo de edema pulmonar indu-

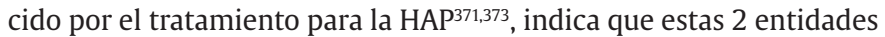
se superponen y se ha propuesto que la HCP podría ser un proceso angioproliferativo secundario causado por la obstrucción poscapilar de la EVOP, en lugar de ser otra enfermedad distinta ${ }^{6,372}$. Por esta razón, la EVOP y la HCP se han clasificado juntas en un subgrupo 
específico de la clasificación clínica cercana a la HAP (tabla 4, grupo 1), dado que comparten características patológicas, genéticas y clínicas similares, y también comparten diferencias con la HAP6. La incidencia real de la EVOP/HCP sigue siendo desconocida debido a que se sigue clasificando muchos de estos casos erróneamente como HAP ${ }^{374}$. La proporción de casos de HAP idiopática que en realidad cumplen los criterios de EVOP/HCP puede ser del 10\% (la estimación más baja de la incidencia y la prevalencia de la EVOP/HCP es < 1 caso/millón $)^{92,374}$. Al contrario que la HAPI, la EVOP afecta predominantemente a los varones y el pronóstico parece ser peor ${ }^{371}$. Se ha informado sobre la incidencia de la EVOP familiar, aunque rara vez se han encontrado mutaciones de BMPR2 en los pacientes que sufren esta enfermedad $^{28,371,375}$. Mientras que la HAP debida a mutaciones de BMPR2 se segrega por vía autosómica dominante con penetración incompleta, los casos de EVOP/HCP familiar ocurren típicamente en hijos jóvenes de padres no afectados, lo cual indica que la enfermedad se segrega como rasgo recesivo ${ }^{28}$. En estas familias, la EVOP/HCP está causada por mutaciones bialélicas en el gen EIF2AK428. Al igual que la HAP, la EVOP/HCP puede complicar el curso de otras enfermedades asociadas (esclerosis sistémica, infección por el VIH, etc.) y la exposición a drogas o toxinas (ciclofosfamida, mitomicina, etc.).

\subsubsection{Diagnóstico}

El diagnóstico de la EVOP/HCP se puede establecer con una alta probabilidad mediante la combinación de sospecha clínica, reconocimiento físico, broncoscopia y resultados radiológicos ${ }^{371}$. Este enfoque no invasivo puede evitar la biopsia pulmonar (técnica estándar para confirmar el diagnóstico histológico de la EVOP/HCP), que ya no está recomendada en la mayoría de los $\operatorname{casos}^{371}$. En los casos de enfermedad heredable, la identificación de una mutación bialélica de EIF2AK4 es suficiente para confirmar el diagnóstico sin necesidad de confirmación mediante pruebas histológicas ${ }^{28,376}$. La mayoría de los pacientes refieren disnea durante el esfuerzo y fatiga, una presentación clínica que no se puede diferenciar de la HAP ${ }^{371,374}$. El reconocimiento físico puede revelar acropaquia y estertores bibasales en la auscultación pulmonar, que son signos inusuales en la $\mathrm{HAP}^{371}$. En series de casos se ha observado que los pacientes con EVOP/HCP tienen hipoxemia más grave y una capacidad de difusión del monóxido de carbono mucho menor que los pacientes con otras formas de HAP ${ }^{92,371}$. Esto puede explicarse por la presencia de edema pulmonar intersticial y proliferación capilar pulmonar típica de la EVOP/HCP.

La radiografía torácica puede revelar líneas de Kerley B, aumento de ganglios linfáticos mediastínicos e infiltrados intersticiales periféricos, además de otros signos de HP92,371. La TCAR torácica es la técnica diagnóstica de elección. Los hallazgos típicos que indican EVOP/HCP son líneas septales subpleurales engrosadas, opacidades en vidrio esmerilado de distribución centrolobular y linfadenopatías mediastínicas ${ }^{92,371}$. La asociación de estos 3 hallazgos tiene una especificidad del $100 \%$ para la EVOP/HCP en los casos de HAP, y una sensibilidad del $66 \%$. Además, su presencia puede estar estrechamente relacionada con el riesgo de edema pulmonar asociado al tratamiento de la HAP. El escáner pulmonar de V/Q no ayuda a discriminar la EVOP/HCP de la $\mathrm{HAPI}^{377}$.

Dado que la EVOP/HCP puede estar asociada con una hemorragia alveolar oculta, la broncoscopia con lavado broncoalveolar puede ser una herramienta útil en la estrategia diagnóstica. En un estudio retrospectivo se analizaron los resultados del lavado broncoalveolar realizado a 19 pacientes con HAP o EVOP/HCP. Comparados con la HAPI, los 8 casos de EVOP presentaron un recuento celular significativamente mayor, mayor porcentaje de macrófagos cargados con hemosiderina y una escala de Golde notablemente alta ${ }^{378}$.

La presentación hemodinámica de la EVOP es similar a la HAPI ${ }^{92,371}$. Hay que destacar que la PEP se mantiene prácticamente normal porque los cambios patológicos ocurren en pequeñas vénulas y vasos capilares, y no afectan a las venas pulmonares más grandes ${ }^{92,371}$. La prueba de vasorreactividad se puede complicar con edema pulmonar agudo $^{92,371}$.

\subsubsection{Tratamiento}

No existe un tratamiento médico establecido para la EVOP/HCP ${ }^{92}$. Y lo que es más importante, se debe emplear con extrema precaución los vasodilatadores, particularmente el epoprostenol i.v., debido al elevado riesgo de edema pulmonar grave inducido por fármacos ${ }^{92,373}$. No obstante, se han publicado casos de mejoría clínica mantenida en pacientes individuales tratados con estos medicamentos ${ }^{379}$. Se recomienda el tratamiento con altas dosis de diuréticos, terapia de $\mathrm{O}_{2} \mathrm{y}$ epoprostenol con aumento lento y paulatino de la dosis ${ }^{379}$. Por todo ello, el tratamiento de la EVOP/HCP solo debe realizarse en centros con amplia experiencia en el manejo de la HP y los pacientes deben ser informados de los riesgos. Se ha considerado el uso experimental de inhibidores de la angiogénesis como el interferón alfa-2a en estos pacientes, pero actualmente no está recomendado ${ }^{379}$. La única terapia curativa para la EVOP/HCP es el trasplante pulmonar, y no hay informes de recurrencia de la enfermedad después del trasplante. Los pacientes con EVOP/HCP candidatos a trasplante deben ser referidos a un centro de trasplante para proceder a su evaluación tan pronto se confirme el diagnóstico ${ }^{379}$.

Las recomendaciones para la EVOP/HCP se resumen en la tabla 29.

Tabla 29

Recomendaciones para la hipertensión arterial pulmonar asociada a hemangiomatosis capilar pulmonar

\begin{tabular}{|c|c|c|c|}
\hline Recomendaciones & Clase $^{\mathrm{a}}$ & Nivel $^{\mathrm{b}}$ & $\operatorname{Ref}^{\mathrm{c}}$ \\
\hline $\begin{array}{l}\text { Para el diagnóstico de EVOP/HCP, se recomienda } \\
\text { una combinación de hallazgos clínicos, examen } \\
\text { físico, broncoscopia y hallazgos radiológicos }\end{array}$ & I & C & $\begin{array}{c}92,371, \\
378\end{array}$ \\
\hline $\begin{array}{l}\text { Para confirmar el diagnóstico de EVOP/HCP } \\
\text { hereditario sin confirmación histológica, se } \\
\text { recomienda la identificación de una mutación } \\
\text { bialélica en EIF2AK4 }\end{array}$ & I & B & 28,376 \\
\hline $\begin{array}{l}\text { Está indicado remitir a un centro de trasplante a } \\
\text { los pacientes candidatos con EVOP/HCP para su } \\
\text { evaluación tan pronto se establezca el diagnóstico }\end{array}$ & I & C & 371 \\
\hline $\begin{array}{l}\text { A los pacientes con EVOP/HCP, se los debe manejar } \\
\text { solo en centros con amplia experiencia en } \mathrm{HP} \\
\text { debido al riesgo de edema pulmonar tras el inicio } \\
\text { de tratamiento para la HAP }\end{array}$ & Ila & C & $\begin{array}{c}371,373 \\
379\end{array}$ \\
\hline
\end{tabular}

EVOP: enfermedad venooclusiva pulmonar; HAP: hipertensión arterial pulmonar; HCP: hemangiomatosis capilar pulmonar; HP: hipertensión pulmonar.

${ }^{a}$ Grado de recomendación.

bNivel de evidencia.

cReferencias que respaldan las recomendaciones.

\section{HIPERTENSIÓN ARTERIAL PULMONAR CAUSADA POR CARDIOPATÍA IZQUIERDA (GRUPO 2)}

La HP es una complicación frecuente de las cardiopatías izquierdas (ECI), que ocurre generalmente como un «síntoma» de la enfermedad subyacente $e^{4,380}$ y está relacionada con la gravedad de la enfermedad. La HP causada por ECI puede complicar cualquier trastorno del corazón izquierdo, como las valvulopatías y las enfermedades congénitas. Sin embargo, esta entidad se ha estudiado fundamentalmente en pacientes con IC y FE conservada o disminuida ${ }^{4,380}$. La HP causada por ECI produce síntomas más graves y una peor tolerancia al ejercicio, además del impacto negativo en la evolución ${ }^{4,380,381}$. En comparación con la HAP, los pacientes con HP causada por ECI (especialmente en caso de IC con FEVI conservada suelen ser mayores, mujeres, con 
mayor prevalencia de comorbilidades cardiovasculares 382 y la mayoría, si no todos, con características de síndrome metabólico ${ }^{383}$.

La prevalencia real de la HP causada por ECI en la IC sigue siendo desconocida, fundamentalmente porque la definición de HP en estudios epidemiológicos estaba basada en la ecocardiografía y se emplearon distintos valores de corte ${ }^{4,384}$. La determinación invasiva de los parámetros hemodinámicos se realizó en un escaso número de estudios monocéntricos ${ }^{4}$. En un análisis retrospectivo realizado en un importante centro de HP, se identificó la ECI como la causa de la HP en el 36\% de todos los pacientes referidos para evaluación, de los que el $55 \%$ presentaba HP "pasiva», definida como un gradiente transpulmo$\operatorname{nar}(\mathrm{GTP})<12 \mathrm{mmHg}^{151,385}$.

La HP se desarrolla en la ECI como respuesta a la transmisión retrógrada pasiva de las presiones de llenado, fundamentalmente debido a la función diastólica del VI, acentuada por la insuficiencia mitral inducida por el ejercicio y una pérdida de compliancia de la aurícula izquierda ${ }^{4}$. En algunos pacientes, estos componentes puramente mecánicos de la congestión venosa pueden desencadenar un componente superpuesto en que se combinaría la vasoconstricción pulmonar, la reducción de la disponibilidad de NO, un aumento de la expresión de la endotelina, la desensibilización de la vasodilatación inducida por péptidos natriuréticos y el remodelado vascular ${ }^{4,380,386}$. Todo ello resulta en un aumento adicional de la PAPm superior a la elevación de la PEP que puede producir enfermedad vascular pulmonar, un aumento de la poscarga del VD e insuficiencia del VD 4 .

Las definiciones de la HP y la diferencia entre HP precapilar y poscapilar se basan en los valores de corte de la presión. Esto explica por qué el GTP (PAPm - PEPm) se ha empleado para distinguir la HP "pasiva» (GTP $<12 \mathrm{mmHg}$ ) de la HP «reactiva» (GTP $\geq 12 \mathrm{mmHg})^{151}$. Sin embargo, esta definición y su terminología han sido insatisfactorias, hasta tal punto que frecuentemente se ha empleado el término HP$\mathrm{ECI}$ «desproporcionada» para caracterizar a un subgrupo de pacientes con cambios significativos en la circulación pulmonar ${ }^{4,151}$. Lo ideal sería que esta entidad estuviese definida por una variable hemodinámica que: a) fuese un marcador de la enfermedad; $b$ ) fuese menos dependiente de los cambios en la PEP y el volumen latido, y c) tuviese en cuenta la naturaleza pulsátil de la circulación pulmonar ${ }^{4,81}$. El GTP está influido por todos los determinantes de la PAPm, como el flujo, la resistencia y la presión de llenado del corazón izquierdo ${ }^{4,81,82}$. Por el contrario, la PAP diastólica, comparada con la PAPs y la PAPm, está menos influida por la PEP en cualquier nivel de volumen latido ${ }^{4,81}$. Por lo tanto, el GTP diastólico (GTPd) (definido como PAPd - PEPm) parece acercarse más a las características necesarias para determinar la enfermedad vascular pulmonar ${ }^{4,81}$. En sujetos normales, el GTPd oscila en la franja de 1-3 mmHg, y en pacientes evaluados por enfermedad cardiaca (a excepción de cortocircuitos), el GTPd se mantiene por debajo de $5 \mathrm{mmHg}$ en la mayoría de los casos ${ }^{4,81,387}$.

Los resultados de estudios sobre el papel del GTP y el GTPd para predecir los resultados en la IC se han publicado recientemente ${ }^{83,385,388 .}$ En un estudio monocéntrico que incluyó a 3.107 pacientes, un GTP $>7 \mathrm{mmHg}$ se asoció con peor pronóstico en un subgrupo de pacientes con GTP $>12 \mathrm{mmHg}^{385}$. En otro estudio que incluyó a 463 pacientes con $\mathrm{FEVI}<40 \%$, el riesgo de muerte fue mayor para los pacientes con HP cuando la definición se basaba en la $\operatorname{RVP}(\mathrm{p}<0,01)$, con una tasa de mortalidad más alta entre los pacientes con RVP $\geq 3 \mathrm{UW}^{387}$. Sin embargo, el resultado no fue diferente según el GTP fuera menor o mayor que $12 \mathrm{mmHg}^{83}$, lo cual indica que esta variable tiene menor poder de discriminación que la RVP en presencia de HP. Pero curiosamente los autores afirmaron que la compliancia arterial pulmonar fue un marcador independiente del pronóstico. Otros investigadores también coinciden con esta observación y señalan que la compliancia de la AP está alterada en la insuficiencia cardiaca ${ }^{389}$, incluso en ausencia de $\mathrm{HP}^{390}$. En Estados Unidos, 25.450 pacientes sometidos a trasplante pulmonar presentaban un GTP $>12 \mathrm{mmHg}^{83}$. En este contexto específico, no se observó que el GTPd fuese un predictor de peor pronóstico en ninguno de los niveles estudiados. Los resultados de otro estudio reciente también confirmaron la falta de valor pronóstico del GTPd, aunque tenía algunas limitaciones metodológicas importantes ${ }^{391}$. Debido a sus limitaciones y su naturaleza retrospectiva, estos estudios no proporcionan una respuesta clara a cuál es la mejor variable para predecir el resultado de la HP causada por ECI. Por todo ello, y por coherencia con la definición de HP, se recomienda emplear la combinación de GTPd y RVP para definir los diferentes tipos de HP causada por ECI, es decir, la HP poscapilar aislada y la HP poscapilar y precapilar combinadas (tabla 3).

\subsection{Diagnóstico}

En las cardiopatías izquierdas, y particularmente en la IC izquierda, se puede sospechar HP fácilmente mediante una estrategia gradual que combina la presentación clínica, algunas características ecocardiográficas específicas y otros métodos diagnósticos, como el ECG y técnicas de imagen. Aunque no hay una sola variable que permita diferenciar la HP causada por ECI de la HP precapilar, la presencia de múltiples factores de riesgo y los hallazgos diagnósticos pueden motivar la sospecha de HP causada por ECI (tabla 30). Se debe sospechar HP cuando los pacientes presentan síntomas que no se puede explicar por otras causas, signos de IC derecha y comorbilidades asociadas a la HP, como el síndrome de apneas del sueño, EPOC, embolia pulmonar previa y factores de riesgo de HAP.

No se ha estandarizado la utilidad de la carga de fluidos y la prueba de esfuerzo para desenmascarar la HP causada por ECI en pacientes con IC con FEVI conservada, y no se han definido valores de corte que permitan establecer recomendaciones claras. Además, se ha señalado que los pacientes con diagnóstico de HAP pueden presentar un aumento anormal de la PEP como respuesta a la carga de fluidos ${ }^{77}$.

Las indicaciones para el cateterismo derecho en la HP causada por $\mathrm{ECI}$, que se debe realizar preferiblemente con el paciente estable, se recogen en la tabla 10 .

Tabla 30

Ejemplos de factores clave que indican hipertensión pulmonar del grupo 2

\begin{tabular}{|c|c|c|}
\hline Presentación clínica & Ecocardiograma & $\begin{array}{l}\text { Otras } \\
\text { características }\end{array}$ \\
\hline Edad > 65 años & $\begin{array}{l}\text { Anomalía estructural del } \\
\text { corazón izquierdo } \\
\text { - Valvulopatía izquierda } \\
\text { - Crecimiento de AI } \\
\text { (> } 4,2 \mathrm{~cm}) \\
\text { - Desplazamiento del SIA } \\
\text { a la izquierda } \\
\text { - Disfunción del VI } \\
\text { - Hipertrofia concéntrica del } \\
\text { VI/aumento de masa del VI }\end{array}$ & $\begin{array}{l}\text { ECG } \\
\cdot \text { HVI o HAI } \\
\cdot \text { FA/FlA } \\
\text { - BRI } \\
\text { - Presencia } \\
\text { de ondas Q }\end{array}$ \\
\hline Signos de IC izquierda & $\begin{array}{l}\text { Índices Doppler indicativos } \\
\text { de incremento de presiones } \\
\text { de llenado } \\
\text { - E/e' aumentado } \\
\text { - Patron de flujo transmitral } \\
\text { tipos 2-3 }\end{array}$ & $\begin{array}{l}\text { Otras modalidades } \\
\text { de imagen } \\
\text { - Líneas B de Kerley } \\
\text { - Derrame pleural } \\
\text { - Edema pulmonar } \\
\text { - Crecimiento de AI }\end{array}$ \\
\hline $\begin{array}{l}\text { Características de síndrome } \\
\text { metabólico }\end{array}$ & $\begin{array}{l}\text { Ausencia de } \\
\text { - Disfunción del VD } \\
\text { - Muesca mesosistólica en } \\
\text { la curva Doppler del flujo } \\
\text { de la arteria pulmonar } \\
\text { - Derrame pericárdico }\end{array}$ & \\
\hline
\end{tabular}

Antecedentes de cardiopatía

(previa o actual)

Fibrilación auricular

persistente

AI: aurícula izquierda; BRI: bloqueo de rama izquierda; FA: fibrilación auricular; FlA: flutter auricular; HAI: hipertrofia/dilatación de la aurícula izquierda; HVI: hipertrofia ventricular izquierda; IC: insuficiencia cardiaca; SIA: septo interauricular; VD: ventrículo derecho; VI: ventrículo izquierdo. 


\subsection{Tratamiento}

El primer objetivo del tratamiento para la HP causada por ECI es mejorar el manejo general de la entidad subyacente antes de considerar las medidas específicas necesarias para tratar la HP. Esto incluye reparación de la valvulopatía cardiaca cuando esté indicado y un tratamiento agresivo para la IC con la función sistólica reducida ${ }^{4,392}$. Algunos pacientes también pueden beneficiarse del tratamiento con vasodilatadores no específicos, como nitratos e hidralazina, aunque la evidencia que respalda esta estrategia es escasa ${ }^{4,392}$. En la IC grave, la optimización del estado del volumen tiene una importancia crítica y puede requerir monitorización invasiva ${ }^{4,393}$. Además, se ha mostrado que el implante de un dispositivo de asistencia ventricular izquierda puede reducir las presiones pulmonares durante la descarga del VI sin aumentar el riesgo de insuficiencia del VD tras el implante ${ }^{4,394,395}$. Se debe controlar los factores de riesgo de enfermedades cardiovasculares y síndrome metabólico ${ }^{4,392}$. Asimismo, se debe identificar y tratar los trastornos concomitantes que llevan a la HP, como la EPOC, el síndrome de apneas del sueño y la embolia pulmonar. Sin embargo, no hay recomendaciones firmes para el tratamiento de la IC con FEVI conservada basadas en la evidencia ${ }^{392}$.

Los fundamentos para el uso de tratamientos de la HAP en la HP causada por ECI se asientan en los resultados a corto y largo plazo de estudios en los que se evaluó el uso de prostanoides, ARE e inhibidores de la PDE. La mayoría de estos estudios concuerdan en haber registrado mejoras en los parámetros hemodinámicos, la capacidad de ejercicio y los síntomas ${ }^{4,396}$. Sin embargo, debido a sus importantes limitaciones metodológicas (pequeño tamaño muestral, monocéntricos, procesos de inclusión poco claros o sin distribución aleatoria), no pueden proporcionar evidencia suficiente para recomendar el uso de estos fármacos en el manejo clínico de estos pacientes ${ }^{4}$. Además, no hay evidencia de que los cambios agudos en la circulación pulmonar tengan valor fuera del contexto de la cirugía cardiaca mayor, como el trasplante cardiaco o el implante de dispositivos de asistencia ventricular izquierda $a^{4,380}$.

En un reciente estudio multicéntrico controlado por placebo ${ }^{397}$, se aleatorizó a 201 pacientes con HP causada por IC sistólica a 1 de los 4 brazos de tratamiento para la comparación de 3 dosis de riociguat diferentes (0,5, 1 y $2 \mathrm{mg} 3$ veces al día) frente a placebo durante un periodo de 16 semanas. No se observó efecto alguno en el criterio primario de valoración (cambio en la PAPm a las 16 semanas) con ninguna de las dosis de riociguat comparadas con placebo ${ }^{397}$.

Actualmente están en curso 2 estudios multicéntricos para evaluar el tratamiento de la HP causada por ECI con sildenafilo (SilHF [NCT01616381]) o macitentán (Melody-1 [NCT02070991]); este es el único que requiere la validación mediante CCD.

Por todo ello, no se dispone de evidencia nueva que permita recomendar el uso de tratamientos específicos de la HAP para la HP causada por ECI, y esto se debe en parte a la ausencia de estudios que estratifiquen específicamente a los pacientes con HP o tengan como objetivo de investigación esta entidad específica. Estudios de este tipo son necesarios para cubrir las carencias en este campo de la medicina, y los pacientes con HP precapilar y poscapilar combinadas deberían estar incluidos. Las recomendaciones para el manejo de la HP causada por ECI se recogen en la tabla 31.

\section{HIPERTENSIÓN PULMONAR CAUSADA POR ENFERMEDADES PULMONARES O HIPOXIA (GRUPO 3)}

La patología, fisiopatología y epidemiología de estas enfermedades ya se han tratado anteriormente (véase la sección 4). Las enfermedades pulmonares asociadas más frecuentemente con la HP son la EPOC, la enfermedad pulmonar intersticial y la combinación de fibrosis pulmonar y enfisema. Las enfermedades raras, como la granulomatosis celular de Langerhans o la sarcoidosis, se resumen en la tabla 8 del anexo web. En cualquier enfermedad pulmonar, la evolu-
Tabla 31

Manejo de la hipertensión pulmonar en la enfermedad cardiaca izquierda

\begin{tabular}{lccc}
\hline Recomendaciones & Clase $^{\mathrm{a}}$ & Nivel $^{\mathrm{b}}$ & Ref $^{\mathrm{c}}$ \\
\hline $\begin{array}{l}\text { Se recomienda optimizar el tratamiento de la } \\
\text { enfermedad subyacente (es decir, la cardiopatía } \\
\text { estructural) antes de evaluar la HP-ECI }\end{array}$ & I & B & 396 \\
\hline $\begin{array}{l}\text { Se recomienda identificar otras causas de HP (EPOC, } \\
\text { síndrome de apneas del sueño, EP, HPTC) y tratarlas } \\
\text { cuando proceda antes de evaluar la HP-ECI }\end{array}$ & I & C & 396 \\
\hline $\begin{array}{l}\text { Se recomienda evaluación invasiva de la HP } \\
\text { para pacientes con volemia optimizada }\end{array}$ & I & C & \\
\hline $\begin{array}{l}\text { Se debería remitir a un centro con experiencia en } \\
\text { PH a los pacientes con HP-ECI y un componente } \\
\text { precapilar grave indicado por un GTPd alto o RVP } \\
\text { alta para una evaluación diagnóstica completa y una } \\
\text { decisión de tratamiento individualizada }\end{array}$ & Ila & C & \\
\hline $\begin{array}{l}\text { La importancia y la utilidad del test de vasodilatación } \\
\text { no están establecidas en la HP-ECI, excepto para } \\
\text { pacientes candidatos a trasplante cardiaco o implante } \\
\text { de dispositivo de asistencia del VI }\end{array}$ & III & C & 396 \\
\hline $\begin{array}{l}\text { No se recomienda para la HP-ECI el uso de terapias } \\
\text { aprobadas para la HAP }\end{array}$ & III & C & 396 \\
\hline
\end{tabular}

ECI: enfermedad cardiaca izquierda; EP: embolia pulmonar; EPOC: enfermedad pulmonar obstructiva crónica; GTPd: gradiente transpulmonar diastólico; HP: hipertensión pulmonar; HPTC: hipertensión pulmonar tromboembólica crónica; RVP: resistencia vascular pulmonar; VI: ventrículo izquierdo.

${ }^{a}$ Grado de recomendación.

bNivel de evidencia.

'Referencias que respaldan las recomendaciones.

ción de la HP se acompaña de deterioro de la capacidad de ejercicio, empeoramiento de la hipoxemia y menor supervivencia ${ }^{398-400}$. La gravedad de la HP se asocia desfavorablemente con la gravedad de la enfermedad pulmonar subyacente ${ }^{401,402}$. En estos pacientes, los indicadores más comunes de la presencia de HP son una DLCO desproporcionadamente baja y un $\mathrm{pCO}_{2}$ bajo $^{401,402}$.

La clasificación hemodinámica de la HP asociada a enfermedades pulmonares se muestra en la tabla $32^{20}$. En caso de HP grave, se debe descartar otras causas potenciales, como ECI o HPTC. En algunos pacientes con enfermedad pulmonar e HP, especialmente aquellos con enfermedad pulmonar leve e HP grave, puede ser difícil determinar si la HP está causada por la enfermedad pulmonar o si el paciente sufre 2 enfermedades, es decir, HAP y enfermedad pulmonar crónica. Estos pacientes deben ser referidos a un centro especializado en HP con experiencia en enfermedades pulmonares.

Tabla 32

Clasificación hemodinámica de la hipertensión pulmonar causada por enfermedad pulmonar $^{9}$

\begin{tabular}{ll}
\hline Terminología & $\begin{array}{l}\text { Hemodinámica (cateterización cardiaca } \\
\text { izquierda) }\end{array}$ \\
\hline EPOC/FPI/CFPE sin HP & PAPm $<25 \mathrm{mmHg}$ \\
\hline EPOC/FPI/CFPE con HP & PAPm $\geq 25 \mathrm{mmHg}$ \\
\hline EPOC/FPI/CFPE con HP grave & $\begin{array}{l}\text { PAPm }>350 \geq 25 \mathrm{mmHg} \text { en presencia } \\
\text { de bajo gasto cardiaco (índice cardiaco } \\
<2,5 \mathrm{l} / \mathrm{min} \text { ) no explicado por otras } \\
\text { causas }\end{array}$ \\
\hline
\end{tabular}

CFPE: combinación de fibrosis pulmonar y enfisema; EPOC: enfermedad pulmonar obstructiva crónica; FPI: fibrosis pulmonar idiopática; HP: hipertensión pulmonar; PAPm: presión arterial pulmonar media. 


\subsection{Diagnóstico}

Los síntomas clínicos y los signos físicos pueden ser difíciles de identificar en pacientes con trastornos respiratorios. Además, en pacientes con enfermedad pulmonar, el edema periférico no indica necesariamente insuficiencia del VD, ya que puede ser el resultado de los efectos de la hipoxemia y la hipercapnia en el sistema reninaangiotensina-aldosterona. Por otra parte, la cardiopatía izquierda concomitante, que se encuentra frecuentemente en pacientes con enfermedad pulmonar crónica, puede contribuir al desarrollo de HP. Como regla general, a los pacientes que presentan síntomas más graves de lo esperado por las pruebas de la función pulmonar, se los debe someter a estudios adicionales, particularmente ecocardiografía, para detectar una posible cardiopatía izquierda o HP concomitante.

La ecocardiografía sigue siendo la herramienta diagnóstica no invasiva más utilizada para la evaluación de la HP. Las indicaciones de ecocardiografía para pacientes con enfermedad pulmonar incluyen la sospecha clínica de HP significativa o la evaluación de la cardiopatía izquierda concomitante. Sin embargo, hay que señalar que la precisión de la ecocardiografía en pacientes con enfermedad pulmonar avanzada es baja ${ }^{403-405}$. Los pacientes con signos clínicos o ecocardiográficos de HP grave o disfunción del VD grave deben ser referidos a un centro especializado en HP.

El diagnóstico definitivo de HP se basa en las mediciones obtenidas durante el CCD. Las indicaciones potenciales del CCD en las enfermedades pulmonares avanzadas son: a) un diagnóstico adecuado o la exclusión de la HP en candidatos a tratamientos quirúrgicos (trasplante, reducción del volumen pulmonar); $b$ ) sospecha de HAP o HPTC; $c$ ) episodios de insuficiencia del VD, y d) hallazgos ecocardiográficos no concluyentes en casos de sospecha alta e implicaciones terapéuticas potenciales.

\subsection{Tratamiento}

Actualmente no existe un tratamiento específico para la HP asociada a enfermedades pulmonares. Con la administración de $\mathrm{O}_{2}$ a largo plazo se ha demostrado una reducción parcial de la progresión de la HP en la EPOC. Sin embargo, la PAP rara vez vuelve a valores normales y las anomalías estructurales de los vasos pulmonares permanecen inalteradas ${ }^{169}$. En la enfermedad pulmonar intersticial, el efecto del tratamiento con $\mathrm{O}_{2}$ a largo plazo en la progresión de la HP es menos claro.

No está recomendado el tratamiento con vasodilatadores convencionales, como los BCC, ya que pueden disminuir el intercambio de gases debido a su efecto inhibidor de la vasoconstricción pulmonar hipóxica ${ }^{406-408}$ y su falta de eficacia tras el uso a largo plazo ${ }^{409,410}$.

Los datos publicados sobre el tratamiento específico de la HAP son escasos y, hasta la fecha, no hay evidencia de ECA de que los fármacos para la HAP resulten en una mejoría de los síntomas o de los resultados en pacientes con enfermedad pulmonar ${ }^{411-416}$.

En resumen, los pacientes con enfermedad pulmonar e HP que están hipoxémicos deben recibir tratamiento con $\mathrm{O}_{2}$ a largo plazo, adaptándose las recomendaciones generales para la EPOC. Se debe optimizar el tratamiento de la enfermedad pulmonar subyacente. El uso de fármacos aprobados para la HAP no está recomendado para pacientes con HP causada por enfermedad pulmonar. Los pacientes con sospecha de HAP y enfermedad pulmonar (caracterizada por anomalías leves del parénquima pulmonar, síntomas insuficientemente explicados por los trastornos mecánicos pulmonares y un "fenotipo hemodinámico de HAP», es decir, HP grave con RVP alta y CO bajo) deben ser tratados de acuerdo a las recomendaciones para la HAP, teniendo presentes las posibles implicaciones de la coexistencia de enfermedad pulmonar para los síntomas y la respuesta al tratamiento.

Las recomendaciones para la HP causada por enfermedades pulmonares se resumen en la tabla 33.
Tabla 33

Recomendaciones para la hipertensión pulmonar causada por enfermedades pulmonares

\begin{tabular}{|c|c|c|c|}
\hline Recomendaciones & Clase $^{\mathrm{a}}$ & Nivel $^{\mathrm{b}}$ & $\operatorname{Ref}^{c}$ \\
\hline $\begin{array}{l}\text { Se recomienda la ecocardiografía para la evaluación } \\
\text { diagnóstica no invasiva de la HP sospechada } \\
\text { en pacientes con enfermedad pulmonar }\end{array}$ & I & C & 403,405 \\
\hline $\begin{array}{l}\text { Se recomienda }{ }^{d} \text { remitir a un centro con experiencia } \\
\text { a los pacientes con signos ecocardiográficos de HP } \\
\text { grave o disfunción del VD grave }\end{array}$ & I & C & \\
\hline $\begin{array}{l}\text { Para pacientes con HP debida a enfermedad } \\
\text { pulmonar, se recomienda un tratamiento óptimo } \\
\text { de la enfermedad pulmonar subyacente que incluya } \\
\text { oxigenoterapia a largo plazo para pacientes } \\
\text { con hipoxemia crónica }\end{array}$ & I & C & 169 \\
\hline $\begin{array}{l}\text { Se debería considerar la remisión a un centro } \\
\text { con experiencia en HP para el tratamiento } \\
\text { individualizado de los pacientes con signos de HP } \\
\text { grave o disfunción del VD grave }\end{array}$ & IIa & C & \\
\hline $\begin{array}{l}\text { No se recomienda el CCD para la HP sospechada } \\
\text { en pacientes con enfermedad pulmonar, a menos } \\
\text { que pueda suponer una modificación del abordaje } \\
\text { terapéutico (trasplante pulmonar, diagnósticos } \\
\text { alternativos como HAP o HPTC o potencial inclusión } \\
\text { en un ensayo clínico) }\end{array}$ & III & C & 169 \\
\hline $\begin{array}{l}\text { No se recomienda el uso de fármacos aprobados } \\
\text { para HAP en pacientes con HP causada por } \\
\text { enfermedad pulmonar }\end{array}$ & III & C & $411-416$ \\
\hline
\end{tabular}

CCD: cateterismo cardiaco derecho; HAP: hipertensión arterial pulmonar; HP: hipertensión pulmonar; HPTC: hipertensión pulmonar tromboembólica crónica.

aGrado de recomendación.

bNivel de evidencia.

'Referencias que respaldan las recomendaciones.

dEsta recomendación no es aplicable a pacientes con enfermedad pulmonar terminal a los que no se considere candidatos a trasplante pulmonar.

\section{HIPERTENSIÓN PULMONAR TROMBOEMBÓLICA CRÓNICA (GRUPO 4)}

La HPTC es una enfermedad producida por el remodelado obstructivo de la AP como consecuencia de la tromboembolia en grandes vasos. Se ha estimado que la incidencia acumulada de la HPTC es de un $0,1-9,1 \%$ en los primeros 2 años desde la presentación de una embolia pulmonar sintomática ${ }^{417}$. Este amplio margen de error probablemente se deba a sesgos de referencia, la escasez de síntomas tempranos y la dificultad para diferenciar la embolia pulmonar aguda de los síntomas de la HPTC preexistente ${ }^{418}$. Aunque se desconoce con exactitud la prevalencia y la incidencia anual de la HPTC, algunos datos apuntan a que esta enfermedad puede ocurrir en aproximadamente 5 individuos/millón/año ${ }^{419}$.

En el diagnóstico diferencial de la HPTC se debe considerar y tratar de acuerdo con el conocimiento actual las siguientes enfermedades: sarcoma de la AP, embolia por células tumorales, parásitos (quistes hidatídicos), embolia por cuerpo extraño y estenosis de la AP congénita o adquirida (tabla 4 ).

\subsection{Diagnóstico}

La evidencia actual no respalda el cribado sistemático de la HPTC tras embolia pulmonar; un número de casos significativo cursan en ausencia de embolia pulmonar aguda previa.

La media de edad de los pacientes al diagnóstico es 63 años y la incidencia es similar en ambos sexos ${ }^{25}$; los casos pediátricos son $\operatorname{raros}^{287,420}$. Los síntomas y signos clínicos no son específicos o están ausentes en la HPTC temprana, y los signos de IC derecha solo son evidentes en estadios de la enfermedad avanzados. Por lo tanto, el 
diagnóstico precoz sigue siendo un reto en la HPTC, y se estima una media de 14 meses entre la aparición de los síntomas y el diagnóstico en centros especializados ${ }^{421}$. Cuando se presentan, los síntomas clínicos de la HPTC pueden parecerse a los de la embolia pulmonar aguda o la HAPI; en este último caso, el edema y la hemoptisis ocurren más frecuentemente en la HPTC, mientras que el síncope es más común en la HAPI ${ }^{422}$.

El diagnóstico de HPTC se basa en los hallazgos obtenidos después de al menos 3 meses de anticoagulación efectiva para poder discriminar esta enfermedad de la embolia pulmonar "subaguda». Los hallazgos incluyen PAPm $\geq 25 \mathrm{mmHg}$ con PEP $\leq 15 \mathrm{mmHg}$, defectos de perfusión incompatibles en la gammagrafía pulmonar y signos diagnósticos específicos de la HPTC observados mediante angio-TC multicorte, RM o cineangiografía pulmonar convencional, como estenosis en forma de anillo, membrana o bandas y oclusiones crónicas totales (lesión tipo «bolsa» o lesión roma).

Algunos pacientes, especialmente aquellos con obstrucción unilateral completa, pueden presentar un perfil hemodinámico pulmonar normal en reposo pese a sufrir enfermedad sintomática. Estos pacientes se incluyen en la HPTC y deben ser tratados en consecuencia. Aún no se ha establecido una terminología adecuada para describir la vasculopatía pulmonar tromboembólica crónica.

El algoritmo para el diagnóstico de la HPTC está representado en la figura 3. Mientras que la angio-TC pulmonar es la herramienta preferida para el diagnóstico de la embolia aguda, la gammagrafía planar V/Q sigue siendo la técnica de primera línea para el diagnóstico de la HPTC, debido a sus altas sensibilidad (96-97\%) y especificidad (90$95 \%)^{47}$. En cambio, la gammagrafía de perfusión muestra típicamente defectos no segmentarios o es normal en la HAPI y EVOP ${ }^{377}$. Estudios más recientes indican que tanto la gammagrafía de $\mathrm{V} / \mathrm{Q}$ como la angio-TC pulmonar son métodos de precisión para detectar HPTC, con una eficacia diagnóstica excelente en manos expertas (sensibilidad del 100\%, especificidad del 93,7\% y precisión del 96,5\% para la gammagrafía de V/Q y del 96,1, el 95,2 y el 95,6\%, respectivamente, para la angio-TC pulmonar) $)^{93,423,424}$.

La angio-TC pulmonar multicorte se ha establecido como la técnica de imagen para confirmar el diagnóstico de $\mathrm{HPTC}^{93}$; sin embargo, esta prueba por sí sola no puede descartar la enfermedad ${ }^{47}$. La angio-TC pulmonar puede ayudar a identificar las complicaciones de la enfermedad, como la dilatación de la AP que resulta en compresión del tronco coronario común izquierdo y colaterales de las arterias bronquiales hipertrofiadas que pueden producir hemoptisis.

La TCAR torácica permite obtener imágenes del parénquima pulmonar e identificar enfisema, enfermedad bronquial o enfermedad pulmonar intersticial, además de infartos, malformaciones vasculares y pericárdicas y deformaciones de la pared torácica. Los trastornos de perfusión se manifiestan como un patrón en mosaico en el parénquima pulmonar, con zonas oscuras que corresponden a zonas de perfusión relativamente disminuida. Aunque este patrón en mosaico es frecuente en la HPTC, también se puede observar en hasta el 12\% de los pacientes con $\mathrm{HAP}^{425}$. La visualización de la vasculatura pulmonar mediante $\mathrm{RM}$ se considera peor que con $\mathrm{TC}^{426}$, pero se considera que esta y también la TC de haz cónico ${ }^{427}$, la angioscopia, la ultrasonografía intravascular y la tomografía de coherencia óptica son técnicas complementarias que se puede emplear dependiendo de la experiencia y práctica del centro.

El CCD es una herramienta diagnóstica esencial. La RVP preoperatoria y posoperatoria inmediata es un predictor pronóstico a largo plazo $^{429}$. El último paso del proceso diagnóstico es la angiografía pulmonar selectiva, con proyecciones anteroposteriores y laterales en las que se visualizan estenosis en forma de anillo, membranas («bandas»), bolsas, irregularidades de la pared y colaterales de las arterias bronquiales, que permiten realizar una evaluación técnica de la operabilidad.

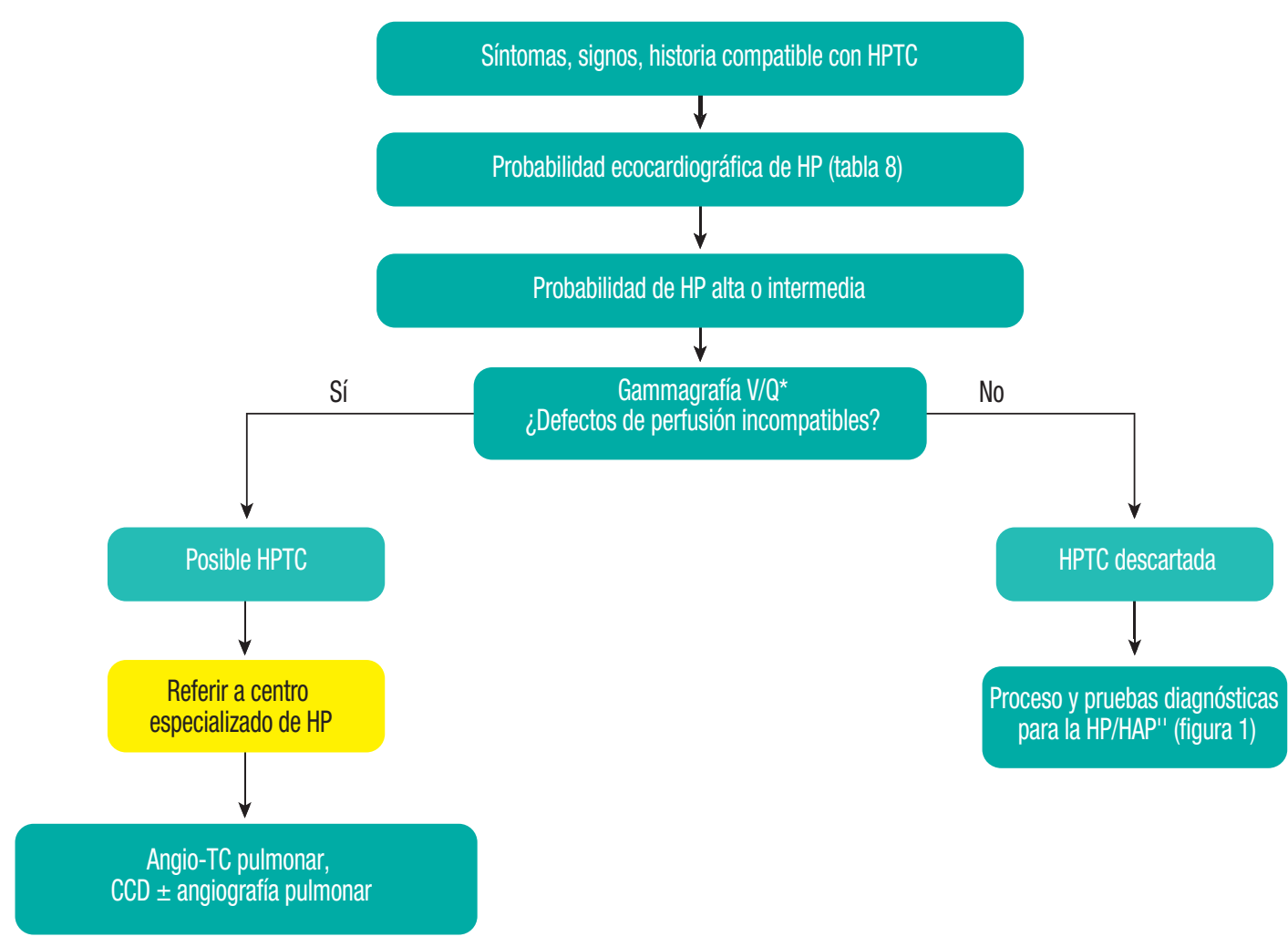

Figura 3. Algoritmo diagnóstico para la HPTC. HAP: hipertensión arterial pulmonar; HP: hipertensión pulmonar; HPTC: hipertensión pulmonar tromboembólica crónica; TC: tomografía computarizada; V/Q: ventilación/perfusión.

*La angio-TC pulmonar por sí sola puede no lograr el diagnóstico de HPTC. 


\subsection{Tratamiento}

\subsubsection{Tratamiento quirúrgico}

La EAP es el tratamiento de elección para la HPTC (figura 4). En Europa, la mortalidad hospitalaria es de solo el $4,7 \% 430$, e incluso es más baja en centros con alto volumen de $\operatorname{casos}^{431}$. La mayoría de los pacientes experimentan un alivio sustancial de los síntomas y la normalización casi completa de los parámetros hemodinámicos ${ }^{430-432}$. Al contrario que la embolectomía quirúrgica para la embolia pulmonar aguda, el tratamiento de la HPTC requiere una endarterectomía realmente bilateral a través de la capa media de las arterias pulmonares, que se realiza en hipotermia profunda y parada circulatoria ${ }^{431}$, sin necesidad de perfusión cerebral ${ }^{433}$.

La operabilidad de los pacientes con HPTC está determinada por múltiples factores que no se puede estandarizar con facilidad; estos factores están relacionados con la viabilidad del paciente, la experiencia del equipo quirúrgico y los recursos disponibles. Los criterios generales incluyen la CF-OMS II-IV preoperatoria y la accesibilidad de los trombos en las arterias pulmonares principales, lobulares y segmentarias. La edad avanzada por sí misma no es una contraindicación para la cirugía. No hay un umbral para la RVP ni una medición de la disfunción del VD que determine la exclusión de la EAP.

El uso de ECMO se considera el estándar de atención recomendado en los centros de EAP para los casos más graves ${ }^{434-436}$. El edema de reperfusión posoperatorio temprano puede requerir ECMO venoarterial, y la HP persistente grave puede requerir el tratamiento puente con ECMO venovenoso hasta el trasplante pulmonar urgente.

Los pacientes que no se someten a EAP o sufren HP persistente o recurrente después de la EAP (HP post-EAP) tienen mal pronóstico.

\subsubsection{Tratamiento médico}

El tratamiento médico óptimo para la HPTC consiste en anticoagulantes y diuréticos, además de $\mathrm{O}_{2}$ en los casos de IC o hipoxemia. Está recomendada la anticoagulación permanente, incluso después de la EAP, aunque no hay datos sobre la eficacia y la seguridad de los nuevos anticoagulantes orales. Aunque no hay consenso, la colocación sistemática de un filtro en la vena cava no está justificada por la evidencia disponible. La enfermedad pulmonar microvascular presente en la HPTC ha proporcionado los fundamentos para el uso fuera de indicación de fármacos aprobados para el tratamiento de la HAP25. Algunos estudios sin grupo de control han recabado evidencia de la mejoría en la capacidad de ejercicio y los parámetros hemodinámicos ${ }^{437-439}$. El tratamiento médico orientado por objetivos para la HPTC puede estar justificado en pacientes técnicamente no operables o cuando el cociente entre riesgo quirúrgico y beneficio sea inaceptable (figura 2). Los pacientes con HP persistente o recurrente después de la EAP también pueden ser candidatos a tratamiento orientado por objetivos. El uso de este tipo de tratamiento para pacientes operables con deterioro hemodinámico grave

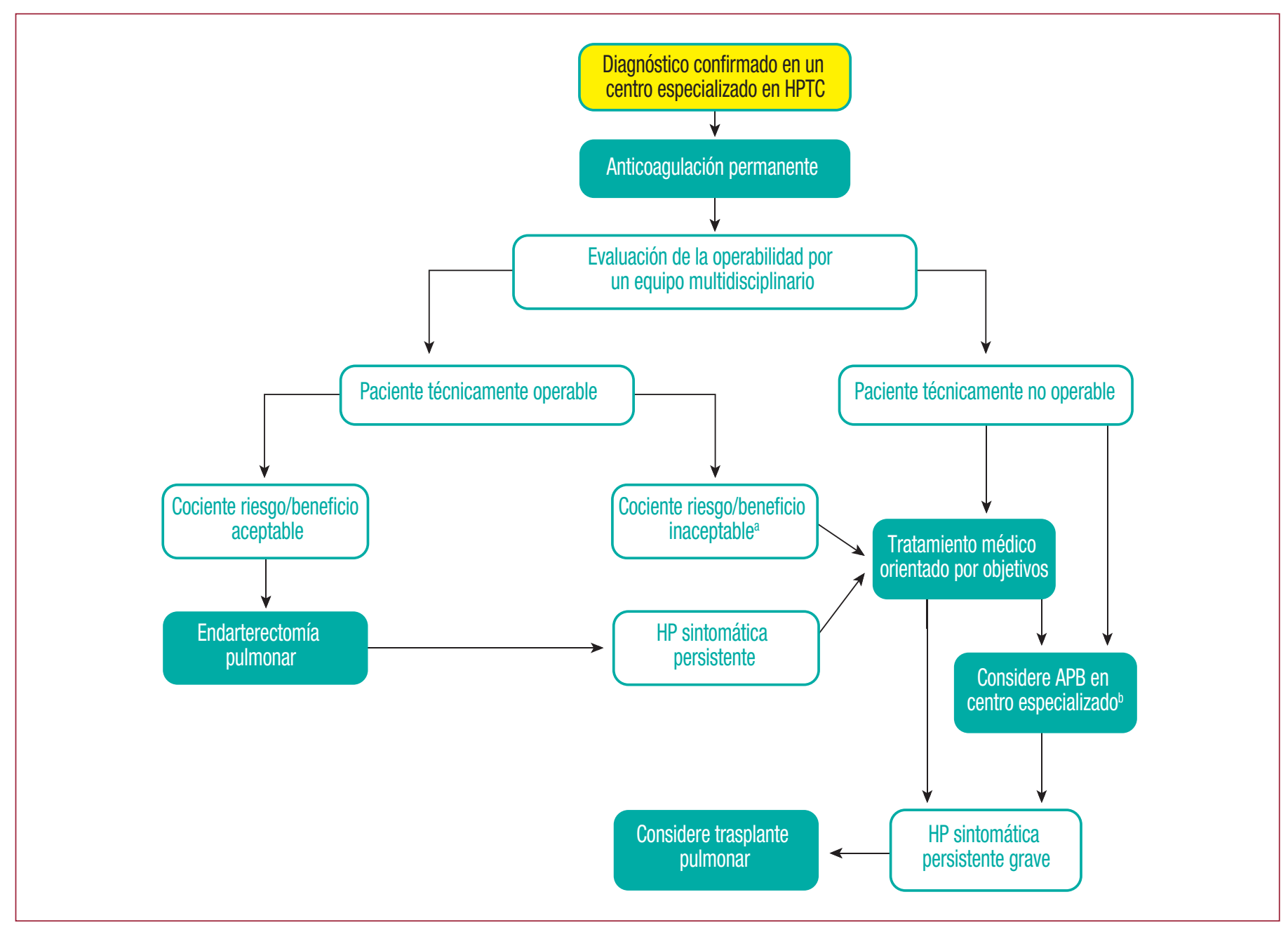

Figura 4. Algoritmo de tratamiento para la HPTC. APB: angioplastia pulmonar con balón; HP: hipertensión pulmonar; HPTC: hipertensión pulmonar tromboembólica crónica. ${ }^{a}$ También se puede valorar para APB a los pacientes técnicamente operables pero con un cociente riesgo/beneficio inaceptable.

bEn algunos centros el tratamiento médico y la APB se inician simultáneamente. 
como tratamiento puente hasta la EAP no está avalado por la evidencia científica.

Un antagonista doble de la entotelina, el bosentán, se evaluó durante 16 semanas en 157 pacientes con HPTC inoperable o HP persistente/recurrente después de la EAP; no se cumplió el criterio primario de reducción de la RVP y aumento en la PM6M ${ }^{440}$. Sin embargo, un inhibidor del GCs, el riociguat, administrado durante 16 semanas a 261 de 446 pacientes con HPTC inoperable o HP persistente/recurrente después de la EAP, llevó a un aumento medio de $39 \mathrm{~m}$ en la PM6M ( $\mathrm{p}<0,001$, criterio primario) y una diferencia media calculada por el método de mínimos cuadrados de 246 din.s.cm ${ }^{-5}$ en la RVP ( $p<0,001$, criterio secundario); el tiempo hasta el empeoramiento clínico permaneció inalterado ${ }^{441}$.

La utilidad del tratamiento médico preoperatorio es incierta, dado el escaso efecto observado en un $\mathrm{ECA}^{442}$. Un estudio retrospectivo no mostró ninguna diferencia en los resultados, pero la cirugía se retrasó en los pacientes tratados médicamente ${ }^{442}$. Son necesarios estudios prospectivos para pacientes que podrían beneficiarse del tratamiento como, por ejemplo, aquellos con RVP alta y anatomía técnicamente compleja.

Después de la EAP, los pacientes deben recibir seguimiento en centros especializados y se debe considerar una evaluación hemodinámica a los 6-12 meses de la intervención.

\subsubsection{Tratamiento intervencionista}

En el año 2001, Feinstein et al ${ }^{443}$ publicaron una serie de 18 pacientes con HPTC no operable a los que se sometió a dilatación de las arterias pulmonares con balón. A pesar de un descenso significativo de la PAPm, 11 pacientes sufrieron edema pulmonar de reperfusión y 3 necesitaron ventilación mecánica.

Recientemente, investigadores japoneses han perfeccionado la APB con el uso de balones más pequeños, limitando el número de dilataciones del balón por sesión a 1 o 2 segmentos vasculares pulmonares y el uso de imagen intravascular ${ }^{444-446}$. Se requiere una media de 4,8 sesiones por paciente para mejorar los parámetros de la función del VD ${ }^{57}$. Este meticuloso abordaje, en el que solo se interviene un lóbulo en cada sesión, y la cuidadosa elección del tamaño del balón han reducido la incidencia del edema pulmonar de reperfusión al $2 \%$ en centros individuales ${ }^{447}$. Aunque todavía no se emplea la APB de manera generalizada ${ }^{448}$, esta técnica está ganando interés rápidamente en todo el mundo. La APB solo se debe realizar en centros de HPTC con experiencia y alto volumen de casos.

Las recomendaciones para la HPTC se resumen en la tabla 34. El algoritmo de tratamiento para la HPTC se encuentra en la figura 4.

\section{HIPERTENSIÓN PULMONAR CON MECANISMOS INDEFINIDOS O MULTIFACTORIALES (GRUPO 5)}

La HP con mecanismos indefinidos o multifactoriales (grupo 5, tabla 4) incluye varios trastornos con múltiples etiologías y patogenias. Una característica común a todas estas enfermedades es que los mecanismos de la HP están poco claros y pueden originarse por vasoconstricción pulmonar, vasculopatía proliferativa, compresión extrínseca, oclusión intrínseca, IC de alto gasto, obliteración vascular e IC izquierda (tabla 8 del anexo web).

Estos pacientes requieren un cuidadoso diagnóstico. El tratamiento debe adaptarse al diagnóstico, y el tratamiento de la HP es secundario. El axioma sería «tratar el pulmón y no la presión». No se han realizado ECA sobre el uso de fármacos aprobados para la HAP en el tratamiento de las enfermedades del grupo $5^{450}$. Es particularmente importante señalar que algunas de las enfermedades descritas en la tabla 7 del anexo web pueden tener un componente venoso (EVOP) que podría empeorar con el empleo de vasodilatadores arteriales pulmonares.
Tabla 34

Recomendaciones para la hipertensión pulmonar tromboembólica crónica

\begin{tabular}{|c|c|c|c|}
\hline Recomendaciones & Clase $^{\mathrm{a}}$ & Nivel $^{\mathrm{b}}$ & $\operatorname{Ref}^{c}$ \\
\hline $\begin{array}{l}\text { Se debería considerar la HPTC en supervivientes } \\
\text { a EP con disnea de ejercicio }\end{array}$ & IIa & C & 449 \\
\hline $\begin{array}{l}\text { Se recomienda anticoagulación de por vida } \\
\text { para todo paciente con HPTC }\end{array}$ & I & C & 91 \\
\hline $\begin{array}{l}\text { Se recomienda que un equipo multidisciplinario de } \\
\text { expertos lleve a cabo la evaluación de operabilidad } \\
\text { de todo paciente con HPTC y tome las decisiones } \\
\text { que afecten a otras estrategias de tratamiento }\end{array}$ & I & $\mathrm{C}$ & 91 \\
\hline $\begin{array}{l}\text { Para pacientes con HPTC, se recomienda la EAP } \\
\text { quirúrgica en parada circulatoria con hipotermia } \\
\text { profunda }\end{array}$ & I & C & 91 \\
\hline $\begin{array}{l}\text { Se recomienda riociguat para pacientes } \\
\text { sintomáticos clasificados como HPTC persistente/ } \\
\text { recurrente tras tratamiento quirúrgico o HPTC } \\
\text { inoperable por un equipo que incluya al menos } \\
\text { a un cirujano experto en EAP }\end{array}$ & I & B & 441 \\
\hline $\begin{array}{l}\text { Para pacientes sintomáticos clasificados como } \\
\text { HPTC inoperable por un equipo que incluya al } \\
\text { menos a un cirujano experto en EAP, se puede } \\
\text { considerar el uso paliativo de fármacos aprobados } \\
\text { para HAP }\end{array}$ & IIb & B & $437-440$ \\
\hline $\begin{array}{l}\text { Se puede considerar la APB para pacientes } \\
\text { técnicamente inoperables o con cociente riesgo/ } \\
\text { beneficio desfavorable para la EAP }\end{array}$ & IIb & $\mathrm{C}$ & $\begin{array}{l}57, \\
444-446 \\
448\end{array}$ \\
\hline $\begin{array}{l}\text { Actualmente no se recomienda el cribado de HPTC } \\
\text { de supervivientes a EP asintomáticos }\end{array}$ & III & C & 417 \\
\hline
\end{tabular}

APB: angioplastia pulmonar con balón; EAP: endarterectomía de la arteria pulmonar: EP: embolia pulmonar; HAP: hipertensión arterial pulmonar; HPTC: hipertensión pulmonar tromboembólica crónica.

aGrado de recomendación.

${ }^{\mathrm{b}}$ Nivel de evidencia.

'Referencias que respaldan las recomendaciones.

\section{DEFINICIÓN DE UN CENTRO DE REFERENCIA DE HIPERTENSIÓN PULMONAR}

La HAP es una enfermedad rara. Dado que, en general, los centros médicos con alto volumen de pacientes tienden a obtener los mejores resultados, el establecimiento de centros expertos de referencia es clínica y económicamente muy deseable, y lo respaldan organizaciones de pacientes. El objetivo de un centro de referencia es admitir a pacientes derivados para la evaluación e investigación de todas las causas de la HP, tratar sistemática y adecuadamente a los pacientes con fármacos específicos para la HAP y la HPTC, colaborar estrechamente con otros profesionales sanitarios para obtener los mejores resultados para los pacientes e implementar programas de investigación, educación y auditoría.

Los centros de referencia deben tener un número de pacientes en terapia crónica y nuevos pacientes referidos suficiente para merecer este rango. Se recomienda que el número mínimo anual de pacientes estudiados en un centro de adultos no sea $<200$, de los que al menos la mitad tiene diagnóstico final de HAP. En países con población $>10$ millones de habitantes, idealmente los centros de adultos deberían ampliarse para que puedan atender a más de 300 pacientes anuales. Se recomienda que un centro de referencia dé seguimiento a al menos 50 pacientes con HAP o HPTC y recibir al menos 2 pacientes referidos nuevos cada mes con HAP o HPTC documentada. Los centros pediátricos deben atender a 30-50 pacientes por año. Estas cifras pueden adaptarse a las características específicas de cada país (distribución de la población, restricciones geográficas, etc.). 


\subsection{Instalaciones y experiencia requeridos para un centro de referencia}

1. Los centros de referencia prestarán atención médica por medio de un equipo interprofesional que como mínimo estará formado por $^{451-456}$ :

- Dos médicos especialistas (normalmente de cardiología o neumología) con experiencia e interés en HP, con sesiones clínicas/ consulta dedicadas a la HP para pacientes ambulatorios y hospitalizados, y reuniones de un equipo multidisciplinario.

- Personal de enfermería especializado.

- Un radiólogo con experiencia en imagen de HP.

- Un cardiólogo o especialista en HP con experiencia en ecocardiografía.

- Un cardiólogo o especialista en HP con experiencia en CCD y pruebas de vasorreactividad.

- Acceso a asistencia psicológica y social.

- Un sistema de guardias completo y competente.

2. Los centros de referencia deben tener acceso a los siguientes servicios:

- Una sala hospitalaria dotada de personal con experiencia en HP.

- Una unidad de terapia intensiva con experiencia adecuada.

- Un servicio ambulatorio especializado.

- Asistencia de emergencia.

- Exploraciones diagnósticas que incluyan ecocardiografía, TC, gammagrafía nuclear, RM, ultrasonografía, pruebas de esfuerzo, pruebas de la función pulmonar y laboratorio de cateterismos.

- Acceso a la gama completa de fármacos específicos para HAP y HPTC disponibles en su país.

3. Los centros de referencia deben establecer una red de atención (que incluya criterios de referencia, protocolos de derivación de pacientes y protocolos de manejo clínico) con otros servicios que no necesariamente tienen que encontrarse en el mismo centro ${ }^{452}$ :

- Genética

- Enfermedad del tejido conectivo

- Planificación familiar

- Endarterectomía pulmonar

- Trasplante pulmonar

- Cardiopatía congénita del adulto

4. Los centros de referencia deberían implementar un programa de auditorías clínicas para verificar la adherencia a las guías y super- visar los resultados clínicos, incluido el análisis de la supervivencia. Las auditorías también deben incluir la comparación de los resultados con otros centros en países donde exista más de un centro de referencia.

5. Los centros de referencia deben participar en programas de investigación clínica colaborativa para el estudio de la HAP y la HPTC, que incluyan estudios clínicos de fase II y III.

6. Los centros de referencia deben dar a conocer los criterios de referencia y proporcionar regularmente instrucción sobre todos los aspectos de la HP a los profesionales sanitarios implicados, sin olvidar la formación de médicos jóvenes.

7. Los centros de referencia deberían participar en el desarrollo y la gestión de una red de centros en los países que cuenten con más de un centro de referencia.

8. Los centros de referencia deberían mantener relaciones con las asociaciones de pacientes de HP nacionales o europeas.

Las recomendaciones para los centros de referencia en HP se recogen en la tabla 35.

Tabla 35

Recomendaciones para los centros de referencia en hipertensión pulmonar

\begin{tabular}{lcc}
\hline Recomendaciones & Clase $^{\mathrm{a}}$ & Nivel $^{\mathrm{b}}$ \\
\hline $\begin{array}{l}\text { Se recomienda que los centros de referencia presten asistencia } \\
\text { con un equipo multidisciplinario (cardiólogos y neumólogos, } \\
\text { enfermera clínica especialista, radiólogos, apoyo psicológico } \\
\text { y social, equipos de guardia apropiados) }\end{array}$ & I & \\
\hline $\begin{array}{l}\text { Se recomienda que los centros de referencia tengan enlaces } \\
\text { directos y protocolos de remisión rápida a otros servicios } \\
\text { (como ETC, planificación familiar, EAP, trasplante pulmonar }\end{array}$ & I & C \\
$\begin{array}{l}\text { y cardiopatías congénitas del adulto) } \\
\text { Se considera que un centro de referencia debe seguir al menos } \\
\text { a } 50 \text { pacientes con HAP o HPTC y debería recibir cada mes al } \\
\text { menos a } 2 \text { pacientes con HAP o HPTC documentada nuevos }\end{array}$ & Ila & C \\
\hline $\begin{array}{l}\text { Se considera que un centro de referencia debe realizar cada } \\
\text { año al menos } 20 \text { tests de vasodilatación a pacientes con HAPI, } \\
\text { HAPH o HAPD }\end{array}$ & IIa & C \\
\hline $\begin{array}{l}\text { Los centros de referencia deben participar en investigación } \\
\text { clínica cooperativa en HAP, incluidos ensayos clínicos en fases }\end{array}$ & Ila \\
\begin{tabular}{l} 
II y III \\
\hline
\end{tabular} & CAP \\
\hline
\end{tabular}

EAP: endarterectomía arterial pulmonar; ETC: enfermedad del tejido conectivo; HAP: hipertensión arterial pulmonar; HAPD: hipertensión arterial pulmonar inducida por drogas o tóxicos; HAPH: hipertensión arterial pulmonar hereditaria; HAPI: hipertensión arterial pulmonar idiopática; HPTC: hipertensión pulmonar tromboembólica crónica.

aGrado de recomendación.

bNivel de evidencia.

\section{MENSAJES SOBRE QUÉ HACER Y QUÉ NO HACER}

\begin{tabular}{|c|c|c|}
\hline \multicolumn{3}{|l|}{ Diagnóstico de hipertensión pulmonar } \\
\hline Se recomienda el cateterismo cardiaco derecho para confirmar el diagnóstico de HAP (grupo 1) y respaldar las decisiones terapéuticas & I & C \\
\hline $\begin{array}{l}\text { Se recomienda el test de vasodilatación para pacientes con HAPI, HAPH y HAPD, para detectar a los tratables con dosis altas de un bloqueador de los } \\
\text { canales de calcio }\end{array}$ & I & C \\
\hline \multicolumn{3}{|l|}{ Gravedad de la HAP } \\
\hline $\begin{array}{l}\text { Se recomienda evaluar la gravedad de los pacientes con HAP mediante un panel de datos obtenidos de evaluación clínica, tests de ejercicio, marcadores } \\
\text { bioquímicos y evaluación ecocardiográfica y hemodinámica (tablas } 13 \text { y 14) y realizar regularmente evaluaciones de seguimiento cada } 3-6 \text { meses a los } \\
\text { pacientes estables (tabla 14) }\end{array}$ & I & C \\
\hline \multicolumn{3}{|l|}{ Medidas generales en HAP } \\
\hline Se recomienda a las pacientes con HAP evitar el embarazo & I & $\mathrm{C}$ \\
\hline
\end{tabular}


13. Mensajes sobre qué se debe hacer y qué no se debe hacer (continuación)

\begin{tabular}{|c|c|c|}
\hline \multicolumn{3}{|l|}{ Tratamiento de la HAP } \\
\hline $\begin{array}{l}\text { Se recomienda a los centros de referencia proporcionar asistencia con un equipo multidisciplinario (cardiólogos y neumólogos, enfermera clínica } \\
\text { especialista, radiólogos, apoyo psicológico y social y equipos de guardia apropiados) }\end{array}$ & I & C \\
\hline Para el tratamiento de pacientes con HAP de riesgo mínimo, bajo o intermedio, se recomienda monoterapia de inicio con fármacos aprobados (tabla 19) & I & A \\
\hline $\begin{array}{l}\text { Para el tratamiento de pacientes con HAP de riesgo mínimo, bajo o intermedio, se recomienda el tratamiento de inicio con combinaciones de fármacos } \\
\text { aprobados (tabla 20) }\end{array}$ & I & B \\
\hline $\begin{array}{l}\text { Para pacientes con respuesta inadecuada al tratamiento inicial en monoterapia o en combinación doble, se recomienda la combinación secuencial } \\
\text { de fármacos (tabla 21) }\end{array}$ & I & B \\
\hline \multicolumn{3}{|l|}{ Recomendaciones en enfermedades pulmonares y del corazón izquierdo } \\
\hline No se recomienda el uso de terapias aprobadas en HAP para pacientes con hipertensión pulmonar debida a enfermedad pulmonar o del corazón izquierdo & III & C \\
\hline \multicolumn{3}{|l|}{ Recomendaciones para la HPTC } \\
\hline $\begin{array}{l}\text { Se recomienda la endarterectomía pulmonar quirúrgica en parada circulatoria con hipotermia profunda para pacientes con HPTC y que un equipo } \\
\text { multidisciplinario de expertos evalúe la operabilidad y tome las decisiones que afecten a otras estrategias de tratamiento (fármacos o angioplastia } \\
\text { pulmonar con balón) }\end{array}$ & I & $\mathrm{C}$ \\
\hline
\end{tabular}

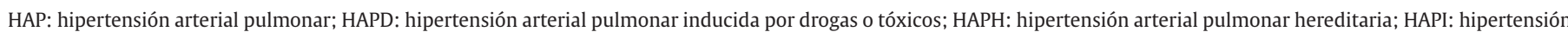
arterial pulmonar idiopática; HPTC: hipertensión pulmonar tromboembólica crónica.

\section{ANEXO WEB}

En este epígrafe se recoge el anexo web, cuyo original está disponible en: http://www.escardio.org/static_file/Escardio/Guidelines/ Publications/PAH/2015\%20ESC-ERS\%20Gles\%20PH-Web\%20addendaehv317.pdf.

\section{Lista de tablas web}

14.1. Patología de la hipertensión pulmonar 42

14.2. Biopatología de la hipertensión pulmonar . .42

14.3. Programa de cribado de la hipertensión arterial pulmonar .....44

14.4. Medición de la calidad de vida .............................................................49

14.5. Bibliografía... .50

\subsection{Patología de la hipertensión pulmonar}

Los distintos grupos de hipertensión pulmonar (HP) se distinguen por tener características patológicas diferentes ${ }^{51,52}$.

- Grupo 1, hipertensión arterial pulmonar (HAP): los cambios patológicos afectan fundamentalmente a las arterias pulmonares distales $(<500 \mu \mathrm{m})$, como la hipertrofia de la media, cambios proliferativos y fibróticos en la íntima, engrosamiento de la adventicia con presencia de infiltrados inflamatorios perivasculares leve o moderada y neogénesis linfoidea, lesiones complejas (plexiformes, dilatadas) y trombóticas. Clásicamente, las venas pulmonares no están afectadas.

- Grupo 1': incluye principalmente enfermedad venooclusiva pulmonar (EVOP) que afecta a las venas septales y vénulas preseptales con lesiones fibróticas oclusivas, musculación venosa, proliferación capilar parcheada con hemangiomatosis capilar pulmonar (HCP), edema pulmonar, hemorragia alveolar oculta, dilatación linfática, adenopatía (transformación vascular del seno) e infiltrados inflamatorios. Las arterias pulmonares distales están afectadas por hipertrofia de la media y fibrosis de la íntima.

- Grupo 1": la hipertensión pulmonar (HP) persistente del recién nacido (HPPRN) se caracteriza por cambios en la vasorreactividad y en la estructura parietal, además de reducciones de la densidad vascular pulmonar con alveolización disminuida.

- Grupo 2: la HP causada por enfermedad cardiaca izquierda (ECI) se caracteriza por aumento y engrosamiento de las venas pulmonares, dilatación capilar pulmonar, edema intersticial, hemorragia alveolar, vasos linfáticos y adenopatía. La AP distal puede estar afectada por hipertrofia de la media y fibrosis de la íntima.
- Grupo 3: la HP causada por enfermedades pulmonares o hipoxemia se caracteriza por hipertrofia de la media, proliferación fibrótica obstructiva en la íntima de la AP distal y musculación de arteriolas. También puede ocurrir en mayor o menor grado la destrucción del lecho vascular en zonas con enfisema o fibrosis.

- Grupo 4, HP causada por obstrucción crónica de la AP. Las lesiones de la hipertensión tromboembólica crónica (HPTC) incluyen trombos organizados muy adheridos a la pared de la media en la AP elástica que sustituyen a la íntima normal. Estos trombos pueden ocluir la luz del vaso o formar distintos grados de estenosis, membranas y bandas ${ }^{53}$. Se puede desarrollar enfermedad microvascular pulmonar en zonas ocluidas y no ocluidas, similar a la HAP (con la excepción de las lesiones plexiformes, poco comunes en la HPTC), con remodelado poscapilar parcheado relacionado con cortocircuitos venosos bronquiopulmonares ${ }^{54,55}$. También pueden desarrollarse vasos colaterales de la circulación sistémica (a partir de arterias bronquiales, costales, diafragmáticas y coronarias) para reperfundir las áreas distales a la obstrucción completa.

- Grupo 5: la HP con mecanismos indefinidos o multifactoriales incluye enfermedades heterogéneas con distintas características patológicas.

\subsection{Biopatología de la hipertensión pulmonar}

Los distintos grupos clínicos de HP se caracterizan también por sus distintas características biopatológicas ${ }^{56-58}$.

- Grupo 1: la HAP tiene una biopatología multifactorial. La excesiva vasoconstricción se ha relacionado con una función o expresión anormal de los canales de potasio en las células de músculo liso y con la disfunción endotelial que lleva a la disminución crónica de la producción de agentes vasodilatadores y antiproliferativos, como NO y prostaciclina, junto con una expresión excesiva de sustancias vasoconstrictoras y proliferativas como tromboxano $\mathrm{A}_{2}$ y la endotelina 1. Muchas de estas alteraciones elevan el tono vascular y promueven el remodelado vascular mediado por cambios proliferativos que afectan a las células musculares lisas y endoteliales, además de fibroblastos y pericitos. Distintos factores de crecimiento (como los derivados de plaquetas y de fibroblastos y el factor transformador beta [TGF $\beta]$ ) y las proteínas óseas morfogénicas participan en el proceso de remodelado. La expresión reducida del receptor de proteínas morfogenéticas óseas tipo 2 (BMPR2) contribuye a la biopatología de la HAP heredable y otras formas de esta enfermedad. Otros tipos de células (células inflamatorias y plaquetas) y mediadores (citocinas, quimiocinas, serotonina, etc.) tam- 
Tabla web 1

Clasificación clínica resumida de la hipertensión pulmonar (actualizada de Simonneau et $\mathrm{al}^{1}$ )
1. Hipertensión arterial pulmonar (HAP)

1.1. Idiopática

1.2. Heredable

1.2.1. Mutación de BMPR2

1.2.2. Otras mutaciones

1.3. Inducida por drogas y toxinas

1.4. Asociada a:

1.4.1. Enfermedad del tejido conectivo

1.4.2. Infección por el VIH

1.4.3. Hipertensión portal

1.4.4. Cardiopatías congénitas (tabla 6)

1.4.5. Esquistosomiasis

1'. Enfermedad venooclusiva pulmonar/hemangiomatosis capilar pulmonar

1". Hipertensión pulmonar persistente del recién nacido

2. Hipertensión pulmonar secundaria a cardiopatía izquierda

2.1. Disfunción sistólica del ventrículo izquierdo

2.2. Disfunción diastólica del ventrículo izquierdo

2.3. Valvulopatías

2.4. Obstrucción al tracto de entrada/salida del ventrículo izquierdo congénita/ adquirida y miocardiopatías congénitas

2.5. Otras

3. Hipertensión pulmonar secundaria a enfermedades pulmonares o hipoxia

3.1. Enfermedad pulmonar obstructiva crónica

3.2. Enfermedad intersticial pulmonar

3.3. Otras enfermedades pulmonares con patrón mixto restrictivo y obstructivo

3.4. Trastornos respiratorios del sueño

3.5. Trastornos de hipoventilación alveolar

3.6. Exposición crónica a grandes alturas

3.7. Enfermedades del desarrollo pulmonar (tabla web 3)

4. Hipertensión pulmonar tromboembólica crónica y otras obstrucciones de arterias pulmonares

4.1. Hipertensión pulmonar tromboembólica crónica

4.2. Otras obstrucciones de arterias pulmonares

5. Hipertensión pulmonar de mecanismo desconocido o multifactorial

5.1. Trastornos hematológicos

5.2. Trastornos sistémicos

5.3. Trastornos metabólicos

5.4. Otros

bién tienen un papel en la HAP. Se han descrito anomalías protrombóticas en pacientes con HAP, y hay trombos tanto en pequeñas arterias pulmonares distales como en arterias pulmonares elásticas proximales. La autoinmunidad es también una característica de algunos subgrupos de HAP, como indica la circulación de autoanticuerpos que reconocen células vasculares pulmonares y la detección de neogénesis linfática en los pulmones de pacientes con HAP idiopática (HAPI).

- Grupo 1': en la EVOP, las mutaciones bialélicas del gen EIF2AK4, la inflamación y la exposición a agentes tóxicos inducen daños oxidativos e inflamatorios.

- Grupo 1": en la HPPRN, la disfunción celular endotelial (producción y actividad de NO disminuida) y mecanismos angiogénicos son las anomalías subyacentes al factor de crecimiento vascular pulmonar.

- Grupo 2, HP causada por enfermedad cardiaca izquierda (ECI): los mecanismos causales del aumento de la presión arterial pulmonar (PAP) incluyen la transmisión retrógrada pasiva del aumento de presión (HP poscapilar aislada, tabla 3). En estos casos, la resistencia vascular pulmonar (RVP) se encuentra en la franja de normalidad. En otras circunstancias, la elevación de la PAP es mayor que la presión de enclavamiento pulmonar (PEP), lo que lleva a un aumento de la RVP (HP poscapilar y precapilar combinadas, tabla 3 ). El aumento de la RVP se debe a un aumento del tono vasomotor de
Tabla web 2

Clasificación anatomofisiopatológica de los cortocircuitos congénitos sistemicopulmonares asociados con hipertensión arterial pulmonar (adaptada de Simonneau et $\mathrm{al}^{2}$ )

\section{Tipo}

1.1. Cortocircuitos pretricuspídeos simples

1.1.1. Defecto septal auricular (DSA)

1.1.1.1. Ostium secundum

1.1.1.2. Seno venoso

1.1.1.3. Ostium primum

1.1.2. Drenaje venoso pulmonar anómalo total o parcial no obstructivo

1.2. Cortocircuitos postricuspídeos simples

1.2.1. Defecto septal ventricular (DSV)

1.2.2. Ductus arteriosus persistente

1.3. Cortocircuitos combinados

Describir la combinación y definir el defecto predominante

1.4. Cardiopatías congénitas complejas

1.4.1. Defecto septal auriculoventricular completo

1.4.2. Truncus arteriosus

1.4.3. Fisiología de ventrículo único con flujo pulmonar no obstructivo

1.4.4. Transposición de grandes vasos con DSV (sin estenosis pulmonar) o ductus arteriosus persistente

1.4.5. Otros

2. Dimensión (especificar de cada defecto si hay más de un defecto cardiaco congénito)

2.1. Hemodinámica (especificar $Q p / Q s)^{a}$

2.1.1. Restrictiva (gradiente de presión a través del defecto)

2.1.2. No restrictiva

2.2. Anatómica ${ }^{b}$

2.2.1. Pequeño a moderado (DSA $\leq 2,0 \mathrm{~cm}$ y DSV $\leq 1,0 \mathrm{~cm}$ )

2.2.2. Grande (DSA $>2,0 \mathrm{~cm}$ y DSV $>1,0 \mathrm{~cm}$ )

\section{Dirección del cortocircuito}

3.1. Predominantemente sistemicopulmonar

3.2. Predominantemente pulmonar-sistémico

3.3. Bidireccional

4. Anormalías cardiacas y extracardiacas asociadas

5. Estado de reparación

5.1. No operado

5.2. Paliado (especificar tipo de operación y edad a la cirugía)

5.3. Reparado (especificar tipo de operación y edad a la cirugía)

Qp/Qs: cociente flujo sanguíneo pulmonar/sistémico.

bEl tamaño se aplica a pacientes adultos.

la AP o el remodelado estructural obstructivo fijo de los vasos de resistencia de la $\mathrm{AP}^{59}$; el primero es un componente de la HP reactiva, reversible en pruebas farmacológicas agudas, mientras que el segundo, que se caracteriza por hipertrofia de la media y proliferación de arteriolas pulmonares en la íntima, no responde a la prueba aguda ${ }^{60}$.

- Grupo 3, HP causada por enfermedades pulmonares o hipoxia: entre los mecanismos implicados, se encuentran la vasoconstricción hipóxica, el estrés mecánico de los pulmones con hiperinsuflación, la pérdida de capilares, la inflamación y los efectos tóxicos del humo del tabaco. También hay datos que sostienen cierto desequilibrio entre vasoconstrictores y vasodilatadores derivados del endotelio.

- Grupo 4, HP causada por obstrucción crónica de la AP: se cree que el proceso biopatológico más importante en la HPTC es la falta de resolución de masas embólicas agudas que posteriormente sufren una fibrosis que lleva a la obstrucción mecánica de arterias pulmonares. Sin embargo, la visión "mecanicista» de la HPTC, como una enfermedad causada exclusivamente por la pérdida de arterias pulmonares centrales debido a la formación de émbolos pulmonares, parece demasiado simple. La embolia pulmonar podría seguirse de un proceso de remodelado vascular pulmonar causado por infección, fenómenos inmunológicos, inflamación y células progenitoras circulantes o residentes en la vasculatura. Solo un 
Tabla web 3

Enfermedades del desarrollo pulmonar asociadas con hipertensión pulmonar (adaptada de Ivi et $\mathrm{al}^{3}$ )

2. Displasia broncopulmonar

3. Displasia capilar alveolar (DCA)

4. DCA con mal alineamiento venoso

5. Hipoplasia pulmonar ("primaria» 0 "secundaria»)

6. Anomalías de las proteínas surfactantes

a. Deficiencia de proteína surfactante $B$

b. Deficiencia de proteína surfactante $C$

c. Mutación en ATP-binding cassette A3

d. Mutación en el factor de transcripción tiroideo 1/homeobox Nkx2.1

7. Glucogenosis intersticial pulmonar

8. Proteinosis alveolar pulmonar

9. Linfangiectasia pulmonar
1. Hernia diafragmática congénita

nes preventivas para personas que no han buscado atención médica debido a síntomas de dicha enfermedad ${ }^{65}$. Por lo tanto, el cribado de la HP/HAP se aplica a individuos asintomáticos que forman parte de grupos en los que la HP/HAP tiene alta prevalencia, como el de pacientes con esclerosis sistémica ${ }^{66,67}$, los portadores de mutaciones en BMPR2 o los familiares de pacientes con HAP heredable (HAPH $)^{68}$, los pacientes con enfermedad de células falciformes y los pacientes con hipertensión portal referidos a trasplante de hepático ${ }^{69}$.

Un método de cribado debe emplear herramientas no invasivas, reproducibles, asociadas a un valor predictivo de la enfermedad negativo alto y coste-efectivas ${ }^{61}$. En la HP/HAP, estas herramientas son las pruebas de la función pulmonar, la determinación de biomarcadores circulantes y la ecocardiografía. En la esclerosis sistémica, las pruebas de la funcion pulmonar se han utilizado desde hace mucho tiempo como herramienta de cribado, especialmente los cambios en la capacidad de difusión de monóxido de carbono (DLCO $)^{70,71}$. Se ha observado un aumento del riesgo de HAP en pacientes adultos con esclerosis sistémica y menos de un $60 \%$ del valor predicho ${ }^{67}$. Hoy hay nueva evidencia de que algunos biomarcadores (como la fracción $\mathrm{N}$-terminal del propéptido natriurético cerebral [NT-proBNP]), solos ${ }^{73}$ o combinados con $\mathrm{PFP}^{74}$, pueden identificar a los pacientes con mayor riesgo de HAP asociada a esclerosis sistémica. Por último, un reciente estudio en pacientes sometidos a cateterismo cardiaco derecho (CCD) como parte de la evaluación de la esclerosis sistémica indica que, en ausencia de HP, un aumento del gradiente de presión transpulmonar (GTP) se asocia a mayor riesgo de posterior aparición de HP precapi-

número de factores trombofílicos, como anticuerpos fosfolipídicos, anticoagulante lúpico y factor VIII elevado, se ha asociado estadísticamente con la HPTC, y no se ha demostrado de manera concordante la presencia de anomalías de la fibrinolisis. La enfermedad microvascular podría estar relacionada con las fuerzas de desgarro en zonas no obstruidas, el remodelado poscapilar relacionado con cortocircuitos venosos bronquiopulmonares, la presión, la inflamación y la liberación de citocinas y mediadores vasculotróficos ${ }^{55}$.

- Grupo 5: por definición, en este grupo la biopatología es indefinida o multifactorial.

\subsection{Programa de cribado de la hipertensión arterial pulmonar}

El pronóstico de la HAP es significativamente peor en los pacientes con enfermedad avanzada ${ }^{61,62}$. Los tratamientos de la HAP retrasan el deterioro clínico ${ }^{63}$, y los datos obtenidos indican que el tratamiento precoz mejora los resultados a largo plazo ${ }^{13,63,64}$. El cribado de una enfermedad es la aplicación sistemática de una prueba para identificar a los sujetos con un riesgo de una enfermedad concreta suficiente para motivar pruebas diagnósticas adicionales o directamente accio-

\section{Tabla web 5}

Clasificación funcional de la hipertensión pulmonar modificada siguiendo la clasificación funcional de la NYHA acorde con la clasificación de la OMS de $1998^{9}$

Clase I: pacientes con hipertensión pulmonar pero sin limitación de la actividad física. La actividad física habitual no causa disnea o fatiga excesivas, dolor torácico o presíncope

Clase II: pacientes con hipertensión pulmonar que limita ligeramente su actividad física. Se encuentran asintomáticos en reposo. La actividad física habitual causa disnea o fatiga excesivas, dolor torácico o presíncope

Clase III: pacientes con hipertensión pulmonar que produce marcada limitación de la actividad física. Se encuentran asintomáticos en reposo. Menos actividad que lo normal ya causa disnea o fatiga excesivas, dolor torácico o presíncope

Clase IV: pacientes con hipertensión pulmonar incapaces de llevar a cabo ninguna actividad física sin síntomas. Estos pacientes presentan signos de insuficiencia cardiaca derecha. Pueden tener disnea o fatiga incluso en reposo. Los síntomas se acentúan con cualquier actividad física

NYHA: New York Heart Association; OMS: Organización Mundial de la Salud.

Tabla web 4

Vía de administración, vida media, gamas de dosis, incremento de dosis y duración de la administración de los fármacos más frecuentemente usados para los tests de vasorreactividad pulmonar

\begin{tabular}{|c|c|c|c|c|c|c|c|c|}
\hline Fármaco & Vía & Vida media & Gama de dosis $^{\mathrm{d}}$ & Incremento de dosise & Duración ${ }^{f}$ & Clase $^{\mathrm{a}}$ & Nivel $^{\mathrm{b}}$ & Ref \\
\hline Óxido nítrico & Inh & $15-30 s$ & $10-20 \mathrm{ppm}$ & - & $5 \min ^{g}$ & I & C & 4,5 \\
\hline Epoprostenol & i.v. & $3 \mathrm{~min}$ & $2-12 \mathrm{ng} / \mathrm{kg} / \mathrm{min}$ & $2 \mathrm{ng} / \mathrm{kg} / \mathrm{min}$ & $10 \mathrm{~min}$ & I & C & 4,6 \\
\hline Adenosina & i.v. & $5-10 s$ & $50-350 \mu \mathrm{g} / \mathrm{kg} / \mathrm{min}$ & $50 \mu \mathrm{g} / \mathrm{kg} / \mathrm{min}$ & $2 \mathrm{~min}$ & Ila & C & 7 \\
\hline Iloprost & Inh & $30 \mathrm{~min}$ & $5-20 \mu \mathrm{g}$ & - & $15 \mathrm{~min}$ & IIb & $\mathrm{C}$ & 8 \\
\hline
\end{tabular}

Inh: inhalado; i.v.: intravenoso; NO: óxido nítrico; ppm: partes por millón.

aClase de recomendación.

bNivel de evidencia.

'Referencias que respaldan las recomendaciones.

dDosis inicial y dosis máxima recomendadas.

eIncremento de dosis en cada etapa.

fDuración de la administración en cada etapa.

gPara el NO se recomienda una única etapa dentro de la gama de dosis. 
Tabla web 6A

Características de los ensayos clínicos aleatorizados con fármacos para la hipertensión arterial pulmonar que interfieren con la vía de la endotelina (antagonistas de los receptores de la endotelina)

\begin{tabular}{|c|c|c|c|c|c|c|}
\hline Fármaco estudiado & Estudio & Pacientes, n & Duración (semanas) & Tratamiento de base & Objetivo primario & Resultados principales \\
\hline \multirow[t]{2}{*}{ Ambrisentán } & ARIES-10 & 202 & 12 & No & PM6M & $\begin{array}{l}\text { Mejora en la PM6M, ausencia } \\
\text { de mejora en el TEC }\end{array}$ \\
\hline & ARIES-2 $2^{10}$ & 192 & 12 & No & PM6M & $\begin{array}{l}\text { Mejora en la PM6M, mejora } \\
\text { en el TEC }\end{array}$ \\
\hline \multirow[t]{5}{*}{ Bosentán } & Study-35111 & 32 & 12 & No & PM6M & $\begin{array}{l}\text { Mejora en la PM6M, mejora } \\
\text { en el TEC }\end{array}$ \\
\hline & BREATHE- $1^{12}$ & 213 & 16 & No & PM6M & $\begin{array}{c}\text { Mejora en la PM6M, mejora } \\
\text { en el TEC }\end{array}$ \\
\hline & EARLY $^{13}$ & 185 & 24 & No o sildenafilo (16\%) & RVP, PM6M & $\begin{array}{l}\text { Mejora en RVP y TEC, ausencia } \\
\text { de mejora en PM6M }\end{array}$ \\
\hline & BREATHE-5 ${ }^{14}$ & 54 & 12 & No & $\mathrm{SaO}_{2}, \mathrm{RVP}$ & Mejora en RVP y PM6M \\
\hline & COMPASS- $2^{15}$ & 334 & 99 & Sildenafilo & TEC & $\begin{array}{c}\text { Ausencia de mejora en TEC, mejora } \\
\text { en PM6M y NT-proBNP }\end{array}$ \\
\hline Macitentán & SERAPHIN ${ }^{16}$ & 742 & 115 & No o iloprost inh. & TEC & $\begin{array}{l}\text { Mejora en el TEC en monoterapia } \\
\text { y en combinación }\end{array}$ \\
\hline
\end{tabular}

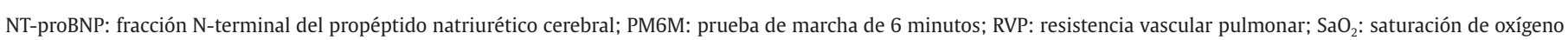
mediante pulsioximetría; TEC: tiempo hasta empeoramiento clínico.

Tabla web 6B

Características de los ensayos clínicos aleatorizados con fármacos contra la hipertensión arterial pulmonar que interfieren con la vía del óxido nítrico (estimuladores de la guanilato cliclasa solubles, inhibidores de la fosfodiesterasa tipo 5)

\begin{tabular}{|c|c|c|c|c|c|c|}
\hline Fármaco probado & Estudio & Pacientes, $\mathrm{n}$ & Duración (semanas) & Tratamiento de base & Objetivos primarios & Resultados principales \\
\hline \multirow[t]{2}{*}{ Riociguat } & PATENT $^{17}$ & 443 & 12 & $\begin{array}{l}\text { No o bosentán } \\
\text { o prostanoides }\end{array}$ & PM6M & Mejora en PM6M, mejoría hemodinámica \\
\hline & PATENT plus ${ }^{18}$ & 30 & 18 & Sildenafilo & TAS en supino & $\begin{array}{l}\text { Suspendido por exceso de EAG } \\
\text { en el grupo de tratamiento }\end{array}$ \\
\hline \multirow[t]{6}{*}{ Sildenafilo } & SUPER- $1^{19}$ & 277 & 12 & No & PE & Mejora en PM6M, sin mejora en TEC \\
\hline & Sastry ${ }^{20}$ & 22 & 12 & No & PE & Mejora en PE \\
\hline & Singh ${ }^{21}$ & 20 & 6 & No & PM6M & Mejora en PM6M \\
\hline & PACES $^{22}$ & 264 & 16 & Epoprostenol & PM6M & $\begin{array}{c}\text { Mejora en PM6M y TEC, mejoría } \\
\text { hemodinámica }\end{array}$ \\
\hline & Iversen $^{23}$ & 20 & 12 & Bosentán & PM6M & Sin mejora en la PM6M \\
\hline & $\begin{array}{l}\text { Estudio Pfizer } \\
\text { A1481243 }\end{array}$ & 103 & 12 & Bosentán & PM6M & Sin mejora en la PM6M \\
\hline Tadalafilo & PHIRST $^{24}$ & 405 & 16 & No o bosentán (54\%) & PM6M & $\begin{array}{l}\text { Mejora en PM6M (pacientes tratados con } \\
\text { bosentán, +23 m; IC95\%, -2 a } 48 \text { m) y TEC }\end{array}$ \\
\hline Vardenafilo* & EVALUATION ${ }^{25}$ & 66 & 12 & No & PM6M & Mejora en PM6M y TEC \\
\hline
\end{tabular}

EAG: eventos adversos graves; IC95\%: intervalo de confianza del 95\%; PE: prueba de esfuerzo; PM6M: prueba de marcha de 6 minutos; TEC: tiempo hasta empeoramiento clínico.

*Este fármaco no está aprobado por la EMEA en el momento de publicarse el presente documento. 
Tabla web 6C

Características de los ensayos clínicos aleatorizados con fármacos contra la hipertensión arterial pulmonar en la vía de las prostaciclinas (análogos de prostaciclina y agonistas del receptor de prostaciclina)

\begin{tabular}{|c|c|c|c|c|c|c|}
\hline Fármaco probado & Estudio & Pacientes, $\mathrm{n}$ & Duración (semanas) & Tratamiento de base & Objetivo primario & Resultados principales \\
\hline \multirow[t]{2}{*}{ Beraprost* } & ALPHABET ${ }^{26}$ & 130 & 12 & No & PM6M & $\begin{array}{c}\text { Mejora en PM6M, sin mejoría } \\
\text { hemodinámica }\end{array}$ \\
\hline & Barst $^{27}$ & 116 & 52 & No & $\mathrm{EC}$ & Sin mejora en EC \\
\hline \multirow[t]{3}{*}{ Epoprostenol } & Rubin $^{28}$ & 23 & 12 & No & PM6M & $\begin{array}{l}\text { Mejora en PM6M y mejoría } \\
\text { hemodinámica }\end{array}$ \\
\hline & Barst $^{29}$ & 81 & 12 & No & PM6M & $\begin{array}{c}\text { Mejora en PM6M y mejoría } \\
\text { hemodinámica, aumento } \\
\text { de supervivencia }\end{array}$ \\
\hline & Badesch $^{30}$ & 111 & 12 & No & PM6M & Mejora en PM6M \\
\hline \multirow[t]{3}{*}{ Iloprost inhalado } & $\mathrm{AIR}^{31}$ & 203 & 12 & No & PM6M y CF & $\begin{array}{l}\text { Mejora en PM6M y CF-OMS, } \\
\text { mejoría hemodinámica }\end{array}$ \\
\hline & $\mathrm{STEP}^{32}$ & 67 & 12 & Bosentán & PM6M & $\begin{array}{c}\text { Mejora en PM6M }(p=0,051) \\
\text { y TEC }\end{array}$ \\
\hline & $\mathrm{COMBI}^{33}$ & 40 & 12 & Bosentán & PM6M & $\begin{array}{c}\text { Suspendido por ausencia } \\
\text { de mejora en PM6M, sin mejoría } \\
\text { clínica }\end{array}$ \\
\hline \multirow[t]{5}{*}{ Treprostinil } & SC-Pivotal Study ${ }^{34}$ & 470 & 12 & No & PM6M & $\begin{array}{c}\text { Mejoría hemodinámica y mejora } \\
\text { en PM6M; dolor en la zona } \\
\text { de infusión }\end{array}$ \\
\hline & Inhala TRIUMPH ${ }^{35}$ & 235 & 12 & Bosentán & PM6M & $\begin{array}{l}\text { Mejora en PM6M (+20 m para } \\
\text { el pico, }+12 \text { m para el valle), } \\
\text { sin mejora en el EC }\end{array}$ \\
\hline & $\mathrm{PO}^{*}$-Freedom $\mathrm{M}^{36}$ & 185 & 16 & No & PM6M & $\begin{array}{c}\text { Mejora en PM6M (+26 m para } \\
\text { el pico, }+17 \text { m para el valle), } \\
\text { sin mejora en TEC }\end{array}$ \\
\hline & $\mathrm{PO}^{*}$-Freedom $\mathrm{C1}^{37}$ & 354 & 16 & ARE y/o PDE-5i & PM6M & Sin mejora en PM6M y TEC \\
\hline & PO*-Freedom C2 ${ }^{38}$ & 310 & 16 & ARE y/o PDE-5i & PM6M & Sin mejora en PM6M y TEC \\
\hline \multirow[t]{2}{*}{ Selexipag* } & Phase- $2^{39}$ & 43 & 17 & ARE y/o PDE-5i & RVP & $\begin{array}{c}\text { Mejora de la RVP, sin mejora } \\
\text { en PM6M }\end{array}$ \\
\hline & GRIPHON $^{40}$ & 1.156 & 74 & ARE y/o PDE-5i & TEC & Mejora en TEC \\
\hline
\end{tabular}

EC: empeoramiento clínico; PE: prueba de esfuerzo; PM6M: prueba de marcha de 6 minutos; RVP: resistencia vascular pulmonar; TEC: tiempo hasta empeoramiento clínico. *Este fármaco no está aprobado por la EMEA en el momento de publicarse el presente documento.

Tabla web 6D

Características de los ensayos clínicos aleatorizados sobre diferentes terapias combinadas de inicio contra la hipertensión arterial pulmonar

\begin{tabular}{|c|c|c|c|c|c|c|}
\hline Fármacos probados & Estudio & Pacientes, n & Duración (semanas) & Tratamiento de base & Objetivo primario & Resultados principales \\
\hline $\begin{array}{l}\text { Epoprostenol frente a } \\
\text { epoprostenol+bosentán }\end{array}$ & BREATHE- $2^{41}$ & 33 & 12 & No & RVP & $\begin{array}{l}\text { Sin mejora en RVP } \\
\text { y PM6M }\end{array}$ \\
\hline $\begin{array}{l}\text { Ambrisentán o tadalafilo frente } \\
\text { a ambrisentán+tadalafilo }\end{array}$ & AMBITION $^{42}$ & 500 & 78 & No & TEC & $\begin{array}{l}\text { Mejora en TEC } \\
\text { y PM6M }\end{array}$ \\
\hline
\end{tabular}

PM6M: prueba de marcha de 6 minutos; RVP: resistencia vascular pulmonar; TEC: tiempo hasta empeoramiento clínico.

$\operatorname{lar}^{75}$. La ecocardiografía en reposo sigue siendo el mejor método para estimar las presiones pulmonares elevadas. Se ha empleado en programas grandes de cribado de HAP asociada a esclerosis sistémica ${ }^{67,76}$ estratificando a los pacientes según la PAPs estimada por la velocidad de regurgitación tricuspídea (VRT). Las recomendaciones para el manejo diagnóstico acorde con la probabilidad ecocardiográfica de HP de los pacientes asintomáticos con/sin factores de riesgo de HAP o HPTC se encuentran en la tabla web 9. Por el contrario, la ecocardiografía de esfuerzo tiene limitaciones técnicas y metodológicas y no está recomendada para el cribado de $\mathrm{HP} / \mathrm{HAP}^{77-81}$. 
Tabla web 7

Interacciones farmacológicas potencialmente significativas con fármacos para la hipertensión arterial pulmonar

\begin{tabular}{|c|c|c|c|}
\hline Fármaco para HAP & Mecanismo de interacción & Fármaco con el que interactúa & Interacción \\
\hline Ambrisentán & $?$ & Ciclosporina, ketoconazol & $\begin{array}{l}\text { Se recomienda precaución en la administración } \\
\text { de ambrisentán con ketoconazol y ciclosporina }\end{array}$ \\
\hline \multirow[t]{10}{*}{ Bosentán } & Inductor de CYP3A4 & Sildenafilo & $\begin{array}{l}\text { La concentración de sildenafilo disminuye un } 50 \% \text {, la de } \\
\text { bosentán aumenta un } 50 \% \text {; puede no requerir ajuste } \\
\text { de dosis de ningún fármaco }\end{array}$ \\
\hline & Sustrato de CYP3A4 & Ciclosporina & $\begin{array}{l}\text { La concentración de ciclosporina disminuye un } \\
50 \% \text {, la de bosentán se cuadruplica; combinación } \\
\text { contraindicada }\end{array}$ \\
\hline & Sustrato de CYP3A4 & Eritromicina & $\begin{array}{l}\text { Aumenta la concentración de bosentán; puede no } \\
\text { requerir ajuste de dosis de bosentán durante un ciclo } \\
\text { corto }\end{array}$ \\
\hline & Sustrato de CYP3A4 & Ketoconazol & La concentración de bosentán se duplica \\
\hline & $\begin{array}{l}\text { Sustrato de CYP3A4+inhibidor de la } \\
\text { bomba de sales biliares }\end{array}$ & Glibenclamida & $\begin{array}{l}\text { Mayor incidencia de elevación de transaminasas; } \\
\text { potencial disminución del efecto hipoglucemiante de la } \\
\text { glibenclamida; combinación contraindicada }\end{array}$ \\
\hline & Sustrato de CYP2C9 y CYP3A4 & Fluconazol, amiodarona & $\begin{array}{l}\text { La concentración de bosentán aumenta } \\
\text { considerablemente; combinación contraindicada }\end{array}$ \\
\hline & Inductores de CYP2C9 y CYP3A4 & Rifampicina, fenitoína & $\begin{array}{l}\text { La concentración de bosentán disminuye un } 58 \% \text {; no se } \\
\text { sabe si requiere ajuste de dosis }\end{array}$ \\
\hline & Inductor de CYP2C9 & Estatinas & $\begin{array}{l}\text { Disminuye la concentración de simvastatina un } \\
\text { 50\%: probablemente tenga un efecto similar con } \\
\text { atorvastatina; se debe controlar la colesterolemia }\end{array}$ \\
\hline & Inductor de CYP2C9 & Warfarina & $\begin{array}{l}\text { Aumenta el metabolismo de warfarina, puede requerir } \\
\text { ajuste de dosis de warfarina; se recomienda un control } \\
\text { intensivo de warfarina tras el inicio, pero no suele ser } \\
\text { necesario ajuste de dosis }\end{array}$ \\
\hline & Inductor de CYP2C9 y CYP3A4 & Anticonceptivos hormonales & $\begin{array}{l}\text { Disminución de las concentraciones hormonales; } \\
\text { anticoncepción no fiable }\end{array}$ \\
\hline Macitentán & & & Por determinar \\
\hline Selexipag & & & Por determinar \\
\hline \multirow[t]{8}{*}{ Sildenafilo ${ }^{43}$} & Sustrato de CYP3A4 & Bosentán & $\begin{array}{l}\text { La concentración de sildenafilo disminuye un } 50 \% \text {; la de } \\
\text { bosentán aumenta un } 50 \% \text {; puede no requerirse ajuste } \\
\text { de dosis de ningún fármaco }\end{array}$ \\
\hline & Sustrato de CYP3A4 & Estatinas & $\begin{array}{l}\text { Puede aumentar la concentración de simvastatina/ } \\
\text { atorvastatina por competición por el metabolismo; } \\
\text { puede aumentar la concentración de sildenafilo; posible } \\
\text { aumento de riesgo de rabdomiolisis }\end{array}$ \\
\hline & Sustrato de CYP3A4 & Inhibidores de la proteasa del VIH & $\begin{array}{l}\text { Ritonavir y saquinovir aumentan notablemente la } \\
\text { concentración de sildenafilo }\end{array}$ \\
\hline & Inductor de CYP3A4 & Fenitoína & La concentración de sildenafilo puede disminuir \\
\hline & Sustrato de CYP3A4 & Eritromicina & $\begin{array}{l}\text { Aumenta la concentración de sildenafilo; puede no } \\
\text { requerir ajuste de dosis para un ciclo corto }\end{array}$ \\
\hline & Sustrato de CYP3A4 & Ketoconazol & $\begin{array}{l}\text { Aumenta la concentración de sildenafilo; puede no } \\
\text { requerir ajuste de dosis }\end{array}$ \\
\hline & Sustrato de CYP3A4 & Cimetidina & $\begin{array}{l}\text { Aumenta la concentración de sildenafilo; puede no } \\
\text { requerir ajuste de dosis }\end{array}$ \\
\hline & GMPc & Nitratos, nicorandil, molsidomina & $\begin{array}{l}\text { Hipotensión sistémica profunda, combinación } \\
\text { contraindicada }\end{array}$ \\
\hline \multirow[t]{2}{*}{ Tadalafilo ${ }^{44}$} & Sustrato de CYP3A4 & Bosentán & $\begin{array}{l}\text { La exposición a tadalafilo disminuye un } 42 \% \text {, no hay } \\
\text { cambios significativos en la concentración } \\
\text { de bosentán }{ }^{44} ; \text { puede no requerir ajuste de dosis }\end{array}$ \\
\hline & GMPc & Nitratos, nicorandil & $\begin{array}{l}\text { Hipotensión sistémica profunda, combinación } \\
\text { contraindicada }\end{array}$ \\
\hline \multirow[t]{2}{*}{ Riociguat $^{18}$} & GMPc & Sildenafilo, otros inhibidores de PDE-5 & $\begin{array}{l}\text { Hipotensión, efectos adversos graves, combinación } \\
\text { contraindicada }\end{array}$ \\
\hline & GMPc & Nitratos, nicorandil & $\begin{array}{l}\text { Hipotensión sistémica profunda, combinación } \\
\text { contraindicada }\end{array}$ \\
\hline
\end{tabular}

GMPc: monofosfato de guanosina cíclico; PDE-5: fosfodiesterasa tipo 5.

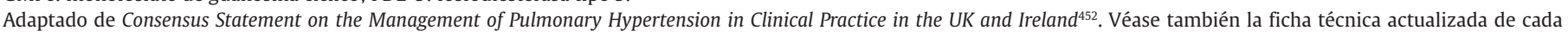
fármaco. 
Tabla web 8

Enfermedades del grupo 5 que pueden causar hipertensión pulmonar

\section{Alteraciones hematológicas}

a. Anemia hemolítica crónica

La característica común de las anemias hemolíticas es que la hemolisis intravascular libera al plasma hemoglobina que secuestra el óxido nítrico. Esta pérdida de óxido nítrico, vasodilatador fisiológico de la circulación pulmonar, puede causar vasoconstricción y cambios obstructivos vasculares patológicos

b. Anemia falciforme

Las células que contienen hemoglobina falciforme ( $\mathrm{HbS}$ ) pueden quedar atrapadas en la microcirculación y causar una obstrucción local del flujo sanguíneo. Un factor adicional que conduce a hipertensión pulmonar (HP) es que estos pacientes pueden sufrir asplenia funcional o quirúrgica que los pone en riesgo de tromboembolias e hipertensión pulmonar tromboembólica crónica (HPTC). Hay algunos estudios pequeños no controlados, pero los resultados de tratamientos como bosentán y sildenafilo son como mucho moderados

c. Betatalasemia

La HP en los pacientes con talasemia también es multifactorial e implica hemolisis intravascular (véase arriba), cambios en el sistema de coagulación e inflamación local

d. Esferocitosis hereditaria/estomatocitosis

La esferocitosis hereditaria es una alteración autosómica poco común de la membrana eritrocitaria que favorece la hemolisis intravascular. Además, hay alto riesgo de complicaciones trombóticas pero, una vez más, a menudo está asociado a la esplenectomía que se hace para evitar la hemolisis

e. Síndromes mieloproliferativos

Los síndromes mieloproliferativos crónicos (SMPC) se asocian con HP. Se cree que hay 2 etiologías principales:

1. Los SMPC pueden aumentar el riesgo de trombosis venosa

2. Los SMPC pueden originar una vasculopatía proliferativa precapilar. Puede ser interesante el dasatinib, un inhibidor de la tirosincinasa, que es uno de los tratamientos para la leucemia mieloide crónica y también parece que revierte parcialmente la $\mathrm{HP}^{45,46}$

f. Esplenectomía

La esplenectomía implica riesgo aumentado de HPTC e incluso hipertensión arterial pulmonar idiopática

\section{Enfermedades sistémicas asociadas con hipertensión pulmonar}

Entre otras, sarcoidosis, histiocitosis y linfangioleiomiomatosis

a. Sarcoidosis

La HP ocurre en un 5-15\% ${ }^{47}$. La causa de HP en la sarcoidosis es multifactorial e incluye enfermedad fibrosante pulmonar, granulomas en las arterias pulmonares, mediastinitis fibrosante, vasculitis pulmonar, hipertensión portopulmonar y enfermedad venooclusiva pulmonar ${ }^{48}$

b. Histiocitosis de células de Langerhans

La HP se asocia a la enfermedad del parénquima pulmonar relacionada con el tabaco

c. Linfangioleiomiomatosis (LAM)

La HP asociada a enfermedad del parénquima pulmonar ocurre en aproximadamente un 7\% de los pacientes con LAM no seleccionados

Alteraciones metabólicas

a. Enfermedad tiroidea

La HP se asocia a hipotiroidismo e hipertiroidismo ${ }^{50}$

b. Enfermedades por depósito de glucógeno

Se desconoce la patogenia de la HP, pero puede incluir la enfermedad venooclusiva pulmonar. El tratamiento de remplazo enzimático (TRE) parece tener poco efecto, a diferencia de la enfermedad de Gaucher (véase abajo)

c. Enfermedad de Gaucher

Aproximadamente un 30\% de los pacientes con enfermedad de Gaucher no tratada sufren HP, causada por una combinación de factores, entre otros taponamiento de la vasculatura por macrófagos anómalos, proliferación celular vascular pulmonar anómala y asplenia (véase arriba). El TRE, que actualmente es el tratamiento principal de la enfermedad de Gaucher, puede mejorar la HP. Sin embargo, el inicio del TRE también puede desenmascarar una HP subyacente

\section{Otras alteraciones}

a. Insuficiencia renal crónica

La HP es muy común en la enfermedad renal terminal y es multifactorial: la anemia y las fístulas arteriovenosas (usadas para hemodiálisis) causan un estado hiperdinámico. Puede deberse a una disfunción de la proliferación vascular relacionada en parte con la uremia, de la que se sabe que también afecta a la vasculatura sistémica. La mayoría de los expertos coinciden en que la HP en la insuficiencia renal crónica es principalmente de origen venoso por disfunción ventricular izquierda, que a su vez se debe al daño miocárdico causado por los procesos de la insuficiencia renal

b. Mediastinitis fibrosante

En HP debida a mediastinitis fibrosante, la lesión principal es la obliteración de las venas centrales y las arterias por el proceso fibrosante ${ }^{47,48}$

c. Tumores

Aproximadamente un 25\% de los pacientes que fallecen por cáncer tienen émbolos tumorales en la circulación pulmonar. Los tumores que parecen estar particularmente asociados con la HP son de estómago, mama, ovario, pulmón, riñón y colon. Las células tumorales migran a la circulación pulmonar, donde aparentemente causan microangiopatía 
Tabla web 9

Manejo diagnóstico propuesto según la probabilidad ecocardiográfica de hipertensión pulmonar para pacientes asintomáticos con o sin factores de riesgo de hipertensión arterial pulmonar o hipertensión pulmonar tromboembólica crónica

\begin{tabular}{|c|c|c|c|c|c|c|c|}
\hline $\begin{array}{l}\text { Probabilidad ecocardiográfica } \\
\text { de HP }\end{array}$ & $\begin{array}{c}\text { Sin factores de riesgo o enfermedades } \\
\text { asociadas a HAP o HPTC }{ }^{d, e}\end{array}$ & Clase $^{\mathrm{a}}$ & Nivel $^{\mathrm{b}}$ & $\begin{array}{c}\text { Con factores de riesgo o enfermedades } \\
\text { asociadas a HAP o HPTC d,e }\end{array}$ & Clase $^{\mathrm{a}}$ & Nivel $^{\mathrm{b}}$ & $\operatorname{Ref}^{c}$ \\
\hline Baja & No se necesita estudio de HAP & III & C & $\begin{array}{l}\text { Se puede considerar seguimiento } \\
\text { ecocardiográfico }\end{array}$ & IIb & C & \\
\hline \multirow[t]{2}{*}{ Intermedia } & $\begin{array}{l}\text { Se debería considerar seguimiento } \\
\text { ecocardiográfico }\end{array}$ & IIa & C & $\begin{array}{l}\text { Se recomienda seguimiento } \\
\text { ecocardiográfico }\end{array}$ & I & B & $67,76,88$ \\
\hline & & & & $\begin{array}{l}\text { Si asociado a esclerodermia, se debería } \\
\text { considerar } C_{C D}\end{array}$ & Ila & B & $8,17,29$ \\
\hline Alta & Se debería considerar $C C D^{\mathrm{f}}$ & IIa & C & Se recomienda CCD & I & $\mathrm{C}$ & \\
\hline
\end{tabular}

CCD: cateterismo cardiaco derecho; HAP: hipertensión arterial pulmonar; HP: hipertensión pulmonar; HPTC: hipertensión pulmonar tromboembólica crónica.

aClase de recomendación.

${ }^{\mathrm{b}}$ Nivel de evidencia.

'Referencias que respaldan las recomendaciones.

dSe aplica a los hallazgos accidentales en un ecocardiograma realizado para una indicación distinta de la sospecha de HP. Las recomendaciones sobre programas prospectivos institucionales de cribado de HAP o HPTC se describen en una sección específica de esta guía.

eEstas recomendaciones no afectan a los pacientes con enfermedad parenquimatosa pulmonar difusa o enfermedad cardiaca izquierda.

fDependiendo de la presencia de factores de riesgo de HP de los grupos 2, 3 o 5.

La estrategia de investigación posterior puede diferir dependiendo de que los factores de riesgo o las enfermedades asociadas indiquen mayor probabilidad de HAP o de HPTC (véase algoritmo diagnóstico, figura 1).

Recientes estudios sobre esclerosis sistémica y enfermedad de células falciformes han demostrado que la HAP en pacientes asintomáticos podría pasar inadvertida en la ecocardiografía Doppler (falsos negativos), lo que destaca la necesidad de una estrategia diagnóstica de pruebas múltiples. El estudio DETECT ha propuesto una combinación de mediciones para la esclerosis sistémica ${ }^{67}$. En este estudio, se sometió a pruebas no invasivas y CCD a pacientes adultos con esclerosis sistémica de duración $>3$ años y DLCO $<60 \%$ del valor predicho. Propone una estrategia gradual de detección de la enfermedad con 6 sencillas pruebas clínicas y biológicas en el paso 1 del algoritmo, las cuales determinan la indicación de ecocardiografía. En el paso 2, la puntuación pronóstica obtenida en el paso 1 más 2 variables ecocardiográficas determinan la indicación de CCD. Según este algoritmo, en el estudio DETECT se recomendó CCD al 62\% de los pacientes (tasa de referencia), y el $4 \%$ de los pacientes con HAP pasaron inadvertidos (falsos negativos). De estos, el diagnóstico de HAP se confirmó mediante CCD en el $19 \%{ }^{67}$. Esta estrategia de cribado parece interesante, pero hasta el momento no hay información sobre los resultados a largo plazo de los pacientes asintomáticos con HAP asociada a esclerosis sistémica detectada mediante el algoritmo del estudio DETECT. Hay que destacar también que el estudio DETECT no proporcionó recomendaciones para los pacientes con DLCO $\geq 60 \%$ y que sus hallazgos deben ser validados en otra cohorte. Después de la fase inicial de cribado, no está claro con qué frecuencia hay que realizar las pruebas no invasivas a sujetos asintomáticos con alto riesgo de HAP. Se ha propuesto un cribado anual con ecocardiografía, DLCO y determinación del NT-proBNP para pacientes con esclerosis sistémica $^{66,82}$.

La HP precapilar es una conocida complicación de la enfermedad de celulas falciformes, pero la prevalencia de esta entidad se ha sobrevalorado en estudios basados en ecocardiografía ${ }^{83}$. En 2 estudios recientes $^{84,85}$ que emplearon una metodología similar, todos los pacientes con una VRT de cribado $\geq 2,5 \mathrm{~m} / \mathrm{s}$ en la ecocardiografía fueron referidos a CCD de confirmación. La prevalencia de HP osciló entre el 6,2 y el 10\% (HP poscapilar en el 3,3 y el 6,2\% e HP precapilar en el 2,9 y el 3,8\% respectivamente). Un análisis posterior halló que la calibración de la VRT a $\geq 2,9 \mathrm{~m} / \mathrm{s}$ o en la banda de $2,5-2,8 \mathrm{~m} / \mathrm{s}$, además de NT-proBNP $>164,5$ $\mathrm{pg} / \mathrm{ml}$ o una distancia en la PM6M $<333 \mathrm{~m}$, redujo el número de pacientes referidos a $\mathrm{CCD}$, comparado con el empleo de un único umbral de VRT $\geq 2,5 \mathrm{~m} / \mathrm{s}^{84}$.

Los portadores de una mutación en BMPR2 tienen riesgo vitalicio del $20 \%$ de desarrollar HAP ${ }^{68,86}$. Actualmente no es posible predecir qué pacientes van a sufrir HAP, aunque las mujeres tienen mayor riesgo que los varones ${ }^{86}$. Para los pacientes portadores de esta mutación, se desconoce con qué frecuencia se debe realizar las pruebas de cribado. Actualmente se ofrece un estudio ecocardiográfico anual a los pacientes asintomáticos con resultado positivo de mutación asociada a la HAP y a los familiares de primer grado de pacientes con HAP heredable en los que no se han detectado estas mutaciones. Un estudio longitudinal actualmente en curso podría aclarar algunos aspectos sobre la estrategia de cribado óptima y los predictores del progreso de la HAP en portadores asintomáticos de la mutación en BMPR2 (DELPHI [NCT01600898]).

Se recomienda el cribado de HAP en la evaluación de pacientes referidos a trasplante hepático. La ecocardiografía con Doppler es la única modalidad de cribado que se ha evaluado sistemáticamente en la hipertensión portopulmonar (HPPo $)^{87}$. Las recomendaciones para el cribado de HAP se resumen en la tabla web 10.

\subsection{Medición de la calidad de vida}

La medición de la calidad de vida describe la propia percepción del paciente sobre su salud y cómo le afecta. Esta información es complementaria a la típica información clínica obtenida por los profesionales de la salud. Se ha demostrado que los cuestionarios generales sobre calidad de vida han sido útiles en la HAP, entre ellos el denominado Short Form Health Survey (SF-36) ${ }^{91}$, que incluye 36 preguntas y cuya puntuación sobre componentes físicos tuvo valor pronóstico en un estudio ${ }^{92}$. Dado que muchos cuestionarios genéricos sobre calidad de vida no reflejan bien el estado clínico en la $\mathrm{HAP}^{93}$, se han desarrollado y validado cuestionarios específicos para esta enfermedad. Estos son el Cambridge Pulmonary Hypertension Outcome Review (CAMPHOR) ${ }^{94-96}$, emPHasis-10 ${ }^{97}$, el Minnesota Living with Heart Failure-PH ${ }^{98,99}$ y la Pulmonary Arterial Hypertension Symptom Scale (PAHSS) ${ }^{100}$. Debido a que no se han realizado comparaciones directas, no se puede recomendar el uso de uno o de otro. 
Tabla web 10

Recomendaciones para el cribado de la hipertensión arterial pulmonar

\begin{tabular}{|c|c|c|c|}
\hline Recomendaciones & Clase $^{\mathrm{a}}$ & Nivel $^{\mathrm{b}}$ & $\operatorname{Ref}^{\mathrm{c}}$ \\
\hline Se recomienda la ecocardiografía de reposo como test de cribado para pacientes asintomáticos con esclerosis sistémica & I & B & 66,76 \\
\hline $\begin{array}{l}\text { Se recomienda la ecocardiografía de reposo como test de cribado para portadores de mutación en BMPR2 o familiares de primer grado } \\
\text { de pacientes con } \mathrm{HAPH} \text { y para pacientes con HPPo remitidos a trasplante hepático }\end{array}$ & I & $\mathrm{C}$ & 69,89 \\
\hline $\begin{array}{l}\text { Se debe considerar una aproximación combinada (que incluya biomarcadores, pruebas de función pulmonar y ecocardiografía) para predecir HP } \\
\text { en la esclerosis sistémica }\end{array}$ & IIa & B & 66,67 \\
\hline Se debe controlar estrechamente a los pacientes con esclerosis sistémica y PAPm de 21-24 mmHg debido al mayor riesgo de HAP & Ila & B & 75 \\
\hline $\begin{array}{l}\text { Se puede considerar un cribado inicial usando el algoritmo secuencial DETECT en pacientes adultos con esclerosis sistémica con más de } 3 \text { años } \\
\text { de evolución y una DLCO }<60 \% \text { de la predicha }\end{array}$ & IIb & B & 67 \\
\hline $\begin{array}{l}\text { Se puede considerar un cribado anual con ecocardiograma, pruebas de función pulmonar y biomarcadores para pacientes con esclerosis } \\
\text { sistémica }\end{array}$ & IIb & B & 66,90 \\
\hline $\begin{array}{l}\text { Se puede considerar un ecocardiograma anual de cribado para portadores confirmados de mutaciones causantes de HAP y familiares de primer } \\
\text { grado de casos de HAPH }\end{array}$ & IIb & $\mathrm{C}$ & 68 \\
\hline No se recomienda el ecocardiograma de esfuerzo para predecir HP en población de alto riesgo & III & $\mathrm{C}$ & 79 \\
\hline
\end{tabular}

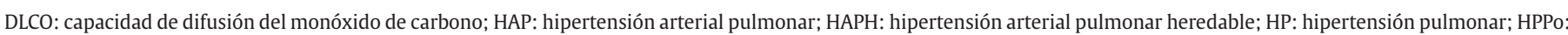
hipertensión portopulmonar; PAPm: presión arterial pulmonar media.

aClase de recomendación.

bNivel de evidencia.

'Referencias que respaldan las recomendaciones.

\subsection{Bibliografía}

1. Simonneau G, Gatzoulis MA, Adatia I, Celermajer D, Denton C, Ghofrani A, Gomez Sanchez MA, Krishna Kumar R, Landzberg M, Machado RF, Olschewski H, Robbins IM, Souza R. Updated clinical classification of pulmonary hypertension. J Am Coll Cardiol. 2013;62:D34-D41.

2. Simonneau G, Galiè N, Rubin LJ, Langleben D, Seeger W, Domenighetti G, Gibbs S, Lebrec D, Speich R, Beghetti M. Clinical classification of pulmonary hypertension. J Am Coll Cardiol. 2004;43(Suppl 1):S5-S12.

3. Ivy DD, Abman SH, Barst RJ, Berger RMF, Bonnet D, Fleming TR, Haworth SG, Raj JU, Rosenzweig EB, SchulzeNeick I, Steinhorn RH, Beghetti M. Pediatric pulmonary hypertension. J Am Coll Cardiol. 2013;62:D117-26.

4. Sitbon O, Brenot F, Denjean A, Bergeron A, Parent F, Azarian R, Herve P, Raffestin $\mathrm{B}$, Simonneau $\mathrm{G}$. Inhaled nitric oxide as a screening vasodilator agent in primary pulmonary hypertension. A dose-response study and comparison with prostacyclin. Am J Respir Crit Care Med. 1995;151:384-9.

5. Sitbon O, Humbert M, Jaïs X, Ioos V, Hamid AM, Provencher S, Garcia G, Parent F, Herve P, Simonneau G. Long-term response to calcium channel blockers in idiopathic pulmonary arterial hypertension. Circulation. 2005;111:3105-11.

6. Galiè N, Ussia G, Passarelli P, Parlangeli R, Branzi A, Magnani B. Role of pharmacologic tests in the treatment of primary pulmonary hypertension. Am J Cardiol. 1995; 75:55A-62A.

7. Rich S, Kaufmann E, Levy PS. The effect of high doses of calcium-channel blockers on survival in primary pulmonary hypertension [see comments]. N Engl J Med. 1992;327:76-81

8. Jing ZC, Jiang X, Han ZY, Xu XQ, Wang Y, Wu Y, Lv H, Ma CR, Yang YJ, Pu JL. Iloprost for pulmonary vasodilator testing in idiopathic pulmonary arterial hypertension. Eur Respir J. 2009;33:1354-60.

9. Barst RJ, McGoon M, Torbicki A, Sitbon O, Krowka MJ, Olschewski H, Gaine S. Diagnosis and differential assessment of pulmonary arterial hypertension. J Am Coll Cardiol. 2004;43(Suppl 1):S40-7.

10. Galiè N, Olschewski H, Oudiz RJ, Torres F, Frost A, Ghofrani HA, Badesch DB, McGoon MD, McLaughlin VV, Roecker EB, Gerber MJ, Dufton C, Wiens BL, Rubin LJ. Ambrisentan for the treatment of pulmonary arterial hypertension. Results of the ambrisentan in pulmonary arterial hypertension, randomized, double-blind, placebo-controlled, multicenter, efficacy (ARIES) study 1 and 2. Circulation. 2008; 117:3010-9.

11. Channick RN, Simonneau G, Sitbon O, Robbins IM, Frost A, Tapson VF, Badesch DB, Roux S, Rainisio M, Bodin F, Rubin LJ. Effects of the dual endothelinreceptor antagonist bosentan in patients with pulmonary hypertension: a randomised placebo-controlled study. Lancet. 2001;358:1119-23.

12. Rubin LJ, Badesch DB, Barst RJ, Galiè N, Black CM, Keogh A, Pulido T, Frost A, Roux S, Leconte I, Landzberg M, Simonneau G. Bosentan therapy for pulmonary arterial hypertension. N Engl J Med. 2002;346:896-903.

13. Galiè N, Rubin LJ, Hoeper M, Jansa P, Al-Hiti H, Meyer GMB, Chiossi E, Kusic-Pajic A, Simonneau G. Treatment of patients with mildly symptomatic pulmonary arterial hypertension with bosentan (EARLY study): a double-blind, randomised controlled trial. Lancet. 2008;371:2093-100.

14. Galiè N, Beghetti M, Gatzoulis MA, Granton J, Berger RMF, Lauer A, Chiossi E, Landzberg M, for the Bosentan Randomized Trial of Endothelin Antagonist Therapy. Bosentan therapy in patients with Eisenmenger syndrome: a multicenter, doubleblind, randomized, placebo-controlled study. Circulation. 2006;114:48-54.

15. McLaughlin V, Channick RN, Ghofrani HA, Lemarié JC, Naeije R, Packer M, Souza R, Tapson VF, Tolson J, Al Hit Hi, Meyer G, Hoeper MM. Bosentan added to sildenafil therapy in patients with pulmonary arterial hypertension. Eur Respir J. 2015;46:405-13.
16. Pulido T, Adzerikho I, Channick RN, Delcroix M, Galiè N, Ghofrani HA, Jansa P, Jing ZC, Le Brun FO, Mehta S, Mittelholzer CM, Perchenet L, Sastry BKS, Sitbon O, Souza R, Torbicki A, Zeng X, Rubin LJ, Simonneau G. Macitentan and morbidity and mortality in pulmonary arterial hypertension. New Engl J Med. 2013;369:809-18.

17. Ghofrani HA, Galiè N, Grimminger F, Grunig E, Humbert M, Jing ZC, Keogh AM Langleben D, Kilama MO, Fritsch A, Neuser D, Rubin LJ. Riociguat for the treatment of pulmonary arterial hypertension. N Engl J Med. 2013:369:330-40.

18. Galiè N, Muller K, Scalise AV, Grunig E. PATENT PLUS: a blinded, randomised and extension study of riociguat plus sildenafil in PAH. Eur Respir J. 2015;45:1314-22.

19. Galiè N, Ghofrani HA, Torbicki A, Barst RJ, Rubin LJ, Badesch D, Fleming T, Parpia T, Burgess G, Branzi A, Grimminger F, Kurzyna M, Simonneau G, for the Sildenafil Use in Pulmonary Arterial Hypertension (SUPER) Study Group. Sildenafil citrate therapy for pulmonary arterial hypertension. New Engl J Med. 2005;353: 2148-57.

20. Sastry BKS, Narasimhan C, Reddy NK, Raju BS. Clinical efficacy of sildenafil in primary pulmonary hypertension: a randomized, placebo-controlled, doubleblind, crossover study. J Am Coll Cardiol. 2004;43:1149-53.

21. Singh T, Rohit M, Grover A, Malhotra S, Vijayvergiya R. A randomized, placebocontrolled, double-blind, crossover study to evaluate the efficacy of oral sildenafil therapy in severe pulmonary artery hypertension. Am Heart J. 2006;151:851.e1-851.e5.

22. Simonneau G, Rubin L, Galiè N, Barst RJ, Fleming T, Frost A, Engel PJ, Kramer MR, Burgess G, Collings L, Cossons N, Sitbon O, Badesch BD, for the Pulmonary Arterial Hypertension Combination Study of Epoprostenol and Sildenafil (PACES) Study Group. Addition of sildenafil to long-term intravenous epoprostenol therapy in patients with pulmonary arterial hypertension. Ann Intern Med. 2008;149:521-30.

23. Iversen K, Jensen AS, Jensen TV, Vejlstrup NG, Søndergaard L. Combination therapy with bosentan and sildenafil in Eisenmenger syndrome: a randomized, placebo-controlled, double-blinded trial. Eur Heart J. 2010;31:1124-31.

24. Galiè N, Brundage BH, Ghofrani HA, Oudiz RJ, Simonneau G, Safdar Z, Shapiro S, White RJ, Chan M, Beardsworth A, Frumkin L, Barst RJ, on behalf of the Pulmonary Arterial Hypertension and Response to Tadalafil (PHIRST) Study Group. Tadalafil therapy for pulmonary arterial hypertension. Circulation. 2009;119:2894-903.

25. Jing ZC, Yu ZX, Shen JY, Wu BX, Xu KF, Zhu XY, Pan L, Zhang ZL, Liu XO, Zhang YS Jiang X, Galiè N, for the Efficacy and Safety of Vardenafil in the Treatment of Pulmonary Arterial Hypertension (EVALUATION) Study Group. Vardenafil in pulmonary arterial hypertension: a randomized, double-blind, placebocontrolled study. Am J Respir Crit Care Med. 2011:183:1723-9.

26. Galiè N, Humbert M, Vachiery JL, Vizza CD, Kneussl M, Manes A, Sitbon $O$, Torbicki A, Delcroix M, Naeije R, Hoeper M, Chaouat A, Morand S, Besse B, Simonneau G. Effects of beraprost sodium, an oral prostacyclin analogue, in patients with pulmonary arterial hypertension: a randomised, double-blind placebocontrolled trial. J Am Coll Cardiol. 2002;39:1496-502.

27. Barst RJ, McGoon M, McLaughlin VV, Tapson V, Rich S, Rubin L, Wasserman K, Oudiz R, Shapiro S, Robbins I, Channick R, Badesch BD, Rayburn BK, Flinchbaugh R, Sigman J, Arneson K, Jeffs R, for the Beraprost Study Group. Beraprost therapy for pulmonary arterial hypertension. J Am Coll Cardiol. 2003;41:2119-25.

28. Rubin LJ, Mendoza J, Hood M, McGoon M, Barst R, Williams WB, Diehl JH, Crow J, Long W. Treatment of primary pulmonary hypertension with continuous intravenous prostacyclin (epoprostenol). Results of a randomized trial. Ann Intern Med. 1990;112:485-91.

29. Barst RJ, Rubin LJ, Long WA, McGoon MD, Rich S, Badesch DB, Groves BM, Tapson VF, Bourge RC, Brundage BH. A comparison of continuous intravenous epoprostenol (prostacyclin) with conventional therapy for primary pulmonary hypertension. The Primary Pulmonary Hypertension Study Group [see comments]. N Engl J Med. 1996;334:296-302. 
30. Badesch DB, Tapson VF, McGoon MD, Brundage BH, Rubin LJ, Wigley FM, Rich S, Barst RJ, Barrett PS, Kral KM, Jobsis MM, Loyd JE, Murali S, Frost A, Girgis R, Bourge RC, Ralph DD, Elliott CG, Hill NS, Langleben D, Schilz RJ, McLaughlin VV, Robbins IM, Groves BM, Shapiro S, Medsger TA Jr. Continuous intravenous epoprostenol for pulmonary hypertension due to the scleroderma spectrum of disease. A randomized, controlled trial [see comments]. Ann Intern Med. 2000;132:425-34.

31. Olschewski H, Simonneau G, Galiè N, Higenbottam T, Naeije R, Rubin LJ, Nikkho S, Sitbon O, Speich R, Hoeper M, Behr J, Winkler J, Seeger W, for the AIR Study Group. Inhaled iloprost in severe pulmonary hypertension. $\mathrm{N}$ Engl J Med. 2002;347:322-9.

32. McLaughlin VV, Oudiz RJ, Frost A, Tapson VF, Murali S, Channick RN, Badesch DB, Barst RJ, Hsu HH, Rubin LJ. Randomized study of adding inhaled iloprost to existing bosentan in pulmonary arterial hypertension. Am J Respir Crit Care Med 2006; 174:1257-63.

33. Hoeper M, Leuchte H, Halank M, Wilkens H, Meyer FJ, Seyfarth HJ, Wensel R, Ripken F, Bremer H, Kluge S, Hoeffken G, Behr J. Combining inhaled iloprost with bosentan in patients with idiopathic pulmonary arterial hypertension. Eur Respir J. 2006;4:691-4.

34. Simonneau G, Barst RJ, Galiè N, Naeije R, Rich S, Bourge RC, Keogh A, Oudiz R, Frost A, Blackburn SD, Crow JW, Rubin LJ. Continuous subcutaneous infusion of treprostinil, a prostacyclin analogue, in patients with pulmonary arterial hypertension. A double-blind, randomized, placebo-controlled trial. Am J Respir Crit Care Med. 2002;165:800-4.

35. McLaughlin V, Rubin L, Benza RL, Channick R, Vosswinkel R, Tapson V, Robbins I, Olschewski H, Seeger W. Addition of inhaled treprostinil to oral therapy for pulmonary arterial hypertension: a randomized controlled clinical trial. J Am Coll Cardiol. 2010;55:1915-22.

36. Jing ZC, Parikh K, Pulido T, Jerjes-Sanchez C, White RJ, Allen R, Torbicki A, Xu KF, Yehle D, Laliberte K, Arneson C, Rubin LJ. Efficacy and safety of oral treprostinil monotherapy for the treatment of pulmonary arterial hypertension: a randomized, controlled trial. Circulation. 2013;127:624-33.

37. Tapson VF, Torres F, Kermeen F, Keogh AM, Allen RP, Frantz RP, Badesch DB, Frost AE, Shapiro SM, Laliberte K, Sigman J, Arneson C, Galiè N. Oral treprostinil for the treatment of pulmonary arterial hypertension in patients on background endothelin receptor antagonist and/or phosphodiesterase type 5 inhibito therapy (the FREEDOM-C study): a randomized controlled trial. Chest. 2012;142:1383-90.

38. Tapson VF, Jing ZC, Xu KF, Pan L, Feldman J, Kiely DG, Kotlyar E, McSwain CS Laliberte K, Arneson C. Oral treprostinil for the treatment of pulmonary arterial hypertension in patients on background endothelin receptor antagonist and/or phosphodiesterase type 5 inhibitor therapy (the FREEDOM-C2 study): a randomized controlled trial. Chest. 2013;144:952-8.

39. Simonneau G, Torbicki A, Hoeper MM, Delcroix M, Karlocai K, Galie N, Degano B Bonderman D, Kurzyna M, Efficace M, Giorgino R, Lang IM. Selexipag, an oral, selective prostacyclin receptor agonist for the treatment of pulmonary arterial hypertension. Eur Respir J. 2012;40:874-80.

40. McLaughlin VV, Channick R, Chin KM, Frey A, Gaine S, Ghofrani A, Hoeper M, Lang I, Preiss R, Rubin LJ, Simonneau G, Sitbon O, Stefani M, Tapson V, Galiè N. Effect of selexipag on morbidity/mortality in pulmonary arterial hypertension: results of the GRIPHON Study. J Am Coll Cardiol. 2015;65(Suppl A):A380.

41. Humbert M, Barst RJ, Robbins IM, Channick RN, Galie N, Boonstra A, Rubin LJ Horn EM, Manes A, Simonneau G. Combination of bosentan with epoprostenol in pulmonary arterial hypertension: BREATHE-2. Eur Respir J. 2004;24:353-9.

42. Galie N, Barbera JA, Frost A, Ghofrani A, Hoeper M, Mc Laughlin VV, Peacock A, Simonneau G, Vachiery JL, Grunig E, Oudiz RG, Vonk-Nordegraaf A, White J, Blai C, Gillies HC, Miller L, Harris JHN, Langley J, Rubin LJ. Initial Use of Ambrisentan plus Tadalafil in Pulmonary Arterial Hypertension. New Engl J Med. 2015;373:834-44.

43. Paul GA, Gibbs JS, Boobis AR, Abbas A, Wilkins MR. Bosentan decreases the plasma concentration of sildenafil when coprescribed in pulmonary hypertension. Br J Clin Pharmacol. 2005;60:107-12.

44. Wrishko RE, Dingemanse J, Yu A, Darstein C, Phillips DL, Mitchell MI. Pharmacokinetic interaction between tadalafil and bosentan in healthy male subjects. J Clin Pharmacol. 2008;48:610-8.

45. Montani D, Bergot E, Günther S, Savale L, Bergeron A, Bourdin A, Bouvaist $H$ Canuet M, Pison C, Macro M, Poubeau P, Girerd B, Natali D, Guignabert C, Perros F, O'Callaghan DS, Jaïs X, Tubert-Bitter P, Zalcman G, Sitbon O, Simonneau G, Humbert M. Pulmonary arterial hypertension in patients treated by dasatinib. Circulation. 2012;125:2128-37.

46. Adir Y, Humbert M. Pulmonary hypertension in patients with chronic myeloproliferative disorders. Eur Respir J. 2010;35:1396-406.

47. Lahm T, Chakinala MM.World Health Organization group 5 pulmonary hypertension. Clin Chest Med. 2013;34:753-78.

48. Toonkel RL, Borczuk AC, Pearson GD, Horn EM, Thomashow BM. Sarcoidosisassociated fibrosing mediastinitis with resultant pulmonary hypertension: a case report and review of the literature. Respiration. 2010;79:341-5.

49. Le Pavec J, Lorillon G, Jaïs X, Tcherakian C, Feuillet S, Dorfmuller P, Simonneau G, Humbert M, Tazi A. Pulmonary Langerhans cell histiocytosis-associated pulmonary hypertension: clinical characteristics and impact of pulmonary arterial hypertension therapies. Chest. 2012;142:1150-7.

50. Bogaard HJ, Al Husseini A, Farkas L, Farkas D, Gomez-Arroyo J, Abbate A, Voelkel NF. Severe pulmonary hypertension: the role of metabolic and endocrine disorders. Pulm Circ. 2012:2:148-54

51. Pietra GG, Capron F, Stewart S, Leone O, Humbert M, Robbins IM, Reid LM, Tuder RM. Pathologic assessment of vasculopathies in pulmonary hypertension. J Am Coll Cardiol. 2004;43(Suppl 1):S25-S32.
52. Tuder RM, Abman SH, Braun T, Capron F, Stevens T, Thistlethwaite PA, Haworth S. Pulmonary circulation: development and pathology. J Am Coll Cardiol. 2009;54(Suppl):S3-S9.

53. Fedullo PF, Auger WR, Kerr KM, Rubin LJ. Chronic thromboembolic pulmonary hypertension. N Engl J Med. 2001;345:1465-72.

54. Galiè N, Kim NHS. Pulmonary microvascular disease in chronic thromboembolic pulmonary hypertension. Proc Am Thorac Soc. 2006;3:571-76.

55. Dorfmü ller P, Günther S, Ghigna MR, Thomas de Montpréville V, Boulate D, Paul JF, Jaïs X, Decante B, Simonneau G, Dartevelle P, Humbert M, Fadel E, Mercier O. Microvascular disease in chronic thromboembolic pulmonary hypertension: a role for pulmonary veins and systemic vasculature. Eur Respir J. 2014:44:1275-88.

56. Humbert M, Morrell NW, Archer SL, Stenmark KR, MacLean MR, Lang IM, Christman BW, Weir EK, Eickelberg O, Voelkel NF, Rabinovitch M. Cellular and molecular pathobiology of pulmonary arterial hypertension. J Am Coll Cardiol. 2004;43(Suppl 1):S13-S24.

57. Hassoun PM, Mouthon L, Barbera JA, Eddahibi S, Flores SC, Grimminger F, LloydJones P, Maitland ML, Michelakis E, Morrell N, Newman B, Rabinovitch MSchermuly R, Stenmark KR, Voelkel N, Yuan JX, Humber DM. Inflammation, growth factors, and pulmonary vascular remodeling. J Am Coll Cardiol. 2009;54(Suppl):S10-9.

58. Morrell N, Adnot S, Archer S, Dupuis J, Jones P, MacLean MR, McMurtry IF, Stenmark KR, Thistlethwaite PA, Weissmann N, Yuan JX, Weir EK. Cellular and molecular basis of pulmonary arterial hypertension. J Am Coll Cardiol. 2009;54(Suppl):S20-S31.

59. Delgado JF, Conde E, Sánchez V, López-Rios F, Gómez-Sánchez MA, Escribano P, Sotelo T, Gómez de la Cámara A, Cortina J, de la Calzada CS. Pulmonary vascular remodeling in pulmonary hypertension due to chronic heart failure. Eur J Heart Fail. 2005; 7:1011-6.

60. Oudiz RJ. Pulmonary hypertension associated with left-sided heart disease. Clin Chest Med. 2007;28:233-41.

61. Vachiery JL, Coghlan G. Screening for pulmonary arterial hypertension in systemic sclerosis. Eur Respir Rev. 2009;18:162-9.

62. Condliffe R, Kiely D, Peacock AJ, Corris PA, Gibbs JS, Vrapi F, Das C, Elliot CA, Johnson M, DeSoyza J, Torpy C, Goldsmith K, Hodgkins D, Hughes RJ, Pepke-Zaba J, Coghlan JG. Connective tissue disease-associated pulmonary arterial hypertension in the modern treatment era. Am J Respir Crit Care Med. 2009;179:91-2.

63. Galiè N, Palazzini M, Manes A. Pulmonary arterial hypertension: from the kingdom of the near-dead to multiple clinical trial meta-analyses. Eur Heart J. 2010;31:2080-6.

64. Humbert M, Sitbon O, Chaouat A, Bertocchi M, Habib G, Gressin V, Yaici A, Weitzenblum E, Cordier JF, Chabot F, Dromer C, Pison C, Reynaud- Gaubert M, Haloun A, Laurent M, Hachulla E, Cottin V, Degano B, Jaïs X, Montani D, Souza R, Simonneau G. Survival in patients with idiopathic, familial, and anorexigenassociated pulmonary arterial hypertension in the modern management era. Circulation. 2010;122:156-63.

65. Wald NJ. The definition of screening. J Med Screen. 2001;8:1.

66. Khanna D, Gladue H, Channick R, Chung L, Distler O, Furst DE, Hachulla E, Humbert M, Langleben D, Mathai SC, Saggar R, Visovatti S, Altorok N, Townsend W, FitzGerald J, McLaughlin VV. Recommendations for screening and detection of connective tissue disease associated pulmonary arterial hypertension. Arthritis Rheum. 2013;65:3194-201.

67. Coghlan JG, Denton CP, Grünig E, Bonderman D, Distler O, Khanna D, MüllerLadner U, Pope JE, Vonk MC, Doelberg M, Chadha-Boreham H, Heinzl $\mathrm{H}$, Rosenberg DM, McLaughlin VV, Seibold JR, on behalf of the DETECT study group. Evidence-based detection of pulmonary arterial hypertension in systemic sclerosis: the DETECT study. Ann Rheum Dis. 2014;73:1340-9.

68. Soubrier F, Chung WK, Machado R, Grunig E, Aldred M, Geraci M, Loyd JE, Elliott CG, Trembath RC, Newman JH, Humbert M. Genetics and genomics of pulmonary arterial hypertension. J Am Coll Cardiol. 2013;62(Suppl):D13-D21.

69. Krowka MJ, Swanson KL, Frantz RP, McGoon MD, Wiesner RH. Portopulmonary hypertension: results from a 10-year screening algorithm. Hepatology. 2006;44:1502-10.

70. Steen V, Medsger TA. Predictors of isolated pulmonary hypertension in patients with systemic sclerosis and limited cutaneous involvement. Arthritis Rheum. 2003;48:516-22.

71. Schreiber BE, Valerio CJ, Keir GJ, Handler C, Wells AU, Denton CP, Coghlan JG. Improving the detection of pulmonary hypertension in systemic sclerosis using pulmonary function tests. Arthritis Rheum. 2011;63:3531-9.

72. Williams MH, Handler CE, Akram R, Smith CJ, Das C, Smee J, Nair D, Denton CP, Black CM, Coghlan JG. Role of N-terminal brain natriuretic peptide (N-TproBNP) in scleroderma-associated pulmonary arterial hypertension. Eur Heart J. 2006;27:1485-94.

73. Cavagna L, Caporali R, Klersy C, Ghio S, Albertini R, Scelsi L, Moratti R, Bonino C, Montecucco C. Comparison of brain natriuretic peptide (BNP) and NT-proBNP in screening for pulmonary arterial hypertension in patients with systemic sclerosis. J Rheumatol. 2010;37:2064-70.

74. Allanore Y, Borderie D, Avouac J, Zerkak D, Meune C, Hachulla E, Mouthon L, Guillevin L, Meyer O, Ekindjian OG, Weber S, Kahan A. High N-terminal probrain natriuretic peptide levels and low diffusing capacity for carbon monoxide as independent predictors of the occurrence of precapillary pulmonary arterial hypertension in patients with systemic sclerosis. Arthritis Rheum. 2008:58:284-91.

75. Valerio CJ, Schreiber BE, Handler CE, Denton CP, Coghlan JG. Borderline mean pulmonary artery pressure in patients with systemic sclerosis: transpulmonary gradient predicts risk of developing pulmonary hypertension. Arthritis Rheum. 2013;65:1074-84

76. Hachulla E, Gressin V, Guillevin L, Carpentier P, Diot E, Sibilia J, Kahan A, Cabane J, Frances C, Launay D, Mouthon L, Allanore Y, Kiet PT, Clerson P, de Groote P, 
Humbert M. Early detection of pulmonary arterial hypertension in systemic sclerosis: a French nationwide prospective multicenter study. Arthritis Rheum. 2005;52:3792-800.

77. Alkotob ML, Soltani P, Sheatt MA, Katsetos MC, Rothfield N, Hager WD, Foley RJ, Silverman DI. Reduced exercise capacity and stress-induced pulmonary hypertension in patients with scleroderma. Chest. 2006;130:176-81.

78. Huez S, Roufosse F, Vachiery JL, Pavelescu A, Derumeaux G, Wautrecht JC, Cogan E, Naeije R. Isolated right ventricular dysfunction in systemic sclerosis: latent pulmonary hypertension? Eur Respir J. 2007;30:928-36.

79. Grunig E, Weissmann S, Ehlken N, Fijalkowska A, Fischer C, Fourme T, Galie N, Ghofrani A, Harrison RE, Huez S, Humbert M, Janssen B, Kober J, Koehler R, Machado RD, Mereles D, Naeije R, Olschewski H, Provencher S, Reichenberger F, Retailleau K, Rocchi G, Simonneau G, Torbicki A, Trembath R, Seeger W. Stress Doppler echocardiography in relatives of patients with idiopathic and familial pulmonary arterial hypertension: results of a multicenter European analysis of pulmonary artery pressure response to exercise and hypoxia. Circulation. 2009;119:1747-57.

80. D'Alto M, Ghio S, D'Andrea A, Pazzano AS, Argiento P, Camporotondo R, Allocca F, Scelsi L, Cuomo G, Caporali R, Cavagna L, Valentini G, Calabro R. Inappropriate exercise-induced increase in pulmonary artery pressure in patients with systemic sclerosis. Heart. 2011;97:112-7.

81. Pavelescu A, Vanderpool R, Vachiery JL, Grunig E, Naeije R. Echocardiography of pulmonary vascular function in asymptomatic carriers of BMPR2 mutations. Eur Respir J. 2012;40:1287-9.

82. Hachulla E, Carpentier P, Gressin V, Diot E, Allanore Y, Sibilia J, Launay D, Mouthon L, Jego P, Cabane J, de Groote P, Chabrol A, Lazareth I, Guillevin L, Clerson P, Humbert $\mathrm{M}$, the ItinerAIR-Sclerodermie Study Investigators. Risk factors for death and the 3-year survival of patients with systemic sclerosis: the French ItinerAIR-Sclerodermie study. Rheumatology. 2009;48:304-8.

83. Gladwin MT, Sachdev V, Jison ML, Shizukuda Y, Plehn JF, Minter K, Brown B, Coles WA, Nichols JS, Ernst I, Hunter LA, Blackwelder WC, Schechter AN, Rodgers GP Castro O, Ognibene FP. Pulmonary hypertension as a risk factor for death in patients with sickle cell disease. N Engl J Med. 2004;350:886-95.

84. Parent F, Bachir D, Inamo J, Lionnet F, Driss F, Loko G, Habibi A, Bennani S, Savale L, Adnot S, Maitre B, Yaici A, Hajji L, O’Callaghan DS, Clerson P, Girot R, Galacteros F, Simonneau G. A hemodynamic study of pulmonary hypertension in sickle cell disease. N Engl J Med. 2011;365:44-53.

85. Fonseca GHH, Souza R, Salemi VMC, Jardim CVP, Gualandro SFM. Pulmonary hypertension diagnosed by right heart catheterisation in sickle cell disease. Eur Respir J. 2012;39:112-8.

86. Larkin EK, Newman JH, Austin ED, Hemnes AR, Wheeler L, Robbins IM, West JD, Phillips JA, Hamid R, Loyd JE. Longitudinal analysis casts doubt on the presence of genetic anticipation in heritable pulmonary arterial hypertension. Am J Respir Crit Care Med. 2012;186:892-6.

87. Colle IO, Moreau R, Godinho E, Belghiti J, Ettori F, Cohen-Solal A, Mal H, Bernuau J, Marty J, Lebrec D, Valla D, Durand F. Diagnosis of portopulmonary hypertension in candidates for liver transplantation: a prospective study. Hepatology. 2003;37:401-9.

88. Humbert M, Yaici A, de Groote P, Montani D, Sitbon O, Launay D, Gressin V Guillevin L, Clerson P, Simonneau G, Hachulla E. Screening for pulmonary arterial hypertension in patients with systemic sclerosis: clinical characteristics at diagnosis and long-term survival. Arthritis Rheum. 2011;63:3522-30.

89. CastroM, Krowka MJ, Schroeder DR, Beck KC, Plevak DJ, Rettke SR, Cortese DA, Wiesner RH. Frequency and clinical implications of increased pulmonary artery pressures in liver transplant patients. Mayo Clin Proc. 1996;71:543-51.

90. Hachulla E, de Groote P, Gressin V, Sibilia J, Diot E, Carpentier P, Mouthon L, Hatron PY, Jego P, Allanore Y, Tiev KP, Agard C, Cosnes A, Cirstea D, Constans J, Farge D, Villard JF, Harle JF, Patat F, Imbert B, Kahan A, Cabane J, Clerson P, Guillevin L, Humbert M. The 3-year incidence of pulmonary arterial hypertension associated with systemic sclerosis in a multicenter nationwide longitudinal study (ItinérAIR-Sclérodermie Study). Arthritis Rheum. 2009;60:1831-9.

91. Matura LA, McDonough A, Carroll DL. Health-related quality of life and psychological states in patients with pulmonary arterial hypertension. J Cardiovasc Nurs. 2014;29:178-84.

92. Fernandes CJ, Martins BC, Jardim CV, Ciconelli RM, Morinaga LK, Breda AP, Hoette S, Souza R. Quality of life as a prognostic marker in pulmonary arterial hypertension. Health Qual Life Outcomes. 2014;12:130.

93. Rubenfire M, Lippo G, Bodini BD, Blasi F, Allegra L, Bossone E. Evaluating healthrelated quality of life, work ability, and disability in pulmonary arteria hypertension: an unmet need. Chest. 2009;136:597-603.

94. McKenna S, Doughty N, Meads D, Doward L, Pepke-Zaba J. The Cambridge Pulmonary Hypertension Outcome Review (CAMPHOR): a measure of healthrelated quality of life and quality of life for patients with pulmonary hypertension. Qual Life Res. 2006;15:103-15.

95. Cima K, Twiss J, Speich R, McKenna SP, Grunig E, Kahler CM, Ehlken N, Treder U, Crawford SR, Huber LC, Ulrich S. The German adaptation of the Cambridge Pulmonary Hypertension Outcome Review (CAMPHOR). Health Qual Life Outcomes. 2012:10:110.

96. Swetz KM, Shanafelt TD, Drozdowicz LB, Sloan JA, Novotny PJ, Durst LA, Frantz RP, McGoon MD. Symptom burden, quality of life, and attitudes toward palliative care in patients with pulmonary arterial hypertension: results from a crosssectional patient survey. J Heart Lung Transplant. 2012;31:1102-8.

97. Yorke J, Corris P, Gaine S, Gibbs JS, Kiely DG, Harries C, Pollock V, Armstrong I. emPHasis-10: development of a health-related quality of life measure in pulmonary hypertension. Eur Respir J. 2014;43:1106-13.

98. Cenedese E, Speich R, Dorschner L, Ulrich S, Maggiorini M, Jenni R, Fischler M. Measurement of quality of life in pulmonary hypertension and its significance. Eur Respir J. 2006;28:808-15.
99. Zlupko M, Harhay MO, Gallop R, Shin J, Archer-Chicko C, Patel R, Palevsky HI, Taichman DB. Evaluation of disease-specific health-related quality of life in patients with pulmonary arterial hypertension. Respir Med. 2008;102:1431-8.

100. Matura LA, McDonough A, Hanlon AL, Carroll DL. Development and initia psychometric properties of the Pulmonary Arterial Hypertension Symptom Scale (PAHSS). Appl Nurs Res. 2015;28:42-7.

\section{APÉNDICE}

\section{Comité de la ESC para las guías de práctica clínica (CPG)}

José Luis Zamorano (coordinador) (España), Victor Aboyans (Francia), Stephan Achenbach (Alemania), Stefan Agewall (Noruega), Lina Badimon (España), Gonzalo Barón-Esquivias (España), Helmut Baumgartner (Alemania), Jeroen J. Bax (Países Bajos), Héctor Bueno (España), Scipione Carerj (Italia), Veronica Dean (Francia), Çetin Erol (Turkey), Donna Fitzsimons (Reino Unido), Oliver Gaemperli (Suiza), Paulus Kirchhof (Alemania/Reino Unido), Philippe Kolh (Bélgica), Patrizio Lancellotti (Bélgica), Gregory Y.H. Lip (Reino Unido), Petros Nihoyannopoulos (Reino Unido), Massimo F. Piepoli (Italia), Piotr Ponikowski (Polonia), Marco Roffi (Suiza), Adam Torbicki (Polonia), Antonio Vaz Carneiro (Portugal) y Stephan Windecker (Suiza).

Sociedades Nacionales de Cardiología de la ESC que han colaborado activamente en el proceso de revisión de la Guía ESC 2015 sobre diagnóstico y tratamiento de la hipertensión pulmonar

Albania: Sociedad Albana de Cardiología, Sokol Myftiu; Alemania: Sociedad Alemana de Cardiología, Christian Opitz; Antigua República Yugoslava de Macedonia: Sociedad Macedonia de Cardiología, Elizabeta Srbinovska-Kostovska; Austria: Sociedad Austriaca de Cardiología, Diana Bonderman; Azerbaiyán: Sociedad Azerbaiyana de Cardiología, Ibrahimov Firdovsi; Bélgica: Sociedad Belga de Cardiología, Michel De Pauw; Bielorrusia: Sociedad Cientifíca Bielorrusa de Cardiólogos, Irina Lazareva; Bosnia-Herzegovina: Asociación de Cardiólogos de Bosnia-Herzegovina, Sekib Sokolovi'c; Bulgaria: Sociedad Búlgara de Cardiología, Vasil Velchev; Croacia: Sociedad Croata de Cardiología, Maja Cikes; Chipre: Sociedad Chipriota de Cardiología, Josef Antoniou Moutiris; Dinamarca: Sociedad Danesa de Cardiología, Jens Erik Nielsen-Kudsk; Eslovaquia: Sociedad Eslovaca de Cardiología, Iveta Simková; Estonia: Sociedad Estonia de Cardiología, Ly Anton; Finlandia: Sociedad Finlandesa de Cardiología, Pertti Jääskeläinen; Francia: Sociedad Francesa de Cardiología, Fabrice Bauer; Georgia: Sociedad Georgiana de Cardiología, Archil Chukhrukidze; Grecia: Sociedad Cardiológica Helena, George Giannakoulas; Hungría: Sociedad Húngara de Cardiología, Kristóf Karlócai; Irlanda: Fundación Irlandesa del Corazón, Sean Gaine; Islandia: Sociedad Islandesa de Cardiología, Hjörtur Oddsson; Israel: Sociedad del Corazón del Israel, Doron Menachemi; Italia: Federación Italiana de Cardiología, Michele Emdin; Kirguistán: Sociedad de Cardiología de Kirguistán, Talant Sooronbaev; Letonia: Sociedad Letona de Cardiología, Ainars Rudzitis; Lituania: Sociedad Lituana de Cardiología, Lina Gumbiene; Luxemburgo: Sociedad de Cardiología de Luxemburgo, Frederic Lebrun; Malta: Sociedad Maltesa de Cardiología, Josef Micallef; Marruecos: Sociedad Marroquí de Cardiología, Latifa Oukerraj; Moldavia: Sociedad Moldava de Cardiología, Victor Botnaru; Noruega: Sociedad Noruega de Cardiología, Arne K. Andreassen; Países Bajos: Sociedad Holandesa de Cardiología, Arie P.J. van Dijk; Polonia: Sociedad Polaca de Cardiología, Marcin Kurzyna; Portugal: Sociedad Portuguesa de Cardiología, Maria Joaõ Ribeiro Leite Baptista; Reino Unido: Sociedad Cardiovascular Británica, Gerry Coghlan; República Checa: Sociedad Checa de Cardiología, Pavel Jansa; Rumania: Sociedad Rumana de Cardiología, Ioan Mircea Coman; Rusia: Sociedad Rusa de Cardiología, Olga Moiseeva; Serbia: Sociedad de Cardiología de Serbia, Branislav S. Stefanovic; Suecia: Sociedad Sueca de Cardiología, Gerhard Wikström; Suiza: Sociedad Suiza de Cardiología, Markus Schwerzmann; Túnez: Sociedad Tunecina de Cardiología y Cirugía Cardiovascular, Abdallah Mahdhaoui; Turquía: Sociedad Turca de Cardiología, Cihangir Kaymaz; Ucrania: Asociación Ucraniana de Cardiología, Yuriy Sirenko. 
El texto CME de la "Guía ESC 2015 sobre diagnóstico y tratamiento de la hipertensión pulmonar » está acreditado por el European Board for Accreditation in Cardiology (EBAC). El EBAC trabaja de acuerdo con los estándares de calidad del European Accreditation Council for Continuing Medical Education (EACCME), institución dependiente de la European Union of Medical Specialists (UEMS). En cumplimiento con las guías EBAC/EACCME, todos los autores participantes en este programa han declarado sus potenciales conflictos de intereses que pudieran afectar a este documento. El Comité Organizador es responsable de asegurar que todos los potenciales conflictos de intereses relevantes al programa sean declarados a los participantes antes de iniciar las actividades CME.

Las preguntas sobre esta CME para este artículo están disponibles en European Heart Journal (http://www.oxforde-learning.com/eurheartj) y en la página web de la Sociedad Europea de Cardiología (http://www.escardio.org/guidelines).

\section{BIBLIOGRAFÍA}

1. Hoeper MM, Bogaard HJ, Condliffe R, Frantz R, Khanna D, Kurzyna M, Langleben D, Manes A, Satoh T, Torres F,Wilkins MR, Badesch DB. Definitions and diagnosis of pulmonary hypertension. J Am Coll Cardiol. 2013;62(Suppl):D42-D50.

2. Kovacs G, Berghold A, Scheidl S, Olschewski H. Pulmonary arterial pressure during rest and exercise in healthy subjects A systematic review. Eur Respir J. 2009;34:888-94.

3. Herve P, Lau E, Sitbon O, Savale L, Montani D, Godinas L, Lador F, Jaïs X, Parent F, Günther S, Humbert M, Simonneau G, Chemla D. Criteria for diagnosis of exercise pulmonary hypertension. Eur Respir J. 2015;46:728-37.

4. Vachiery JL, Adir Y, Barbera JA, Champion HC, Coghlan JG, Cottin V, DeMarco T, Galiè N, Ghio S, Gibbs JS, Martinez FJ, Semigran MJ, Simonneau G, Wells AU, Seeger W. Pulmonary hypertension due to left heart disease. J Am Coll Cardiol. 2013;62:D100-8.

5. Simonneau G, Galiè N, Rubin LJ, Langleben D, Seeger W, Domenighetti G, Gibbs S, Lebrec D, Speich R, Beghetti M. Clinical classification of pulmonary hypertension. J Am Coll Cardiol. 2004;43(Suppl 1):S5-S12.

6. Simonneau G, Gatzoulis MA, Adatia I, Celermajer D, Denton C, Ghofrani A, Gomez Sanchez MA, Krishna Kumar R, Landzberg M, Machado RF, Olschewski H, Robbins IM, Souza R. Updated clinical classification of pulmonary hypertension. J Am Coll Cardiol. 2013;62:D34-D41.

7. Dhillon R. The management of neonatal pulmonary hypertension. Arch Dis Child Fetal Neonatal Ed. 2012;97:F223-8.

8. Porta NF, Steinhorn RH. Pulmonary vasodilator therapy in the NICU: inhaled nitric oxide, sildenafil, and other pulmonary vasodilating agents. Clin Perinatol. 2012;39:149-64

9. Ivy DD, Abman SH, Barst RJ, Berger RMF, Bonnet D, Fleming TR, Haworth SG, Raj JU, Rosenzweig EB, Schulze Neick I, Steinhorn RH, Beghetti M. Pediatric pulmonary hypertension. J Am Coll Cardiol. 2013;62:D117-26.

10. Humbert M, Sitbon O, Chaouat A, Bertocchi M, Habib G, Gressin V, Yaici A, Weitzenblum E, Cordier JF, Chabot F, Dromer C, Pison C, Reynaud-Gaubert M Haloun A, Laurent M, Hachulla E, Simonneau G. Pulmonary arterial hypertension in France: results from a national registry. Am J Respir Crit Care Med. 2006;173:1023-30.

11. Peacock AJ, Murphy NF, McMurray JJV, Caballero L, Stewart S. An epidemiological study of pulmonary arterial hypertension. Eur Respir J. 2007;30:104-9.

12. McGoon MD, Benza RL, Escribano-Subias P, Jiang X, Miller DP, Peacock AJ, PepkeZaba J, Pulido T, Rich S, Rosenkranz S, Suissa S, Humbert M. Pulmonary arteria hypertension: epidemiology and registries. J Am Coll Cardiol. 2013;62(Suppl): D51-D59.

13. Simonneau G, Robbins I, Beghetti M, Channick RN, Delcroix M, Denton CP, Elliott CG, Gaine S, Gladwin MT, Jing ZC, Krowka MJ, Langleben D, Nakanishi N, Souza R. Updated clinical classification of pulmonary hypertension. J Am Coll Cardiol 2009;54(Suppl):S43-S54.

14. Montani D, Bergot E, Günther S, Savale L, Bergeron A, Bourdin A, Bouvaist $H$ Canuet M, Pison C, Macro M, Poubeau P, Girerd B, Natali D, Guignabert C, Perros F, O'Callaghan DS, Jaïs X, Tubert-Bitter P, Zalcman G, Sitbon O, Simonneau G, Humbert M. Pulmonary arterial hypertension in patients treated by dasatinib. Circulation. 2012;125:2128-37.

15. Savale L, Chaumais MC, Cottin V, Bergot E, Frachon I, Prevot G, Pison C, Dromer C Poubeau P, Lamblin N, Habib G, Reynaud-Gaubert M, Bourdin A, Sanchez O, Tubert-Bitter P, Jaïs X, Montani D, Sitbon O, Simonneau G, Humbert M. Pulmonary hypertension associated with benfluorex exposure. Eur Respir J. 2012;40:1164-72.

16. Savale L, Sattler C, Gunther S, Montani D, Chaumais MC, Perrin S, Jaïs X, Seferian A, Jovan R, Bulifon S, Parent F, Simonneau G, Humbert M, Sitbon O. Pulmonary arterial hypertension in patients treated with interferon. Eur Respir J. 2014; 44:1627-34

17. Badesch BD, Champion HC, Gomez-Sanchez MA, Hoeper M, Loyd J, Manes A, McGoon M, Naeije R, Olschewski H, Oudiz R, Torbicki A. Diagnosis and assessment of pulmonary arterial hypertension. J Am Coll Cardiol. 2009;54(Suppl):S55-6.

18. Oudiz RJ. Pulmonary hypertension associated with left-sided heart disease. Clin Chest Med. 2007;28:233-41.

19. Vahanian A Alfieri O, Andreotti $F$ Antunes MJ, Baron-Esquivias G, Baumgartner H, Borger MA, Carrel TP, De Bonis M, Evangelista A, Falk V, Iung B, Lancellotti P, Pierard L, Price S, Schafers HJ, Schuler G, Stepinska J, Swedberg K, Takkenberg J, Von Oppell UO, Windecker S, Zamorano JL, Zembala M. Guidelines on the management of valvular heart disease (version 2012). Eur Heart J. 2012;33:2451-96.

20. Seeger W, Adir Y, Barberà JA, Champion H, Coghlan JG, Cottin V, De Marco T, Galiè N, Ghio S, Gibbs S, Martinez FJ, Semigran MJ, Simonneau G, Wells AU, Vachiéry JL. Pulmonary hypertension in chronic lung diseases. J Am Coll Cardiol. 2013;62(Suppl):D109-16

21. Hurdman J, Condliffe R, Elliot CA, Swift A, Rajaram S, Davies C, Hill C, Hamilton N Armstrong IJ, Billings C, Pollard L, Wild JM, Lawrie A, Lawson R, Sabroe I, Kiely DC.
Pulmonary hypertension in COPD: results from the ASPIRE registry. Eur Respir J. 2013;41:1292-301.

22. Cottin V, Nunes H, Brillet PY, Delaval P, Devouassoux G, Tillie-Leblond I IsraelBiet D, Court-Fortune, Valeyre D, Cordier JF. Combined pulmonary fibrosis and emphysema: a distinct underrecognised entity. Eur Respir J. 2005;26:586-93.

23. Escribano-Subias P, Blanco I, Lopez-Meseguer M, Lopez-Guarch CJ, Roman A, Morales P, Castillo-Palma MJ, Segovia J, Gomez-Sanchez MA, Barbera JA. Survival in pulmonary hypertension in Spain: insights from the Spanish registry. Eur Respir J. 2012;40:596-603.

24. Pengo V, Lensing AW, Prins MH, Marchiori A, Davidson BL, Tiozzo F, Albanese P, Biasiolo A, Pegoraro C, Iliceto S, Prandoni P. Incidence of chronic thromboembolic pulmonary hypertension after pulmonary embolism. $N$ Engl J Med. 2004:350:2257-64.

25. Pepke-Zaba J, Delcroix M, Lang I, Mayer E, Jansa P, Ambroz D, Treacy C, D'Armini AM, Morsolini M, Snijder R, Bresser P, Torbicki A, Kristensen B, Lewczuk J, Simkova I, Barberà JA, de Perrot M, Hoeper MM, Gaine S, Speich R, GomezSanchez MA, Kovacs G, Hamid AM, Jaïs X, Simonneau G. Chronic thromboembolic pulmonary hypertension (CTEPH): results from an international prospective registry. Circulation. 2011;124:1973-81.

26. Soubrier F, Chung WK, Machado R, Grunig E, Aldred M, Geraci M, Loyd JE, Elliott CG, Trembath RC, Newman JH, Humbert M. Genetics and genomics of pulmonary arterial hypertension. J Am Coll Cardiol. 2013;62(Suppl):D13-D21.

27. Ma L, Roman-Campos D, Austin ED, Eyries M, Sampson KS, Soubrier F, Germain M, Tregouet DA, Borczuk A, Rosenzweig EB, Girerd B, Montani D, Humbert M, Loyd JE, Kass RS, Chung WK. A novel channelopathy in pulmonary arterial hypertension. N Engl J Med. 2013;369:351-61.

28. Eyries M, Montani D, Girerd B, Perret C, Leroy A, Lonjou C, Chelghoum N, Coulet F, Bonnet D, Dorfmuller P, Fadel E, Sitbon O, Simonneau G, Tregouet DA, Humbert $\mathrm{M}$, Soubrier F. EIF2AK4 mutations cause pulmonary veno-occlusive disease, a recessive form of pulmonary hypertension. Nat Genet. 2014;46:65-9.

29. Eddahibi S, Chaouat A, Morrell N, Fadel E, Fuhrman C, Bugnet AS, Dartevelle P, Housset B, Hamon M, Weitzenblum E, Adnot S. Polymorphism of the serotonin transporter gene and pulmonary hypertension in chronic obstructive pulmonary disease Circulation. 2003:108:1839-44.

30. Bonderman D, Wexberg P, Martischnig AM, Heinzl H, Lang MB, Sadushi R, SkoroSajer N, Lang IM. A noninvasive algorithm to exclude pre-capillary pulmonary hypertension. Eur Respir J. 2011;37:1096-103.

31. Rich JD, Thenappan T, Freed B, Patel AR, Thisted RA, Childers R, Archer SL. OTc prolongation is associated with impaired right ventricular function and predicts mortality in pulmonary hypertension. Int J Cardiol. 2013;167:669-76.

32. Sun PY, Jiang X, Gomberg-Maitland M, Zhao QH, He J, Yuan P, Zhang R, Jing ZC. Prolonged QRS duration: a new predictor of adverse outcome in idiopathic pulmonary arterial hypertension. Chest. 2012;141:374-80.

33. Olsson KM, Nickel NP, Tongers J, Hoeper MM. Atrial flutter and fibrillation in patients with pulmonary hypertension. Int J Cardiol. 2013;167:2300-5.

34. Rich S, Dantzker DR, Ayres SM, Bergofsky EH, Brundage BH, Detre KM, Fishman AP, Goldring RM, Groves BM, Koerner SK. Primary pulmonary hypertension: a national prospective study. Ann Intern Med. 1987;107:216-23.

35. Milne EN. Forgotten gold in diagnosing pulmonary hypertension: the plain chest radiograph. Radiographics. 2012;32:1085-7.

36. Trip P, Nossent EJ, de Man FS, van den Berk IA, Boonstra A, Groepenhoff $H$, Leter EM,Westerhof N, Grunberg K, Bogaard HJ, Vonk-Noordegraaf A. Severely reduced diffusion capacity in idiopathic pulmonary arterial hypertension: patient characteristics and treatment responses. Eur Respir J. 2013;42:1575-85.

37. Sun XG, Hansen JE, Oudiz RJ,Wasserman K. Pulmonary function in primary pulmonary hypertension. J Am Coll Cardiol. 2003;41:1028-35.

38. Hoeper MM, Pletz MW, Golpon H, Welte T. Prognostic value of blood gas analyses in patients with idiopathic pulmonary arterial hypertension. Eur Respir J. 2007;29:944-50.

39. Pellegrino R, Viegi G, Brusasco V, Crapo RO, Burgos F, Casaburi R, Coates A, van der Grinten CP, Gustafsson P, Hankinson J, Jensen R, Johnson DC, Macintyre N, McKay R, Miller MR, Navajas D, Pedersen OF,Wanger J. Interpretative strategies for lung function tests. Eur Respir J. 2005;26:948-68.

40. Holverda S, Bogaard HJ, Groepenhoff H, Postmus PE, Boonstra A, VonkNoordegraaf A. Cardiopulmonary exercise test characteristics in patients with chronic obstructive pulmonary disease and associated pulmonary hypertension. Respiration. 2008;76:160-7.

41. Jilwan FN, Escourrou P, Garcia G, Jaïs X, Humbert M, Roisman G. High occurrence of hypoxemic sleep respiratory disorders in precapillary pulmonary hypertension and mechanisms. Chest. 2013;143:47-55.

42. Rafanan AL, Golish JA, Dinner DS, Hague LK, Arroliga AC. Nocturnal hypoxemia is common in primary pulmonary hypertension. Chest. 2001:120:894-9.

43. Rudski LG, Lai WW, Afilalo J, Hua L, Handschumacher MD, Chandrasekaran K, Solomon SD, Louie EK, Schiller NB. Guidelines for the echocardiographic assessment of the right heart in adults: a report from the American Society 
of Echocardiography endorsed by the European Association of Echocardiography, a registered branch of the European Society of Cardiology, and the Canadian Society of Echocardiography. J Am Soc Echocardiogr. 2010; 23:685-713.

44. Lang RM, Badano LP, Mor-Avi V, Afilalo J, Armstrong A, Ernande L, Flachskampf FA, Foster E, Goldstein SA, Kuznetsova T, Lancellotti P, Muraru D, Picard MH, Rietzschel ER, Rudski L, Spencer KT, TsangW, Voigt JU. Recommendations for cardiac chamber quantification by echocardiography in adults: an update from the American Society of Echocardiography and the European Association of Cardiovascular Imaging. Eur Heart J Cardiovasc Imaging. 2015;16:233-71.

45. Foale R, Nihoyannopoulos P, McKenna W, Kleinebenne A, Nadazdin A, Rowland E, Smith G. Echocardiographic measurement of the normal adult right ventricle. $\mathrm{Br}$ Heart J. 1986;56:33-44.

46. Hachulla E, Gressin V, Guillevin L, Carpentier P, Diot E, Sibilia J, Kahan A, Cabane J. Frances C, Launay D, Mouthon L, Allanore Y, Kiet PT, Clerson P, de Groote P, Humbert M. Early detection of pulmonary arterial hypertension in systemic sclerosis: a French nationwide prospective multicenter study. Arthritis Rheum. 2005; $52: 3792-800$.

47. Tunariu N, Gibbs SJR, Win Z, Gin-Sing W, Graham A, Gishen P, AL-Nahhas A. Ventilation-perfusion scintigraphy Is more sensitive than multidetector CTPA in detecting chronic thromboembolic pulmonary disease as a treatable cause of pulmonary hypertension. J Nucl Med. 2007;48:680-4.

48. Meng JJ, Zhang LJ, Wang Q Fang W, Dai HJ, Yan J, Wang T, Yao ZM, He J, Li M, Mi $\mathrm{HZ}$, Jiao J, Zheng YM. [A comparison of ventilation/perfusion single photon emission CT and CT pulmonary angiography for diagnosis of pulmonary embolism]. Zhonghua Jie He He Hu Xi Za Zhi. 2013;36:177-81.

49. Rajaram S, Swift AJ, Telfer A, Hurdman J, Marshall H, Lorenz E, Capener D, Davies C, Hill C, Elliot C, Condliffe R, Wild JM, Kiely DG. 3D contrast-enhanced lung perfusion MRI is an effective screening tool for chronic thromboembolic pulmonary hypertension: results from the ASPIRE Registry. Thorax. 2013;68:677-8.

50. Rajaram S, Swift AJ, Condliffe R, Johns C, Elliot CA, Hill C, Davies C, Hurdman J, Sabroe I, Wild JM, Kiely DG. CT features of pulmonary arterial hypertension and its major subtypes: a systematic CT evaluation of 292 patients from the ASPIRE Registry. Thorax. 2015;70:382-7.

51. Shen Y,Wan C, Tian P, WuY, Li X, Yang T, An J.Wang T, Chen L,Wen F. CT-base pulmonary artery measurement in the detection of pulmonary hypertension: a meta-analysis and systematic review. Medicine (Baltimore). 2014;93:e256.

52. Tan RT, Kuzo R, Goodman LR, Siegel R, Haasler GB, Presberg KW. Utility of CT scan evaluation for predicting pulmonary hypertension in patients with parenchymal lung disease. Chest. 1998;113:1250-6.

53. Resten A, Maitre S, Humbert M, Rabiller A, Sitbon O, Capron F, Simonneau G, Musset D. Pulmonary hypertension: $\mathrm{CT}$ of the chest in pulmonary venoocclusive disease. Am J Roentgenol. 2004;183:65-70.

54. Dartevelle P, Fadel E, Mussot S, Chapelier A, Herve P, de Perrot M, Cerrina J, Ladurie FL, Lehouerou D, Humbert M, Sitbon O, Simonneau G. Chronic thromboembolic pulmonary hypertension. Eur Respir J. 2004:23:637-48.

55. Reichelt A, Hoeper MM, Galanski M, Keberle M. Chronic thromboembolic pulmonary hypertension: evaluation with 64-detector row CT versus digital substraction angiography. Eur J Radiol. 2008;71:49-54.

56. Fedullo PF, Auger WR, Kerr KM, Rubin LJ. Chronic thromboembolic pulmonary hypertension. N Engl J Med. 2001;345:1465-72.

57. Fukui S, Ogo T, Morita Y, Tsuji A, Tateishi E, Ozaki K, Sanda Y, Fukuda T, Yasuda S, Ogawa $\mathrm{H}$, Nakanishi $\mathrm{N}$. Right ventricular reverse remodelling after balloon pulmonary angioplasty. Eur Respir J. 2014;43:1394-402.

58. Castaner E, Alguersuari A, Andreu M, Gallardo X, Spinu C, Mata JM. Imaging findings in pulmonary vasculitis. Semin Ultrasound CT MR. 2012:33:567-79.

59. Nawaz A, Litt HI, Stavropoulos SW, Charagundla SR, Shlansky-Goldberg RD, Freiman DB, Chittams J, Pyeritz RE, Trerotola SO. Digital subtraction pulmonary arteriography versus multidetector CT in the detection of pulmonary arteriovenous malformations. J Vasc Interv Radiol. 2008;19:1582-8.

60. Peacock AJ, Vonk Noordegraaf A. Cardiac magnetic resonance imaging in pulmonary arterial hypertension. Eur Respir Rev. 2013;22:526-34.

61. Swift AJ, Rajaram S, Condliffe R, Capener D, Hurdman J, Elliot CA, Wild JM, Kiely DG. Diagnostic accuracy of cardiovascular magnetic resonance imaging of right ventricular morphology and function in the assessment of suspected pulmonary hypertension results from the ASPIRE registry. J Cardiovasc Magn Reson. 2012; $14: 40-50$.

62. Swift AJ, Rajaram S, Hurdman J, Hill C, Davies C, Sproson TW, Morton AC, Capener D, Elliot C, Condliffe R, Wild JM, Kiely DG. Noninvasive estimation of PA pressure, flow, and resistance with CMR imaging: derivation and prospective validation study from the ASPIRE registry. JACC Cardiovasc Imaging. 2013;6:1036-47.

63. Ley S, Kauczor HU, Heussel CP, Kramm T, Mayer E, Thelen M, Kreitner KF. Value of contrast-enhanced MR angiography and helical CT angiography in chronic thromboembolic pulmonary hypertension. Eur Radiol. 2003;13:2365-71.

64. van Wolferen SA, Marcus JT, Boonstra A, Marques KMJ, Bronzwaer JGF, Spreeuwenberg MD, Postmus PE, Vonk-Noordegraaf A. Prognostic value of right ventricular mass, volume, and function in idiopathic pulmonary arterial hypertension. Eur Heart J. 2007;28:1250-7.

65. Peacock AJ, Crawley S, McLure L, Blyth K, Vizza CD, Poscia R, Francone M, Iacucci I, Olschewski H, Kovacs G, VonkNoordegraaf A, Marcus JT, van de Veerdonk MC, Oosterveer FPT. Changes in right ventricular function measured by cardiac magnetic resonance imaging in patients receiving pulmonary arterial hypertension-targeted therapy: the EURO-MR Study. Circ Cardiovasc Imaging. 2014; 7:107-14.

66. van de Veerdonk MC, Kind T, Marcus JT, Mauritz GJ, Heymans MW, Bogaard HJ, Boonstra A, Marques KM, Westerhof N, Vonk-Noordegraaf A. Progressive right ventricular dysfunction in patients with pulmonary arterial hypertension responding to therapy. J Am Coll Cardiol. 2011;58:2511-9.

67. Albrecht T, Blomley MJ, Cosgrove DO, Taylor-Robinson SD, Jayaram V, Eckersley R, Urbank A, Butler-Barnes J, Patel N. Non-invasive diagnosis of hepatic cirrhosis by transit-time analysis of an ultrasound contrast agent. Lancet. 1999;353:1579-83.

68. Naeije R. Hepatopulmonary syndrome and portopulmonary hypertension. Swiss Med Wkly. 2003;133:163-9.

69. Hoeper MM, Lee SH, Voswinckel R, Palazzini M, Jaïs X, Marinelli A, Barst RJ Ghofrani HA, Jing ZC, Opitz C, Seyfarth HJ, Halank M, McLaughlin V, Oudiz RJ, Ewert R, Wilkens H, Kluge S, Bremer HC, Baroke E, Rubin LJ. Complications of right heart catheterization procedures in patients with pulmonary hypertension in experienced centers. J Am Coll Cardiol. 2006;48:2546-52.

70. Kovacs G, Avian A, Pienn M, Naeije R, Olschewski H. Reading pulmonary vascular pressure tracings. How to handle the problems of zero leveling and respiratory swings. Am J Respir Crit Care Med. 2014;190:252-7.

71. Hoeper MM, Maier R, Tongers J, Niedermeyer J, Hohlfeld JM, Hamm M, Fabel H Determination of cardiac output by the Fick method, thermodilution, and acetylene rebreathing in pulmonary hypertension. Am J Respir Crit Care Med. 1999; $160: 535-41$.

72. Frost AE, FarberHW, Barst RJ, Miller DP, Elliott CG, McGoon MD. Demographics and outcomes of patients diagnosed with pulmonary hypertension with pulmonary capillary wedge pressures 16 to $18 \mathrm{~mm} \mathrm{Hg}$ : insights from the REVEAL Registry. Chest. 2013;143:185-95.

73. AbrahamWT, Adamson PB, Bourge RC, Aaron MF, Costanzo MR, Stevenson LW, Strickland W, Neelagaru S, Raval N, Krueger S, Weiner S, Shavelle D, Jeffries B, Yadav JS. Wireless pulmonary artery haemodynamic monitoring in chronic heart failure: a randomised controlled trial. Lancet. 2011;377:658-66.

74. Prasad A, Hastings JL, Shibata S, Popovic ZB, Arbab-Zadeh A, Bhella PS, Okazaki K, Fu Q Berk M, Palmer D, Greenberg NL, Garcia MJ, Thomas JD, Levine BD. Characterization of static and dynamic left ventricular diastolic function in patients with heart failure with a preserved ejection fraction. Circ Heart Fail. 2010;3:617-26

75. Fujimoto N, Borlaug BA, Lewis GD, Hastings JL, Shafer KM, Bhella PS, CarrickRanson G, Levine BD. Hemodynamic responses to rapid saline loading: the impact of age, sex, and heart failure. Circulation. 2013;127:55-62.

76. Fox BD, Shimony A, Langleben D, Hirsch A, Rudski L, Schlesinger R, Eisenberg MJ, Joyal D, Hudson M, Boutet K, Serban A, Masetto A, Baron M. High prevalence of occult left heart disease in scleroderma-pulmonary hypertension. Eur Respir J. 2013:42:1083-91.

77. Robbins IM, Hemnes AR, Pugh ME, Brittain EL, Zhao DX, Piana RN, Fong PP Newman JH. High prevalence of occult pulmonary venous hypertension revealed by fluid challenge in pulmonary hypertension. Circ Heart Fail. 2014;7:116-22.

78. Borlaug BA, Nishimura RA, Sorajja P, Lam CS, Redfield MM. Exercise hemodynamics enhance diagnosis of early heart failure with preserved ejection fraction. Circ Heart Fail. 2010;3:588-95.

79. Hager WD, Collins I, Tate JP, Azrin M, Foley R, Lakshminarayanan S, Rothfield NF Exercise during cardiac catheterization distinguishes between pulmonary and left ventricular causes of dyspnea in systemic sclerosis patients. Clin Respir J. 2013;7:227-36.

80. Halpern SD, Taichman DB. Misclassification of pulmonary hypertension due to reliance on pulmonary capillary wedge pressure rather than left ventricular enddiastolic pressure. Chest. 2009;136:37-43.

81. Naeije R, Vachiery JL, Yerly P, Vanderpool R. The transpulmonary pressure gradient for the diagnosis of pulmonary vascular disease. Eur Respir J. 2013;41:217-23.

82. Provencher S, Herve P, Sitbon O, Humbert M, Simonneau G, Chemla D. Changes in exercise haemodynamics during treatment in pulmonary arterial hypertension. Eur Respir J. 2008;32:393-8.

83. Tedford RJ, Beaty CA, Mathai SC, Kolb TM, Damico R, Hassoun PM, Leary PJ, Kass DA, Shah AS. Prognostic value of the pre-transplant diastolic pulmonary artery pressure-to-pulmonary capillary wedge pressure gradient in cardiac transplant recipients with pulmonary hypertension. J Heart Lung Transplant. 2014;33: 289-97.

84. Rich S, Kaufmann E, Levy PS. The effect of high doses of calcium-channel blockers on survival in primary pulmonary hypertension [see comments]. N Engl J Med. 1992;327:76-81.

85. Sitbon O, Humbert M, Jaïs X, Ioos V, Hamid AM, Provencher S, Garcia G, Parent F Herve P, Simonneau G. Long-term response to calcium channel blockers in idiopathic pulmonary arterial hypertension. Circulation. 2005;111:3105-11.

86. Barst R, McGoon M, Torbicki A, Sitbon O, Krowka MJ, Olschewski A, Gaine S. Diagnosis and differential assessment of pulmonary arterial hypertension. J Am Coll Cardiol. 2004;43(Suppl 1):S40-7.

87. Morgan JM, McCormack DG, Griffiths MJ, Morgan CJ, Barnes PJ, Evans TW. Adenosine as a vasodilator in primary pulmonary hypertension [see comments]. Circulation. 1991;84:1145-9.

88. Nootens M, Schrader B, Kaufmann E, Vestal R, LongW, Rich S. Comparative acute effects of adenosine and prostacyclin in primary pulmonary hypertension. Chest. 1995; 107:54-7.

89. Hoeper MM, Olschewski H, Ghofrani HA, Wilkens H, Winkler J, Borst MM, Niedermeyer J, Fabel H, SeegerW. A comparison of the acute hemodynamic effects of inhaled nitric oxide and aerosolized iloprost in primary pulmonary hypertension. J Am Coll Cardiol. 2000;35:176-82.

90. Opitz CF,Wensel R, Bettmann M, Schaffarczyk R, Linscheid M, Hetzer R, Ewert R. Assessment of the vasodilator response in primary pulmonary hypertension. Comparing prostacyclin and iloprost administered by either infusion or inhalation. Eur Heart J. 2003;24:356-65. 
91. Kim NH, Delcroix M, Jenkins DP, Channick R, Dartevelle P, Jansa P, Lang I, Madani MM, Ogino $\mathrm{H}$, Pengo V, Mayer E. Chronic thromboembolic pulmonary hypertension. J Am Coll Cardiol. 2013;62:D92-9.

92. Montani D, Price LC, Dorfmuller P, Achouh L, Jaïs X, Yaici A, Sitbon O, Musset D, Simonneau G, Humbert M. Pulmonary veno-occlusive disease. Eur Respir J. 2009;33:189-200.

93. He J, Fang W, Lv B, He JG, Xiong CM, Liu ZH, He ZX. Diagnosis of chronic thromboembolic pulmonary hypertension: comparison of ventilation/perfusion scanning and multidetector computed tomography pulmonary angiography with pulmonary angiography. Nucl Med Commun. 2012;33:459-63.

94. Cottin V, Le Pavec J, Prevot G, Mal H, Humbert M, Simonneau G, Cordier JF. Pulmonary hypertension in patients with combined pulmonary fibrosis and emphysema syndrome. Eur Respir J. 2010;35:105-11.

95. Taichman DB, McGoon MD, Harhay MO, Archer-Chicko C, Sager JS, Murugappan M, Chakinali MM, Palevsky HI, Gallop R. Wide variation in clinicians' assessment of New York Heart Association/World Health Organization functional class in patients with pulmonary arterial hypertension. Mayo Clin Proc. 2009;84: 586-92.

96. Sitbon O, Humbert M, Nunes H, Parent F, Garcia G, Herve P, Rainisio M, Simonneau G. Long-term intravenous epoprostenol infusion in primary pulmonary hypertension: prognostic factors and survival. J Am Coll Cardiol. 2002;40:780-8

97. Nickel N, Golpon H, Greer M, Knudsen L, Olsson K, Westerkamp V, Welte T, Hoeper MM. The prognostic impact of follow-up assessments in patients with idiopathic pulmonary arterial hypertension. Eur Respir J. 2012;39:589-96.

98. Barst RJ, Chung L, Zamanian RT, Turner M, McGoon MD. Functional class improvement and 3-year survival outcomes in patients with pulmonary arterial hypertension in the REVEAL Registry. Chest. 2013;144:160-8.

99. Benza RL, Miller DP, Gomberg-Maitland M, Frantz RP, Foreman AJ, Coffey CS, Frost A, Barst RJ, Badesch DB, Elliott CG, Liou TG, McGoon MD. Predicting survival in pulmonary arterial hypertension: insights from the Registry to Evaluate Early and Long-Term Pulmonary Arterial Hypertension Disease Management (REVEAL). Circulation. 2010;122:164-72.

100. McLaughlin VV, Sitbon O, Badesch DB, Barst RJ, Black C, Galiè N, Rainisio M, Simonneau G, Rubin LJ. Survival with first-line bosentan in patients with primary pulmonary hypertension. Eur Respir J. 2005;25:244-9.

101. Sachdev A, Villarraga HR, Frantz RP, McGoon MD, Hsiao JF, Maalouf JF, Ammash NM, McCully RB, Miller FA, Pellikka PA, Oh JK, Kane GC. Right ventricular strain for prediction of survival in patients with pulmonary arterial hypertension. Chest. 2011:139:1299-309.

102. Raymond RJ, Hinderliter AL, Willis PW, Ralph D, Caldwell EJ, Williams W, Ettinger NA, Hill NS, Summer WR, de Boisblanc B, Schwartz T, Koch G, Clayton LM, Jobsis MM, Crow JW, LongW. Echocardiographic predictors of adverse outcomes in primary pulmonary hypertension. J Am Coll Cardiol. 2002;39:1214-9.

103. Bustamante-Labarta M, Perrone S, De La Fuente RL, Stutzbach P, De La Hoz RP, Torino A, Favaloro R. Right atrial size and tricuspid regurgitation severity predict mortality or transplantation in primary pulmonary hypertension. J Am Soc Echocardiogr. 2002;15:1160-4.

104. Forfia PR, Fisher MR, Mathai SC, Housten-Harris T, Hemnes AR, Borlaug BA Chamera E, Corretti MC, Champion HC, Abraham TP, Girgis RE, Hassoun PM. Tricuspid annular displacement predicts survival in pulmonary hypertension. Am J Respir Crit Care Med. 2006;174:1034-41.

105. Thenappan T, Shah SJ, Rich S, Tian L, Archer SL, Gomberg-Maitland M. Survival in pulmonary arterial hypertension: a reappraisal of the NIH risk stratification equation. Eur Respir J. 2010;35:1079-87.

106. Wensel R, Opitz CF, Anker SD, Winkler J, Hoffken G, Kleber FX, Sharma R, Hummel $\mathrm{M}$, Hetzer R, Ewert R. Assessment of survival in patients with primary pulmonary hypertension: importance of cardiopulmonary exercise testing. Circulation. 2002;106:319-24.

107. McLaughlin VV, Shillington A, Rich S. Survival in primary pulmonary hypertension: the impact of epoprostenol therapy. Circulation. 2002;106:147782 .

108. Fine NM, Chen L, Bastiansen PM, Frantz RP, Pellikka PA, Oh JK, Kane GC. Outcome prediction by quantitative right ventricular function assessment in 575 subjects evaluated for pulmonary hypertension. Circ Cardiovasc Imaging. 2013;6:711-21.

109. Shimada YJ, Shiota M, Siegel RJ, Shiota T. Accuracy of right ventricular volumes and function determined by three-dimensional echocardiography in comparison with magnetic resonance imaging: a meta-analysis study. J Am Soc Echocardiogr. 2010;23:943-53.

110. Smith BC, Dobson G, Dawson D, Charalampopoulos A, Grapsa J, Nihoyannopoulos $P$. Three-dimensional speckle tracking of the right ventricle: toward optimal quantification of right ventricular dysfunction in pulmonary hypertension. J Am Coll Cardiol. 2014;64:41-51.

111. Grunig E, Tiede H, Enyimayew EO, Ehlken N, Seyfarth HJ, Bossone E, D'Andrea A Naeije R, Olschewski H, Ulrich S, Nagel C, Halank M, Fischer C. Assessment and prognostic relevance of right ventricular contractile reserve in patients with severe pulmonary hypertension. Circulation. 2013;128:2005-15.

112. Swift AJ, Rajaram S, Marshall H, Condliffe R, Capener D, Hill C, Davies C, Hurdman J, Elliot CA, Wild JM, Kiely DG. Black blood MRI has diagnostic and prognostic value in the assessment of patients with pulmonary hypertension. Eur Radiol. 2012;22:695-702.

113. Swift AJ, Rajaram S, Campbell MJ, Hurdman J, Thomas S, Capener D, Elliot C, Condliffe R, Wild JM, Kiely DG. Prognostic value of cardiovascular magnetic resonance imaging measurements corrected for age and sex in idiopathic pulmonary arterial hypertension. Circ Cardiovasc Imaging. 2014;7:100-6.

114. Sitbon O, McLaughlin VV, Badesch DB, Barst RJ, Black C, Galiè N, Humbert M, Rainisio M, Rubin LJ, Simonneau G. Survival in patients with class III idiopathic pulmonary arterial hypertension treated with first line oral bosentan compared with an historical cohort of patients started on intravenous epoprostenol. Thorax. 2005;60:1025-30.

115. Rich JD, Archer SL, Rich S. Noninvasive cardiac output measurements in patients with pulmonary hypertension. Eur Respir J. 2013;42:125-33.

116. Savarese G, Paolillo S, Costanzo P, D’Amore C, Cecere M, Losco T, Musella F, Gargiulo P, Marciano C, Perrone-Filardi P. Do changes of 6-minute walk distance predict clinical events in patients with pulmonary arterial hypertension?: a meta-analysis of 22 randomized trials. J Am Coll Cardiol. 2012;60:1192-201.

117. Gabler NB, French B, Strom BL, Palevsky HI, Taichman DB, Kawut SM, Halpern SD. Validation of 6-minute walk distance as a surrogate end point in pulmonary arterial hypertension trials. Circulation. 2012;126:349-56.

118. Fritz JS, Blair C, Oudiz RJ, Dufton C, Olschewski H, Despain D, Gillies H, Kawut SM. Baseline and follow-up 6-min walk distance and brain natriuretic peptide predict 2-year mortality in pulmonary arterial hypertension. Chest. 2013;143:315-23.

119. Paciocco G, Martinez F, Bossone E, Pielsticker E, Gillespie B, Rubenfire M. Oxygen desaturation on the six-minute walk test and mortality in untreated primary pulmonary hypertension. Eur Respir J. 2001;17:647-52.

120. Provencher S, Chemla D, Herve P, Sitbon O, Humbert M, Simonneau G. Heart rate responses during the 6 -minute walk test in pulmonary arterial hypertension. Eur Respir J. 2006;27:114-20.

121. Sun XG, Hansen JE, Oudiz RJ, Wasserman K. Exercise pathophysiology in patients with primary pulmonary hypertension. Circulation. 2001;104:429-35.

122. Wensel R, Francis DP, Meyer FJ, Opitz CF, Bruch L, Halank M, Winkler J, Seyfarth HJ, Glaser S, Blumberg F, Obst A, Dandel M, Hetzer R, Ewert R. Incremental prognostic value of cardiopulmonary exercise testing and resting haemodynamics in pulmonary arterial hypertension. Int J Cardiol. 2013;167:1193-8.

123. Blumberg FC, Arzt M, Lange T, Schroll S, Pfeifer M,Wensel R. Impact of right ventricular reserve on exercise capacity and survival in patients with pulmonary hypertension. Eur J Heart Fail. 2013;15:771-5.

124. Diller GP, Dimopoulos K, Okonko D, Li W, Babu-Narayan SV, Broberg CS, Johansson B, Bouzas B, Mullen MJ, Poole-Wilson PA, Francis DP, Gatzoulis MA. Exercise intolerance in adult congenital heart disease: comparative severity, correlates, and prognostic implication. Circulation. 2005;112:828-35.

125. Arena R, Lavie CJ, Milani RV, Myers J, Guazzi M. Cardiopulmonary exercise testing in patients with pulmonary arterial hypertension: an evidence-based review. J Heart Lung Transplant. 2010;29:159-73.

126. Pullamsetti S, Kiss L, Ghofrani HA, Voswinckel R, Haredza P, Klepetko W, Aigner C, Fink L, Muyal JP, Weissmann N, Grimminger F, Seeger W, Schermuly RT. Increased levels and reduced catabolism of asymmetric and symmetric dimethylarginines in pulmonary hypertension. FASEB J. 2005;19:1175-7.

127. Kielstein JT, Bode-Boger SM, Hesse G, Martens-Lobenhoffer J, Takacs A, Fliser D, Hoeper MM. Asymmetrical dimethylarginine in idiopathic pulmonary arterial hypertension. Arterioscler Thromb Vasc Biol. 2005;25:1414-8.

128. Kielstein JT, Impraim B, Simmel S, Bode-Boger SM, Tsikas D, Frolich JC, Hoeper MM, Haller H, Fliser D. Cardiovascular effects of systemic nitric oxide synthase inhibition with asymmetrical dimethylarginine in humans. Circulation. 2004;109:172-7.

129. Kawut SM, Horn EM, Berekashvili KK, Widlitz AC, Rosenzweig EB, Barst RJ. von Willebrand factor independently predicts long-term survival in patients with pulmonary arterial hypertension. Chest. 2005;128:2355-62.

130. Kumpers P, Nickel N, Lukasz A, Golpon H,Westerkamp V, Olsson KM, Jonigk D, Maegel L, Bockmeyer CL, David S, Hoeper MM. Circulating angiopoietins in idiopathic pulmonary arterial hypertension. Eur Heart J. 2010;31:2291-300.

131. Rubens C, Ewert R, Halank M, Wensel R, Orzechowski HD, Schultheiss HP, Hoeffken G. Big endothelin-1 and endothelin-1 plasma levels are correlated with the severity of primary pulmonary hypertension. Chest. 2001;120:1562-9.

132. Quarck R, Nawrot T, Meyns B, Delcroix M. C-reactive protein: a new predictor of adverse outcome in pulmonary arterial hypertension. J Am Coll Cardiol. 2009;53:1211-8.

133. Balabanian K, Foussat A, Dorfmuller P, Durand-Gasselin I, Capel F, BouchetDelbos L, Portier A, Marfaing-Koka A, Krzysiek R, Rimaniol AC, Simonneau G, Emilie D, Humbert M. CX(3)C chemokine fractalkine in pulmonary arterial hypertension. Am J Respir Crit Care Med. 2002;165:1419-25.

134. Dorfmuller P, Zarka V, Durand-Gasselin I, Monti G, Balabanian K, Garcia G, Capron F, Coulomb-Lhermine A, Marfaing-Koka A, Simonneau G, Emilie D, Humbert M. Chemokine RANTES in severe pulmonary arterial hypertension. Am J Respir Crit Care Med. 2002; 165:534-9.

135. Humbert M, Monti G, Brenot F, Sitbon O, Portier A, Grangeot-Keros L, Duroux P, Galanaud P, Simonneau G, Emilie D. Increased interleukin-1 and interleukin-6 serum concentrations in severe primary pulmonary hypertension. Am J Respir Crit Care Med. 1995;151:1628-31.

136. Nagaya N, Nishikimi T, Uematsu M, Satoh T, Kyotani S, Sakamaki F, Kakishita M, Fukushima K, Okano Y, Nakanishi N, Miyatake K, Kangawa K. Plasma brain natriuretic peptide as a prognostic indicator in patients with primary pulmonary hypertension. Circulation. 2000;102:865-70.

137. Leuchte HH, El NM, Tuerpe JC, Hartmann B, Baumgartner RA, Vogeser M, Muehling O, Behr J. N-terminal pro-brain natriuretic peptide and renal insufficiency as predictors of mortality in pulmonary hypertension. Chest. 2007; 131:402-9.

138. Fijalkowska A, Kurzyna M, Torbicki A, Szewczyk G, Florczyk M, Pruszczyk P, Szturmowicz M. Serum N-terminal brain natriuretic peptide as a prognostic parameter in patients with pulmonary hypertension. Chest. 2006;129: 1313-21.

139. Torbicki A, Kurzyna M, Kuca P, Fijalkowska A, Sikora J, Florczyk M, Pruszczyk P, Burakowski J, Wawrzynska L. Detectable serum cardiac troponin T as a marker of 
poor prognosis among patients with chronic precapillary pulmonary hypertension. Circulation. 2003;108:844-8.

140. Nickel N, Kempf T, Tapken H, Tongers J, Laenger F, Lehmann U, Golpon H, Olsson K, Wilkins MR, Gibbs JS, Hoeper MM,Wollert KC. Growth differentiation factor-15 in idiopathic pulmonary arterial hypertension. Am J Respir Crit Care Med. 2008; $178: 534-41$

141. Nagaya N, Uematsu M, Satoh T, Kyotani S, Sakamaki F, Nakanishi N, Yamagishi M, Kunieda T, Miyatake K. Serum uric acid levels correlate with the severity and the mortality of primary pulmonary hypertension. Am J Respir Crit Care Med. 1999;160:487-92.

142. Lorenzen JM, Nickel N, Kramer R, Golpon H, Westerkamp V, Olsson KM, Haller H, Hoeper MM. Osteopontin in patients with idiopathic pulmonary hypertension. Chest. 2011;139:1010-7.

143. Warwick G, Thomas PS, Yates DH. Biomarkers in pulmonary hypertension. Eur Respir J. 2008;32:503-12

144. Hoeper MM, Markevych I, Spiekerkoetter E, Welte T, Niedermeyer J. Goaloriented treatment and combination therapy for pulmonary arterial hypertension. Eur Respir J. 2005;26:858-63.

145. McLaughlin VV, Gaine SP, Howard LS, Leuchte HH, Mathier MA, Mehta S, Palazzini M, Park MH, Tapson VF, Sitbon O. Treatment goals of pulmonary hypertension. J Am Coll Cardiol. 2013;62(Suppl):D73-D81.

146. Galiè N, Manes A, Negro L, Palazzini M, Bacchi Reggiani ML, Branzi A. A metaanalysis of randomized controlled trials in pulmonary arterial hypertension. Eur Heart J. 2009;30:394-403.

147. Bai Y, Sun L, Hu S, Wei Y. Combination therapy in pulmonary arterial hypertension: a meta-analysis. Cardiology. 2011;120:157-65.

148. Galiè N, Simonneau G. The Fifth World Symposium on Pulmonary Arterial Hypertension. J Am Coll Cardiol. 2013;62(Suppl):D1-D3.

149. Galiè N, Corris P, Frost A, Girgis R, Granton J, Jing ZC, KlepetkoW, McGoon M, McLaughlin VV, Preston RJ, Rubin LJ, Sandoval J, Seeger W, Keogh AM. Updated treatment algorithm of pulmonary hypertension. J Am Coll Cardiol. 2013;62(Suppl):D60-D72.

150. Löwe B, Gräfe K, Ufer C, Kroenke K, Grünig E, HerzogW, BorstMM. Anxiety and depression in patients with pulmonary hypertension. Psychosom Med. 2004;66:831-6.

151. Galiè N, Hoeper M, Humbert M, Torbicki A, Vachiery JL, Barbera JA, Beghetti M, Corris P, Gaine S, Gibbs JS, Gomez-Sanchez MA, Klepetko W, Joendeau G, Opitz C, Peacock A, Rubin L, Zellweger M, Simonneau G. Guidelines on diagnosis and treatment of pulmonary hypertension: the Task Force on Diagnosis and Treatment of Pulmonary Hypertension of the European Society of Cardiology and of the European Respiratory Society. Eur Heart J. 2009;30:2493-537.

152. Mereles D, Ehlken N, Kreuscher S, Ghofrani S, Hoeper MM, Halank M, Meyer FJ, Karger G, Buss J, Juenger J, Holzapfel N, Opitz C, Winkler J, Herth FF, Wilkens H, Katus HA, Olschewski $\mathrm{H}$, Grunig E. Exercise and respiratory training improve exercise capacity and quality of life in patients with severe chronic pulmonary hypertension. Circulation. 2006;114:1482-9.

153. de Man FS, Handoko ML, Groepenhoff H, van 't Hul AJ, Abbink J, Koppers RJH, Grotjohan HP, Twisk JWR, Bogaard HJ, Boonstra A, Postmus PE, Westerhof N Van Der Laarse WJ, Vonk-Noordegraaf A. Effects of exercise training in patients with idiopathic pulmonary arterial hypertension. Eur Respir J. 2009;34: 669-75.

154. Grunig E, Ehlken N, Ghofrani A, Staehler G, Meyer FJ, Juenger J, Opitz CF, Klose H, Wilkens $\mathrm{H}$, Rosenkranz S, Olschewski H, Halank M. Effect of exercise and respiratory training on clinical progression and survival in patients with severe chronic pulmonary hypertension. Respiration. 2011;81:394-401.

155. Grunig E, Maier F, Ehlken N, Fischer C, Lichtblau M, Blank N, Fiehn C, Stockl F Prange F, Staehler G, Reichenberger F, Tiede H, Halank M, Seyfarth HJ, Wagner S, Nagel C. Exercise training in pulmonary arterial hypertension associated with connective tissue diseases. Arthritis Res Ther. 2012;14:R148.

156. Grunig E, Lichtblau M, Ehlken N, Ghofrani HA, Reichenberger F, Staehler G, Halank M, Fischer C, Seyfarth HJ, Klose H, Meyer A, Sorichter S, Wilkens H, Rosenkranz S, Opitz C, Leuchte H, Karger G, Speich R, Nagel C. Safety and efficacy of exercise training in various forms of pulmonary hypertension. Eur Respir J. 2012;40:84-92.

157. Becker-Grunig T, Klose H, Ehlken N, Lichtblau M, Nagel C, Fischer C, Gorenflo M, Tiede H, Schranz D, Hager A, Kaemmerer H, Miera O, Ulrich S, Speich R, Uiker S, Grunig E. Efficacy of exercise training in pulmonary arterial hypertension associated with congenital heart disease. Int J Cardiol. 2013;168:375-81.

158. Weinstein AA, Chin LMK, Keyser RE, Kennedy M, Nathan SD, Woolstenhulme JG, Connors G, Chan L. Effect of aerobic exercise training on fatigue and physical activity in patients with pulmonary arterial hypertension. Respir Med. 2013;107:778-84

159. Chan L, Chin LM, Kennedy M, Woolstenhulme JG, Nathan SD, Weinstein AA Connors G, Weir NA, Drinkard B, Lamberti J, Keyser RE. Benefits of intensive treadmill exercise training on cardiorespiratory function and quality of life in patients with pulmonary hypertension. Chest. 2013;143:333-43.

160. Jaïs X, Olsson KM, Barbera JA, Blanco I, Torbicki A, Peacock A, Vizza CD, Macdonald $P$, Humbert $M$, Hoeper MM. Pregnancy outcomes in pulmonary arterial hypertension in the modern management era. Eur Respir J. 2012;40:881-5.

161. Duarte AG, Thomas S, Safdar Z, Torres F, Pacheco LD, Feldman J, deBoisblanc B. Management of pulmonary arterial hypertension during pregnancy: a retrospective, multicenter experience. Chest. 2013;143:1330-6.

162. Thorne S, Nelson-Piercy C, MacGregor AJ, Gibbs S, Crowhurst J, Panay N, Rosenthal E, Walker F, Williams D, de Swiet M, Guillebaud J. Pregnancy and contraception in heart disease and pulmonary arterial hypertension. J Fam Plann Reprod Health Care. 2006;32:75-81.
163. Bendayan D, Hod M, Oron G, Sagie A, Eidelman L, Shitrit D, Kramer MR. Pregnancy outcome in patients with pulmonary arterial hypertension receiving prostacyclin therapy. Obstet Gynecol. 2005;106:1206-10.

164. Bonnin M, Mercier FJ, Sitbon O, Jaïs X, Humbert M, Audibert F, Frydman R, Simonneau G, Benhamou D. Severe pulmonary hypertension during pregnancy: mode of delivery and anesthetic management of 15 consecutive cases. Anesthesiology. 2005;102:1133-7.

165. Meyer S, McLaughlin VV, Seyfarth HJ, Bull TM, Vizza CD, Gomberg-Maitland M, Preston IR, Barberà JA, Hassoun PM, Halank M, Jaïs X, Nickel N, Hoeper MM Humbert M. Outcomes of noncardiac, nonobstetric surgery in patients with PAH: an international prospective survey. Eur Respir J. 2013;41:1302-7.

166. Olofsson C, Bremme K, Forssell G, Ohqvist G. Cesarean section under epidural ropivacaine $0.75 \%$ in a parturient with severe pulmonary hypertension. Acta Anaesthesiol Scand. 2001;45:258-60.

167. Raines DE, Liberthson RR, Murray JR. Anesthetic management and outcome following noncardiac surgery in nonparturients with Eisenmenger's physiology. J Clin Anesth. 1996;8:341-7.

168. Guillevin L, Armstrong I, Aldrighetti R, Howard LS, Ryftenius H, Fischer A Lombardi S, Studer S, Ferrari P. Understanding the impact of pulmonary arterial hypertension on patients' and carers' lives. Eur Respir Rev. 2013;22:535-42.

169. Weitzenblum E, Sautegeau A, Ehrhart M, Mammosser M, Pelletier A. Long-term oxygen therapy can reverse the progression of pulmonary hypertension in patients with chronic obstructive pulmonary disease. Am Rev Respir Dis. 1985;131:493-8.

170. Frydman N, Steffann J, Girerd B, Frydman R, Munnich A, Simonneau G, Humbert M. Pre-implantation genetic diagnosis in pulmonary arterial hypertension due to BMPR2 mutation. Eur Respir J. 2012;39:1534-5.

171. Fuster V, Steele PM, Edwards WD, Gersh BJ, McGoon MD, Frye RL. Primary pulmonary hypertension: natural history and the importance of thrombosis. Circulation. 1984;70:580-7.

172. Herve P, Humbert M, Sitbon O, Parent F, Nunes H, Legal C, Garcia G, Simonneau G. Pathobiology of pulmonary hypertension: the role of platelets and thrombosis. Clin Chest Med. 2001;22:451-8.

173. Hoeper MM, Sosada M, Fabel H. Plasma coagulation profiles in patients with severe primary pulmonary hypertension. Eur Respir J. 1998;12:1446-9.

174. Huber K, Beckmann R, Frank H, Kneussl M, Mlczoch J, Binder BR. Fibrinogen, t-PA and PAI-1 plasma levels in patients with pulmonary hypertension. Am J Respir Crit Care Med. 1994;150:929-33.

175. Olsson KM, Delcroix M, Ghofrani HA, Tiede H, Huscher D, Speich R, Grünig E, Staehler G, Rosenkranz S, Halank M, Held M, Lange TJ, Behr J, Klose H, Claussen M, Ewert R, Opitz CF, Vizza CD, Scelsi L, Vonk-Noordegraaf A, Kaemmerer H, Gibbs JS, Coghlan G, Pepke-Zaba J, Schulz U, Gorenflo M, Pittrow D, Hoeper MM. Anticoagulation and survival in pulmonary arterial hypertension: results from the Comparative, Prospective Registry of Newly Initiated Therapies for Pulmonary Hypertension (COMPERA). Circulation. 2014;129:57-65.

176. Galiè N, Delcroix M, Ghofrani A, Jansa P, Minai OA, Perchenet L, Rubin LJ, Sastry BKS, Torbicki A, Simonneau G. Anticoagulant therapy does not influence longterm outcomes in patients with pulmonary arterial hypertension (PAH): insights from the randomised controlled SERAPHIN trial of macitentan. Eur Heart J. 2014;35:10.

177. Preston RJ, Roberts KE, Miller DP, Hill NS, Farber HW. Effect of warfarin treatment on survival of patients with pulmonary arterial hypertension (PAH) in the Registry to Evaluate Early and Long-Term PAH Disease Management (REVEAL). Am J Respir Crit Care Med. 2014;189:A2464.

178. Cohn JN. Optimal diuretic therapy for heart failure. Am J Med. 2001;111:577

179. Sandoval J, Aguirre JS, Pulido T, Martinez-Guerra ML, Santos E, Alvarado P, Rosas $M$, Bautista E. Nocturnal oxygen therapy in patients with the Eisenmenger syndrome. Am J Respir Crit Care Med. 2001;164:1682-7.

180. Rich S, Seidlitz M, Dodin E, Osimani D, Judd D, Genthner D, McLaughlin V, Francis $\mathrm{G}$. The short-term effects of digoxin in patients with right ventricular dysfunction from pulmonary hypertension. Chest. 1998;114:787-92.

181. Ruiter G, Lankhorst S, Boonstra A, Postmus PE, Zweegman S,Westerhof N, Van Der Laarse WJ, Vonk-Noordegraaf A. Iron deficiency is common in idiopathic pulmonary arterial hypertension. Eur Respir J. 2011;37:1386-91.

182. Ruiter G, Lanser IJ, de Man FS, Van Der Laarse WJ, Wharton J, Wilkins MR, Howard LS, Vonk-Noordegraaf A, Voskuyl AE. Iron deficiency in systemic sclerosis patients with and without pulmonary hypertension. Rheumatology (Oxford) 2014;53:285-92.

183. Broberg CS, Bax BE, Okonko DO, RamplingMW, Bayne S, Harries C, Davidson SJ, Uebing A, Khan AA, Thein S, Gibbs JS, Burman J, Gatzoulis MA. Blood viscosity and its relationship to iron deficiency, symptoms, and exercise capacity in adults with cyanotic congenital heart disease. J Am Coll Cardiol. 2006;48:356-65.

184. Rhodes CJ, Howard LS, Busbridge M, Ashby D, Kondili E, Gibbs JS, Wharton J, Wilkins MR. Iron deficiency and raised hepcidin in idiopathic pulmonary arterial hypertension clinical prevalence, outcomes, and mechanistic insights. J Am Coll Cardiol. 2011;58:300-9.

185. Van De Bruaene A, Delcroix M, Pasquet A, De BJ, De PM, Naeije R, Vachiery JL Paelinck B, Morissens M, BudtsW. Iron deficiency is associated with adverse outcome in Eisenmenger patients. Eur Heart J. 2011;32:2790-9.

186. Viethen T, Gerhardt F, Dumitrescu D, Knoop-Busch S, ten Freyhaus H, Rudolph TK Baldus S, Rosenkranz S. Ferric carboxymaltose improves exercise capacity and quality of life in patients with pulmonary arterial hypertension and iron deficiency: a pilot study. Int J Cardiol. 2014;175:233-9.

187. Galié N, Ussia G, Passarelli P, Parlangeli R, Branzi A, Magnani B. Role of pharmacologic tests in the treatment of primary pulmonary hypertension. Am J Cardiol. 1995; 75:55A-62A. 
188. Mukerjee D, St George D, Coleiro B, Knight C, Denton CP, Davar J, Black CM, Coghlan JG. Prevalence and outcome in systemic sclerosis associated pulmonary arterial hypertension: application of a registry approach. Ann Rheum Dis. 2003;62:1088-93.

189. Montani D, Savale L, Natali D, Jaïs X, Herve P, Garcia G, Humbert M, Simonneau $G$, Sitbon O. Long-term response to calcium-channel blockers in nonidiopathic pulmonary arterial hypertension. Eur Heart J. 2010;31:1898-907.

190. Giaid A, Yanagisawa M, Langleben D, Michel RP, Levy R, Shennib H, Kimura S, Masaki T, Duguid WP, Stewart DJ. Expression of endothelin-1 in the lungs of patients with pulmonary hypertension. N Engl J Med. 1993;328:1732-39.

191. Stewart DJ, Levy RD, Cernacek P, Langleben D. Increased plasma endothelin-1 in pulmonary hypertension: marker or mediator of disease? Ann Intern Med. 1991;114:464-9.

192. Galié N, Manes A, Branzi A. The endothelin system in pulmonary arterial hypertension. Cardiovasc Res. 2004;61:227-37.

193. Galié N, Badesch BD, Oudiz R, Simonneau G, McGoon M, Keogh A, Frost A, Zwicke D, Naeije R, Shapiro RS, Olschewski H, Rubin L. Ambrisentan therapy for pulmonary arterial hypertension. J Am Coll Cardiol. 2005;46:529-35.

194. Galié N, Olschewski H, Oudiz RJ, Torres F, Frost A, Ghofrani HA, Badesch DB, McGoon MD, McLaughlin VV, Roecker EB, Gerber MJ, Dufton C, Wiens BL, Rubin LJ. Ambrisentan for the treatment of pulmonary arterial hypertension. Results of the ambrisentan in pulmonary arterial hypertension, randomized, doubleblind, placebo-controlled, multicenter, efficacy (ARIES) study 1 and 2. Circulation. 2008;117:3010-9.

195. McGoon M, Frost A, Oudiz R, Badesch BD, Galiè N, Olschewski H, McLaughlin VV, Gerber MJ, Dufton C, Despain DJ, Rubin LJ. Ambrisentan therapy in patients with pulmonary arterial hypertension who discontinued bosentan or sitaxsentan due to liver function test abnormalities. Chest. 2009;135:122-9.

196. Channick RN, Simonneau G, Sitbon O, Robbins IM, Frost A, Tapson VF, Badesch DB, Roux S, Rainisio M, Bodin F, Rubin LJ. Effects of the dual endothelinreceptor antagonist bosentan in patients with pulmonary hypertension: a randomised placebo-controlled study. Lancet. 2001;358:1119-23.

197. Rubin LJ, Badesch DB, Barst RJ, Galiè N, Black CM, Keogh A, Pulido T, Frost A, Roux S, Leconte I, Landzberg M, Simonneau G. Bosentan therapy for pulmonary arterial hypertension. N Engl J Med. 2002;346:896-903.

198. Humbert M, Barst RJ, Robbins IM, Channick RN, Galiè N, Boonstra A, Rubin LJ, Horn EM, Manes A, Simonneau G. Combination of bosentan with epoprostenol in pulmonary arterial hypertension: BREATHE-2. Eur Respir J. 2004;24:353-9.

199. Galiè N, Rubin LJ, Hoeper M, Jansa P, Al-Hiti H, Meyer GMB, Chiossi E, Kusic-Pajic A, Simonneau G. Treatment of patients with mildly symptomatic pulmonary arterial hypertension with bosentan (EARLY study): a double-blind, randomised controlled trial. Lancet. 2008:371:2093-100.

200. Galiè N, Beghetti M, Gatzoulis MA, Granton J, Berger RMF, Lauer A, Chiossi E, Landzberg M. Bosentan therapy in patients with Eisenmenger syndrome: a multicenter, double-blind, randomized, placebo-controlled study. Circulation. 2006:114:48-54.

201. Pulido T, Adzerikho I, Channick RN, Delcroix M, Galiè N, Ghofrani HA, Jansa P, Jing ZC, Le Brun FO, Mehta S, Mittelholzer CM, Perchenet L, Sastry BKS, Sitbon O, Souza R, Torbicki A, Zeng X, Rubin LJ, Simonneau G. Macitentan and morbidity and mortality in pulmonary arterial hypertension. N Engl J Med. 2013;369:80918.

202. Wharton J, Strange JW, Moller GMO, Growcott EJ, Ren X, Franklyn AP, Phillips SC Wilkins MR. Antiproliferative effects of phosphodiesterase type 5 inhibition in human pulmonary artery cells. Am J Respir Crit Care Med. 2005;172:105-13.

203. Tantini B, Manes A, Fiumana E, Pignatti C, Guarnieri G, Zannoli R, Branzi A, Galiè $\mathrm{N}$. Antiproliferative effect of sildenafil on human pulmonary artery smooth muscle cells. Basic Res Cardiol. 2005;100:131-8.

204. Ghofrani HA, Voswinckel R, Reichenberger F, Olschewski H, Haredza P, Karadas B, Schermuly RT, Weissmann N, Seeger W, Grimminger F. Differences in hemodynamic and oxygenation responses to three different phosphodiesterase- 5 inhibitors in patients with pulmonary arterial hypertension: a randomized prospective study. J Am Coll Cardiol. 2004;44:1488-96.

205. Galiè N, Ghofrani HA, Torbicki A, Barst RJ, Rubin LJ, Badesch D, Fleming T, Parpia T, Burgess G, Branzi A, Grimminger F, Kurzyna M, Simonneau G, the Sildenafil Use in Pulmonary Arterial Hypertension (SUPER) Study Group. Sildenafil citrate therapy for pulmonary arterial hypertension. N Engl J Med. 2005;353:2148-57.

206. Sastry BKS, Narasimhan C, Reddy NK, Raju BS. Clinical efficacy of sildenafil in primary pulmonary hypertension: a randomized, placebo-controlled, doubleblind, crossover study. J Am Coll Cardiol. 2004:43:1149-53.

207. Iversen K, Jensen AS, Jensen TV, Vejlstrup NG, Søndergaard L. Combination therapy with bosentan and sildenafil in Eisenmenger syndrome: a randomized, placebo-controlled, double-blinded trial. Eur Heart J. 2010;31:1124-31.

208. Singh T, Rohit M, Grover A, Malhotra S, Vijayvergiya R. A randomized, placebocontrolled, double-blind, crossover study to evaluate the efficacy of ora sildenafil therapy in severe pulmonary artery hypertension. Am Heart J. 2006;151:851.e1-851.e5.

209. Simonneau G, Rubin L, Galiè N, Barst RJ, Fleming T, Frost A, Engel PJ, Kramer MR, Burgess G, Collings L, Cossons N, Sitbon O, Badesch BD. Addition of sildenafil to long-term intravenous epoprostenol therapy in patients with pulmonary arterial hypertension. Ann Intern Med. 2008:149:521-30.

210. Vachiery JL, Huez S, Gillies H, Layton G, Hayashi N, Gao X, Naeije R. Safety, tolerability and pharmacokinetics of an intravenous bolus of sildenafil in patients with pulmonary arterial hypertension. Br J Clin Pharmacol. 2011:71:289-92.

211. Galiè N, Brundage BH, Ghofrani HA, Oudiz RJ, Simonneau G, Safdar Z, Shapiro S, White RJ, Chan M, Beardsworth A, Frumkin L, Barst RJ. Tadalafil therapy for pulmonary arterial hypertension. Circulation. 2009;119:2894-903.
212. Jing ZC, Yu ZX, Shen JY, Wu BX, Xu KF, Zhu XY, Pan L, Zhang ZL, Liu XQ, Zhang YS, Jiang $X$, Galiè N. Vardenafil in pulmonary arterial hypertension: a randomized, double-blind, placebo-controlled study. Am J Respir Crit Care Med. 2011:183:1723-9.

213. Giaid A, Saleh D. Reduced expression of endothelial nitric oxide synthase in the lungs of patients with pulmonary hypertension. N Engl J Med. 1995;333:214-21.

214. Ghofrani HA, Galiè N, Grimminger F, Grunig E, Humbert M, Jing ZC, Keogh AM, Langleben D, Kilama MO, Fritsch A, Neuser D, Rubin LJ. Riociguat for the treatment of pulmonary arterial hypertension. N Engl J Med. 2013;369:330-40.

215. Galiè N, Muller K, Scalise AV, Grunig E. PATENT PLUS: a blinded, randomised and extension study of riociguat plus sildenafil in PAH. Eur Respir J. 2015;45:1314-22.

216. Jones DA, Benjamin CW, Linseman DA. Activation of thromboxane and prostacyclin receptors elicits opposing effects on vascular smooth muscle cell growth and mitogen-activated protein kinase signaling cascades. Mol Pharmacol. 1995;48:890-6.

217. Galiè N, Manes A, Branzi A. Prostanoids for pulmonary arterial hypertension. Am J Respir Med. 2003;2:123-37.

218. Galiè N, Humbert M, Vachiery JL, Vizza CD, Kneussl M, Manes A, Sitbon O, Torbicki A, Delcroix M, Naeije R, Hoeper M, Chaouat A, Morand S, Besse B, Simonneau G. Effects of beraprost sodium, an oral prostacyclin analogue, in patients with pulmonary arterial hypertension: a randomised, double-blind placebocontrolled trial. J Am Coll Cardiol. 2002;39:1496-502.

219. Barst RJ, McGoon M, McLaughlin VV, Tapson V, Rich S, Rubin L, Wasserman K, Oudiz R, Shapiro S, Robbins I, Channick R, Badesch BD, Rayburn BK, Flinchbaugh R, Sigman J, Arneson K, Jeffs R. Beraprost therapy for pulmonary arterial hypertension. J Am Coll Cardiol. 2003;41:2119-25.

220. Rubin LJ, Mendoza J, Hood M, McGoon M, Barst R, Williams WB, Diehl JH, Crow J, Long W. Treatment of primary pulmonary hypertension with continuous intravenous prostacyclin (epoprostenol). Results of a randomized trial. Ann Intern Med. 1990;112:485-91.

221. Barst RJ, Rubin LJ, Long WA, McGoon MD, Rich S, Badesch DB, Groves BM, Tapson VF, Bourge RC, Brundage BH, Koerner SK, Langleben D, Keller C, Murali S, Uretsky BF, Clayton LM, Jöbsis MM, Blackburn SD, Shortino D, Crow JW. A comparison of continuous intravenous epoprostenol (prostacyclin) with conventional therapy for primary pulmonary hypertension [see comments]. N Engl J Med. 1996;334:296-302.

222. Badesch DB, Tapson VF, McGoon MD, Brundage BH, Rubin LJ, Wigley FM, Rich S, Barst RJ, Barrett PS, Kral KM, Jobsis MM, Loyd JE, Murali S, Frost A, Girgis R, Bourge RC, Ralph DD, Elliott CG, Hill NS, Langleben D, Schilz RJ, McLaughlin VV, Robbins IM, Groves BM, Shapiro S, Medsger TA Jr. Continuous intravenous epoprostenol for pulmonary hypertension due to the scleroderma spectrum of disease. A randomized, controlled trial [see comments]. Ann Intern Med. 2000;132:425-34.

223. Rosenzweig EB, Kerstein D, Barst RJ. Long-term prostacyclin for pulmonary hypertension with associated congenital heart defects. Circulation. 1999;99: 1858-65.

224. Krowka MJ, Frantz RP, McGoon MD, Severson C, Plevak DJ, Wiesner RH. Improvement in pulmonary hemodynamics during intravenous epoprostenol (prostacyclin): a study of 15 patients with moderate to severe portopulmonary hypertension. Hepatology. 1999;30:641-8.

225. Nunes H, Humbert M, Sitbon O, Morse JH, Deng Z, Knowles JA, Le Gall C, Parent F, Garcia G, Herve P, Barst RJ, Simonneau G. Prognostic factors for survival in human immunodeficiency virus-associated pulmonary arterial hypertension. Am J Respir Crit Care Med. 2003;167:1433-9.

226. Cabrol S, Souza R, Jaïs X, Fadel E, Ali RHS, Humbert M, Dartevelle P, Simonneau G, Sitbon O. Intravenous epoprostenol in inoperable chronic thromboembolic pulmonary hypertension. J Heart Lung Transplant. 2007;26:357-62.

227. Doran AK, Ivy DD, Barst RJ, Hill N, Murali S, Benza RL. Guidelines for the prevention of central venous catheter-related blood stream infections with prostanoid therapy for pulmonary arterial hypertension. Int J Clin Pract Suppl. 2008; $160: 5-9$

228. Sitbon O, Delcroix M, Bergot E, Boonstra AB, Granton J, Langleben D, Subías PE, Galiè N, Pfister T, Lemarié JC, Simonneau G. EPITOME-2: an open-label study assessing the transition to a new formulation of intravenous epoprostenol in patients with pulmonary arterial hypertension. Am Heart J. 2014;167:210-7.

229. Olschewski H, Simonneau G, Galiè N, Higenbottam T, Naeije R, Rubin LJ, Nikkho S, Sitbon O, Speich R, Hoeper M, Behr J, Winkler J, Seeger W. Inhaled iloprost in severe pulmonary hypertension. N Engl J Med. 2002;347:322-9.

230. McLaughlin VV, Oudiz RJ, Frost A, Tapson VF, Murali S, Channick RN, Badesch DB, Barst RJ, Hsu HH, Rubin LJ. Randomized study of adding inhaled iloprost to existing bosentan in pulmonary arterial hypertension. Am J Respir Crit Care Med. 2006; 174:1257-63.

231. Hoeper M, Leuchte $H$, Halank M, Wilkens $H$, Meyer FJ, Seyfarth $H J$, Wensel R, Ripken F, Bremer H, Kluge S, Hoeffken G, Behr J. Combining inhaled iloprost with bosentan in patients with idiopathic pulmonary arterial hypertension. Eur Respir J. 2006;4:691-4

232. Higenbottam T, Butt AY, McMahon A, Westerbeck R, Sharples L. Long-term intravenous prostaglandin (epoprostenol or iloprost) for treatment of severe pulmonary hypertension. Heart. 1998;80:151-5.

233. Simonneau G, Barst RJ, Galiè N, Naeije R, Rich S, Bourge RC, Keogh A, Oudiz R, Frost A, Blackburn SD, Crow JW, Rubin LJ. Continuous subcutaneous infusion of treprostinil, a prostacyclin analogue, in patients with pulmonary arterial hypertension. A double-blind, randomized, placebo-controlled trial. Am J Respir Crit Care Med. 2002;165:800-4.

234. Hiremath J, Thanikachalam S, Parikh K, Shanmugasundaram S, Bangera S, Shapiro L, Pott GB, Vnencak-Jones CL, Arneson C, Wade M, White RJ. Exercise improvement 
and plasma biomarker changes with intravenous treprostinil therapy for pulmonary arterial hypertension: a placebo-controlled trial. J Heart Lung Transplant. 2010;29:137-49.

235. Tapson VF, Gomberg-Maitland M, McLaughlin VV, Benza RL, Widlitz AC, Krichman A, Barst RJ. Safety and efficacy of IV treprostinil for pulmonary arterial hypertension: a prospective, multicenter, open-label, 12-week trial. Chest. 2006;129:683-8

236. Sitbon O, Manes A, Jaïs X, Pallazini M, Humbert M, Presotto L, Paillette L, Zaccardelli D, Davis G, Jeffs R, Simonneau G, Galiè N. Rapid switch from intravenous epoprostenol to intravenous treprostinil in patients with pulmonary arterial hypertension. J Cardiovasc Pharmacol. 2007:49:1-5.

237. McLaughlin V, Rubin L, Benza RL, Channick R, Vosswinkel R, Tapson V, Robbins I, Olschewski $\mathrm{H}$, SeegerW. Addition of inhaled treprostinil to oral therapy for pulmonary arterial hypertension: a randomized controlled clinical trial. J Am Coll Cardiol. 2010;55:1915-22.

238. Tapson VF, Torres F, Kermeen F, Keogh AM, Allen RP, Frantz RP, Badesch DB, Frost AE, Shapiro SM, Laliberte K, Sigman J, Arneson C, Galiè N. Oral treprostinil for the treatment of pulmonary arterial hypertension in patients on background endothelin receptor antagonist and/or phosphodiesterase type 5 inhibitor therapy (the FREEDOM-C study): a randomized controlled trial. Chest. 2012;142:1383-90.

239. Tapson VF, Jing ZC, Xu KF, Pan L, Feldman J, Kiely DG, Kotlyar E, McSwain CS, Laliberte K, Arneson C. Oral treprostinil for the treatment of pulmonary arterial hypertension in patients on background endothelin receptor antagonist and/or phosphodiesterase type 5 inhibitor therapy (the FREEDOM-C2 study): a randomized controlled trial. Chest. 2013;144:952-8.

240. Jing ZC, Parikh K, Pulido T, Jerjes-Sanchez C, White RJ, Allen R, Torbicki A, Xu KF, Yehle D, Laliberte K, Arneson C, Rubin LJ. Efficacy and safety of oral treprostinil monotherapy for the treatment of pulmonary arterial hypertension: a randomized, controlled trial. Circulation. 2013;127:624-33.

241. Simonneau G, Torbicki A, Hoeper MM, Delcroix M, Karlocai K, Galiè N, Degano B, Bonderman D, Kurzyna M, Efficace M, Giorgino R, Lang IM. Selexipag, an oral, selective prostacyclin receptor agonist for the treatment of pulmonary arterial hypertension. Eur Respir J. 2012;40:874-80.

242. Chen SL, Zhang FF, Xu J, Xie DJ, Zhou L, Nguyen T, StoneGW. Pulmonary artery denervation to treat pulmonary arterial hypertension: the single-center, prospective, first-in-man PADN-1 study (first-in-man pulmonary artery denervation for treatment of pulmonary artery hypertension). J Am Coll Cardiol. 2013;62:1092-100

243. Galiè N, Manes A. New treatment strategies for pulmonary arterial hypertension: hopes or hypes? J Am Coll Cardiol. 2013;62:1101-2.

244. Galiè N, Palazzini M, Manes A. Pulmonary arterial hypertension: from the kingdom of the near-dead to multiple clinical trial meta-analyses. Eur Heart J. 2010;31:2080-6.

245. Kemp K, Savale L, O'Callaghan DS, Jaïs X, Montani D, Humbert M, Simonneau G, Sitbon 0 . Usefulness of first-line combination therapy with epoprostenol and bosentan in pulmonary arterial hypertension: an observational study. J Heart Lung Transplant. 2012;31:150-8

246. Sitbon O, Jaïs X, Savale L, Cottin V, Bergot E, Macari EA, Bouvaist H, Dauphin C, Picard F, Bulifon S, Montani D, Humbert M, Simonneau G. Upfront triple combination therapy in pulmonary arterial hypertension: a pilot study. Eur Respir J. 2014;43:1691-7.

247. Galiè N, Barbera JA, Frost A, Ghofrani A, Hoeper M, Mc Laughlin VV, Peacock A, Simonneau G, Vachiery JL, Grunig E, Oudiz RG, Vonk-Nordegraaf A, White J, Blair C, Gillies HC, Miller L, Harris JHN, Langley J, Rubin LJ. Initial Use of Ambrisentan plus Tadalafil in Pulmonary Arterial Hypertension. New Engl J Med. 2015:379:834-44.

248. McLaughlin VV, Channick R, Chin KM, Frey A, Gaine S, Ghofrani A, Hoeper M, Lang I, Preiss R, Rubin LJ, Simonneau G, Sitbon O, Stefani M, Tapson V, Galiè N. Effect of selexipag on morbidity/mortality in pulmonary arterial hypertension: results of the GRIPHON study. J Am Coll Cardiol. 2015;65(Suppl A):A380.

249. Badesch BD, Feldman J, Keogh A, Mathier MA, Oudiz R, Shapiro S, Farber HW, McGoon M, Frost A, Allard M, Despain D, Dufton C, Rubin LJ. ARIES-3: ambrisentan therapy in a diverse population of patients with pulmonary hypertension. Cardiovasc Ther. 2012;30:93-9.

250. Provencher S, Sitbon O, Humbert M, Cabrol S, Jaïs X, Simonneau G. Long-term outcome with first-line bosentan therapy in idiopathic pulmonary arterial hypertension. Eur Heart J. 2006;27:589-95.

251. McLaughlin V, Channick RN, Ghofrani HA, Lemarié JC, Naeije R, Packer M, Souza R, Tapson VF, Tolson J, Al Hit Hi, Meyer G, Hoeper M.M.. Bosentan added to sildenafil therapy in patients with pulmonary arterial hypertension. Eur Respir J. 2015;46:405-13

252. Dardi F, Manes A, Palazzini M, Bachetti C, Mazzanti G, Rinaldi A, Albini A, Gotti E, Monti E, Bacchi Reggiani ML, Galiè N. Combining bosentan and sildenafil in pulmonary arterial hypertension patients failing monotherapy: real-world insights. Eur Respir J. 2015;46:414-21.

253. Sandoval J, Gaspar J, Pulido T, Bautista E, Martínez Guerra ML, Zeballos M, Palomar A, Gómez A. Graded balloon dilation atrial septostomy in severe primary pulmonary hypertension. A therapeutic alternative for patients nonresponsive to vasodilator treatment. J Am Coll Cardiol. 1998;32:297-304.

254. Kurzyna M, Dabrowski M, Bielecki D, Fijalkowska A, Pruszczyk P, Opolski G, Burakowski J, Florczyk M, Tomkowski WZ, Wawrzynska L, Szturmowicz M, Torbicki A. Atrial septostomy in treatment of end-stage right heart failure in Patients with pulmonary hypertension. Chest. 2007;131:977-83.

255. Althoff TF, Knebel F, Panda A, McArdle J, Gliech V, Franke I, Witt C, Baumann G, Borges AC. Long-term follow-up of a fenestrated Amplatzer atrial septal occluder in pulmonary arterial hypertension. Chest. 2008;133:283-5.
256. Keogh A, Benza RL, Corris P, Dartevelle P, Frost A, Kim NH, Lang I, Pepke-Zaba J, Sandoval J, Mayer E. Interventional and surgical modalities of treatment in pulmonary arterial hypertension. J Am Coll Cardiol. 2009;54(Suppl):S67-S77.

257. Sztrymf B, Souza R, Bertoletti I, Jaïs X, Price LC, Simonneau G, Humbert M. Prognostic factors of acute heart failure in patients with pulmonary arterial hypertension. Eur Respir J. 2010;35:1286-93.

258. Zamanian RT, Haddad F, Doyle RL,Weinacker AB. Management strategies for patients with pulmonary hypertension in the intensive care unit. Crit Care Med. 2007;35:2037-50.

259. Price LC,Wort SJ, Finney SJ, Marino PS, Brett SJ. Pulmonary vascular and right ventricular dysfunction in adult critical care: current and emerging options for management: a systematic literature review. Crit Care. 2010;14:R169.

260. Hoeper MM, Granton J. Intensive care unit management of patients with severe pulmonary hypertension and right heart failure. Am J Respir Crit Care Med. 2011; $184: 1114-24$

261. Rosenzweig EB, Brodie D, Abrams DC, Agerstrand CL, Bacchetta M. Extracorporeal membrane oxygenation as a novel bridging strategy for acute right heart failure in group 1 pulmonary arterial hypertension. ASAIO J. 2014:60:129-33.

262. Olsson KM, Simon A, Strueber M, Hadem J, Wiesner O, Gottlieb J, Fuehner T Fischer S,Warnecke G, Kuhn C, Haverich A,Welte T, Hoeper MM. Extracorporeal membrane oxygenation in nonintubated patients as bridge to lung transplantation. Am J Transplant. 2010;10:2173-8.

263. Fuehner T, Kuehn C, Hadem J, Wiesner O, Gottlieb J, Tudorache I, Olsson KM Greer M, SommerW,Welte T, Haverich A, Hoeper MM,Warnecke G. Extracorporea membrane oxygenation in awake patients as bridge to lung transplantation. Am J Respir Crit Care Med. 2012;185:763-8.

264. de Perrot M, Granton JT, McRae K, Cypel M, Pierre A, Waddell TK, Yasufuku K, Hutcheon M, Chaparro C, Singer L, Keshavjee S. Impact of extracorporeal life support on outcome in patients with idiopathic pulmonary arterial hypertension awaiting lung transplantation. J Heart Lung Transplant. 2011;30:997-1002.

265. Strueber M, Hoeper MM, Fischer S, Cypel M, Warnecke G, Gottlieb J, Pierre A, Welte T, Haverich A, Simon AR, Keshavjee S. Bridge to thoracic organ transplantation in patients with pulmonary arterial hypertension using a pumpless lung assist device. Am J Transplant. 2009;9:853-7.

266. Trulock EP, Edwards LB, Taylor DO, Trulock EP, Waltz DA, Keck BM, Hertz MI. Registry of the International Society for Heart and Lung Transplantation: twentythird official adult lung and heart lung transplantation report-2006.J Heart Lung Transplant. 2006;25:880-92.

267. Toyoda Y, Thacker J, Santos R, Nguyen D, Bhama J, Bermudez C, Kormos R, Johnson B, Crespo M, Pilewski J, Teuteberg J, Alvarez R, Mathier M, McNamara D, McCurry $\mathrm{K}$, Zenati M, Hattler B. Long-term outcome of lung and heart-lung transplantation for idiopathic pulmonary arterial hypertension. Ann Thorac Surg. 2008;86: $1116-22$

268. Fadel E, Mercier O, Mussot S, Leroy-Ladurie F, Cerrina J, Chapelier A, Simonneau G, Dartevelle P. Long-term outcome of double-lung and heart2lung transplantation for pulmonary hypertension: a comparative retrospective study of 219 patients. Eur J Cardiothorac Surg. 2010;38:277-84.

269. de Perrot M, Granton JT, McRae K, Pierre AF, Singer LG,Waddell TK, Keshavjee S. Outcome of patients with pulmonary arterial hypertension referred for lung transplantation: a 14-year single-center experience. J Thorac Cardiovasc Surg. 2012;143:910-8.

270. Christie JD, Edwards LB, Kucheryavaya AY, Benden C, Dipchand AI, Dobbels F, Kirk R, Rahmel AO, Stehlik J, Hertz MI. The Registry of the International Society for Heart and Lung Transplantation: 29th adult lung and heart-lung transplant report-2012. J Heart Lung Transplant. 2012;31:1073-86.

271. Waddell TK, Bennett L, Kennedy R, Todd TR, Keshavjee SH. Heart-lung or lung transplantation for Eisenmenger syndrome. J Heart Lung Transplant. 2002;21:731-7.

272. Choong CK, Sweet SC, Guthrie TJ, Mendeloff EN, Haddad FJ, Schuler P, De LaMorena M, Huddleston CB. Repair of congenital heart lesions combined with lung transplantation for the treatment of severe pulmonary hypertension: a 13year experience. J Thorac Cardiovasc Surg. 2005;129:661-9.

273. Fleming TR, Powers JH. Biomarkers and surrogate endpoints in clinical trials. Statistic Med. 2012;31:2973-84

274. Fleming TR. Surrogate endpoints and FDA accelerated approval process. Health Affairs. 2005;24:67-78.

275. Tongers J, Schwerdtfeger B, Klein G, Kempf T, Schaefer A, Knapp JM, Niehaus M, Korte T, Hoeper MM. Incidence and clinical relevance of supraventricular tachyarrhythmias in pulmonary hypertension. Am Heart J. 2007;153:127-32.

276. Hoeper MM, Galiè N, Murali S, Olschewski H, Rubenfire M, Robbins IM, Farber HW, McLaughlin V, Shapiro S, Pepke-Zaba J, Winkler J, Ewert R, Opitz C,Westerkamp V, Vachiery JL, Torbicki A, Behr J, Barst RJ. Outcome after cardiopulmonary resuscitation in patients with pulmonary arterial hypertension. Am J Respir Crit Care Med. 2002;165:341-4.

277. Showkathali R, Tayebjee MH, Grapsa J, Alzetani M, Nihoyannopoulos P, Howard LS, Lefroy DC, Gibbs JS. Right atrial flutter isthmus ablation is feasible and results in acute clinical improvement in patients with persistent atrial flutter and severe pulmonary arterial hypertension. Int J Cardiol. 2011;149:279-80.

278. Zylkowska J, Kurzyna M, Pietura R, Fijalkowska A, Florczyk M, Czajka C, Torbicki A. Recurrent hemoptysis: an emerging life-threatening complication in idiopathic pulmonary arterial hypertension. Chest. 2011;139:690-3.

279. Zylkowska J, Kurzyna M, Florczyk M, Burakowska B, Grzegorczyk F, Burakowski J, Wieteska M, Oniszh K, Biederman A, Wawrzynska L, Szturmowicz M, Fijalkowska A. Torbicki A. Pulmonary artery dilatation correlates with the risk of unexpected death in chronic arterial or thromboembolic pulmonary hypertension. Chest. 2012;142:1406-16 
280. Russo V, Zompatori M, Galiè N. Extensive right pulmonary artery dissection in young patient with chronic pulmonary hypertension. Heart. 2012;98:265-6.

281. Demerouti EA, Manginas AN, Athanassopoulos GD, Karatasakis GT. Complications leading to sudden cardiac death in pulmonary arterial hypertension. Respiratory Care. 2013;58:1246-54.

282. Lee MS, Oyama J, Bhatia R, Kim YH, Park SJ. Left main coronary artery compression from pulmonary artery enlargement due to pulmonary hypertension: a contemporary review and argument for percutaneous revascularization. Catheter Cardiovasc Interv. 2010;76:543-50

283. Barst RJ, Ertel SI, Beghetti M, Ivy DD. Pulmonary arterial hypertension: a comparison between children and adults. Eur Respir J. 2011;37:665-77.

284. Barst RJ, McGoon MD, Elliott CG, Foreman AJ, Miller DP, Ivy DD. Survival in childhood pulmonary arterial hypertension. Circulation. 2012;125:113-22.

285. van Loon RL, Roofthooft MTR, Hillege HL, ten Harkel ADJ, van Osch-Gevers M, Delhaas T, Kapusta L, Strengers JLM, Rammeloo L, Clur SA, Mulder BJM, Berger RMF. Pediatric pulmonary hypertension in the Netherlands: epidemiology and characterization during the period 1991 to 2005. Circulation. 2011;124:1755-64.

286. Moledina S, Hislop AA, Foster H, Schulze-Neick I, Haworth SG. Childhood idiopathic pulmonary arterial hypertension: a national cohort study. Heart. 2010;96:1401-6.

287. Berger RM, Beghetti M, Humpl T, Raskob GE, Ivy DD, Jing ZC, Bonnet D, SchulzeNeick I, Barst RJ. Clinical features of paediatric pulmonary hypertension: a registry study. Lancet. 2012;379:537-46.

288. Hansmann G, Hoeper MM. Registries for paediatric pulmonary hypertension. Eur Respir J. 2013:42:580-3.

289. Cerro MJ, Abman S, Diaz G, Freudenthal AH, Freudenthal F, Harikrishnan S, Haworth SG, Ivy D, Lopes AA, Raj JU, Sandoval J, Stenmark K, Adatia I. A consensus approach to the classification of pediatric pulmonary hypertensive vascular disease: report from the PVRI Pediatric Taskforce, Panama 2011. Pulm Circ. 2011;1:286-98.

290. Beghetti M, Berger RM, Schulze-Neick I, Day RW, Pulido T, Feinstein J, Barst RJ, Humpl T. Diagnostic evaluation of paediatric pulmonary hypertension in current clinical practice. Eur Respir J. 2013;42:689-700.

291. Schulze-Neick I, Beghetti M. Issues related to the management and therapy of paediatric pulmonary hypertension. Eur Respir Rev. 2010;19:331-9.

292. Adatia I, Haworth SG, Wegner M, Barst RJ, Ivy D, Stenmark KR, Karkowsky A Rosenzweig E, Aguilar C. Clinical trials in neonates and children: report of the Pulmonary Hypertension Academic Research Consortium Pediatric Advisory Committee. Pulm Circ. 2013;3:252-66.

293. Lammers AE, Hislop AA, Flynn Y, Haworth SG. Epoprostenol treatment in children with severe pulmonary hypertension. Heart. 2007;93:739-43.

294. Barst RJ, Maislin G, Fishman AP. Vasodilator therapy for primary pulmonary hypertension in children. Circulation. 1999;99:1197-208.

295. Levy M, Celermajer DS, Bourges-Petit E, Del Cerro MJ, Bajolle F, Bonnet D. Add-on therapy with subcutaneous treprostinil for refractory pediatric pulmonary hypertension. J Pediatr. 2011;158:584-8.

296. Ivy DD, Doran AK, Smith KJ, Mallory GB Jr, Beghetti M, Barst RJ, Brady D, Law Y, Parker D, Claussen L, Abman SH. Short- and long-term effects of inhaled iloprost therapy in children with pulmonary arterial hypertension. J Am Coll Cardiol. 2008;51:161-9.

297. Barst R, Ivy D, Widlitz AC, Moore K, Doran A, Nguyen N, Gaitonde M. Pharmacokinetics, safety, and efficacy of bosentan in pediatric patients with pulmonary arterial hypertension. Clin Pharmacol Ther. 2003;73:372-82.

298. Rosenzweig EB, Ivy DD, Widlitz A, Doran A, Claussen LR, Yung D, Abman SH, Morganti A, Nguyen N, Barst RJ. Effects of long-term bosentan in children with pulmonary arterial hypertension. J Am Coll Cardiol. 2005;46:697-704.

299. Beghetti M, Haworth SG, Bonnet D, Barst RJ, Acar P, Fraisse A, Ivy DD, Jaïs X Schulze-Neick I, Galiè N, Morganti A, Dingemanse J, Kusic-Pajic A, Berger RM. Pharmacokinetic and clinical profile of a novel formulation of bosentan in children with pulmonary arterial hypertension: the FUTURE-1 study. Br J Clin Pharmacol. 2009;68:948-55.

300. Barst RJ, Ivy DD, Gaitan G, Szatmari A, Rudzinski A, Garcia AE, Sastry BKS, Pulido T, Layton GR, Serdarevic-Pehar M, Wessel DL. A randomized, doubleblind, placebocontrolled, dose-ranging study of oral sildenafil citrate in treatment-naive children with pulmonary arterial hypertension. Circulation. 2012;125:324-34.

301. Barst RJ, Beghetti M, Pulido T, Layton G, Konourina I, Zhang M, Ivy DD. STARTS-2: long-term survival with oral sildenafil monotherapy in treatmentnaive pediatric pulmonary arterial hypertension. Circulation. 2014;129:1914-23.

302. Takatsuki S, Calderbank M, Ivy DD. Initial experience with tadalafil in pediatric pulmonary arterial hypertension. Pediatr Cardiol. 2012;33:683-8.

303. Douwes JM, Roofthooft MT, Van Loon RL, Ploegstra MJ, Bartelds B, Hillege HL, Berger RM. Sildenafil add-on therapy in paediatric pulmonary arteria hypertension, experiences of a national referral centre. Heart. 2014;100:224-30.

304. Micheletti A, Hislop AA, Lammers A, Bonhoeffer P, Derrick G, Rees P, Haworth SG. Role of atrial septostomy in the treatment of children with pulmonary arterial hypertension. Heart. 2006;92:969-72.

305. Boudjemline Y, Patel M, Malekzadeh-Milani S, Szezepanski I, Levy M, Bonnet D. Patent ductus arteriosus stenting (transcatheter Potts shunt) for palliation of suprasystemic pulmonary arterial hypertension: a case series. Circ Cardiovasc Interv. 2013;6:e18-e20.

306. Baruteau AE, Belli E, Boudjemline Y, Laux D, Levy M, Simonneau G, Carotti A, Humbert M, Bonnet D. Palliative Potts shunt for the treatment of children with drug-refractory pulmonary arterial hypertension: updated data from the first 24 patients. Eur J Cardiothorac Surg. 2015;47:e105-10.

307. Esch JJ, Shah PB, Cockrill BA, Farber HW, Landzberg MJ, Mehra MR, Mullen MP, Opotowsky AR, Waxman AB, Lock JE, Marshall AC. Transcatheter Potts shun creation in patients with severe pulmonary arterial hypertension: initial clinical experience. J Heart Lung Transplant. 2013;32:381-7.

308. Ploegstra MJ, Douwes JM, Roofthooft MT, Zijlstra WM, Hillege HL, Berger RM. Identification of treatment goals in paediatric pulmonary arterial hypertension. Eur Respir J. 2014;44:1616-26.

309. Galiè N, Manes A, Palazzini M, Negro L, Marinelli A, Gambetti S, Mariucci E, Donti A, Branzi A, Picchio FM. Management of pulmonary arterial hypertension associated with congenital systemic-to-pulmonary shunts and Eisenmenger's syndrome. Drugs. 2008;68:1049-66.

310. Engelfriet PM, Duffels MGJ, Moller T, Boersma E, Tijssen JGP, Thaulow E, Gatzoulis MA, Mulder BJM. Pulmonary arterial hypertension in adults born with a heart septal defect: the Euro Heart Survey on adult congenital heart disease. Heart. 2007;93:682-7.

311. Beghetti M, Galiè N. Eisenmenger syndrome: a clinical perspective in a new therapeutic era of pulmonary arterial hypertension. J Am Coll Cardiol. 2009;53:733-40.

312. Daliento L, Somerville J, Presbitero P, Menti L, Brach-Prever S, Rizzoli G, Stone S. Eisenmenger syndrome. Factors relating to deterioration and death. Eur Heart J. 1998; 19:1845-55.

313. Hopkins WE, Ochoa LL, Richardson GW, Trulock EP. Comparison of the hemodynamics and survival of adults with severe primary pulmonary hypertension or Eisenmenger syndrome. J Heart Lung Transplant. 1996;15:100-5.

314. Manes A, Palazzini M, Leci E, Bacchi Reggiani ML, Branzi A, Galiè N. Current era survival of patients with pulmonary arterial hypertension associated with congenital heart disease: a comparison between clinical subgroups. Eur Heart J. 2014;35:716-24.

315. Hopkins WE. The remarkable right ventricle of patients with Eisenmenger syndrome. Coron Artery Dis. 2005;16:19-25.

316. Diller GP, Gatzoulis MA. Pulmonary vascular disease in adults with congenital heart disease. Circulation. 2007;115:1039-50.

317. Moller JH, Patton C, Varco RL, Lillehei CW. Late results (30 to 35 years) after operative closure of isolated ventricular septal defect from 1954 to 1960 . Am J Cardiol. 1991;68:1491-7.

318. van Albada ME, Berger RM. Pulmonary arterial hypertension in congenital cardiac disease-the need for refinement of the Evian-Venice classification. Cardiol Young. 2008;18:10-7.

319. Schulze-Neick I, Beghetti M. Classifying pulmonary hypertension in the setting of the congenitally malformed heart-cleaning up a dog's dinner. Cardiol Young. 2008; $18: 22-25$

320. Lopes AA, Leary PW. Measurement, interpretation and use of hemodynamic parameters. Cardiol Young. 2009;19(Suppl 1):8-12.

321. Broberg CS, Ujita M, Prasad S, Li W, Rubens M, Bax BE, Davidson SJ, Bouzas B, Gibbs JS, Burman J, Gatzoulis MA. Pulmonary arterial thrombosis in Eisenmenger syndrome is associated with biventricular dysfunction and decreased pulmonary flow velocity. J Am Coll Cardiol. 2007;50:634-42.

322. Gatzoulis MA, Beghetti M, Galiè N, Granton J, Berger RMF, Lauer A, Chiossi E, Landzberg M. Longer-term bosentan therapy improves functional capacity in Eisenmenger syndrome: results of the BREATHE-5 open-label extension study. Int J Cardiol. 2007;127:27-32.

323. ZuckermanWA, Leaderer D, Rowan CA, Mituniewicz JD, Rosenzweig EB. Ambrisentan for pulmonary arterial hypertension due to congenital heart disease. J Am Coll Cardiol. 2011;107:1381-5.

324. Mukhopadhyay S, Sharma M, Ramakrishnan S, Yusuf J, Gupta MD, Bhamri N, Trehan V, Tyagi S. Phosphodiesterase-5 inhibitor in Eisenmenger syndrome: a preliminary observational study. Circulation. 2006;114:1807-10.

325. Khanna D, Gladue $H$, Channick $R$, Chung $L$, Distler O Furst DE, Hachulla $E$, Humbert M, Langleben D, Mathai SC, Saggar R, Visovatti S, Altorok N, Townsend W, FitzGerald J, McLaughlin VV. Recommendations for screening and detection of connective tissue disease-associated pulmonary arterial hypertension. Arthritis Rheum. 2013:65:3194-201.

326. Gashouta MA, Humbert M, Hassoun PM. Update in systemic sclerosis-associated pulmonary arterial hypertension. Presse Med. 2014;43:e293-e304.

327. Coghlan JG, Denton CP, Gruenig E, Bonderman D, Distler O, Khanna D, MullerLadner U, Pope JE, Vonk MC, Doelberg M, Chadha-Boreham H, Heinzl H, Rosenberg DM, McLaughlin VV, Seibold JR. Evidence-based detection of pulmonary arterial hypertension in systemic sclerosis: the DETECT study. Ann Rheum Dis. 2014:73:1340-9.

328. Humbert M, Yaici A, de Groote P, Montani D, Sitbon O, Launay D, Gressin V, Guillevin L, Clerson P, Simonneau G, Hachulla E. Screening for pulmonary arterial hypertension in patients with systemic sclerosis: clinical characteristics at diagnosis and long-term survival. Arthritis Rheum. 2011;63:3522-30.

329. Hao YJ, Jiang X, ZhouW, Wang Y, Gao L,Wang Y, Li GT, Hong T, Huo Y, Jing ZC, Zhang ZL. Connective tissue disease-associated pulmonary arterial hypertension in Chinese patients. Eur Respir J. 2014;44:963-72.

330. Hachulla E, Carpentier P, Gressin V, Diot E, Allanore Y, Sibilia J, Launay D, Mouthon L, Jego P, Cabane J, de Groote P, Chabrol A, Lazareth I, Guillevin L, Clerson P, Humbert M, ItinerAIR-Sclerodermie Study Investigators. Risk factors for death and the 3-year survival of patients with systemic sclerosis: the French ItinerAIRSclerodermie study. Rheumatology. 2009;48:304-8.

331. Avouac J, Airo P, Meune C, Beretta C, Dieude P, Caramaschi P, Cappelli S, Diot E, Vacca A, Cracowski JL, Sibilia J, Kahan A, Matucci-Cerinic M, Allanore Y. Prevalence of pulmonary hypertension in systemic sclerosis in European Caucasians and metaanalysis of 5 studies. J Rheumatol. 2010;37:2290-8.

332. Gunther S, Jaïs X, Maitre S, Berezne A, Dorfmuller P, Seferian A, Savale L, Mercier O, Fadel E, Sitbon O, Mouthon L, Simonneau G, Humbert M, Montani D. Computed tomography findings of pulmonary venoocclusive disease in scleroderma 
patients presenting with precapillary pulmonary hypertension. Arthritis Rheum. 2012;64:2995-3005

333. Coghlan G. Does left heart disease cause most systemic sclerosis associated pulmonary hypertension? Eur Respir J. 2013;42:888-90.

334. Humbert M, Sitbon O, Yaïci A, Montani D, O'Callaghan DS, Jaïs X, Parent F, Savale L, Natali D, Günther S, Chaouat A, Chabot F, Cordier JF, Habib G, Gressin V, Jing ZC, Souza R, Simonneau G. Survival in incident and prevalent cohorts of patients with pulmonary arterial hypertension. Eur Respir J. 2010;36:549-55.

335. Fisher MR, Mathai SC, Champion HC, Girgis RE, Housten-Harris T, Hummers L, Krishnan JA, Wigley F, Hassoun PM. Clinical differences between idiopathic and scleroderma-related pulmonary hypertension. Arthritis Rheum. 2006:54:3043-50.

336. Launay D, Sitbon O, Hachulla E, Mouthon L, Gressin V, Rottat L, Clerson P, Cordier JF, Simonneau G, Humbert M. Survival in systemic sclerosis-associated pulmonary arterial hypertension in the modern management era. Ann Rheum Dis. 2013:72:1940-6.

337. O'Callaghan DS, Dorfmuller P, Jaïs X, Mouthon L, Sitbon O, Simonneau G, Humbert $\mathrm{M}$, Montani D. Pulmonary veno-occlusive disease: the bete noire of pulmonary hypertension in connective tissue diseases? Presse Med. 2011;40:e65-e78.

338. Demling RH, Smith M, Gunther R, Flynn JT, Gee MH. Pulmonary injury and prostaglandin production during endotoxemia in conscious sheep. Am J Physiol. 1981;240:H348-53.

339. Jaïs X, Launay D, Yaici A, Le PJ, Tcherakian C, Sitbon O, Simonneau G, Humbert M. Immunosuppressive therapy in lupus- and mixed connective tissue diseaseassociated pulmonary arterial hypertension: a retrospective analysis of twentythree cases. Arthritis Rheum. 2008;58:521-31.

340. Avouac J, Wipff J, Kahan A, Allanore Y. Effects of oral treatments on exercise capacity in systemic sclerosis related pulmonary arterial hypertension: a metaanalysis of randomised controlled trials. Ann Rheum Dis. 2008;67:808-14.

341. Launay D, Savale L, Berezne A, Le PJ, Hachulla E, Mouthon L, Sitbon O, Lambert B, Gaudric M, Jaïs X, Stephan F, Hatron PY, Lamblin N, Vignaux O, Cottin V, Farge D, Wallaert B, Guillevin L, Simonneau G, Mercier O, Fadel E, Dartevelle P, Humbert $\mathrm{M}$, Mussot S. Lung and heart-lung transplantation for systemic sclerosis patients. A monocentric experience of 13 patients, review of the literature and position paper of a multidisciplinary working group. Presse Med. 2014;43:e345-63.

342. Hoeper MM, Krowka MJ, Strassburg CP. Portopulmonary hypertension and hepatopulmonary syndrome. Lancet. 2004;363:1461-8.

343. Zopey R, Susanto I, Barjaktarevic I, Wang T. Transition from hepatopulmonary syndrome to portopulmonary hypertension: a case series of 3 patients. Case Rep Pulmonol. 2013:2013:561870.

344. Krowka MJ, Swanson KL, Frantz RP, McGoon MD, Wiesner RH. Portopulmonary hypertension: results from a 10-year screening algorithm. Hepatology. 2006:44:1502-10.

345. Kawut SM, Krowka MJ, Trotter JF, Roberts KE, Benza RL, Badesch DB, Taichman DB, Horn EM, Zacks S, Kaplowitz N, Brown RS Jr, Fallon MB. Clinical risk factors for portopulmonary hypertension. Hepatology. 2008;48:196-203.

346. Roberts KE, Fallon MB, Krowka MJ, Brown RS, Trotter JF, Peter I, Tighiouart H, Knowles JA, Rabinowitz D, Benza RL, Badesch DB, Taichman DB, Horn EM, Zacks S, Kaplowitz N, Kawut SM. Genetic risk factors for portopulmonary hypertension in patients with advanced liver disease. Am J Respir Crit Care Med. 2009;179:835-42.

347. Krowka MJ, Miller DP, Barst RJ, Taichman D, Dweik RA, Badesch DB, McGoon MD. Portopulmonary hypertension: a report from the US-based REVEAL Registry. Chest. 2012;141:906-15.

348. Le Pavec J, Souza R, Herve P, Lebrec D, Savale L, Tcherakian C, Jaïs X, Yaici A, Humbert M, Simonneau G, Sitbon O. Portopulmonary hypertension: survival and prognostic factors. Am J Respir Crit Care Med. 2008;178:637-43.

349. Provencher S, Herve P, Jaïs X, Lebrec D, Humbert M, Simonneau G, Sitbon O. Deleterious effects of beta-blockers on exercise capacity and hemodynamics in patients with portopulmonary hypertension. Gastroenterology. 2006;130:120-6.

350. Hoeper MM, Seyfarth HJ, Hoeffken G, Wirtz H, Spiekerkoetter E, Pletz MW, Welte T, Halank M. Experience with inhaled iloprost and bosentan in portopulmonary hypertension. Eur Respir J. 2007;30:1096-102.

351. Halank M, Knudsen L, Seyfarth HJ, Ewert R, Wiedemann B, Kolditz M, Hoffken G Hoeper MM. Ambrisentan improves exercise capacity and symptoms in patients with portopulmonary hypertension. Z Gastroenterol. 2011;49:1258-62.

352. Reichenberger F, Voswinckel R, Steveling E, Enke B, Kreckel A, Olschewski H, Grimminger F, Seeger W, Ghofrani HA. Sildenafil treatment for portopulmonary hypertension. Eur Respir J. 2006;28:563-7.

353. Kuo PC, Johnson LB, Plotkin JS, Howell CD, Bartlett ST, Rubin LJ. Continuous intravenous infusion of epoprostenol for the treatment of portopulmonary hypertension. Transplantation. 1997;63:604-6.

354. Swanson KL, Wiesner RH, Nyberg SL, Rosen CB, Krowka MJ. Survival in portopulmonary hypertension: Mayo Clinic experience categorized by treatment subgroups. Am J Transplant. 2008;8:2445-53.

355. Sakai T, Planinsic RM, Mathier MA, de Vera ME, Venkataramanan R. Initial experience using continuous intravenous treprostinil to manage pulmonary arterial hypertension in patients with end-stage liver disease. Transpl Int. 2009;22:554-61.

356. Savale L, Magnier R, Le Pavec J, Jaïs X, Montani D, O'Callaghan DS, Humbert M, Dingemanse J, Simonneau G, Sitbon O. Efficacy, safety and pharmacokinetics of bosentan in portopulmonary hypertension. Eur Respir J. 2013;41:96-103.

357. Humbert M, Segal ES, Kiely DG, Carlsen J, Schwierin B, Hoeper MM. Results of European post-marketing surveillance of bosentan in pulmonary hypertension. Eur Respir J. 2007;30:338-44.

358. Kia L, Shah SJ, Wang E, Sharma D, Selvaraj S, Medina C, Cahan J, Mahon H, Levitsky $\mathrm{J}$. Role of pretransplant echocardiographic evaluation in predicting outcomes following liver transplantation. Am J Transplant. 2013;13:2395-401.
359. Krowka MJ, Plevak DJ, Findlay JY, Rosen CB, Wiesner RH, Krom RA. Pulmonary hemodynamics and perioperative cardiopulmonary-related mortality in patients with portopulmonary hypertension undergoing liver transplantation. Liver Transplant. 2000;6:443-50.

360. Ashfaq M, Chinnakotla S, Rogers L, Ausloos K, Saadeh S, Klintmalm GB, Ramsay M, Davis GL. The impact of treatment of portopulmonary hypertension on survival following liver transplantation. Am J Transplant. 2007; 7:1258-64.

361. Raevens S, De Pauw M, Reyntjens K, Geerts A, Verhelst X, Berrevoet F, Rogiers X Troisi RI, Van Vlierberghe H, Colle I. Oral vasodilator therapy in patients with moderate to severe portopulmonary hypertension as a bridge to liver transplantation. Eur J Gastroenterol Hepatol. 2013;25:495-502.

362. Plotkin JS, Kuo PC, Rubin LJ, Gaine S, Howell CD, Laurin J, Njoku MJ, Lim JW Johnson LB. Successful use of chronic epoprostenol as a bridge to liver transplantation in severe portopulmonary hypertension. Transplantation. 1998;65:457-9.

363. Austin MJ, McDougall NI, Wendon JA, Sizer E, Knisely AS, Rela M, Wilson C Callender ME, O'Grady JG, Heneghan MA. Safety and efficacy of combined use of sildenafil, bosentan, and iloprost before and after liver transplantation in severe portopulmonary hypertension. Liver Transplant. 2008;14:287-91.

364. Grannas G, Neipp M, Hoeper MM, Gottlieb J, Luck R, Becker T, Simon A, Strassburg CP, Manns MP, Welte T, Haverich A, Klempnauer J, Nashan B, Strueber M. Indications for and outcomes after combined lung and liver transplantation: a single-center experience on 13 consecutive cases. Transplantation. 2008;85: 524-31.

365. Robalino BD, Moodie DS. Association between primary pulmonary hypertension and portal hypertension: analysis of its pathophysiology and clinical, laboratory and hemodynamic manifestations. J Am Coll Cardiol. 1991;17:492-8.

366. Barbaro G, Lucchini A, Pellicelli AM, Grisorio B, Giancaspro G, Barbarini G. Highly active antiretroviral therapy compared with HAART and bosentan in combination in patients with HIV-associated pulmonary hypertension. Heart. 2006;92: 1164-6.

367. Degano B. HIV-associated pulmonary arterial hypertension: survival and prognostic factors in the modern therapeutic era. AIDS. 2010;24:67-75.

368. Opravil M, Pechère M, Speich R, Joller Jemelka HI, Jenni R, Russi EW, Hirschel B, Lü thy R. HIV-associated primary pulmonary hypertension. A case control study. Swiss HIV Cohort Study. Am J Respir Crit Care Med. 1997;155:990-5.

369. Sitbon O, Lascoux-Combe C, Delfraissy JF, Yeni PG, Raffi F, De Zuttere D, Gressin V, Clerson P, Sereni D, Simonneau G. Prevalence of HIV-related pulmonary arterial hypertension in the current antiretroviral therapy era. Am J Respir Crit Care Med. 2008;177:108-13.

370. Sitbon O, Gressin V, Speich R, Macdonald PS, Opravil M, Cooper DA, Fourme T, Humbert M, Delfraissy JF, Simonneau G. Bosentan for the treatment of human immunodeficiency virus-associated pulmonary arterial hypertension. Am J Respir Crit Care Med. 2004;170:1212-7.

371. Montani D, Achouh L, Dorfmuller P, Le Pavec J, Sztrymf B, Tcherakian C, Rabille A, Haque R, Sitbon O, Jaïs X, Dartevelle P, Maitre S, Capron F, Musset D, Simonneau G, Humbert M. Pulmonary veno-occlusive disease: clinical, functional, radiologic, and hemodynamic characteristics and outcome of 24 cases confirmed by histology. Medicine (Baltimore). 2008;87:220-33.

372. Lantuejoul S, Sheppard MN, Corrin B, Burke MM, Nicholson AG. Pulmonary venoocclusive disease and pulmonary capillary hemangiomatosis: a clinicopathologic study of 35 cases. Am J Surg Pathol. 2006;30:850-7.

373. Humbert M, Maître S, Capron F, Rain B, Musset D, Simonneau G. Pulmonary edema complicating continuous intravenous prostacyclin in pulmonary capillary hemangiomatosis. Am J Respir Crit Care Med. 1998;157:1681-5.

374. Mandel J, Mark EJ, Hales CA. Pulmonary veno-occlusive disease. Am J Respir Crit Care Med. 2000;162:1964-73.

375. Langleben D, Heneghan JM, Batten AP, Wang NS, Fitch N, Schlesinger RD, Guerraty A, Rouleau JL. Familial pulmonary capillary hemangiomatosis resulting in primary pulmonary hypertension. Ann Intern Med. 1988;109:106-9 [published erratum appears in Ann Intern Med 1988;109:439].

376. Best DH, Sumner KL, Austin ED, Chung WK, Brown LM, Borczuk AC, Rosenzweig EB, Bayrak-Toydemir P, Mao R, Cahill BC, Tazelaar HD, Leslie KO, Hemnes AR, Robbins IM, Elliott CG. EIF2AK4 mutations in pulmonary capillary hemangiomatosis. Chest. 2014;145:231-6.

377. Seferian A, Helal B, Jaïs X, Girerd B, Price LC, Gunther S, Savale L, Dorfmuller P, Parent F, Sitbon O, Humbert M, Simonneau G, Montani D. Ventilation/perfusion lung scan in pulmonary veno-occlusive disease. Eur Respir J. 2012;40:75-83.

378. Rabiller A, Jaïs X, Hamid A, Resten A, Parent F, Haque R, Capron F, Sitbon O, Simonneau G, Humbert M. Occult alveolar haemorrhage in pulmonary venoocclusive disease. Eur Respir J. 2006;27:108-13.

379. Montani D, Jaïs X, Price LC, Achouh L, Degano B, Mercier O, Mussot S, Fadel E Dartevelle P, Sitbon O, Simonneau G, Humbert M. Cautious epoprostenol therapy is a safe bridge to lung transplantation in pulmonary veno-occlusive disease. Eur Respir J. 2009;34:1348-56.

380. Fang JC, DeMarco T, Givertz MM, Borlaug BA, Lewis GD, Rame JE, GombergMaitland M, Murali S, Frantz RP, McGlothlin D, Horn EM, Benza RL. World Health Organization Pulmonary Hypertension Group 2: pulmonary hypertension due to left heart disease in the adult-a summary statement from the Pulmonary Hypertension Council of the International Society for Heart and Lung Transplantation. J Heart Lung Transplant. 2012;31:913-33.

381. Ghio S, Gavazzi A, Campana C, Inserra C, Klersy C, Sebastiani R, Arbustini E Recusani F, Tavazzi L. Independent and additive prognostic value of right ventricular systolic function and pulmonary artery pressure in patients with chronic heart failure. J Am Coll Cardiol. 2001;37:183-8. 
382. Thenappan T, Shah SJ, Gomberg-Maitland M, Collander B, Vallakati A, Shroff P, Rich S. Clinical characteristics of pulmonary hypertension in patients with heart failure and preserved ejection fraction. Circ Heart Fail. 2011;4:257-65.

383. Robbins IM, Newman JH, Johnson RF, Hemnes AR, Fremont RD, Piana RN, Zhao DX, Byrne DW. Association of the metabolic syndrome with pulmonary venous hypertension. Chest. 2009;136:31-6.

384. Bursi F, McNallan SM, Redfield MM, Nkomo VT, Lam CS, Weston SA, Jiang R, Roger VL. Pulmonary pressures and death in heart failure: a community study. J Am Coll Cardiol. 2012;59:222-31.

385. Gerges C, Gerges M, Lang MB, Zhang Y, Jakowitsch J, Probst P, Maurer G, Lang IM. Diastolic pulmonary vascular pressure gradient: a predictor of prognosis in "outof-proportion" pulmonary hypertension. Chest. 2013;143:758-66.

386. Moraes DL, ColucciWS, Givertz MM. Secondary pulmonary hypertension in chronic heart failure: the role of the endothelium in pathophysiology and management. Circulation. 2000;102:1718-23.

387. Rapp AH, Lange RA, Cigarroa JE, Keeley EC, Hillis LD. Relation of pulmonary arterial diastolic and mean pulmonary arterial wedge pressures in patients with and without pulmonary hypertension. Am J Cardiol. 2001;88:823-4.

388. Miller WL, Grill DE, Borlaug BA. Clinical features, hemodynamics, and outcomes of pulmonary hypertension due to chronic heart failure with reduced ejection fraction: pulmonary hypertension and heart failure. JACC Heart Fail. 2013;1:290-9.

389. Tampakakis E, Leary PJ, Selby VN, De Marco T, Cappola TP, Felker GM, Russell SD, Kasper EK, Tedford RJ. The diastolic pulmonary gradient does not predict survival in patients with pulmonary hypertension due to left heart disease. JACC Heart Fail. 2015;3:9-16.

390. Pellegrini P, Rossi A, Pasotti M, Raineri C, Cicoira M, Bonapace S, Dini FL, Temporelli PL, Vassanelli C, Vanderpool R, Naeije R, Ghio S. Prognostic relevance of pulmonary arterial compliance in patients with chronic heart failure. Chest. 2014; $145: 1064-70$

391. Chatterjee NA, Lewis GD. Characterization of pulmonary hypertension in heart failure using the diastolic pressure gradient: limitations of a solitary measurement. JACC Heart Fail. 2015;3:17-21.

392. McMurray JJ, Adamopoulos S, Anker SD, Auricchio A, Bohm M, Dickstein K, Falk V, Filippatos G, Fonseca C, Gomez-Sanchez MA, Jaarsma T, Kober L, Lip GY, Maggioni AP, Parkhomenko A, Pieske BM, Popescu BA, Ronnevik PK, Rutten FH, Schwitter J, Seferovic P, Stepinska J, Trindade PT, Voors AA, Zannad F, Zeiher A ESC Guidelines for the diagnosis and treatment of acute and chronic heart failure 2012: the Task Force for the Diagnosis and Treatment of Acute and Chronic Heart Failure 2012 of the European Society of Cardiology. Developed in collaboration with the Heart Failure Association (HFA) of the ESC. Eur Heart J. 2012;33: 1787-847.

393. Khush KK, Tasissa G, Butler J, McGlothlin D, De MT. Effect of pulmonary hypertension on clinical outcomes in advanced heart failure: analysis of the Evaluation Study of Congestive Heart Failure and Pulmonary Artery Catheterization Effectiveness (ESCAPE) database. Am Heart J. 2009;157:1026-34.

394. Patel ND, Weiss ES, Schaffer J, Ullrich SL, Rivard DC, Shah AS, Russell SD, Conte JV. Right heart dysfunction after left ventricular assist device implantation: a comparison of the pulsatile HeartMate I and axial-flow HeartMate II devices. Ann Thorac Surg. 2008;86:832-40.

395. Torre-Amione G, Southard RE, Loebe MM, Youker KA, Bruckner B, Estep JD, Tierney M, Noon GP. Reversal of secondary pulmonary hypertension by axial and pulsatile mechanical circulatory support. J Heart Lung Transplant. 2010;29: 195-200.

396. Barnett CF, DeMarco T. Pulmonary hypertension associated with left-sided heart disease. Heart Fail Clin. 2012;8:447-59.

397. Bonderman D, Ghio S, Felix SB, Ghofrani HA, Michelakis E, Mitrovic V, Oudiz RJ Boateng F, Scalise AV, Roessig L, Semigran MJ. Riociguat for patients with pulmonary hypertension caused by systolic left ventricular dysfunction: a phase IIb double-blind, randomized, placebo-controlled, dose-ranging hemodynamic study. Circulation. 2013;128:502-11.

398. Oswald-Mammosser M, Weitzenblum E, Quoix E, Moser G, Chaouat A Charpentier C, Kessler R. Prognostic factors in COPD patients receiving longterm oxygen therapy. Importance of pulmonary artery pressure. Chest. 1995;107:1193-8.

399. Kessler R, Faller M,Weitzenblum E, Chaouat A, Aykut A, Ducolone A, Ehrhart M Oswald-Mammosser M. "Natural history" of pulmonary hypertension in a series of 131 patients with chronic obstructive lung disease. Am J Respir Crit Care Med. 2001;164:219-24

400. Lettieri CJ, Nathan SD, Barnett SD, Ahmad S, Shorr AF. Prevalence and outcomes of pulmonary arterial hypertension in advanced idiopathic pulmonary fibrosis. Chest. 2006;129:746-52.

401. Thabut G, Dauriat G, Stern JB, Logeart D, Levy A, Marrash-Chahla R, Mal H Pulmonary hemodynamics in advanced COPD candidates for lung volume reduction surgery or lung transplantation. Chest. 2005;127:1531-6.

402. Chaouat A, Bugnet AS, Kadaoui N, Schott R, Enache I, Ducolone A, Ehrhart M Kessler R,Weitzenblum E. Severe pulmonary hypertension and chronic obstructive pulmonary disease. Am J Respir Crit Care Med. 2005;172:189-94.

403. Arcasoy SM, Christie JD, Ferrari VA, St John SM, Zisman DA, Blumenthal NP, Pochettino A, Kotloff RM. Echocardiographic assessment of pulmonary hypertension in patients with advance lung disease. Am J Respir Crit Care Med. 2003;167:735-40.

404. Fisher MR, Forfia PR, Chamera E, Housten-Harris T, Champion HC, Girgis RE Corretti MC, Hassoun PM. Accuracy of Doppler echocardiography in the hemodynamic assessment of pulmonary hypertension. Am J Respir Crit Care Med. 2009;179:615-21.

405. Nathan SD, Shlobin OA, Barnett SD, Saggar R, Belperio JA, Ross DJ, Ahmad S, Saggar R, Libre E, Lynch JP III, Zisman DA. Right ventricular systolic pressure by echocardiography as a predictor of pulmonary hypertension in idiopathic pulmonary fibrosis. Respir Med. 2008;102:1305-10.

406. Agusti AG, Barbera JA, Roca J, Wagner PD, Guitart R, Rodriguez-Roisin R. Hypoxic pulmonary vasoconstriction and gas exchange during exercise in chronic obstructive pulmonary disease. Chest. 1990;97:268-75.

407. Barbera JA, Roger N, Roca J, Rovira I, Higenbottam TW, Rodriguez-Roisin R. Worsening of pulmonary gas exchange with nitric oxide inhalation in chronic obstructive pulmonary disease. Lancet. 1996;347:436-40.

408. Simonneau G, Escourrou P, Duroux P, Lockhart A. Inhibition of hypoxic pulmonary vasoconstriction by nifedipine. N Engl J Med. 1981;304:1582-5.

409. Morrell NW, Higham MA, Phillips PG, Shakur BH, Robinson PJ, Beddoes RJ. Pilot study of losartan for pulmonary hypertension in chronic obstructive pulmonary disease. Respir Res. 2005;6:88-95.

410. Saadjian A, Philip-Joet F, Paganelli F, Arnaud A, Levy S. Long-term effects of cicletanine on secondary pulmonary hypertension. J Cardiovasc Pharmacol. 1998;31:364-71.

411. Stolz D, Rasch H, Linka A, Di Valentino M, Meyer A, Brutsche M, Tamm M. A randomised, controlled trial of bosentan in severe COPD. Eur Respir J. 2008;32:619-28.

412. Blanco I, Gimeno E, Munoz PA, Pizarro S, Gistau C, Rodriguez-Roisin R, Roca J, Barbera JA. Hemodynamic and gas exchange effects of sildenafil in patients with chronic obstructive pulmonary disease and pulmonary hypertension. Am J Respir Crit Care Med. 2010;181:270-8.

413. Zisman DA, Schwarz M, Anstrom KJ, Collard HR, Flaherty KR, HunninghakeGW. A controlled trial of sildenafil in advanced idiopathic pulmonary fibrosis. N Engl J Med. 2010;363:620-8.

414. Blanco I, Santos S, Gea J, Guell R, Torres F, Gimeno-Santos E, Rodriguez DA, Vilaro J, Gomez B, Roca J, Barbera JA. Sildenafil to improve respiratory rehabilitation outcomes in COPD: a controlled trial. Eur Respir J. 2013;42:982-92.

415. Lederer DJ, Bartels MN, Schluger NW, Brogan F, Jellen P, Thomashow BM, Kawut SM. Sildenafil for chronic obstructive pulmonary disease: a randomized crossover trial. COPD. 2012;9:268-75.

416. Goudie AR, Lipworth BJ, Hopkinson PJ,Wei L, Struthers AD. Tadalafil in patients with chronic obstructive pulmonary disease: a randomised, double-blind, parallel-group, placebo-controlled trial. Lancet Respir Med. 2014;2:293-300.

417. Lang IM, Pesavento R, Bonderman D, Yuan JX. Risk factors and basic mechanisms of chronic thromboembolic pulmonary hypertension: a current understanding. Eur Respir J. 2013;41:462-8.

418. Guerin L, Couturaud F, Parent F, Revel MP, Gillaizeau F, Planquette B, Pontal D, Guegan M, Simonneau G, Meyer G, Sanchez O. Prevalence of chronic thromboembolic pulmonary hypertension after acute pulmonary embolism. Prevalence of CTEPH after pulmonary embolism. Thromb Haemost. 2014;112: 598-605.

419. Pepke-Zaba J, Jansa P, Kim NH, Naeije R, Simonneau G. Chronic thromboembolic pulmonary hypertension: role of medical therapy. Eur Respir J. 2013;41:985-90.

420. Madani MM, Wittine LM, Auger WR, Fedullo PF, Kerr KM, Kim NH, Test VJ, Kriett JM, Jamieson SW. Chronic thromboembolic pulmonary hypertension in pediatric patients. J Thorac Cardiovasc Surg. 2011;141:624-30.

421. Pepke-Zaba J, Hoeper MM, Humbert M. Chronic thromboembolic pulmonary hypertension: advances from bench to patient management. Eur Respir J. 2013;41:8-9.

422. Lang IM, Simonneau G, Pepke-Zaba JW, Mayer E, Ambroz D, Blanco I, Torbicki A Mellemkjaer S, Yaici A, Delcroix M. Factors associated with diagnosis and operability of chronic thromboembolic pulmonary hypertension. A case-control study. Thromb Haemost. 2013;110:83-91.

423. Lang IM, Plank C, Sadushi-Kolici R, Jakowitsch J, KlepetkoW, Maurer G. Imaging in pulmonary hypertension. JACC Cardiovasc Imaging. 2010;3:1287-95.

424. Hoeper MM, Mayer E, Simonneau G, Rubin LJ. Chronic thromboembolic pulmonary hypertension. Circulation. 2006;113:2011-20.

425. Sherrick AD, Swensen SJ, Hartman TE. Mosaic pattern of lung attenuation on CT scans: frequency among patients with pulmonary artery hypertension of different causes. Am J Roentgenol. 1997;169:79-82.

426. Ley S, Ley-Zaporozhan J, Pitton MB, Schneider J, Wirth GM, Mayer E, Duber C, Kreitner KF. Diagnostic performance of state-of-the-art imaging techniques for morphological assessment of vascular abnormalities in patients with chronic thromboembolic pulmonary hypertension (CTEPH). Eur Radiol. 2012;22:607-16.

427. Sugiyama M, Fukuda T, Sanda Y, Morita Y, Higashi M, Ogo T, Tsuji A, Demachi J, Nakanishi N, Naito H. Organized thrombus in pulmonary arteries in patients with chronic thromboembolic pulmonary hypertension; imaging with cone beam computed tomography. Jpn J Radiol. 2014;32:375-82.

428. Shure D, Gregoratos G, Moser KM. Fiberoptic angioscopy: role in the diagnosis of chronic pulmonary arterial obstruction. Ann Intern Med. 1985;103:844-50.

429. Skoro-Sajer N, Marta G, Gerges C, Hlavin G, Nierlich P, Taghavi S, Sadushi-Kolici R, Klepetko W, Lang IM. Surgical specimens, haemodynamics and long-term outcomes after pulmonary endarterectomy. Thorax. 2014;69:116-22.

430. Mayer E, Jenkins D, Lindner J, D’Armini A, Kloek J, Meyns B, Ilkjaer LB, Klepetko W, Delcroix M, Lang I, Pepke-Zaba J, Simonneau G, Dartevelle P. Surgical management and outcome of patients with chronic thromboembolic pulmonary hypertension: results from an international prospective registry. J Thorac Cardiovasc Surg. 2011;141:702-10.

431. Madani MM, Auger WR, Pretorius V, Sakakibara N, Kerr KM, Kim NH, Fedullo PF, Jamieson SW. Pulmonary endarterectomy: recent changes in a single institution's experience of more than 2,700 patients. Ann Thorac Surg. 2012;94:97-103.

432. Jenkins D, Mayer E, Screaton N, Madani M. State-of-the-art chronic thromboembolic pulmonary hypertension diagnosis and management. Eur Respir Rev. 2012;21:32-9. 
433. Vuylsteke A, Sharples L, Charman G, Kneeshaw J, Tsui S, Dunning J, Wheaton E, Klein A, Arrowsmith J, Hall R, Jenkins D. Circulatory arrest versus cerebral perfusion during pulmonary endarterectomy surgery (PEACOG): a randomised controlled trial. Lancet. 2011;378:1379-87.

434. Thistlethwaite PA, Madani MM, Kemp AD, Hartley M, Auger WR, Jamieson SW. Venovenous extracorporeal life support after pulmonary endarterectomy: indications, techniques, and outcomes. Ann Thorac Surg. 2006;82:2139-45.

435. Berman M, Tsui S, Vuylsteke A, Snell A, Colah S, Latimer R, Hall R, Arrowsmith JE, Kneeshaw J, Klein AA, Jenkins DP. Successful extracorporeal membrane oxygenation support after pulmonary thromboendarterectomy. Ann Thorac Surg. 2008;86:1261-7.

436. Mydin M, Berman M, Klein A, Tsui S, Dunning J, Valchanov K, Vuylsteke A, Jenkins DP. Extracorporeal membrane oxygenation as a bridge to pulmonary endarterectomy. Ann Thorac Surg. 2011;92:e101-3.

437. Hughes RJ, Jaïs X, Bonderman D, Suntharalingam J, Humbert M, Lang I, Simonneau G, Pepke-Zaba J. The efficacy of bosentan in inoperable chronic thromboembolic pulmonary hypertension: a 1-year follow-up study. Eur Respir J. 2006;28:138-43.

438. Skoro-Sajer N, Bonderman D, Wiesbauer F, Harja E, Jakowitsch J, Klepetko W, Kneussl MP, Lang IM. Treprostinil for severe inoperable chronic thromboembolic pulmonary hypertension. Thromb Haemost. 2007;5:483-9.

439. Reichenberger F, Voswinckel R, Enke B, Rutsch M, Fechtali EE, Schmehl T, Olschewski H, Schermuly R, Weissmann N, Ghofrani HA, Grimminger F, Mayer E Seeger W. Long-term treatment with sildenafil in chronic thromboembolic pulmonary hypertension. Eur Respir J. 2007;30:922-7.

440. Jaïs X, D’Armini AM, Jansa P, Torbicki A, Delcroix M, Ghofrani HA, Hoeper MM, Lang IM, Mayer E, Pepke-Zaba J, Perchenet L, Morganti A, Simonneau G, Rubin LJ. Bosentan for treatment of inoperable chronic thromboembolic pulmonary hypertension: BENEFiT (Bosentan Effects in iNopErable Forms of chronIc Thromboembolic pulmonary hypertension), a randomized, placebo-controlled trial. J Am Coll Cardiol. 2008;52:2127-34.

441. Ghofrani HA, D’Armini AM, Grimminger F, Hoeper MM, Jansa P, Kim NH, Mayer E, Simonneau G, Wilkins MR, Fritsch A, Neuser D, Weimann G, Wang C. Riociguat for the treatment of chronic thromboembolic pulmonary hypertension. $\mathrm{N} \mathrm{Engl} \mathrm{J}$ Med. 2013;369:319-29.

442. Reesink HJ, Surie S, Kloek JJ, Tan HL, Tepaske R, Fedullo PF, Bresser P. Bosentan as a bridge to pulmonary endarterectomy for chronic thromboembolic pulmonary hypertension. J Thorac Cardiovasc Surg. 2010;139:85-91.

443. Feinstein JA, Goldhaber SZ, Lock JE, Ferndandes SM, Landzberg MJ. Balloon pulmonary angioplasty for treatment of chronic thromboembolic pulmonary hypertension. Circulation. 2001;103:10-3.

444. Kataoka M, Inami T, Hayashida K, Shimura N, Ishiguro H, Abe T, Tamura Y, Ando M, Fukuda K, Yoshino $\mathrm{H}$, Satoh T. Percutaneous transluminal pulmonary angioplasty for the treatment of chronic thromboembolic pulmonary hypertension. Circ Cardiovasc Interv. 2012;5:756-62.

445. Mizoguchi H, Ogawa A, Munemasa M, Mikouchi H, Ito H, Matsubara H. Refined balloon pulmonary angioplasty for inoperable patients with chronic thromboembolic pulmonary hypertension. Circ Cardiovasc Interv. 2012;5:748-55.

446. Sugimura K, Fukumoto Y, Satoh K, Nochioka K, Miura Y, Aoki T, Tatebe S Miyamichi-Yamamoto S, Shimokawa H. Percutaneous transluminal pulmonary angioplasty markedly improves pulmonary hemodynamics and longtermprognosis in patients with chronic thromboembolic pulmonary hypertension. Circ J. 2012;76:485-8.

447. Inami T, Kataoka M, Shimura N, Ishiguro H, Yanagisawa R, Taguchi H, Fukuda K, Yoshino H, Satoh T. Pulmonary edema predictive scoring index (PEPSI), a new index to predict risk of reperfusion pulmonary edema and improvement of hemodynamics in percutaneous transluminal pulmonary angioplasty. JACC Cardiovasc Interv. 2013;6:725-36.

448. Andreassen AK, Ragnarsson A, Gude E, Geiran O, Andersen R. Balloon pulmonary angioplasty in patients with inoperable chronic thromboembolic pulmonary hypertension. Heart. 2013;99:1415-20.

449. Rubin LJ, Hoeper MM, Klepetko W, Galiè N, Lang IM, Simonneau G. Current and future management of chronic thromboembolic pulmonary hypertension: from diagnosis to treatment responses. Proc Am Thorac Soc 2006;3:601-7.

450. Peacock A. Pulmonary hypertension due to chronic hypoxia. BMJ. 1990;300:763

451. Recommendations on the management of pulmonary hypertension in clinical practice. Heart. 2001;86(Suppl 1):I1-I13.

452. Consensus statement on the management of pulmonary hypertension in clinical practice in the UK and Ireland. Thorax. 2008;63(Suppl 2):ii1-ii41.

453. Barbera JA, Escribano P, Morales P, Gomez MA, Oribe M, Martinez A, Roman A Segovia J, Santos F, Subirana MT. [Standards of care in pulmonary hypertension. Consensus statement of the Spanish Society of Pulmonology and Thoracic Surgery (SEPAR) and the Spanish Society of Cardiology (SEC)]. Rev Esp Cardiol. 2008;61:170-84

454. Armstrong I, Rochnia N, Harries C, Bundock S, Yorke J. The trajectory to diagnosis with pulmonary arterial hypertension: a qualitative study. BMJ Open. 2012;2:e000806.

455. Ghofrani HA, Distler O, Gerhardt F, Gorenflo M, Grunig E, Haefeli WE, Held M, Hoeper MM, Kahler CM, Kaemmerer H, Klose H, Kollner V, Kopp B, Mebus S, Meyer A, Miera O, Pittrow D, Riemekasten G, Rosenkranz S, Schranz D, Voswinckel $\mathrm{R}$, Olschewski $\mathrm{H}$. Treatment of pulmonary arterial hypertension (PAH): updated Recommendations of the Cologne Consensus Conference 2011. Int J Cardiol. 2011;154(Suppl 1):S20-S33.

456. Vachiery JL, Gaine S. Challenges in the diagnosis and treatment of pulmonary arterial hypertension. Eur Respir Rev. 2012;21:313-20. 